UNIVERSIDAD NACIONAL DE LA PLATA

FACULTAD DE HUMANIDADES Y CIENCIAS DE LA EDUCACIÓN

SECRETARÍA DE POSGRADO

\title{
Construcciones identitarias en la narrativa escrita por mujeres cubanas a fines del siglo $X X$
}

\section{María Virginia González}

Tesis para optar por el grado de Doctor en Letras

Director: Celina Manzoni, Universidad Nacional de Buenos Aires Codirector: Alejandra Mailhe, Universidad Nacional de La Plata 


\section{Índice}

Agradecimientos...................................................... 5

\section{Introducción}

Presentación general........................................................ 7

1. Algunas consideraciones teórico-metodológicas....................................14

1.1. Estudios de género........................................................19

1.1.1. Los aportes de Simone de Beauvoir................................22

1.1.2. El feminismo de la diferencia.....................................25

1.1.3. Avatares de la concepción de género en América Latina......................29

2. Cuba: una aproximación al contexto socio-cultural después de los sesenta............. 35

2.1. Derivas literarias de fines de siglo......................................47

2.2. La situación de las escritoras y de los estudios de género en y sobre Cuba .........52

I. Empezar no es partir de cero. Un análisis crítico de Estatuas de sal. Cuentistas

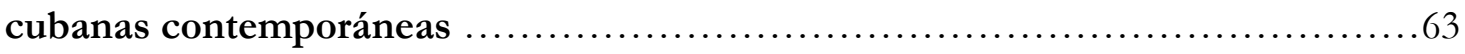

1.1. Sobre el acto de compilar y las estrategias de autolegitimación intelectual..............66

1.2. Desde los umbrales: la apoyatura crítica................................... 86

1.3. De la biblioteca heredada a la biblioteca creada...............................95

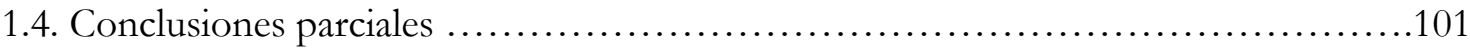

II. Modos heterogéneos de construir la identidad y la genealogía literaria Margarita

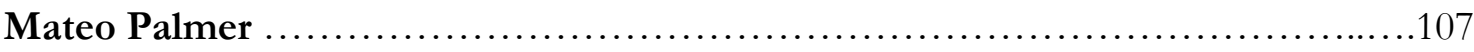

2.1. Ella escribía poscrítica: la construcción discursiva del sujeto escritora................108

2.1.1 De los muros y la escritura o la puesta en acto del cruce de géneros...............119 
2.1.2 Los embates de escribir en Cuba en los noventa 123

2.1.3. Reflexiones preliminares. 125

2.2. Desde los blancos manicomios: devorar (para homenajear) la literatura. .128

2.2.1. Confinar la locura 131

2.2.2. Construir la identidad (múltiple). 136

2.3. Decir el Caribe 150

2.3.1. Ella escribía poscrítica o los modos de ser caribeños 152

2.3.2. El aIslamiento: pensar la isla y el Caribe desde los blancos manicomios.....160

2.4. Conclusiones parciales. 176

III. Torsiones de género (sexual y literario): la construcción de la subjetividad en la narrativa de Ena Lucía Portela.... 179

3.1. Ars poética: el autorretrato en "El viejo, el asesino y yo".

3.1.1. La escritura del cuerpo y el cuerpo de la escritura..... 188

3.1.2. Batallar la tradición: sujetos que desestabilizan el campo literario 194

3.2. (Re)visiones de género: Cien botellas en una pared...............................196

3.2.1. Lecturas y relecturas del policial en Cuba. 200

3.2.1.1 Torsiones al/del género: "Inmóvil, sedentaria, fija como un musguito a la piedra" .202

3.2.1.2 Nuevos trazos de la ciudad: La Habana y los espacios de creación......211

3.2.1.3 Balconear la ciudad y elegir el adentro.............................218

3.2.2. Tensiones en torno a la ficción.....................................222

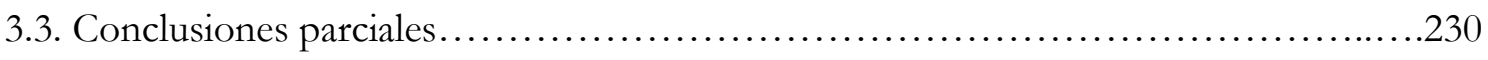

IV. Cuando el silencio dibuja el comienzo. Karla Suárez y Wendy Guerra. .235 
4. 1. La lengua del silencio: una urdimbre identitaria

.237

4.1.1. Apre(he)nder el silencio como práctica de resistencia.....................242

4.1.2. Apre(he)nder la literatura como refugio del silencio .....................250

4.1.3. El cuerpo de la escritura y la escritura del cuerpo......................257

4.1.4. El silencio como imperativo estético e identitario.......................260

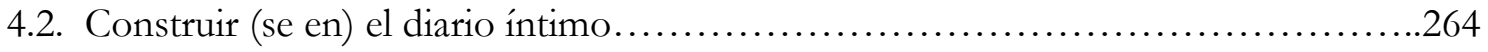

4.2.1. Flirtear con la autobiografía: el diario íntimo..........................271

4.2.2. Los límites del cuerpo: la escritura y el hambre.........................280

4.2.3. La imposibilidad de la (auto) (re) presentación: Nieve en La Habana........287

4.3. Conclusiones parciales.................................................292

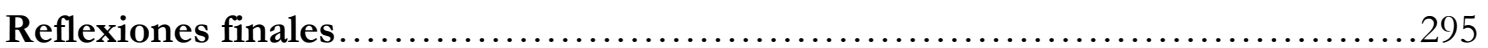

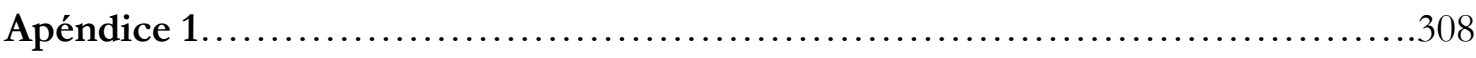

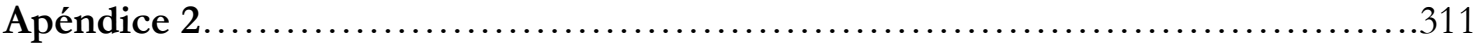

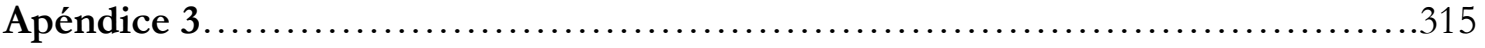

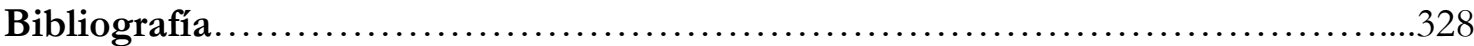




\section{Agradecimientos}

Durante los años que duró el periplo de esta investigación, muchas personas e instituciones me ayudaron de manera diversa y en diferentes momentos. En primer lugar quiero agradecer a las tres personas que me guiaron en este camino de aprendizaje: Celina Manzoni, Alejandra Mailhe y Graciela Salto. Gracias: por la generosidad intelectual, por la lectura atenta y minuciosa, y por haberme abierto las puertas de sus grupos de estudio. Durante estos años aprendí al escucharlas, al leerlas y, claro, en sus múltiples (y, por qué no, agobiantes) correcciones. Me enseñaron el rigor y la pasión que conlleva la investigación. Gracias por el apoyo constante, por haberme acompañado, respetado y aconsejado en los tramos difíciles de este obstinado tema (o, mejor dicho, de la obstinada tesista). En especial, quiero agradecer a Graciela Salto porque lo que comenzó ya hace algunos años cuando, sin saberlo, me deslumbró en sus clases de literatura latinoamericana de la UNLPam, se materializa, de alguna manera, en estas páginas que mucho tienen de su acompañamiento intelectual y emocional.

También quiero agradecer a quienes conocí en este camino. A mis compañeras/os del Grupo de Estudios Caribeños que dirige Celina Manzoni en el ILH de la UBA: María Fernanda Pampín, Francisco Aiello, Guadalupe Silva, Elsa Noya, Ana Eichenbronner, Mariela Escobar y Ariela Schnirmajer. Gracias por las lecturas sugeridas, por las discusiones compartidas y por los enriquecedores intercambios de pasiones caribeñas. También a mis compañeras/os del grupo de estudio del Centro de Estudios de Teoría y Crítica Literaria de la UNLP dirigido por Alejandra Mailhe y Carolina Sancholuz: Martín Catilla, Rosario Pascual, Javier Planas, Roxana Calvo, Simón Henao y Julieta Novau. Gracias por la maravillosa idea de compartir la experiencia de escritura: las suspicaces y minuciosas 
correcciones me permitieron revisar lo hecho; leer sus proyectos me ayudó a conocer nuevos temas.

Son numerosos los compañeros de trabajo de la Facultad de Humanas de la UNLPam con los que compartí lecturas en los sucesivos proyectos de investigación dirigidos por Graciela Salto: Pía, Sonia, Daniela, Nancy, Marisa, Carolina. En especial, agradezco a Diana Moro, por las conversaciones sobre los avatares de la tesis, por el apoyo concreto y cotidiano.

Debido a los problemas de circulación editorial que aqueja a nuestra América, debo agradecer infinitamente a quienes me ayudaron en la difícil tarea de acceder a las fuentes. A Nacho, mi hermano, obligado a realizar itinerarios no turísticos por La Habana. A Mirta Yáñez, por su predisposición, por su generosidad, por los libros y por su amistad. A Amir Valle, por los datos que hubieran sido inaccesibles sin su contacto directo. También debo agradecer a Nancy Sad y a Ana Eichenbronner por los libros traídos (y de paso pedir disculpas por el peso extra).

En un plano institucional, deseo mencionar al Conicet y a la UNLPam, porque la beca de doctorado me permitió disponer de un tiempo para pensar, estudiar, leer y escribir que, de otro modo, la vorágine del trabajo docente no me lo hubiera permitido.

Como creo que la vida profesional no se desliga de la intensidad de la vida afectiva, por último, debo agradecer a las personas de mi círculo más íntimo. A Agus y María, mis queridas hermanas, por la presencia constante en otros acompañamientos. A Ana María Jose, Susy y Marián, por el cálido cobijo en estos años que mucho han tenido de trashumantes. Un lugar especial tienen mis amigas y compañeras de estudio en este camino en el que quemamos tantas naves y construimos nuevas: Silvia, Pía y Ceci. Gracias por el espacio que inventamos, nuestro "cuarto no tan propio" que nos permitió crear un clima de trabajo, camaradería, intercambios de múltiples experiencias emotivas e intelectuales y, 
por sobre todo, aprender nosotras y hacer entender a los demás que, "investigar es trabajar". Gracias, amigas, por el apoyo incondicional y por el sostén emocional.

Y si algo ha sido intenso en estos años, ha sido mi vida afectiva. Por eso, ante todo, agradezco a mis tres amores. Sin ellos hubiera contado con más tiempo pero con menos pasión: el cable a tierra que me sustraía del mundo de la tesis para recordarme, todos los días, que la vida es mucho más. A Camilo: tu alegría y tus preguntas distendieron momentos de brumas y me dieron fuerzas para cumplir este proyecto. Perdón por las ausencias, los tantos viajes y los paseos postergados en triciclo y luego en bicicleta. A Ulises, porque tu llegada fue el impulso final para dar un cierre a esta etapa y comenzar una nueva. Y mis disculpas por los nervios transmitidos en la cuna de mi cuerpo y luego, mientras un brazo te acunaba y una mano bosquejaba ideas sobre el teclado. A Jorge, mi gran evaluador, por acompañarme y sostenerme en este largo camino. Gracias. Gracias, por confiar en mí más que yo misma.

A mis padres porque desde pequeña me inculcaron, con palabras y con actos, la importancia que tiene el conocimiento. En especial a mi madre porque se fue cuando esto comenzaba: $\sin$ (y con) vos aprendí sobre la relatividad del espacio-tiempo. Mi curiosidad por lo que no sé y el amor por la lectura nacieron de (y por) vos. Gracias por iniciarme (un poco a tu pesar) en este maravilloso mundo de la literatura y de la docencia. 


\title{
Introducción
}

\author{
Un espejo, quizás. \\ La mijer se sentó ante un espejo \\ y alrededor de su cabeza \\ revoloteaban pájaros \\ y las luces mortecinas de la cindad. \\ En el espejo \\ habia un pan sobre la mesa \\ y un farol chino que alumbraba dos libros. \\ El corazón de la mujer \\ alivió a los enfermos.
}

Nancy Morejón, Cuerda veloz:

\section{Presentación general}

Desde mediados del siglo pasado, el ámbito cultural cubano ha generado sucesivas miradas críticas que atendieron a las singulares características de su producción y a las mediaciones que ha significado la Revolución Cubana. La crítica ha advertido que, en las últimas décadas, una de las características de las realizaciones literarias cubanas es la diseminación espacial en que se produce y la variedad estilística de un cuerpo literario que dialoga y batalla entre sí (Rojas, 2006). Es en este contexto que las obras literarias de escritoras cubanas adquieren una inusitada visibilidad que debe pensarse en el marco de un proceso cultural, económico y tecnológico que alcanza a toda la producción tanto dentro como fuera de la isla. En este proceso las revistas culturales y los nuevos medios tecnológicos de diseminación de la información han tenido un papel protagónico (Valle, 2001). ${ }^{1}$ Sin

\footnotetext{
${ }^{1}$ Desde hace más de una década, Cuba se inserta en el mundo electrónico y cibernético a través de una proliferación de revistas virtuales y de blogs. Entre las primeras, se encuentran La Jiribilla, La Ventana (noticiero de Casa de las Américas), Opus Habana (órgano de la Oficina del Historiador de La Habana, que regularmente publica entrevistas con intelectuales), La Habana Elegante, Cubaliteraria, Arteamérica (de la revista
} 
embargo, aunque hoy el éxito editorial acompaña parcial e incipientemente a la narrativa escrita por mujeres, cuando se habla de la historia literaria cubana, la voz masculina (José Martí, Julián del Casal, Fernando Ortiz, Nicolás Guillén, Alejo Carpentier, José Lezama Lima, Cintio Vitier, Virgilio Piñera, Reinaldo Arenas, Guillermo Cabrera Infante, Severo Sarduy, entre otros $)^{2}$ sigue estando en el centro de las disputas ideológicas y estéticas en que se debate la construcción de las historias de la literatura nacional. ${ }^{3}$ En este sentido, Rafael Rojas advierte que esta teleología del sujeto nacional -letrados blancos, católicos y criollos — ha marcado la cultura cubana desde el siglo XIX y que "es probable que detrás de estos mecanismos del canon estético actúe una voluntad de silenciamiento o ‘neutralización’ de la voz femenina dentro del metarrelato de la identidad nacional” (Rojas,

de Casa de las Américas), Mujeres en Line@ (del Programa de Estudios de la Mujer en Casa de las Américas), por mencionar sólo algunas. Entre los blogs, el caso más difundido es el Yoany Sánchez (Generación Y). También el de una escritora considerada en el corpus: Wendy Guerra tiene el blog Habáname en el diario español ElMundo.

${ }^{2}$ El proceso de canonización de José Lezama Lima, operación institucional que en Cuba tiene carácter estatal, merece una investigación aparte y no podré desarrollarlo aquí. Sin embargo, resulta necesario aclarar que la recuperación oficial de Lezama estuvo acompañada por la reivindicación de todo el grupo origenista, y esto se debe en buena medida al trabajo revisionista de Cintio Vitier, quien al integrarse en los setenta al proyecto revolucionario (junto a Fina García Marruz y Eliseo Diego), se propuso demostrar que, en realidad, Lezama y su grupo ya avizoraban la inminencia de la revolución. En "Lo cubano en Vitier" (2012) Guadalupe Silva realiza un minucioso desarrollo de la operación de este integrante de Orígenes. Un libro interesante sobre cómo fue leído Lezama en Cuba es El libro perdido de los origenistas (2002) de Antonio José Ponte. También hubo otras recuperaciones no oficiales realizadas desde el exilio: por ejemplo, Lorenzo García Vega escribe Los años de Orígenes (1978); los "marielitos" (entre ellos, Reinaldo Arenas) publican en Miami la revista Mariel (1983-5) cuyo primer número se dedica a Lezama; Severo Sarduy se declara heredero de Lezama y realiza una lectura muy influyente de su obra.

${ }^{3}$ En el cuerpo del trabajo señalo "voz masculina” pero, para ser más precisa, debería agregar "masculina y blanca" debido a las controversias que la cuestión de lo negro-africano tiene en Cuba. Por eso, aclaro que, excepto en casos como el de Nicolás Guillén y Nancy Morejón y esfuerzos descolonizadores como el de Fernando Ortiz, Lydia Cabrera, Alejo Carpentier o Roberto Fernández Retamar, pocos artistas e intelectuales han asumido y legitimado la condición negro-africana del origen cultural cubano. En Cuba, lo canónico es la cosmovisión del grupo dominante blanco y masculino (Fowler, 2002; Zurbano, 2006). Aunque el triunfo de la Revolución incorporó nuevos elementos al debate, la concepción del racismo en la tradición marxista reconoce la presencia de esta práctica dentro del lugar de trabajo (por ejemplo, la discriminación en el empleo y la desigualdad estructural de los salarios), pero guarda silencio sobre esas operaciones en otros espacios. En este sentido, Roberto Zurbano (2006) señala que ni en el plano familiar, ni en la mentalidad social, ni en las nuevas estructuras y pensamientos institucionales fueron encauzadas las críticas y las posibles soluciones emancipatorias para un grupo social que llega a la etapa revolucionaria con evidentes desventajas históricas. Y precisa que, en el campo literario "se observa [tanto] una zona minada de prejuicios y otras dificultades para el estudioso" (Zurbano 2006: 112), como la necesidad de "nuevos enfoques y cartografías, para interrogar la situación del sujeto escritor negro en la historia social cubana" (Zurbano, 2006: 112). Para ampliar esta problemática, consultar: Fowler (2002); Zurbano (2006); Espina Prieto (2006); Alfonso (2012); Fernández Martínez (2012). 
2000: 56). En un campo tan diseminado como el cubano, los escritores administran sus guerras y alianzas por medio de lo que se ha dado en llamar "políticas intelectuales de la escritura" (Rojas, 2006: 363). Por eso, a lo largo de este estudio analizo la producción narrativa escrita por mujeres durante los últimos años ya que entiendo que ha sido silenciada y excluida del canon, sin que se consideren los rasgos literarios sino, fundamentalmente, porque sus autoras son mujeres (Campuzano, 1988 y 2004; Capote Cruz, 2004 y 2008; Yáñez, 1996). ${ }^{5}$ Esta tesis se ocupa de estudiar un corpus producido por escritoras cubanas como parte de un grupo que ha sido marginado, en términos simbólicos, respecto del campo cultural cubano. ${ }^{6}$ En este sentido, procuro contribuir al conocimiento de un área escasamente trabajada en la bibliografía académica. Tal como señala acertadamente Jean Franco,

...no se trata de averiguar si las escritoras tienen temas específicos o un estilo diferente a los hombres, sino explorar las relaciones del poder. Todo escritor, tanto hombre como mujer, enfrenta el problema de la autoridad textual o de la voz poética ya que, desde el momento en que empieza a escribir, establece

\footnotetext{
${ }^{4}$ En el centro del canon, la crítica y la historiografía han ubicado, ya desde los años cuarenta y cincuenta, a José Martí. Rafael Rojas propone una lectura de los mecanismos de autoridad literaria que formalizan el canon de la literatura cubana. Uno de los mecanismos es el paralelo estilístico o la estructura binaria, como forma de establecer el canon y el contracanon. El primero estaría integrado por Zequeira, Manzano, Martí, Boti, Ballagas y Lezama; quienes prefieren esta galería "se afilian a una noción dura y centrada de la cubanidad donde predominan los ontologemas de 'lo autóctono', lo 'propio', lo ‘sincero', lo ‘telúrico”' (Rojas, 2000: 60). En el contracanon estarían Rubalcava, Plácido, Casal, Poveda, Florit, Piñera y quienes se inclinan hacia él “admiten cierta 'cubanización' de la 'ingravidez', el 'nihilismo', la 'artificialidad', la 'rareza”' (Rojas, 2000: 61). Rojas discute el canon establecido por Harold Bloom en El canon occidental, obra en la que aparecen seis cubanos: Nicolás Guillén, Alejo Carpentier, José Lezama Lima, Reinaldo Arenas, Guillermo Cabrera Infante y Severo Sarduy.

${ }^{5}$ Rafael Rojas (2006) distingue y analiza tres políticas de la escritura en la narrativa cubana actual: "la política del cuerpo, la de la cifra y la del sujeto. Estas políticas gravitan desde la periferia hacia el centro del campo, forcejeando unas con otras, disputándose los mensajes públicos, protagonizando sus trifulcas y alborotos" (Rojas, 2006: 363). Este crítico intenta demostrar que estas tres políticas intelectuales movilizan la narrativa cubana hacia un espacio de significaciones centrado en lo nacional.

${ }^{6}$ Cabe aclarar que considero el concepto "marginal" no como un estado constante, sino en un sentido dinámico y relativo, ya que las mujeres pertenecen a diferentes grupos (familiares, laborales, barriales, etc.) con reglas propias. Así, es posible encontrar escritoras que entren y salgan de la condición de marginalidad según las diferentes situaciones y circunstancias en que se encuentren. Además, cada mujer, a su vez, está determinada por la clase a la que pertenece, la edad, la etnia, la religión, la profesión y el grado de inserción en espacios institucionales, entre otras variables. Estos elementos actúan como diferenciadores, en virtud de los cuales puede ser considerado como "marginal" con respecto a cada uno de los campos en los que interviene.
} 
relaciones de afiliación o de diferencia para con los "maestros" del pasado (Franco 1986: 41).

El recorrido crítico ofrecido en estas páginas responde a esta preocupación, y al intento de establecer las maneras en que los textos aquí analizados realizan una ficcionalización del espacio cultural. En esa ficcionalización se construyen recurrentemente figuraciones de mujeres artistas/escritoras presentadas sobre todo como sujetos "marginales" que, en un contexto de crisis, cuestionan las reglas del campo intelectual (vivenciado en los textos como "patriarcal") y pugnan por (re)construir su identidad. Esta construcción rompe con cualquier esencialismo y homogeneización.

En la disposición argumental de esta tesis, la secuencia de los capítulos es, hasta cierto punto, cronológica, lo cual no significa necesariamente que haya continuidad entre las escritoras. Elegí tomar como punto de partida de este complejo entramado la primera antología de escritoras cubanas, titulada Estatuas de sal. Cuentistas cubanas contemporáneas, publicada en 1996, pleno "Período especial”, por Mirta Yáñez y Marilyn Bobes. Así, en el primer capítulo analizo los supuestos que subyacen en la publicación de este controvertido libro que buscó construir una genealogía de mujeres escritoras. Si esta compilación contribuye al ejercicio de crear una tradición, resulta imprescindible pensar las tensiones subterráneas que sostienen sus cimientos. Estatuas de sal propone rupturas y desvíos para intentar ampliar el canon y, en este sentido, construye una genealogía paralela o por fuera de la canónica. ${ }^{7}$ En esta dirección me pregunto por qué se publica en ese momento; si es el

\footnotetext{
${ }^{7}$ Existen distintas posiciones respecto de si es posible hablar de canon en Cuba o, en sentido continental, en América Latina. Rojas (2000) da por supuesto el concepto y señala que el canon cubano persigue el objetivo de establecer la jerarquía valorativa de aquellos textos literarios en los que mejor se narra la nación. Demuestra su hipótesis con un recorrido que va desde las primeras historias de la literatura cubana a mediados del siglo XIX hasta la actualidad. Desde otra perspectiva, Susana Zanetti (2000) pone en duda la existencia del canon literario latinoamericano: "Me parece que, cuando empezamos a avanzar en el tema,
} 
resultado de una presión del campo cultural o si responde a un encargo oficial convergente con una preocupación estatal que impulsa atender cuestiones de género. En este capítulo también reviso cómo la misma operación de publicar la antología coloca en la palestra a un grupo de escritoras contemporáneas a la publicación del libro y busca proyectar el porvenir de la narrativa escrita por mujeres.

El segundo capítulo está dedicado a la obra ensayística y literaria de Margarita Mateo Palmer (La Habana, 1950). Hasta 1996 su producción no se encuadraba en los límites de lo ficcional -para ese entonces ya circulaban dos libros de crítica de su autoría: Del bardo que te canta, 1988 y Literatura caribeña: reflexiones y pronósticos, 1990—, aunque su obra ensayística bordea reiteradamente las fronteras del género. Para pensar en torno de los desplazamientos genéricos en estas páginas analizo Ella escribía poscrítica (1995), publicado en pleno "Período Especial en Tiempos de Paz". Se trata de un ensayo que transita por la ficción, el testimonio, la autobiografía, las epístolas, géneros todos que apuntan a un tema central: la reflexión sobre la posmodernidad en el contexto latinoamericano, caribeño y cubano en particular. Por estar enmarcado claramente dentro del discurso literario, pero con irrupciones de la mano ensayística de la escritora, también estudio la proliferación intertextual como una de las claves de lectura en Desde los blancos manicomios (2010), su primera novela. En ambos textos la multiplicación de géneros e intertextos, así como la construcción de sujetos que rompen con la homogeneidad, constituyen marcas que ponen en entredicho el canon establecido.

Los capítulos tercero y cuarto se centran en la producción narrativa de Ena Lucía Portela (La Habana, 1972), Karla Suárez (La Habana, 1969) y Wendy Guerra (La Habana,

comienza a merodear, hasta a veces imponerse de manera abrupta, la idea de que nuestro canon, en el sentido más habitual de 'textos y/o autores dignos de ser preservados', y 'preservados de diferentes modos por las instituciones a lo largo del tiempo’ forma parte de una 'iluso', en el sentido de Bourdieu, mucho más palpable, mucho más evidente que en otros recortes de experiencias culturales, siempre abiertos a la suspicacia (¿Qué quiere decir "canon occidental'?)" (Zanetti, 2000: 228). Y señala que los cánones en América Latina son "en verdad, nacionales" (Zanetti, 2000: 234). 
1970). En las obras de estas jóvenes escritoras se producen desvíos de género (sexual y literario); en este sentido, la escritura se constituye en un espacio fundamental para procesar la identidad del sujeto. En estos capítulos analizo cómo se construyen figuras de escritoras, lo cual permite leer cómo se configura el lugar del sujeto de enunciación en el campo literario en relación con sus contemporáneos y con los precursores, así como también entender cómo se perciben a sí mismas. La reclusión en el ámbito de lo privado, en el silencio, en la soledad producto del abandono de los seres queridos, o como elección de vida, constituyen recurrentes posiciones adoptadas por las protagonistas de estas historias enmarcadas en la crisis que atraviesa Cuba desde principios de los noventa. Este corpus narrativo se produce, por otra parte, en un momento en que el mercado editorial cubano adquiere tintes específicos debido a la proliferación de ediciones realizadas, principalmente, en España (Rojas, 2007). En este sentido, los textos que integran este corpus procesan las fracturas internas, la densidad y los bordes del campo cultural cubano signado por el conflicto inherente al contexto socio-histórico en que se enmarcan, a las tensiones culturales y políticas que suscita la diáspora y a la evidente supremacía patriarcal de las leyes que regulan el funcionamiento del mismo campo. ${ }^{8}$

\footnotetext{
${ }^{8}$ En el campo cultural cubano hay diferentes posiciones respecto de cómo nombrar a los que se fueron de la isla y, en el caso analizado, su producción literaria. Sin entrar en un debate que excede ampliamente los límites de este estudio, mencionaré dos posiciones: aquellos que optan por el término "diáspora" y los que eligen "exilio" u optan por el neutro "emigración" (este último, por ejemplo, adoptado por José Antonio García Miranda, 2002). En 1993 Ambrosio Fornet inicia en La Gaceta de Cuba la publicación de textos de la diáspora, una selección de los cuales reúne luego en Memorias recobradas. Fornet propone incorporar "la producción simbólica de la diáspora al horizonte de expectativas de nuestras reflexiones críticas, es decir a la corriente interna de la literatura cubana" (Fornet, 2000: 22). Víctor Fowler (1996) también se acerca a esta idea. Por el contrario, Rafael Rojas critica esta opción porque sostiene que responde a un "canibalismo selectivo" (Rojas, 2006: 49) y elige "exilio" por su carga política. Los escritores cubano-americanos que escriben en las últimas décadas (Cristina García, Pablo Medina, Gustavo Pérez Firmat, Achy Obejas, Antonio Vera León, por nombrar algunos) se alejan de este término y se acercan a la localización bicultural debido a la hibridez de su propia identidad: dos lenguas, dos costumbres, dos culturas, dos naciones. Respecto de esta situación bicultural, Rojas habla de una "estetización del limbo" (Rojas, 2006: 416). La idea de "exilio" también fue rechazada desde mediados de los ochenta por autores cubano-americanos debido a su infatuada política de la nostalgia. Para un desarrollo de este debate, consultar Rafael Rojas (1999 y 2006).
} 
En relación con esta investigación, debo señalar primero que el objetivo no consiste en estudiar la totalidad de la producción literaria de escritoras cubanas (no sólo por razones tan obvias, como la dificultad de acceso a un terreno tan vasto y complejo). Por otra parte, la lectura realizada desde una distancia geográfica respecto del campo cultural que se indaga se ha visto enriquecida por los aportes de numerosos estudiosos y así lo indico en las notas y en la bibliografía correspondiente.

Antes de ingresar en el análisis del corpus, creo necesario explicitar los conceptos teórico-metodológicos generales sobre los que se apoya el análisis y, específicamente, realizar precisiones sobre la teoría de género porque es uno de los hilos conductores que subyace en mi perspectiva de análisis. Algunos conceptos que me permitieron perfilar las lecturas, también estimularon mi capacidad de percepción. Aunque los pongo en funcionamiento a lo largo de los capítulos (y, en algunos casos, introduzco en su interior algunas cuestiones teóricas), desarrollo a continuación los que considero centrales. En un apartado posterior enmarco socio-históricamente el corpus de investigación a través de referencias breves dado que en esta oportunidad trato de ofrecer apenas un trasfondo histórico de los aspectos culturales que visibilizan la producción de escritoras cubanas, sobre los cuales me centro con mayor profundidad.

\subsection{Algunas consideraciones teórico-metodológicas}

Los textos que integran el corpus son entendidos como espacios de contradicción y de lucha simbólica, como hechos literarios cargados de historicidad, como formas artísticas en relación dinámica con las transformaciones sociales. Apelo a la teoría de Mijail Bajtín (1986) respecto de los géneros discursivos como espacios dialógicos en los que se insertan numerosas voces que rearticulan los discursos sociales y procesan críticamente los lugares discursivos "hegemónicos". Asimismo, atiendo al vínculo que existe entre ciertos géneros 
literarios y las clases sociales en las que se producen. En este sentido, también son útiles los aportes de Roland Barthes (1973) y de Terry Eagleton (1983) respecto del análisis de las formas literarias en épocas de transformación social, porque nos ayudan a caracterizar la situación de la escritura de mujeres cubanas durante el convulsionado fin de siglo XX.

El enfoque de esta investigación ubica la circulación de los discursos en el marco de procesos sociales entendidos en términos de relaciones de poder. En este sentido, para pensar el sistema de posiciones que ocupan las autoras analizadas en el espacio cultural cubano, utilizo el concepto de "campo intelectual" tal como lo formula Pierre Bourdieu (1983 y 1992), aunque no desconozco los debates en torno al uso del concepto de "campo" para el contexto latinoamericano. ${ }^{9}$ En este sentido, considero acertada la postura de Julio Ramos (1989) respecto de pensarlo como un espacio cultural en formación, inestable y dependiente del campo político. ${ }^{10}$ Aunque reconozco las particulares limitaciones del campo intelectual cubano -debido, principalmente, a la fuerte injerencia del Estado-, apelo a este concepto porque resulta útil para explicar la dinámica que adquiere después de 1959. Desde esta perspectiva, tengo en cuenta que la ubicación de los agentes sociales (las autoras) —el lugar desde donde hablan, marcado por múltiples variables— determina su capacidad de producir e imponer sentidos según su posición en el sistema de relaciones. Esto permite explicitar el lugar que ocupan las escritoras analizadas y el espacio en el que circulan sus producciones.

\footnotetext{
${ }^{9}$ El concepto de "campo intelectual" ha sufrido cambios en sus formulaciones; en Las reglas del arte Pierre Bourdieu lo define como "un universo que obedece a sus propias leyes de funcionamiento y de transformación, es decir, la estructura de las relaciones objetivas entre las posiciones que ocupan en él individuos y grupos colocados en situación de competencia por la legitimidad" (Bourdieu, 1995: 298). Su propuesta consiste en analizar la inserción del campo intelectual en el campo del poder y la estructura interna del campo, antes de comenzar por algún agente individual. Para la crítica aún resulta controvertido poner en funcionamiento el concepto de "campo" para pensar América Latina porque fue pensado para el contexto francés.

10 Julio Ramos (1989) estudia un corpus de fines del siglo XIX y principios del XX. Sin embargo, considero que su propuesta para pensar el canon puede extenderse hasta fines del siglo XX, período en que se enmarca mi corpus.
} 
A los efectos de esta investigación, resulta útil el concepto de "hegemonía" utilizado por Raymond Williams (1997), porque se convierte en un concepto que, a la vez, incluye $-\mathrm{y}$ va más allá del— concepto de cultura (entendida como proceso social total en que los hombres definen y configuran sus vidas) y del de ideología (entendida como un sistema de significados y valores que constituyen la expresión de un particular interés de clase). ${ }^{11}$ Desde esta perspectiva es posible pensar la hegemonía no como una totalidad inalterable sino como un proceso, como algo que se transforma y que está acechado por fuerzas contrahegemónicas que la resisten, la limitan, la alteran e intentan desafiarla. Por eso, para que persista como tal debe ser continuamente renovada, recreada, defendida y modificada. Se observa así que la hegemonía para Williams es inestable y porosa porque supone límites y presiones al entrar en juego no sólo el concepto de contrahegemonía sino también el de hegemonía alternativa, entendidos ambos como elementos reales y persistentes de la práctica hegemónica. Para la teoría de Williams, la tradición es la expresión más evidente de las presiones y límites dominantes y hegemónicos. Explicita que una tradición selectiva es una versión intencionalmente selectiva de un pasado configurativo y de un presente preconfigurado; en este sentido, para Williams la noción de tradición constituye una teoría de la incorporación: “el método de incorporación práctico más poderoso" (Williams, 1997: 137), útil para pensar cómo determinadas fuerzas de una cultura (en este caso, la cultura cubana) deciden que ciertos significados y prácticas sean seleccionados y acentuados, y otros, rechazados o excluidos.

Aunque Williams considera que el proceso de la tradición selectiva es muy poderoso porque se liga a una serie de continuidades prácticas — como la familia, las instituciones, la lengua-, también reconoce su vulnerabilidad ya que debe descartar otras

\footnotetext{
${ }^{11}$ El concepto de hegemonía adquiere connotaciones especiales a partir de los escritos de Gramsci. En Palabras claves (2000) Williams realiza un recorrido por las transformaciones que ha sufrido el término.
} 
áreas de significación, reinterpretarlas, diluirlas o convertirlas en formas que sostengan $-\mathrm{O}$ al menos, no contradigan — los elementos de la hegemonía. En este sentido, entiende que el registro de las prácticas alternativas o en oposición siempre está oculto y ejerciendo presión, pero no desaparece. Así, la tradición selectiva es pensada como un campo de disputa sobre el armado de las líneas estéticas e ideológicas; es el campo de un enfrentamiento por la hegemonía cultural en el que cada fracción intelectual se relaciona con el pasado selectivamente.

Para Williams, la conformación de una tradición selectiva depende de instituciones (económicas, culturales y políticas) identificables, y de formaciones (con un papel cada vez más activo en las sociedades actuales), entendidas como los movimientos y tendencias efectivos, en la vida intelectual y artística, con una influencia significativa sobre el desarrollo activo de una cultura, y una relación variable -y a veces solapada- con las instituciones formales. En la construcción de la tradición juega un papel fundamental la crítica, a la que Williams caracteriza, desde la perspectiva del desarrollo socio-histórico, como una forma de control y de especialización de una clase sobre una práctica social general. Sostiene que la crítica se ha convertido en el único medio de validar la categoría "literatura" de modo selectivo y especializado; su tarea consiste en "una discriminación de las obras auténticamente 'grandes' o 'principales', con la consecuente categorización de obras 'menores' y una exclusión efectiva de las obras 'malas' o 'insignificantes', a la vez que una comunicación y una realización prácticas de los 'principales' valores” (Williams, 1997: 66; itálica en el original).

De la teoría williamsiana también retomo los conceptos "dominante", "residual” y "emergente" ya que me permiten pensar las relaciones intrínsecas a la dinámica ideológica implícita en los textos que integran el corpus. En este análisis resulta funcional pensar los elementos de diferente temporalidad que coexisten en una misma formación cultural y que 
caracterizan las relaciones dinámicas y los contrastes en el interior de una misma cultura. También el concepto de "estructuras del sentir" (eje de la teoría williamsiana de la cultura como conflicto) permite pensar la literatura ( $\mathrm{y}$ el arte en general) como malestar y resistencia, como espacio en el que es posible percibir y/o forjar los cambios que aún no se han producido socialmente. Tengo en cuenta la advertencia de Williams acerca de que no todo el arte se relaciona con una estructura del sentir contemporánea, ya que la mayor parte se vincula con formaciones sociales que ya son manifiestas, dominantes o residuales. Frente a un modelo cultural como el cubano (que se pretende unívoco, articulado en un sistema de convenciones, ideas y actitudes valoradas), el concepto de "estructuras del sentimiento" resulta clave para percibir lo disimétrico o divergente respecto del modelo. Como advierte Williams, las formas y los dispositivos de la cultura (procedimientos, tonos, estrategias narrativas, etc.) son "pruebas de los atascos y problemas no resueltos de la sociedad, reacciones y respuestas, presiones y bloqueos con que 'lo vivido' se produce en términos de un excedente que siempre deja 'constancia de las omisiones' y altera tarde o temprano los límites de una hegemonía que sólo parcialmente puede incorporarlo" (Dalmaroni, 2001: 45; itálica en el original). Williams advierte que en todas las configuraciones culturales hay una réplica contra la dominación y siempre alguna significación crítica. En este sentido, la estructura del sentir resulta operativa como hipótesis para el estudio de las obras literarias y de grupos o constelaciones de obras en el contexto cubano de fines del siglo XX.

Por último, para pensar las figuraciones, las filiaciones y las afiliaciones que las escritoras realizan en sus textos, en esta investigación utilizo los aportes de Pierre Bourdieu y Edward Said. El sociólogo francés plantea que los propios escritores suelen construir una representación de sí mismos como intelectuales; más que estar determinados por unas circunstancias históricas o condiciones de existencia, se auto determinan a partir de una multiplicidad de variables como su condición de clase, su etnia, su sexo, su posición en el 
campo cultural, entre otras. Por su parte, Said al preguntarse sobre el intelectual solitario, señala que la conciencia individual está situada en un delicado punto crucial: "por una parte, la mente individual se inscribe en y es muy consciente del todo colectivo" y por otra parte "la conciencia individual no es simple y naturalmente una mera hija de la cultura, sino un factor histórico y social dentro de ella" (Said, 2004: 29). Said menciona dos formas de vinculación de la conciencia crítica con la cultura, a través del trabajo intelectual: la filiación y la afiliación. La primera es natural, biológica, refiere a los vínculos entre padres e hijos y a la transmisión por vía filial de un patrón de valores y concepciones ideológicas; mientras que la afiliación serían los vínculos sociales de segundo orden: un partido político, una institución, una cultura, un conjunto de creencias que proporcionan una nueva forma de relación. De este autor también utilizo la noción de "textos de inicio" que desarrolla en Beginnings. Intention \& Method (1985). Aquí desarrolla la noción de "comienzos" entendido como el primer paso en la producción intencional de sentido que puede recorrer toda o parte de la obra de un autor; en este sentido, la noción de "comienzos" supone un proyecto subyacente. Said advierte el sentido de origen que subyace en este concepto y señala otros: un momento en el tiempo, un lugar, un principio o una acción. Asocia el topos del comienzo a una idea de precedencia y/o de prioridad y considera que, generalmente, involucra también la designación de una intención subsiguiente. Por intención, Said entiende un deseo por hacer algo de una manera particular, consciente o inconscientemente, pero en cualquier caso, en un lenguaje que muestra de alguna forma signos de intención de comienzo y que está deliberadamente relacionado con la producción de sentido. En relación con una obra dada o un conjunto de obras, la intención de comienzo no es otra cosa que las "inclusividades" creadas dentro de la/las cual/es se desarrolla la obra. ${ }^{12}$ En

\footnotetext{
12 La traducción me pertenece. El original dice: "By intention I mean an appetite at the beginning
} intellectually to do something in a characteristic way -either consciously or unconsciously, but at any rate in a 
esta línea, es posible ubicar la categoría de comienzo/inicio para analizar la obra de las escritoras del corpus, el vínculo inicial con el espacio filiativo y el proceso de vinculaciones afiliativas en sus búsquedas éticas, políticas y estéticas.

\subsection{Estudios de género}

Para el análisis del corpus, utilizo algunas contribuciones teóricas importantes del feminismo, atendiendo a las teorías que ponen énfasis en la noción de "multiplicidad de identidades" y que permite comprender las desigualdades entre varones y mujeres. ${ }^{13} \mathrm{El}$ género como categoría transdisciplinaria (Amorós, 1986; Scott, 1993; Femenías, 2000; Gamba, 2007) remite a los rasgos y funciones psicológicas y socioculturales que se atribuyen a cada uno de los sexos en cada momento histórico y en cada sociedad. Ha aportado una mirada que devela cuestiones ocultas en distintos contextos socio-históricos y, en el campo literario, esta categoría ha permitido realizar lecturas que ponen en evidencia los supuestos que subyacen en los discursos (en nuestro caso, tanto en los textos literarios como en las posiciones explícitas de los escritores y de las escritoras, que a veces subvierten y otras reproducen los estereotipos de género). También, pensar esta perspectiva desde el análisis literario, tiene la intención de visibilizar autoras y poner en evidencia que la literatura escrita por mujeres ha sido menospreciada, silenciada o excluida del canon. Esta perspectiva será uno de los enfoques adoptados en esta investigación; por eso partimos de considerar que las relaciones de género suponen relaciones de poder (articuladas con otras relaciones como las de clase, etnia, edad, elección sexual, entre otras) y que estas relaciones

language that always (or nearly always) shows signs of the beginning intention in some form and is always engaged purposefully in the production of meaning. With regard to a given work or body work, a beginning intention is really nothing more than the created inclusiveness which the work develops" (Said 1978: 12).

13 No desconozco que las posiciones teóricas e ideológicas desde las que se aborda la perspectiva de género son variadas, problemáticas y se articulan con una diversidad de reflexiones más amplias de raigambre semiótica, marxista o posestructuralista. 
han sido constituidas social e históricamente. ${ }^{14}$ Por otra parte, esta categoría adquiere diversas significaciones según el lugar de enunciación del autor/a (nacionalidad, formación disciplinar, genealogías teóricas y políticas, etc.) que la aborde. A partir de esta advertencia, y teniendo en cuenta las necesidades teóricas de esta investigación (y las características socio-históricas de Cuba), privilegio el enfoque pionero de Simone de Beauvoir en El segundo sexo (1949). ${ }^{15}$

En segundo lugar, tengo en cuenta los planteos del feminismo de la diferencia, cuyos enfoques son útiles para pensar algunas ficciones cubanas consideradas en esta investigación (aunque tengo algunas diferencias con esta perspectiva). Luego realizo un recorrido por los avatares del concepto de "género" en América Latina a fines de la década del ochenta y comienzos de los noventa para, por último, centrarme en las particularidades de estos estudios en Cuba.

Considero la identidad no como una categoría pre-establecida sino como un complejo entramado que es el resultado de una construcción con carácter performativo (Butler, 1990; Alcoff ,1988). El análisis de Teresa de Lauretis (1984) sobre la importancia de la interacción personal con el lenguaje y con la cultura en la formación de la subjetividad (a partir de las clásicas formulaciones de Bajtin, Voloshinov y Beneveniste ${ }^{16}$, le sirve a Linda Alcoff (1988) para redefinir el concepto de "mujer" en función de la experiencia histórica.

${ }^{14}$ El uso extendido del concepto de "género" ha suscitado discusiones sobre la conveniencia de continuar usándolo. Para ampliar el debate, véase Scott (1993) y Gamba (2007).

${ }^{15}$ Un problema importante a estudiar, pero que excede los límites de esta tesis, es investigar cómo ha sido leído el feminismo de la igualdad en Cuba. En la década del sesenta, el texto de Beauvoir planteó rupturas con el modelo patriarcal. Tanto ella como Jean Paul Sartre tuvieron una fuerte influencia durante los primeros años de la Revolución Cubana.

${ }^{16} \mathrm{El}$ aporte de De Lauretis consiste en señalar que el lenguaje, como realidad cultural externa, no es lo único que determina nuestra forma de pensar y de estar en el mundo. Toma los aportes teóricos de Bajtín / Voloshinov para reconocer que la subjetividad se construye no sólo mediante el influjo de un sistema de ideas culturales, sino también mediante un proceso de interacción entre la cultura y la realidad personal. De Lauretis presenta una subjetividad que dota a la mujer de una capacidad de agencia, a la vez que la sitúa en configuraciones discursivas concretas y concibe el proceso de toma de conciencia como una estrategia. De este modo, imbrica la subjetividad con la raza, la clase y el género. 
De esta manera se puede pensar desde un punto de vista posicional, lo que supone una identidad relativa en base a un contexto cambiante y sesgado por factores económicos, institucionales, culturales, políticos, ideológicos, étnicos, etc. Desde esta perspectiva "posicional", desnaturalizadora del género (que afecta igualmente la concepción de la categoría "escritura de mujeres"), la identidad "femenina" deviene una posición arbitraria, construida en base a la toma — consciente o inconsciente- de actitudes marcadas culturalmente como "femeninas". ${ }^{17}$

A partir de la teoría de Alcoff, he pensado la narrativa escrita por mujeres cubanas, atendiendo no a una "identidad de género" naturalmente plasmada en la escritura, sino a la elaboración de una construcción simbólica atravesada por múltiples factores (económicos, sociales y culturales) que definen el espacio posicional del sujeto de enunciación. Asimismo, esta concepción me permite desarticular las posibles esencializaciones de la "especificidad femenina" contenidas en las obras analizadas en la investigación.

\subsubsection{Los aportes de Simone de Beauvoir}

En el ensayo El segundo sexo (1949), la filósofa francesa Simone de Beauvoir se opone al determinismo que había sido hegemónico en las teorías biológicas y antropológicas de los

\footnotetext{
17 Alcoff realiza una crítica al feminismo cultural y al feminismo post-estructuralista. El primero forma parte o deriva de la corriente de la diferencia y considera que la mujer se caracteriza por su pasividad, carácter emocional, inclinación a la crianza, etc. El feminismo cultural no se opone a definir a la mujer, sino únicamente al modo en que los varones la definen. Se sustenta en la creencia en que existe una naturaleza o esencia femenina, de la que se apropian las mismas feministas para tratar de revalorizar los atributos femeninos depreciados. Según sintetiza Alcoff, para estas feministas, el enemigo de las mujeres no es únicamente el sistema social o las instituciones económicas, sino la masculinidad en sí misma y, en ciertos casos, lo que es masculino desde un punto de vista biológico. Las iniciativas del feminismo cultural se centran en la creación y el mantenimiento de un entorno saludable -libre de valores que favorezcan lo masculino y de todos sus derivados, como la pornografía- para el desarrollo del principio femenino. Quienes defienden esta posición son Mary Daly y Adrienne Rich, entre otras autoras.

El segundo grupo toma como sustento teórico a Jacques Lacan, Jacques Derrida, Michael Foucault y Julia Kristeva. Evita definir a la mujer e intenta reconstruir esta categoría a través de un tratamiento más complejo de la subjetividad. Alcoff reconoce que esta perspectiva realiza aportes interesantes al feminismo - la teorización de la construcción de la subjetividad y la posibilidad de conseguir una libertad mayor para las mujeres, sin que exista ninguna identidad de género predeterminada que les ponga trabas-; sin embargo, al no reconocer la existencia de la categoría "mujer", señala que esta perspectiva conduce al aislamiento político y a la imposibilidad de influir en la realidad social.
} 
siglos XIX y XX, al señalar que "no se nace mujer, se llega a serlo" (Beauvoir, 2007: 207), con lo cual deja en evidencia que cada sociedad ha construido una esencia "mujer" que le es propia; por eso, indaga en la condición femenina como condición de género (esto es, en los modos de existencia histórica del sexo femenino). ${ }^{18}$ El ensayo aborda el análisis de la condición de la mujer en las sociedades occidentales desde la perspectiva de la filosofía existencialista $\mathrm{y}$, desde fuentes basadas en las raíces ilustradas y el sufragismo, da el puntapié inicial para lo que luego se conoció como el feminismo de la igualdad. ${ }^{19}$

Beauvoir señala que el "eterno femenino" es una construcción que, a lo largo de la historia, ha estado hecha por los hombres; por lo tanto, son ellos quienes la han marcado. Esta postura supone que la mujer no es una esencia inmutable sino una construcción cultural sobre el sexo, operada a través de la educación y el adiestramiento desde la niñez. Para Beauvoir, la sexualidad “jamás se nos ha presentado como definidora de un destino, como portadora de la clave de las actitudes humanas, sino como expresión de la totalidad de una situación que contribuye a definir” (Beauvoir, 2007: 711). ${ }^{20}$ Desde esta perspectiva teórica, la inferioridad femenina debe atribuirse no a la singularidad intrínseca de las mujeres, sino a las condiciones adversas a las que siglos de ideología y prácticas patriarcales las han sometido, y que han invisibilizado o destruido obras capitales del patrimonio de la humanidad; por lo tanto, la inferioridad del sexo femenino es el producto de una situación de opresión historizable y sujeta a revisión y cambio.

18 Beauvoir emplea el término "féminité", para referirse a la construcción social del ser mujer, lo que luego otras teorías denominan "género". Realizada esta aclaración, por razones de escritura y de metodología, a lo largo del trabajo utilizaré la expresión "género" para referirme a la construcción social y "sexo" para la distinción biológica.

19 En el ensayo, la autora realiza un recorrido histórico para mostrar cómo se constituyó la "realidad femenina", porqué la mujer ha sido definida como "lo Otro". En la segunda parte desarrolla el punto de vista de las mujeres en el lugar al que han sido relegadas y las dificultades que tienen para salir de allí.

${ }^{20}$ En la primera parte de El segundo sexo destina un capítulo a mostrar que los datos de la biología no constituyen un destino petrificado: "No bastan para definir una jerarquía de los sexos; no explican por qué la mujer es lo Otro; no la condenan a conservar eternamente ese papel subordinado" (Beauvoir, 2007: 43). 
A partir de los aportes de Beauvoir se puede señalar que las actitudes de las mujeres, sus temas y sus hábitos no son dictados por las hormonas ni están prefigurados en los compartimentos del cerebro, sino que están indicados por su "situación". Esta categoría le permite poner en evidencia que el "eterno femenino" responde a un conjunto de condicionamientos económicos, sociales e históricos. ${ }^{21}$ En su indagación histórica, pone en evidencia que el ámbito doméstico, privado, ha sido aquel al que se ha confinado a la mujer, mientras que el varón dejó para sí el espacio de lo público, de lo social. Según su análisis, a la mujer le fue negada la trascendencia, y esto le prohíbe no sólo el acceso a las más altas actitudes humanas de "heroísmo, rebeldía, desprendimiento, inventiva, creación" (Beauvoir, 2007: 613), sino que también, en el caso de inclinarse por la expresión artística, la temática se relega a lo que conoce. ${ }^{22}$ La propuesta de Beauvoir consiste en hacer visible el constructo social de la opresión que hizo que se hayan relegado determinados temas al ámbito femenino y otros al masculino. Al respecto, realiza un recorrido histórico que le permite mostrar que la literatura femenina se ocupa más de los temas de la infancia, del recuerdo, cuando los varones rara vez recurren a esas cuestiones. Argumenta que la tendencia a esos temas se fundamenta en que la niñez es la única etapa en que la mujer es autónoma y le es posible un porvenir, ya que "conquistaban el mundo día a día, en cambio luego se ven relegadas al matrimonio y al amor y se han convertido en sirvientas o en objetos, aprisionadas en el presente" (Beauvoir, 2007: 623). Indagando en las peculiaridades de las mujeres escritoras, señala que

${ }^{21}$ Desde una perspectiva existencialista, Beauvoir sostiene que si bien la libertad es algo constitutivo de la realidad humana, las posibilidades concretas que a cada cual se le ofrecen de realizarse como libertad son finitas y, además, pueden aumentar o disminuir desde los "Otros". Para Beauvoir, la situación es el marco objetivo donde se ejerce la libertad, marco que los "Otros" pueden estrechar o ensanchar.

${ }^{22}$ Beauvoir asimila el producto del proceso de creación a lo experiencial; es decir, se escribe, se pinta, se moldea, lo que se vive. También hay que señalar que no considera que todos los hombres lleguen a la trascendencia, y ubica allí a otros grupos oprimidos como los obreros y los negros, aunque también el burócrata, el comerciante y el empleado están confinados a lo intermediario, a lo inesencial (Beauvoir, 2007: 613). 
...todavía maravilladas por haber recibido permiso para explorar este mundo, hacen su inventario sin tratar de descubrir su sentido. En donde a veces sobresalen es en la observación de lo que está dado [...]. Ellas saben describir ambientes y personajes, indicar entre ellos sutiles relaciones, hacernos participar en los movimientos secretos de sus almas $[\ldots]$ en el hombre, apenas captan otra cosa que al macho; pero, en cambio, han descrito a menudo y con aciertos su vida interior, su experiencia, su universo; apegadas a la secreta sustancia de los objetos, fascinadas por la singularidad de sus propias sensaciones, entregan su experiencia palpitante a través de sabrosos adjetivos e imágenes carnales: por lo general, su vocabulario es más notable que su sintaxis, porque les interesan las cosas más que sus relaciones $[. .$.$] no discuten la condición humana porque$ apenas comienzan a poder asumirla por completo (Beauvoir, 2007: 704-705).

En El segundo sexo Beauvoir considera que, dada una situación de igualdad, los temas que aborden las mujeres, esos "mundos de ideas", no es seguro que sean diferentes de los de los varones: "puesto que la mujer se liberará asimilándose a ellos, para saber en qué medida seguirá siendo singular y en qué medida esas singularidades tendrán importancia, sería preciso arriesgarse a anticipaciones muy audaces. Lo que sí es seguro es que, hasta ahora, las posibilidades de la mujer se han ahogado y perdido para la Humanidad" (Beauvoir, 2007: 709). ${ }^{23}$ En el ensayo demuestra que tradicionalmente se ha identificado a la mujer/madre con la naturaleza porque ambas son caracterizadas como dadoras de vida y como nutricias; pero al mismo tiempo, la naturaleza es asociada a lo indómito, lo sorpresivo, lo irracional y, simultáneamente, esas características también se proyectan en la mujer:

Alternativamente aliada y enemiga, se presenta como el tenebroso caos de donde brota la vida, como esa vida misma y como el más allá hacia el cual tiende, la mujer resume la Naturaleza en tanto que madre, Esposa e Idea, estas figuras tan pronto se

\footnotetext{
${ }^{23}$ Beauvoir considera que el socialismo sería la situación en que el hombre y la mujer serían iguales: "las mujeres, educadas y formadas exactamente como los hombres, trabajarían en las mismas condiciones y por los mismos salarios, la libertad erótica sería admitida por las costumbres, pero el acto sexual ya no sería considerado como un "servicio" que se remunera; la mujer estaría obligada a asegurarse otro medio de vida; el matrimonio descansaría en un libre compromiso que los cónyuges podrían renunciar cuando lo desearan; la maternidad sería libre, es decir que se autorizaría el control de la natalidad y también el aborto, y a todas las madres y a sus hijos se les darían exactamente los mismos derechos, tanto si eran casadas como si no; las vacaciones por causa de embarazo serían costeadas por la colectividad" (Beauvoir, 2007: 718). A los efectos de esta investigación, debemos tener en cuenta este planteo que Beauvoir realizó 1949, cuando la Revolución Rusa ya había tenido sus terribles vaivenes, y cuando la autora ya había tomado distancia (junto a Sartre) de esa experiencia, se habían acercado a la Revolución cultural china y aún no se había concretado la experiencia cubana. Esta posición respecto de la posibilidad de igualdad en el socialismo se puede contrastar con las distintas opiniones respecto de la experiencia cubana detalladas en el punto 2.2. de esta introducción.
} 
confunden como se oponen, y cada una de ellas tiene una doble faz (Beauvoir, 2007: 143).

\subsubsection{La corriente de la diferencia}

En Sobre sujeto y género, María Luisa Femenías desarrolla la argumentación seguida por las "hijas rebeldes de Beauvoir" (Femenías, 2000: 30), es decir, por las teóricas que integran la corriente de la diferencia. Esta corriente se divide en dos líneas fundamentales: el feminismo de la diferencia francés y el llevado adelante por Judith Butler en EE.UU. (que Donna Stanton define como "desconexión transatlántica" -debido a la recepción norteamericana de las teorías postestructuralistas - y que Femenías redefine en términos de "desconexión butleriana" (Femenías, 2007: 31; itálica en el original). En el ámbito literario, esta teoría postula que las diferencias de sexo se corroborarían a través de las especificidades de una escritura femenina; es decir, que el reconocimiento de una diferencia autoriza a hablar de un modo de expresar masculino y femenino. Entre las feministas del movimiento francés de la teoría de la diferencia sexual se encuentran Hélène Cixous, Luce Irigaray y Julia Kristeva. Las dos primeras defienden la existencia de una escritura femenina diferente de la masculina; la última sostiene que la maternidad es lo femenino por excelencia. Ingrid Galster (1997) utiliza el término "neofeministas" para referirse a esta corriente que se formó en París a mediados de los años setenta. Se trata de un feminismo fundado en la crítica de la razón y cuyas representantes, canonizadas en EE.UU., son las tres teóricas mencionadas, denominadas la "Nueva Santa Trinidad" de la teoría feminista francesa.

Según las teóricas francesas de la diferencia, el logos de la mujer no está hecho; sólo hay marcas lexicales (sobre todo ligadas a la oralidad), pero no pertenecen a la estructura de la lengua normativizada; por eso proponen crear una escritura de mujeres, intento experimental de inventar una lengua que dé cuenta de lo femenino. En Speculum (1974), 
Irigaray sostiene que el logos es falogocéntrico, y que hay que romperlo haciendo estallar el discurso. Argumenta que la mujer es quien debe iniciar ese camino creando un nuevo logos y que esto lo logrará transgrediendo las palabras, la gramática y la sintaxis de la lengua. Propone poner todo cabeza abajo, desquiciar el lenguaje: por roturas, por inversiones, por la irrupción de otros circuitos que hagan explotar la energía sin remisión a un origen. Considera que de este modo emergerá la experiencia femenina, que está en los intersticios de la lengua falogocéntrica.

En tono de manifiesto y de denuncia, en La risa de la medusa Cixous postula que es inaceptable el binarismo que sostiene el pensamiento de Beauvoir — trascendencia vs inmanencia, sujeto vs. objeto-, y argumenta que la igualdad que esta autora reivindicaba para las mujeres se concibe como asimilación a los hombres. Para Cixous no existe el domino de lo universal — como sí pensaba Beauvoir-, porque lo que se tenía por universal es en realidad lo masculino disimulado. Para poner en evidencia estas dicotomías, abre el capítulo "La joven nacida” preguntándose dónde está el sujeto femenino:

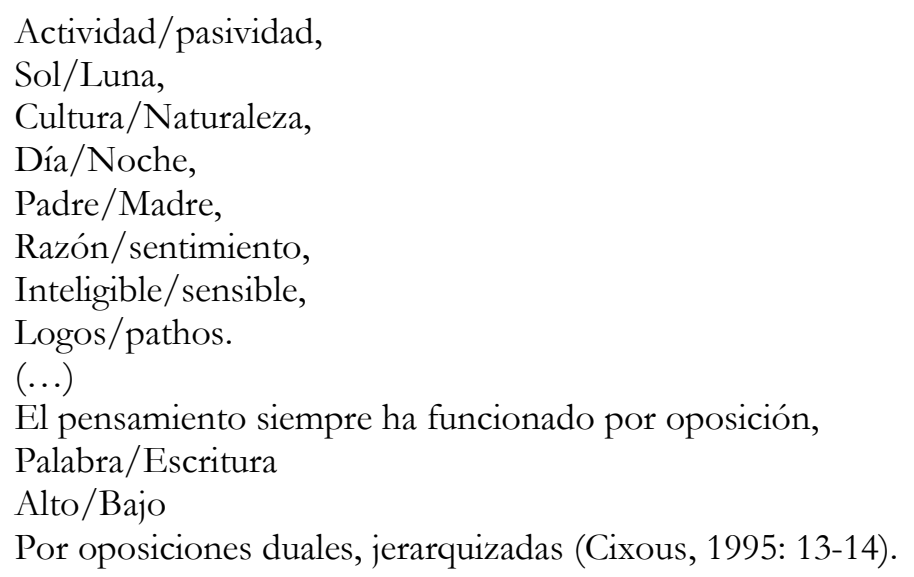

Las oposiciones desnudan una jerarquía en la que el lado "femenino" siempre se considera el negativo. En su crítica al eurocentrismo, además, pone en evidencia cómo el mundo blanco fundamenta su pretendida superioridad, su civilización, en la represión del otro. Sin embargo, la dialéctica del mecanismo yo/otro no permite desaparecer por completo a este 
último: "Gesta banal de la Historia: es preciso que existan dos razas, la de los amos y la de los esclavos" (Cixous, 1995: 24). El proyecto de Cixous para destruir la ideología falologocéntrica se basa en partir de la subversión de la escritura, porque considera que son los libros el único espacio que no está obligado económica ni políticamente a reproducir el sistema: "si hay un otra parte que puede escapar a la repetición infernal está por allí, donde se escribe, donde se sueña, donde se inventan los nuevos mundos" (Cixous, 1995: 26). Desde esta perspectiva, hay que socavar el sistema erigido por los hombres, y esto se hace destruyendo el binarismo y las jerarquías patriarcales. Para ello propone crear una "escritura femenina".

A partir del planteo de Cixous se puede señalar que no existen el varón y la mujer porque esa denominación corresponde a la visión clásica binarista. Por el contrario, esta teórica francesa postula que existen determinaciones sociales y culturales que nos han atrapado en una red que obliga a hablar de "la mujer" y de "el hombre"; a cambio de esto propone reconsiderar la bisexualidad en la mujer y plantear la escritura como "femenina" o "masculina” más allá del sexo biológico. Para Cixous la economía libidinal femenina (no apropiadora como la masculina, sino "dadora") hace que la mujer sea bisexual porque acepta lo del otro, porque no ha eliminado la bisexualidad latente en el niño y en la niña. ${ }^{24}$ De este modo, la práctica femenina de la escritura siempre excederá al discurso regido por el sistema falogocéntrico. Desde este planteo, la feminidad en la escritura pasa por

...un privilegio de la voz: escritura y voz se trenzan, se traman y se intercambian [...], no deja de hacer repercutir el desgarramiento que, para la mujer, es la conquista de la palabra oral [...], su discurso, incluso 'teórico' o político, nunca es sencillo ni lineal, ni 'objetivado' generalizado: la mujer arrastra su historia en la historia (Cixous, 1995: 5455; itálica en el original).

24 "Si existe algo' propio' de la mujer es su capacidad para des-apropiarse sin egoísmo" (Cixous, 1995: 48). 
Para Cixous, la escritura es femenina cuando es subversiva; es necesario que la mujer escriba, porque así inventa una escritura nueva e insurrecta. Esto le permitirá, cuando llegue el momento de su liberación, llevar a cabo las rupturas y las transformaciones indispensables en su historia.

Las teorías de las tres feministas francesas de la diferencia han sido leídas como una vuelta al esencialismo biologicista. Además, la revalorización del cuerpo y de la cultura de las mujeres, así como de los espacios a los que ha sido relegada, implicaría una legitimación de los valores patriarcales que se intentan superar, y una naturalización del carácter histórico y social del género.

Según la perspectiva que adopto en esta investigación, no sería posible hablar de una identidad "mujer", esencializada en términos biológicos o sociohistóricos; el concepto sociológico de "la mujer" se tensa con las diferencias étnicas, de clase, de opción sexual. Defender la diferencia puede ser un modo de justificar la desigualdad jurídica, económica y política entre grupos; y no sólo entre varones y mujeres, ya que la misma problemática se puede pensar, por ejemplo, para las reivindicaciones de diversos grupos sociales (por ejemplo, indígenas o africanos). ${ }^{25}$ Como señaló Christine Delphy (en Portalés, 2005), bajo el término "diferencia" se esconde el concepto de "jerarquía", empleado para justificar un tratamiento diferente (es decir, desigual).

\subsubsection{Avatares de la categoría de "género" en el contexto latinoamericano}

Luego de los extensos períodos signados por dictaduras militares, durante la década del ochenta en América Latina militantes feministas (que, en su mayoría, habían integrado partidos de izquierda revolucionaria en los sesenta y setenta) comenzaron a desarrollar

\footnotetext{
${ }^{25}$ La lógica de la "diferencia” se impone con más fuerza en los grupos dominados y esto implica muchos riesgos, pues ya no se reivindica la igualdad sino el reconocimiento de una identidad cultural y, en esa lectura culturalista, se puede perder de vista la relación asimétrica de dominación.
} 
investigaciones sobre las mujeres. Este fenómeno estuvo acompañado por la aparición de organizaciones de base femeninas en los sectores populares que reclamaban diversas demandas políticas y cotidianas. Hasta mediados de la década del ochenta, en esta región el término "feminismo" era la forma habitual de referirse a las posiciones teóricas y políticas ligadas a la crítica de la subordinación de las mujeres. Luego se produjo una proliferación de posfeminismo y diversas versiones del concepto de "género" que, en el campo intelectual y académico, comenzaron a imponerse frente a la vieja terminología. Para Cecilia Cangiano y Lindsay Dubois (1993), la incorporación de este término significó pasar de la existencia de un único sujeto o identidad femenina, a la de una multiplicidad de sujetos e identidades, y de la creencia en un saber científico objetivo al concepto de la producción de saberes situados. ${ }^{26}$ Según la historiadora inglesa Joan Scott (1993), la utilización del concepto de "género" desplaza el análisis de una noción de la mujer universal, ahistórica y esencialista y propone, en cambio, un análisis relacional contextualizado donde lo femenino y lo masculino se conforman a partir de una relación mutua. En este sentido, demuestra que la sociedad se estructura no sólo por las relaciones de clase o raza sino también por ciertas nociones sobre lo femenino y lo masculino, cultural e históricamente definidas.

Desde una perspectiva ideológica diferente, otras investigadoras feministas consideran que la emergencia y proliferación de teorías en torno del género se debe enmarcar en el actual clima ideológico-político de la globalización capitalista, que establece condiciones para la producción de teoría, pero pone límites y presiones para la realización de formas posibles de práctica política. Desde este punto de vista, para el feminismo el riesgo reside en que, al mismo tiempo que se expanden e internacionalizan los derechos de

\footnotetext{
${ }^{26}$ En el mundo de habla inglesa este cambio se produce a partir del replanteo de los supuestos de la segunda ola feminista en los años sesenta, a partir del cual surge el lema feminista "lo personal es político" que resume el descubrimiento de que incluso las relaciones más íntimas están atravesadas por relaciones de poder. Según consignan Cangiano y Dubois (1993), en Argentina, hasta 1993, cuando se traduce y publica De mujer a género: teoría, interpretación y práctica feminista en las ciencias sociales de Joan Scoot, aún no se ha incorporado la noción teórica de género como un saber sobre la diferencia sexual históricamente construido.
} 
las mujeres (y de las demás diferencias que han proliferado), se restringen de manera brutal las posibilidades de su ejercicio. La feminista argentina Alejandra Ciriza (2007) habla de “atolladeros del género" para referirse a las problemáticas e incomodidades que acarrea dicha noción, sobre todo para la feministas de habla hispana, ya que el término "género" proviene de la tradición teórica y política anglosajona. Por eso advierte los riesgos que implica el uso de este concepto, ya que "soslaya la cuestión del sujeto político y la articulación entre teoría y política feminista, entre pertenencia, prácticas, anclajes ideológico-políticos y subjetivos que la apelación al feminismo convoca" (Ciriza, 2007: 26). En este sentido, cuestiona la transferencia acrítica del planteo de Judith Butler al contexto latinoamericano y plantea que el feminismo, como posición teórica y política, permite ligar la subordinación en razón de la diferencia sexual a las tradiciones, las historias, las determinaciones y las contradicciones de los sujetos; Ciriza opta por el término "feminismo", porque significa apelar a la primacía de la política por sobre la teoría, una apuesta a la rearticulación entre teoría y praxis. ${ }^{27}$ En otras palabras, para una parte de la crítica, el tránsito del feminismo al género marca la inclusión en el espacio académico y la renuncia a la mención del sujeto político en cuestión y, en consecuencia, la noción de género pone en debate términos como "sexo" y "diferencia sexual":

...si la apelación al feminismo y a la diferencia sexual revela con claridad la parcialidad de la perspectiva, la apelación al género implica, en mi modo de ver, limitaciones en la reflexión acerca de las significaciones de la diferencia sexual, en la medida en que acota la referencia al carácter histórico y culturalmente construido de las diferencias procurando desmarcarse de la cuestión de la sexualidad y el sexo (Ciriza, 2007: 27).

También la feminista brasileña Claudia de Lima Costa (2000) realiza preguntas en torno al género. Su análisis se centra en indagar cómo, en el marco del poscolonialismo,

\footnotetext{
${ }^{27}$ Ciriza (2007) advierte que la posición sostenida por Butler en el contexto del debate sexo/género (acerca de la disolución del sexo, en pura posición jugada en interpelaciones y parodias) permite imaginar un juego abierto a infinitas posibilidades. La seducción del postestructuralismo consiste en que disuelve hasta el paroxismo las determinaciones reales en eventos contingentes de posicionamiento y escenificación.
} 
incide la traducción (cultural) de teorías cuando éstas se trasladan atravesando fronteras o, en otras palabras, qué es lo que se pone en juego; qué se gana y qué se pierde en esta traslación que, muchas veces, se realiza acríticamente. ${ }^{28}$ Lima Costa analiza cómo se realiza la traducción cultural de la teoría feminista desde la periferia, y en particular cómo se conceptualiza el "género". Para ello, parte de considerar que las ideas y los conceptos nunca son puros; siempre emergen en determinados lugares y son trasladados a otros; el centro teoriza y la periferia otorga los casos a analizar:

De acordo com Hillis Miller, teorias são maneiras de fazermos coisas com a linguagem, uma delas sendo a possibilidade de ativarmos diferentes leituras do texto social. Quando introduzidas a um novo contexto, as leituras que as teorias promulgarão podem transformar radicalmente esse contexto. Portanto, qualquer tradução sempre implicará em uma desfiguração: quando a teoria viaja, ela desfigura, deforma e transforma a cultura ou a disciplina que a recebe (Lima Costa, 2000: 3).

La autora ancla la emergencia del concepto de "género" en la historia del feminismo en EE.UU., cuando las feministas de la diferencia (como respuesta en el terreno de lo social de las feministas no blancas y de las feministas lesbianas) se aliaron con las teorías de la deconstrucción de la identidad que las llevó a proclamar la desintegración del género mediante la fractura de la clase, la etnia, la elección sexual, etcétera. En este proceso, el riesgo fue "el feminismo sin mujeres"; entonces, otras teóricas propusieron luchar contra la atomización de las diferencias a partir de la afirmación de una identidad positiva para la mujer por medio de la articulación de éstas, señalando las estructuras de dominación que producirían esas diferencias. Advierte que, mientras eso sucedía en EE.UU., muchos estados y agencias de gobierno en América Latina comenzaron a adoptar acríticamente la

\footnotetext{
${ }^{28}$ Lima Costa entiende la traducción cultural según la postula Niranjana (1992): "não assume que o contexto da tradução seja um de simetria entre linguagens, mas assume que qualquer processo de descrição, interpretação e disseminação de idéias e visões de mundo está sempre já imbricado com as relações de poder e as assimetrias entre linguagens, regiões e povos" (en Lima Costa, 2000: 1).
} 
categoría de género. ${ }^{29}$ En la misma línea que Ciriza, Lima Costa señala que esta categoría analítica abrió un espacio para la despolitización del feminismo en la academia de Brasil ya que, mientras el uso de "feminismo" o de "teorías feministas" se vinculaba con la radicalización política que propugnaba la transformación social, el uso de "género" fue adoptado para lograr cierta credibilidad en la comunidad científica. ${ }^{30}$ De esta forma, su trabajo muestra cómo el concepto de "género" tiene una base epistemológica frágil porque se presta para apropiaciones/traducciones contradictorias (politizadas y despolitizadas) y porque los relatos de los mecanismos por los cuales "nos tornamos mujeres" deben incluir otros modos de constitución del sujeto que exceda la oposición entre masculino y femenino, ya que en sociedades donde las asimetrías de raza y de clase son principios organizadores fundamentales, "tornarse mujer" también debe incluir relaciones de oposición con otras mujeres. Por lo tanto, desde esta perspectiva, la categoría "mujeres" debe ser problematizada, y no reducida a un punto de partida "neutro" del feminismo.

A principios de los noventa comenzaron a proliferar críticas a la política de la identidad y al feminismo que la sustentaba. Desde diferentes posiciones se ha problematizado el supuesto que subyace bajo la pregunta “¿qué es una mujer?” por el riesgo de caer en un esencialismo biologicista y, por el contrario, se insiste en advertir que no existen sujetos a priori sino construcciones sociales, en las que interviene, entre otras, la clase, la raza, la edad, la nacionalidad. Desde esta perspectiva, se ha cuestionado la institución heteronormativa que impone una sexualidad binaria y se comenzaron a plantear

\footnotetext{
${ }^{29}$ Cita a Sonia Álvarez cuando dice que "A pesar del papel innegable que tuvieron los lobbies feministas locales y globales en promover las normas internacionales o de género que indirectamente inspiran estos modernos discursos estatales 'pró-género', la 'incorporación de la mujer al desarrollo' no siempre se inspira en el feminismo. La asidua crítica feminista a la subordinación de las mujeres muchas veces se traduce y tergiversa en las prácticas y discursos del Estado. Como me explicó una oficial de la Alcaldía de Cali: 'ahora la cosa cambió, ya no es aquel feminismo radical de los años 70; ahora es perspectiva de género"' (Álvarez en Lima Costa, 2000: 4).

30 Además, demuestra que, aunque se le reconoce al género el haber visibilizado la construcción esencialista del término "mujer", esto ya había sido advertido por los feminismos latinoamericanos al comenzar a utilizar, por ejemplo, el plural "mujeres".
} 
las diferencias entre las mujeres. Esto ha sido llevado adelante por diferentes intervenciones políticas de lesbianas, intersex, travestis, gays, etcétera, que han luchado por visibilizar y cambiar determinadas concepciones. Este tipo de discusiones se plantean no tanto desde círculos netamente académicos sino desde posiciones que anudan el compromiso teórico con el activismo político y, por eso, los planteos ponen el acento en la experiencia. ${ }^{31}$

En esta línea, la activista dominicana Yuderkys Espinosa-Miñosa (2004b) propone revitalizar el feminismo. En esta dirección, sostiene que nombrarse "mujer" debe entenderse no como el deseo de ser lo que se suponía que debíamos ser, sino como el deseo de explotar la categoría, de construir una comunidad política, es decir, entiende el "ser mujer" como una identidad política que agrupa no a las que son iguales sino a las que, desde otras múltiples vidas, posiciones y subordinaciones, han sido objeto de un determinado tipo de subordinación por haber sido generadas como mujeres. Desde esta perspectiva resulta interesante la propuesta de no disolver la categoría "mujeres" sino considerarla una estrategia que permita aunar las luchas y las problemáticas y evitar, de este modo, la absorción de las diferencias en mercancías, sólo visibilizadas, nombradas por la “tolerancia liberal” como señala acertadamente Alejandra Ciriza.

Frente al separatismo como praxis política y a la fragmentación identitaria como consumo de mercado, los activistas argentinos Mabel Bellucci y Flavio Rapisardi (1999) se preguntan por el valor crítico de la diferencia. Para esto, exploran y rescatan los debates, las experiencias y la tentativa de subvertir el orden hegemónico (tanto político-económico como cultural) por parte de dos movimientos sociales en la Argentina contemporánea: el de mujeres y el de las llamadas "minorías" sexuales, y los contrastan con las experiencias

\footnotetext{
31 Desde esta perspectiva, por ejemplo, el argentino Mauro Cabral (2003) testimonia, desde su historia de intersex, cómo este movimiento cuestiona el modelo que desde la psiquiatría, la urología pediátrica, la endocrinología y la cirugía han intentado normalizar, durante décadas, los genitales "indescifrables" de las personas intersexuales.
} 
políticas de estos movimientos en EE.UU. y Europa. Consideran que es necesario pensar la disrupción de la diferencia en un contexto de profundas desigualdades de clase; es decir, los particularismos no deben cerrarse sobre sí mismos; deben cuestionarse los límites políticos, sociales y simbólicos dentro de los cuales éstos se constituyen. En su argumentación, retoman los argumentos de la politóloga estadounidense Nancy Fraser para sostener que:

tanto el género, la raza, como la orientación sexual constituyen modos de distinción cultural que forman parte de la estructura económico-política: mujeres, gays, lesbianas y minorías étnicas ocupan los puestos de trabajo peor remunerados, de bajo perfil y generalmente se convierten en las variables de ajuste de las reestructuraciones empresarias (Belluci y Rapisardi, 1999: 10).

Esta perspectiva concluye, acertadamente, que en el marco del neoliberalismo es imposible pensar la abolición de las desigualdades económicas, el reconocimiento de las heterogeneidades y la posibilidad de construir la propia identidad como modo de ser otro; por eso, proponen que sólo un nuevo proyecto político podrá cambiar esta situación.

A partir de estos enfoques, producidos en el campo latinoamericano, me resulta imprescindible analizar las derivas que han tenido estos estudios en Cuba. Pero, en primer lugar, para considerar el corpus seleccionado, resulta necesario establecer relaciones entre la cultura y la historia más reciente de Cuba e investigar cómo las producciones culturales forman parte de la dinámica y conflictiva constitución del orden social cubano y del complejo ámbito cultural cubano; por eso he procurado una presentación que lo vuelva inteligible mediante el armado de espacios discriminados, de acuerdo a algunos rasgos específicos. Las lecturas buscan poner en evidencia diferentes tramas que den cuenta de los espesores del campo abordado. No pueden dejarse de lado las circunstancias concretas en que surge esta narrativa, ya que en el período de crisis que atraviesa el país (y que repercute en todas las esferas de la vida) se produce una proliferación de cuentos y novelas escritos por mujeres. En este sentido, para ingresar en las líneas de análisis propuestas para cada 
capítulo, realizo un paso previo que consiste en explicitar el contexto cultural cubano en que se inserta el corpus de esta investigación así como los desarrollos de la perspectiva de género en este contexto.

\section{Cuba: una aproximación al contexto socio-cultural después de los sesenta}

La historia político-cultural de estos años es un campo amplio y complejo que no pretendo desarrollar porque no es el objetivo de esta investigación, sin embargo, citaré bibliografía que permite ahondar en las aristas de los debates y estudios que ha suscitado. El panorama que ofrezco aquí -forzosamente sintético y en debate - no pretende tomar en cuenta todas las variables del problema ni todos los personajes que intervinieron sino que procuro que sirva de marco para comprender la producción de las escritoras que integran el corpus ya que, aunque su producción es posterior a los inicios del proceso revolucionario, necesariamente su obra, de diferentes modos, se encuentra atravesada por estos hechos.

La historia latinoamericana del siglo XX está signada, entre otros hechos, por la Revolución Cubana, tal como se la conoció a partir del 1 de enero de 1959. El objetivo del levantamiento fue que el pueblo cubano recuperara la autonomía política nacional perdida con la dictadura de Fulgencio Batista (1952-1959) y que había convertido a la isla en el patio trasero de EE.UU. Este proceso revolucionario tuvo como gesta inicial el frustrado asalto al Cuartel Moncada que el 26 de julio de 1954 había implicado la participación activa de movimientos de izquierda, estudiantiles, de obreros y campesinos.

Entre 1959 y 1961 se produjo una gran adhesión a la Revolución de parte de intelectuales europeos (Hebert Marcuse, Jean-Paul Sartre, Simone de Beauvoir, Waldo Frank, Charles Wright Mills, Hans Magnus Enzensberger, por nombrar algunos) y latinoamericanos (Mario Vargas Llosa, Gabriel García Márquez, Carlos Fuentes, Julio Cortázar, Octavio Paz, entre otros muchos), aunque esta posición fue variando 
vertiginosamente durante los primeros diez años de este proceso. En el ámbito cultural nacional, el triunfo revolucionario provocó la celebración de la mayoría de los artistas cubanos de diferentes ideologías y generaciones. Respecto del campo intelectual cubano, Rojas (2006) divide en tres las posiciones ideológicas: la adhesión acrítica al gobierno revolucionario, el respaldo crítico a la Revolución y el exilio. Señala que ante el triunfo revolucionario, adhirieron la mayoría de los intelectuales cubanos:

los republicanos (Ortiz, Guerra, Mañach, Agramonte, Portell Vilá, Piñera Llera, Novás Calvo...), los comunistas o marxistas (Marinello, Roa, Carpentier, Guillén, Aguirre, Portuondo, Augier...), los católicos (Chacón y Calvo, Lezama, Vitier, Diego, Gaztelu, García Marruz, Valdespino...) y la nueva generación vanguardista, de simpatías liberales o socialistas (Piñera, Cabrera Infante, Casey, Arrufat, Desnoes, Otero, Fernández Retamar, Fornet...) (Rojas 2006: 17-18).

En este ámbito cultural se siguió una lógica institucional y política distributiva que tuvo como consecuencia una intensa creatividad y pluralismo en la literatura, la música, la plástica y el cine. Esta política generó la emergencia de nuevas instituciones, como el Instituto Cubano de Arte e Industria Cinematográfica y Casa de las Américas, de revistas como Lunes de Revolución, El Caimán Barbudo y Pensamiento Crítico. Los primeros años de la Revolución estuvieron signados por conflictos ideológicos, acentuados por la radicalización marxista-leninista de un proceso que, en sus inicios, parecía preservar el nacionalismo en un pacto republicano. ${ }^{32}$

\footnotetext{
32 A los efectos de la rigurosidad terminológica, resulta imprescindible advertir que, en un comienzo, las reivindicaciones fueron netamente electorales y democráticas (lucha contra una dictadura y reivindicación de la democracia parlamentaria) y luego comenzaron a tener un carácter nacional porque entraron en contradicción con los intereses económicos y políticos norteamericanos. Recién en mayo de 1961 la Revolución se autodenominó "socialista", en un discurso pronunciado por Castro. Aunque en ese momento se hizo explícita la dirección de la Revolución, ya antes se habían producido modificaciones hacia este rumbo con medidas desestabilizadoras como rebajas en el precio de los alquileres (acción que generó el reconocimiento de los inquilinos y el exilio de muchos propietarios), la reforma agraria que pasó de la consigna "la tierra es del que la trabaja" a fijar tope de tierras y luego, con la tercera reforma agraria, se crearon las granjas del pueblo para mantener grandes unidades estatales. En este momento, se reduce la extensión máxima de la propiedad individual, hecho que elimina a la burguesía del campo que se exilia a EE.UU. Para revisar la historia cubana de este período consultar: Mesa-Lagos (1994) y Domínguez (1998). El giro hacia el marxismo produjo profundas polarizaciones del campo intelectual cubano. En "Políticas
} 
Las múltiples consecuencias de este hecho determinaron que, durante las décadas del sesenta y del setenta, en América Latina la política constituyera el principal parámetro de legitimidad de la producción textual y, en este contexto, el espacio público se convirtiera en un escenario privilegiado desde donde se autorizó la voz del escritor convertido así en intelectual (Gilman, 2003; Quintero Herencia, 2002; Rojas, 2010) ¿Cuál es el rol del escritor frente a la sociedad? ¿Cómo conectar literatura y política? ¿Cuál es la función de la literatura y de la experimentación artística? ¿Cómo se relacionan los intelectuales con el poder? Estas preguntas condensan algunas de las problemáticas que se debatieron en Cuba y en toda América Latina, luego del triunfo revolucionario, aunque con notables antecedentes en el período anterior. ${ }^{34}$ En esta época (según el concepto utilizado por Gilman, 2003) se constituyó un campo intelectual latinoamericano reunido en torno a la Revolución Cubana. La Habana se convirtió en la capital real y simbólica que los aglutinaba y, además, el campo intelectual se vio reforzado por el incipiente mercado editorial que posibilitó la circulación de las producciones del continente. El prestigio internacional de la cultura cubana fue creciendo poco a poco y se hicieron pujantes todas las artes: el cine, el ballet, el teatro, la música, la literatura, etc. En este contexto, los artistas e intelectuales comenzaron a tener un lugar predominante en el espacio público, bajo la convicción de que debían convertirse en agentes de su transformación radical. La ensayista y crítica cubana

intelectuales", Rojas (2006) realiza un minucioso estudio sobre las posiciones y movimientos de los intelectuales cubanos antes y después del proceso revolucionario.

33 Aclaro que, de aquí en más, cada vez que utilizo la palabra “escritor”, "intelectual” o sinónimos adopto el genérico habitual a los efectos de no dificultar la lectura con la aclaración de los varios géneros implicados.

${ }^{34}$ En Cuba, estos debates estuvieron presentes durante el movimiento vanguardista. En su estudio de la revista de avance (1927-1930) Celina Manzoni (2001) analiza la intensa lucha ideológica que se expresó en las elaboraciones de sus integrantes y en la elección de los colaboradores. Sostiene que las definiciones de "lo nuevo" se enlazan con el modo de pensar las funciones del intelectual. Manzoni vincula estas polémicas presentes en la revista con las reflexiones casi contemporáneas en La tradición de los intelectuales (1927) de Julien Benda quien sostenía que la tradición de los intelectuales ha consistido en su entrega a la política partidista y, en el caso de Francia, al nacionalismo chovinista. 
Graziella Pogolotti ha compilado las principales polémicas de aquel intenso decenio (Pogolotti, 2006).

Ante el dilema de cómo conectar la literatura y la política, una opción consistió en postular la obra literaria como la puesta en discurso de una experiencia de lo social y lo político, una idea de larga tradición desde el realismo decimonónico. Gilman (2003) señala dos momentos en este debate: el primero, desde el triunfo de la Revolución hasta 1968; el otro, en los setenta, década que se inicia a partir de la fecha anterior. En el primer período, el énfasis sobre la experiencia remitía a la conciencia del escritor, que daba sentido a la fórmula del autor comprometido, como un problema circunscripto a los límites de la intencionalidad. Fue Jean-Paul Sartre en ¿Qué es la literatura? (editado por primera vez en francés en 1948) quien forjó la noción de "literatura comprometida" (litérature engagée) que sirvió de base para que el escritor se convirtiera en intelectual. ${ }^{35}$ Desde esta perspectiva el lenguaje debía ser vehículo de ideas; así, las palabras del escritor debían posibilitar el acceso a las cosas, a la realidad vivida o experimentada. El filósofo francés establecía así las bases para una síntesis entre "las armas y las letras", dos soluciones que se habían mantenido separadas y que parecían excluyentes. Sartre tuvo una gran influencia sobre los grupos intelectuales latinoamericanos de izquierda, autoridad que se vio reforzada con su rápida adhesión a la causa cubana y su pronta visita a Cuba: en 1960, invitado por Carlos Franqui, pasó un mes en la isla junto a Simone de Beauvoir; se reunió con Ernesto Guevara y también con un grupo de intelectuales entre los que se encontraban Antón Arrufat, Sergio Rigol, Eduardo Manet, Guillermo Cabrera Infante, Pablo Armando Fernández, Mirta

\footnotetext{
35 El concepto de literatura comprometida fue elaborado por André Gide (Francia, 1861-1961) entre 1920 y 1930 aunque recién publica en 1950 el volumen Litérature engagée que contiene cartas, artículos, conferencias y discursos escritos con anterioridad. Luego el concepto se populariza con Sartre.
} 
Aguirre, Virgilio Piñera, Fausto Masó, Nicolás Guillén, Carlos Rafael Rodríguez, Lisandro Otero y José Rodríguez Feo, entre otros. ${ }^{36}$

Impulsado por los acontecimientos que giran en torno a la Revolución Cubana, el mercado editorial latinoamericano adquirió un auge inusitado. El año 1964 constituyó una fecha clave para la consagración de la nueva narrativa latinoamericana porque Ángel Rama organizó el número 26 de la revista Casa de las Américas "en el que estaban presentes Cortázar, Fuentes, Vargas Llosa, cuyos nombres, a partir de entonces, incluyendo los de Donoso, y García Márquez, comenzaban a hacerse frecuentes acompañando a los de las ya sólidas presencias de Roa Bastos, Rulfo, Onetti y Carpentier” (Gilman, 2003: 89). Desde esta perspectiva, la apelación a nuevas formas de realismo y a la defensa de la criticidad y oposicionalidad intrínsecas a la literatura sostenían su carácter de instrumento en el terreno ideológico lo que, a su vez, le permitía conservar la legitimidad de sus propias reglas y proponer un tipo de acción específica, apropiada a los fines de la voluntad de politización.

En 1968 se desató una nueva coyuntura a partir de la cual la figura del intelectual se tensionó entre el intelectual como conciencia crítica de la sociedad (una suerte de ideal residual) y el intelectual-revolucionario. El hecho medular que estableció el debate fue el Congreso de Cultura de La Habana (1968) -que podría ser pensado, al igual que La Habana durante la década del sesenta, como un polo de religación, según el concepto acuñado por Ángel Rama (1985) y potenciado, luego, por Susana Zanetti (1994)— donde se definió al intelectual revolucionario. ${ }^{37}$ En una entrevista realizada ese año, Alejo Carpentier respondió

\footnotetext{
36 En Sartre visita Cuba -digitalizado por el archivo de Connie- se puede consultar Huracán sobre el azúcar, el ensayo "Ideología y Revolución” publicado por Sartre en la revista Lunes durante su estancia en Cuba, y el debate con los intelectuales. En "El fantasma de Sartre en Cuba” (2007), Duanel Díaz realiza un análisis de la figura de este intelectual y de Beauvoir durante los primeros años de la Revolución. Ver: http://www.habanaelegante.com/Spring2007/Verbosa.html También Díaz (2009) dedica algunas páginas del libro a desarrollar las repercusiones que tuvo la llegada de Sartre a la isla. La influencia de Sartre en la izquierda latinoamericana se intensifica también a partir del prólogo a Los condenados de la tierra (1961) de Franz Fanon.

${ }^{37}$ Susana Zanetti propone el concepto "religación” —en contraposición con el de campo intelectualcomo una herramienta de investigación útil para abordar el problema de la unidad de la literatura
} 
que "las revoluciones no son hechas por los artistas. Por lo tanto, primero son las revoluciones; luego, el arte que habrá de expresarlas y fijarlas; es decir: de mostrarlas por medio de la narrativa, de analizarlas, de representarlas" (citado en Fernández Retamar, 1995: 182). El problema de la relación entre literatura y revolución se convirtió en un tema candente sobre el que se discutía en todos los ámbitos. ${ }^{38} \mathrm{El}$ antiguo concepto de vanguardia cultural adquirió por entonces un sentido aún más definido: convertirse en vanguardia cultural, dentro del marco de la revolución, suponía la participación militante en la vida revolucionaria. Gilman advierte que, para entender este proceso, resulta fundamental tener en cuenta el contexto político de Cuba:

El final de 1968 encontraba a Cuba más amenazada que nunca, en una posición defensiva, en estado de intranquilidad, a causa de los sabotajes contrarrevolucionarios, el bloqueo norteamericano y las restricciones económicas [...]. La dirigencia cubana llamó a 1969 'Año del Esfuerzo Decisivo'. El lema aludía al importante caudal de energías convocado para lograr el objetivo de la zafra de los diez millones (Gilman, 2003: 219).

Luego, con el "caso Padilla", la luna de miel entre la mayoría de los escritoresintelectuales y la Revolución Cubana entró en un punto crítico (Chapad, 2006; Lombardo, 2006; Rojas, 2010). Tras leer su poemario "Provocaciones" (y, supuestamente, por conocerse el proyecto de su novela En el jardín pastan los héroes,) Heberto Padilla es acusado de contrarrevolucionario bajo la denuncia de colaborar con agentes de la CIA (Central Intelligence Agency). Después de pasar treinta y siete días en prisión, realizó una declaración autocrítica de sus errores en un acto público. Estos hechos generan la reacción

latinoamericana. Sostiene que "encara el estudio de los vínculos efectivos concretados de muy diversos modos a lo largo de nuestra historia literaria entre autores y obras, entre éstos y los lectores y críticos, entre los diversos centros de América Latina y entre sus instituciones formales e informales más allá de las fronteras nacionales" (Zanetti, 1994: 6).

38 Una muestra de esta polémica es el artículo "Apuntes sobre Revolución y literatura en Cuba" escritos por Roberto Fernández Retamar en 1969 y publicados en Unión en 1972 (en la bibliografía general citamos la versión definitiva publicada por el Instituto Caro y Cuervo en 1995). 
de los intelectuales que apoyan la Revolución quienes dieron a conocer varias cartas. ${ }^{39}$ Casi en forma simultánea se realizó el Primer Congreso Nacional de Cultura en donde se postularon en forma oficial los criterios ideológico-culturales del nuevo contexto cubano en relación con los intelectuales. Al respecto señala Gilman:

El tipo de antiintelectualismo propulsado por el Congreso suponía el descarte absoluto de cualquier posibilidad de que el 'hombre del futuro' -al que se aludía en la declaración — pudiera provenir de las filas de los 'intelectuales realmente existentes'. El Congreso proclamó la necesidad de mantener 'la unidad monológica ideológica de nuestro pueblo', de combatir 'cualquier forma de desviación entre los jóvenes' -'aberraciones extravagantes', 'desviaciones homosexuales' (Gilman, 2003: 241-242).

De allí en más, la familia latinoamericana quedaría partida entre quienes apoyaban la revolución y definían como intelectual revolucionario a quien toma partido por la clase obrera, militaba en la lucha revolucionaria o admitía las directivas de los líderes políticos revolucionarios, y quienes retomaban, con ahínco y deliberación, la calificación de intelectual sustentada por el ideal crítico. ${ }^{40}$ Una posición diferente (como analistas y no como polemistas) adoptaron tanto Ángel Rama como Rodolfo Walsh y David Viñas (Lombardo, 2006).

La política cultural del país se endureció a partir de la polémica generada en torno a ese caso y por el estrechamiento de las relaciones de dependencia respecto de la Unión Soviética (plasmada en el apoyo a la invasión de Checoslovaquia) y de los países socialistas europeos, estrechamiento provocado, entre otros factores, por el fracaso de la llamada “Zafra de los 10 millones". ${ }^{41}$ En 1972 Cuba ingresó al Consejo de Ayuda Mutua

${ }^{39}$ La más famosa de las declaraciones — la Declaración de los 62 - dirigida a Fidel Castro se publicó en Le Monde el 20 de mayo de 1971. Entre los que piden información sobre el Caso Padilla, firmaron Marguerite Duras, Carlos Barral, Julio Cortázar, Mario Vargas Llosa, Carlos Fuentes, Simone de Beauvoir, Jean Paul Sartre, Octavio Paz, entre otros. Para una minuciosa descripción del "caso Padilla" véase Alburquerque Fuschini (2001), Gilman (2003), Fornet (2006), Croce (2006), Díaz (2009).

${ }^{40}$ La categoría de "familia intelectual" la trabaja Gilman (2003) en todo el ensayo. Hace referencia a los estrechos lazos y filiaciones establecida dentro del campo intelectual latinoamericano durante los años sesenta.

${ }^{41}$ Fidel Castro trazó esta meta para la zafra de 1970: la isla debería alcanzar los 10 millones de toneladas de azúcar, principal moneda de canje para el comercio exterio,,„,r de entonces y, como lo había expresado el 
Económica (CAME) y de esta manera su economía se vinculó estructuralmente con la del campo socialista. Se instaló entonces una política cultural que consumó lo que en los años sesenta habían anunciado las "Palabras a los intelectuales" (1961) de Fidel Castro: el proyecto pretendió institucionalizar la esfera de la cultura y convertirla en aparato ideológico del Estado con el fin de promover en la población los valores de la nueva sociedad. ${ }^{42}$ En consecuencia, desde el ámbito estatal se promovió el realismo socialista como modelo legítimo y único, y se efectuó un recorte en la tradición literaria nacional e internacional. Gilman (2003) analiza el debate en torno a los intelectuales y señala que, hasta 1968, se esperaba de ellos el compromiso con la Revolución; luego, se produjo un desplazamiento que les exigía un papel más activo; hasta exigir que se convirtieran en intelectuales revolucionarios. Algunos de los efectos de estos debates fueron la censura o la sanción por las ideas políticas, las creencias religiosas o las preferencias sexuales. Estos hechos provocaron que algunos escritores dejaran de publicar debido a la censura y a la autocensura, y que se prohibiera o impidiera la circulación de las obras de Reinaldo Arenas, José Lezama Lima, Virgilio Piñera, Guillermo Cabrera Infante y Severo Sarduy, entre otros. ${ }^{43}$ La recreación mimética de la realidad, junto con la rigidez de una política editorial que tendió a censurar lo que se desviara de la norma establecida o que suscitó la auto-

líder, alcanzar tal meta simbolizaba la emulación revolucionaria. Con tal récord, se esperaba darle piso económico independiente a Cuba. No se pudo llegar al record propuesto y esto significó no sólo un fracaso económico sino el inicio de lo que algunos críticos denominaron el "desgaste de la utopía” (Fornet, 2006: 62).

${ }^{42}$ Las "Palabras a los intelectuales" fueron pronunciadas por Fidel Castro en 1961 en la Biblioteca Nacional; la frase que más resonancia tuvo fue "¿Cuáles son los derechos de los escritores y de los artistas revolucionarios o no revolucionarios? Dentro de la Revolución, todo; contra la Revolución ningún derecho”. Estas palabras fueron pronuncias a partir de la polémica que se generó en torno a la censura del documental "PM" (1961) de Sabá Cabrera Infante y Orlando Jiménez Leal y el posterior cierre de Lunes de Revolución dirigido por Carlos Franqui y Guillermo Cabrera Infante. Para un desarrollo de las polémicas en torno a PM y las sucesivas disputas entre revistas culturales, véase Díaz (2009).

43 A partir de 1959 muchos cubanos optaron por el exilio. Con respecto a los escritores, al principio los exiliados fueron excluidos de los circuitos culturales cubanos, pero poco a poco se inició un lento proceso de incorporación de los que se fueron. El texto que se considera como punto de inflexión en este proceso es Los dispositivos en la flor.Cuba: literatura desde la Revolución (1981) en la que Edmundo Desnoes reúne fragmentos de discursos políticos de Fidel y el Che, cuentos, poemas y canciones tanto de escritores residentes en la isla como de exiliados. 
censura, dieron inicio a lo que se conoció como el "quinquenio gris" (1971-1975), expresión con que el crítico Ambrosio Fornet (2006) se refiere a la pobreza literaria que caracteriza la producción de estos años, debido a la "sovietización" de la cultura cubana. ${ }^{44}$

Respecto de este período, sintetiza Fornet:

... en el 71 se quebró, en detrimento nuestro, el relativo equilibrio que nos había favorecido hasta entonces y, con él, el consenso en que se había basado la política cultural. Era una clara situación de antes y después: a una etapa en la que todo se consultaba y discutía —aunque no siempre se llegara a acuerdos entre las partessiguió la de los úkases: una política cultural imponiéndose por decreto y otra complementaria, de exclusiones y marginaciones, convirtiendo el campo intelectual en un páramo (por lo menos para los portadores del virus del diversionismo ideológico y para los jóvenes proclives a la extravagancia, es decir, aficionados a las melenas, los Beatles y los pantalones ajustados, así como a los Evangelios y los escapularios) (Fornet, 2006: 15-16).

En cuanto a la publicación escritoras cubanas durante los primeros quince años posteriores al proceso iniciado en 1959, es casi nula. Las razones que se alegan son de diferente índole, por ejemplo, Mirta Yáñez (1996) constata la casi inexistencia de esta producción y sostiene que las causas principales son los temas revolucionarios promovidos por la política oficial durante el período descripto y las restricciones impuestas por una

${ }^{44}$ Con respecto a los debates actuales sobre el "quinquenio gris" (también llamado "el pavonato, en alusión a Luis Pavón Tamayo quien fuera Presidente del Consejo Nacional de la Cultura durante aquellos años -antes de asumir este cargo había dirigido la revista Verde Olivo), se produjo un ciclo de conferencias y debates convocados por el Centro Teórico-Cultural Criterios bajo el ciclo "La política cultural del período revolucionario: Memoria y reflexión" (los artículos se encuentran disponibles en internet (www.criterios.es/cicloquinqueniogris.htm). Para una síntesis interesante de la cuestión ver la conferencia de Ambrosio Fornet titulada "El quinquenio gris: revisando el término" (2007) y el relato de José María Fernández Pequeño "Gris, gris, ¿el quinquenio es gris?” (2007). Allí también se describen los procesos de “depuración”, el llamado "diversionismo ideológico”, las persecuciones a homosexuales, etc.

No todos acuerdan con el uso de la expresión "quinquenio gris". Por ejemplo, para Rafael Rojas (2006), desde el punto de vista institucional, la frase es precisa, pero "desde el punto de vista ideológico y político resulta doblemente eufemística - por lo de 'quinquenio' y por lo de 'gris'-ya que el control policíaco de la vida intelectual se ha mantenido hasta hoy y la promoción oficial del canon marxista-leninista de creación se extendió, por lo menos, hasta 1992, a pesar de que la versión cubana de dicho canon nunca haya sido tan rígida como la soviética del realismo socialista" y continúa en esta línea al afirmar que esa fórmula "se ha convertido en un oximoron que permite a las élites intelectuales del poder localizar todo el expediente represivo del régimen en materia de política cultural dentro de aquel lapso de cinco años, como si después de 1976 no se hubieran censurado obras de arte, clausurado publicaciones, boicoteado intentos de sociabilidad independientes o encarcelado a poetas como María Elena Cruz Varela y Raúl Rivero” (Rojas, 2006: 450). 
sociedad patriarcal. ${ }^{45}$ Estos hechos serían las causas principales de auto-censura y la marginación experimentadas por las narradoras. Similares razones alega Luisa Campuzano, por ejemplo, cuando denuncia la inexistencia de una narrativa escrita por mujeres debido al "cúmulo infinito de restricciones, de represión, de apocamiento que ha fomentado la cárcel del silencio de la mujer” (Campuzano, 1988: 92). Zaida Capote Cruz (2008) va un poco más allá, porque apunta a la responsabilidad que ha tenido la crítica en la operación de exclusión de un corpus que para Capote Cruz evidencia la productividad de la narrativa escrita por mujeres. Señala que, durante la década del sesenta, las cuentistas cubanas apenas aparecen en las antologías promovidas dentro de Cuba y en el extranjero que conformaron el rostro visible de la literatura cubana no sólo hacia fuera, sino también hacia adentro: "Tanto se las ignoró, que la crítica dominante terminó por olvidarlas. Aún hoy hay quienes, al referirse a esa primera década, obvian mencionar la producción de las mujeres" (Capote Cruz, 2008: 145). ${ }^{46}$ Para Capote Cruz resulta necesario estudiar la "cuentística femenina” (Capote Cruz, 2008: 147) de esos años, sin perder de vista el contexto en que se produjo y las relaciones que estableció con él, así como tomar en cuenta la "feminización”" (Capote Cruz, 2008: 147) de géneros como las memorias, autobiografías y la literatura infantil.

Esta situación pareció modificarse en 1976 a partir de la creación del Ministerio de Cultura, encabezado por Armando Hart, porque se fueron suavizando, entre otros, los

\footnotetext{
45 En su investigación, Yáñez se sumerge en el circuito literario y rescata el nombre de las pocas escritoras que aparecen. El rastreo se realiza en las antologías de aquellos tiempos, los listados de jurados de narrativa, los consejos de redacción de las revistas e instituciones literarias, los catálogos de las diversas editoriales, los textos críticos y ensayísticos, las memorias de los congresos, ferias del libro, etc.

${ }^{46}$ Capote Cruz arremete contra las operaciones de silenciamiento de la crítica y no escatima críticas contra nombres como Salvador Redonet Cook, Luisa Campuzano, por nombrar algunos. Recupera obras publicadas por las editoriales El Puente y R como Mateo y las sirenas (1964) de Ada Abdo , El castigo (1966) de Esther Díaz Llanillo, La reja (1965) de María Elena Llana, Cuentos para abuelas enfermas (1964) de Évora Tamayo y Memorias de un decapitado (1965) de Ángela Martínez. Todas obras narrativas que se distanciaba de la llamada "literatura de la violencia" y, en cambio, optaban por relatos intimistas y del absurdo.
} 
conflictos realismo-no realismo y las secuelas de lo ocurrido en el (controvertido) "quinquenio gris" parecieron disiparse iniciándose una apertura en el proceso cultural. ${ }^{47}$

En las últimas décadas del siglo XX, en el ámbito cubano se produjeron profundos cambios sociales, políticos y económicos. La crisis sociopolítica se inició en 1980 con la ocupación de la embajada del Perú y posterior salida de más de 125.000 cubanos por el puerto del Mariel. Luego, en 1986, se puso en práctica el "Proceso de Rectificación de Errores y Tendencias Negativas", un programa en el que los "errores" y "tendencias" estaban asociados tanto a las estrategias económicas que habían sido aprobadas por el $1^{\circ}$ Congreso del Partido Comunista Cubano y se habían puesto en práctica por medio de dos planes quinquenales, como a la "pérdida de efectividad" en el funcionamiento del partido, las organizaciones de masas y los órganos de poder popular. ${ }^{48}$ La crisis se acentuó en 1989 con la desarticulación del socialismo en Europa del Este y la posterior desintegración de la Unión Soviética, sus socios comerciales durante más de tres décadas. En la configuración del espacio cultural no se puede olvidar el peso político y moral de la caída del muro de Berlín y el inicio del llamado "Período especial en tiempos de paz" (expresión con la que el discurso oficial ha nombrado tanto a la crisis como a las reformas) que significó un conjunto de reformas que abarcaron los órdenes institucional y económico (Font 2004). Esta situación se acentuó a partir de las restricciones provocadas por el recrudecimiento del

${ }^{47}$ Hasta 1959, las funciones culturales gubernamentales eran desempeñadas por la Dirección de Cultura del Ministerio de Educación, y el peso de la gestión cultural recaía en la gestión de instituciones de carácter privado y asociaciones voluntarias. En 1961 se funda el Consejo Nacional de Cultura, como primera institución gubernamental independiente, encargada de la política de desarrollo cultural del país. Dentro del proceso de institucionalización de los Órganos de la Administración Central del Estado, en 1976 se crea el Ministerio de Cultura con la función de dirigir, supervisar y ejecutar la política cultural. La legislación cultural en Cuba tomó fuerza a partir de la proclamación de la Constitución de 1976.

48 Los principios básicos fueron continuar la orientación marxista-leninista de la revolución, ratificar el papel dirigente del Partido Comunista Cubano como partido único y rechazar el mercado y la propiedad privada (Mesa-Lago, 1993). 
bloqueo de EE.UU. ${ }^{49}$ A partir de estos hechos, a comienzos de los noventa, Cuba empezó a atravesar una situación de emergencia económica que produjo un deterioro en todas las instancias de la vida y se evidenciaron retrocesos en sectores prioritarios como la alimentación, el empleo y también la salud y la educación, consideradas las dos grandes conquistas de la Revolución. En 1993 el gobierno tomó algunas medidas de corte financiero (hay quienes hablan de una apertura capitalista) para tratar de mejorar las condiciones de vida; entre estas se encontraban la despenalización del uso y tenencia de divisas y la apertura de los mercados agropecuarios. Estas medidas han dado lugar a una nueva diferenciación social que hace más complejo el escenario social. Las mujeres (en su condición de trabajadoras, ama de casa y madres) han sido quienes más han sufrido los rigores de la crisis: en ellas han tenido particular incidencia las reducciones en los puestos laborales, las dificultades con el transporte, la complejidad de las labores domésticas (cortes de luz, escasez de alimentos, precarización habitacional), etcétera. ${ }^{50}$

\subsection{Derivas literarias de fines de siglo}

Dentro del clima de apertura cultural y rechazo del dogmatismo, durante la década del ochenta, en el interior de la intelectualidad cubana comenzaron a constituirse diversos grupos que, a partir de su actuación en la esfera de la cultura, cuestionaron el sistema de valores establecidos. Esta situación alcanzó a todas las áreas de la creación: la literatura, las artes plásticas, el teatro, la danza, el cine. Esta situación cultural se concretó en varios

\footnotetext{
${ }^{49}$ En julio de 1989 el Senado de los EE.UU. aprobó una Enmienda, presentada por el republicano Connie Mack, referida a la prohibición a las firmas subsidiarias de compañías estadounidenses establecidas en otros países de realizar operaciones comerciales con Cuba. Luego, en julio de 1991, en el marco de las discusiones del Proyecto de Ley de Ayuda Externa, aprobó varias enmiendas tendientes a imponer una serie de condiciones a la Unión Soviética para recibir ayuda exterior estadounidense, entre las que se incluye el cese de la asistencia militar y económica a Cuba.

50 Para profundizar en las diferentes aristas de la situación cubana en los noventa, véase Valdés Fernández (1996); Holgado Fernández (2000); Vega Quintana (2000); Jennissen (2001); Nuñez Sarmiento (2001 y 2004); Font (2004).
} 
proyectos alternativos a la cultura oficial: en las artes escénicas, el grupo Ballet Teatro de La Habana y el teatro Obstáculo; en la literatura, el movimiento de poesía joven y el proyecto Paideia; en la plástica, los proyectos Arte Calle, Hacer y Castillo de la Fuerza, entre otros. Estos grupos tuvieron en común la inmersión crítica en la realidad sociopolítica del país, el desafío al universo de valores dominantes y la búsqueda de espacios no institucionales para desarrollar sus actividades. ${ }^{51}$

Específicamente en la literatura, la crítica observa cambios que resultan de las transformaciones que ha sufrido la sociedad desde fines de los ochenta (Huertas 1993; Redonet Cook, 1999; López Sacha, 1996; Valle, 2000; Fornet, 2006). Salvador Redonet Cook, uno de los críticos más influyentes de la cuentística cubana, en la antología Los últimos serán los primeros (1993), presentó una muestra de la escritura de los narradores de este período, a los que denominó, indistintamente, los "novísimos", los “iconoclastas" y "la tercera generación de la Revolución". ${ }^{52}$ Se ha dicho que esa antología ha sido el primer punto de referencia de esos jóvenes autores (Fowler, 1998; Fornet, 2006; Mateo Palmer, 2002b) y que la nueva narrativa cubana se inicia en 1990 con el relato de Senel Paz, "El lobo, el bosque y el hombre nuevo", ganador del premio "Juan Rulfo" de Radio France Internationale y que sirvió de guión para la película Fresa y chocolate (Strausfeld, 2000; Fornet, 2006). Publicado en un año crucial, este cuento retoma la figura lezamina pero en una

\footnotetext{
51 Para un extenso desarrollo del tema, véase: de la Nuez (1991); Mosquera (1991); Cámara (1991); Bobes (2000).

52 Este crítico tuvo un papel central en la institución y consolidación de este grupo que constituía la primera promoción de escritores y escritoras nacidos y formados luego del triunfo de la Revolución: Rolando Sánchez Mejías, Ernesto Santana, Alberto Garrandés, Roberto Urías, Ronaldo Menéndez, Ena Lucía Portela, Daniel Díaz Mantilla, Pedro de Jesús López, entre otros. Para referirse a la producción de las últimas décadas del siglo XX, el crítico Francisco López Sacha (1996) ha advertido una "vuelta del péndulo", expresión que pretende contraponer la calidad y la cantidad de la producción artística de este período con respecto al inmediatamente precedente. Este crítico los clasifica como iconoclastas, rockeros, tradicionalistas o fabulistas. Amir Valle (2000) organiza a los escritores según los temas que abordan: las becas, la marginalidad, el homerotismo, la guerra, los balseros, la prostitución, etc.
} 
especie de negociación con el discurso oficial, por eso ha sido leído como un evidente esfuerzo de reconciliación entre la política cultural del gobierno y la tradición republicana.

Proclives a utilizar criterios generacionales, tanto los críticos como los mismos escritores han intentado clasificar las producciones de este período. Así, por ejemplo, Jorge Fornet (2006) establece diferencias entre lo que llama "narrativa del desencanto" y la narrativa producida por la generación que nació después de 1959. En el primer grupo (el de los escritores que se conocieron en los ochenta o antes y en cuya obra advierte una preocupación por la historia y por la imagen de Cuba como totalidad), el desencanto no está relacionado con un estado de ánimo sino con un cambio de perspectiva al historiar el proceso revolucionario. Incluye a la generación que creyó o cree en la Revolución y que, en este período, señala las insuficiencias o contradicciones internas. Fornet establece una diferencia entre esta narrativa y la que denomina "narrativa anticastrista" producida desde un tempranísimo exilio y que "basaba su desencanto en el síndrome de la revolución 'traicionada"' (Fornet, 2006: 68). El segundo grupo está integrado por la generación que nació a partir de 1959, publica después de 1989 y cuyos textos -más cercanos a los producidos en el resto del continente en ese período (McOndo y Crack) - se centran en otras preocupaciones, como el cuerpo y los conflictos del presente: "no arrastran el ‘encantamiento' que marcó la vida de sus predecesores; nacieron literalmente, por decirlo de algún modo, en otro país, y no parecen sentir nostalgia por los fantasmas de un pasado que no es el suyo" (Fornet, 2006: 90).

La narrativa de este período ha sido estudiada hasta el momento de modo casi exclusivo a través del cuento, género privilegiado, según algunos críticos, porque las 
condiciones materiales sólo permitían la publicación de antologías (Yáñez, 1996). ${ }^{53}$ En esta línea, Helen Hernández Hormilla señala cómo incidió la crisis en el producto libro porque la depresión económica condujo al cierre de varias revistas culturales, a la disminución de su tirada y a que las editoriales redujeran el número de sus publicaciones. Sin embargo, esta investigadora señala las vías alternativas que surgieron en medio de la crisis:

... plaquettes, folletos o sueltos, en los que aparecieron los primeros textos de los narradores y narradores jóvenes, y otros ya entrados en años. Las antologías fueron entonces una manera de dar a conocer el quehacer de los nuevos creadores, quienes además se abrieron por primera vez al mercado internacional y comenzaron a conquistar importantes premios (Hernández Hormilla, 2011: 117).

En las antologías de esta etapa, las escritoras están poco representadas con las consecuencias negativas que este hecho conlleva: toda antología promueve obras y escritores y, si las nuevas recopilaciones suelen repetir parte de lo aparecido en las anteriores, inevitablemente, contribuyen a reproducir la exclusión. ${ }^{54}$

Tanto fuera como dentro de la isla, el período que se inicia con la caída del Muro de Berlín y que en el campo cultural cubano, como mencionamos, tuvo diversas repercusiones y generó conflictivos movimientos, ha originado debates ensayísticos en torno a sus causas, consecuencias y características. Duanel Díaz (2009) discute las posiciones de Roberto Fernández Retamar, Jesús Díaz y Abel Prieto expresadas en distintos medios y sostiene que las operaciones de rescate del patrimonio cultural que se realizan en la isla son el resultado

\footnotetext{
${ }^{53}$ Cuba tiene una larga tradición en la publicación de antologías. Durante esos años comenzaron a circular varias centradas en la producción contemporánea como: Padura (1994); López Sacha (1996); Yáñez y Bobes (1996); Redonet Cook (1999); Garrandés (1999); Strausfeld (2000).

${ }^{54}$ En el primer capítulo enumeramos las antologías publicadas en Cuba y detallamos el lugar que ocupan, en cada una, las escritoras. Para demostrar el predomino de escritores varones en el ámbito cultural cubano, resulta esclarecedor mencionar la composición de los grupos literarios. Por ejemplo, "Nos-y-otros" surge en La Habana a finales de los años ochenta y, en la vertiente literaria, estuvo formado por Enrique del Risco (1967), Eduardo del Llano (1962), Jorge Fernández Era (1962) y Luis Felipe Calvo (1956); el grupo "El Establo" apareció en 1988, formado por Raúl Aguiar (1962), Ricardo Arrieta (1967), Sergio Cevedo Sosa (1956), Daniel Díaz Mantilla (1970), Karina Mendoza (1971), Ronaldo Menéndez (1970), Verónika Pérez Kónina (1968), Ena Lucía Portela (1972) y José Miguel Sánchez (1969); el proyecto "Diáspora(s)" (tienen una publicación homónima) se creó en La Habana en 1993, compuesto por Carlos Alberto Aguilera (1970), Gerardo Fernández Fe (1971), Pedro Marqués de Armas (1965), Rolando Sánchez Mejías (1959), Ricardo Alberto Pérez (1963) y Rogelio Saunders (1963), entre otros.
} 
del desplome del campo socialista. Se refiere al período de "deshielo" cuyo inicio que ubica en los ochenta, se profundiza en los noventa como consecuencia de la súbita crisis del marxismo-leninismo que siguió a la caída del muro de Berlín y la desintegración de la Unión Soviética. Considera que esta época se inicia con el discurso de clausura de Fernández Retamar en el Primer Coloquio de Literatura Cubana celebrado a fines de 1981 en el que se propone la corrección de los errores del pasado basados en el dogmatismo. Sin embargo, según la lectura de Díaz, no se ha tratado de simples errores sino el resultado del "totalitarismo del sistema" (Díaz, 2009: 167) y, en este sentido, sostiene que este es un deshielo tropical controlado por "el establishment cultural cubano" que se legitima en un calculado reconocimiento de los errores del pasado para declarar superada aquella etapa oscura pero que, en su opinión, responde a un continum histórico que, desde las Palabras a los intelectuales hasta la actualidad, marcaría una diferencia con respecto a la URSS y sus satélites:

aunque haya comenzado un poco antes de 1990, es indiscutible que la recuperación de un patrimonio cultural no perdido sino anteriormente rechazado como diversionista, y la correspondiente ampliación del campo de lo nacional, están condicionadas por el descrédito del marxismo a raíz de la caída del muro de Berlín (Díaz, 2009: 169).

Vincula este movimiento con el desplazamiento desde el marxismo-leninismo a un nacionalismo ecléctico, lo que condicionaría la sacralización de la identidad nacional y la ampliación del canon cubano..$^{55}$ Aunque con algunas diferencias, en esta misma línea se encuentra Rafael Rojas (2006) quien advierte que durante los noventa el conflicto se

\footnotetext{
55 Hay quienes ubican antes este proceso de "relecturas". Por ejemplo, en Contra el silencio. Una lectura de Dulce María Loynaz, Zaida Capote Cruz señala que "en las lecturas que excluyen a Dulce María Loynaz del proceso literario nacional ha influido la propia actitud de la escritora, quien no manifestó nunca su apoyo a la Revolución de 1959, a pesar de que no dejó nunca de aparecer en público esos primeros años. Por esas razones, a la hora de constituir un canon literario institucional, su obra quedó fuera de planes de estudios y editoriales" (Capote Cruz, 2002: 4). A partir de que en 1981 el Ministerio de Cultura le otorga la distinción por la Cultura Nacional, Loynaz se "reincorporará gradualmente a la vida cultural del país y recibirá, en 1987, el Premio Nacional de Literatura, en una carrera que no concluirá hasta la concesión, en España, en 1992, del Premio Cervantes" (Capote Cruz, 2002: 4).
} 
traslada desde la guerra civil hacia el orden simbólico en el que se produce una guerra de la memoria protagonizada por los herederos de los dos bandos (se refiere a los bandos revolucionarios y contrarrevolucionarios, comunistas y anticomunistas, castristas y anticastristas). Sostiene que, en esta etapa, a medida que la guerra política se reduce al enfrentamiento entre dos comunidades vecinas (La Habana y Miami), la guerra cultural se vuelve más simbólica y se libra, sobre todo, en el terreno de la memoria. En este sentido, lee cómo, en la década del noventa, se produce un desplazamiento del tópico “intelectual y sociedad" hacia otras zonas "más complejas de asunción del compromiso ideológico y la crítica pública que no recurren a la tradicional identidad entre la sociedad civil y el Estado" (Rojas, 2006: 399). Rojas señala cómo varios escritores residentes en la isla -Ambrosio Fornet, Leonardo Padura, Arturo Arango, Rafael Hernández, Desiderio Navarro— se han acercado al tema por medio de un sutil abandono de la función del intelectual (en tanto sujeto plenamente adscripto a los aparatos ideológicos del Estado) para comenzar a recuperar el rol de conciencia crítica en la sociedad civil. Para Rojas, estos escritores articulan un nuevo discurso de la autonomía intelectual (generalmente desde una concepción gramsciana de la sociedad civil) que cuestiona el vínculo simbólico entre los intelectuales y la Revolución al tiempo que acentúa el deslinde entre la crítica pública y la ideología estatal.

\subsection{La situación de las escritoras y de los estudios de género en y sobre Cuba}

En Cuba los estudios de género revisten un particular interés y han sido abordados por la crítica tanto desde análisis socio-históricos (Espina, 1997 y 2001; González-Pagés, 2004; Núñez Sarmiento, 2001 y 2004), filosóficos y psicológicos (Vasallo Barrueta, 1995, 2001 y 2002), como desde ámbitos ligados al campo cultural (Araújo, 1986, 1992 y 1997; Cámara, 1991; Mateo Palmer 1995 y 2002; Pogolotti, 1991). En comparación con lo sucedido en 
otras regiones de América Latina, en Cuba la creación de instituciones de carácter académico en torno a los Estudios de Mujeres o de Género, según denominaciones adoptadas en diferentes países, comienza más tarde.

Las principales antecesoras de los estudios de género en Cuba se encuentran sobre todo en los años treinta. En ese entones, un grupo de mujeres abogaba por los derechos femeninos, en conferencias, aulas universitarias, periódicos, etcétera: María Luisa Dolz (1854-1928), Dulce María Borrero de Luján (1883-1945) Camila Henríquez Ureña (18941973), Graziella Garbalosa (1896-1977), Mariblanca Sabas Alomá (1901-1983), Ofelia Rodríguez Acosta (1902-1975), y Dulce María Loynaz (1902-1997) entre otras. Ya en 1939, Camila Henríquez Ureña denunciaba la marginalidad de la mujer en la cultura al señalar que sus problemas no eran sólo de sexo sino de clase social. Además fue quien analizó cuestiones como la defensa de los derechos de la mujer a su propio espacio, en la caracterización de una identidad. ${ }^{56}$ Sabas Alomá publicó Feminismo: cuestiones sociales, crítica literaria (1932) donde sostenía que el principal enemigo de la mujer era ella misma porque reproducía la dominación masculina y transmitía la exclusión de su sexo de la vida pública. A partir del proceso iniciado el 1 de enero de 1959, un trabajo pionero fue "Aspectos de la condición laboral de la mujer” (1975) publicado por Isabel Larguía y John Dumoulin en la revista Casa de las Américas. ${ }^{57}$ A partir de la teoría marxista, realizan una explicación socio-

\footnotetext{
56 Conferencia pronunciada por Camila Henríquez Ureña en el Lyceum en marzo de 1939, en el acto de propaganda del Congreso Nacional Femenino. Véase Camila Henríquez Ureña, 1982 y 1985. Mirta Yáñez publicó un libro sobre esta autora: Camila y Camila (2003): "Este texto no es un testimonio, ni mucho menos una biografía, sino eso que ya he dicho, un álbum de recortes, en donde he tratado de hilar, junto a recuerdos de quienes la conocieron, algunos de sus manuscritos y documentos, cartas, poemas, fotos, fragmentos de diarios, papelería, parte de los lugares y aventuras intelectuales en que intervino a lo largo de su vida; un recorrido sobre algunas de sus reflexiones, y mi propia memoria de lo que fue el inefable privilegio de haber sido su alumna" (Yáñez, 2003: 12). En 1999, esta investigación recibió el Premio Memoria Colección Coloquios y Testimonios del Centro Cultural Pablo de la Torriente Brau.

${ }^{57}$ Isabel Larguía, una argentina Licenciada en Historia que emigró a Francia en la década del cincuenta y, apenas triunfó la Revolución, se fue a vivir a Cuba. Allí estuvo en pareja con John Dumoulin, norteamericano Licenciado en Letras por la Universidad de Harvard. En conjunto publicaron en la revista de Casa de las Américas "Hacia una ciencia de la emancipación de la mujer", en 1971. Luego, en 1983, divulgaron el primer libro del feminismo marxista escrito en Cuba: Hacia una concepción científica de la emancipación de la mujer.
} 
económica de las causas de interiorización femenina que determinaron su diferenciación caracterológica. Introducen la categoría de "trabajo invisible" para indicar el aporte a la reproducción de la vida humana por parte de las mujeres, y plantean la necesidad de socializar el trabajo doméstico y de implantar la venta libre de anticonceptivos.

En el contexto cubano, entonces, el feminismo está atravesado por su vinculación con una sociedad que propone erigirse como socialista. Los proyectos tendientes a lograr la igualdad y la justicia social significaron un cambio en la situación de la mujer, ya que el programa social y liberador del país y su teoría marxista se centró en un sistema de aprendizaje y de realización que proponía la igualdad de género y un acceso desprejuiciado a los centros de trabajo y de la ciencia. ${ }^{58} \mathrm{~A}$ este hecho se sumó la masiva campaña de alfabetización que erradicó el analfabetismo y permitió el paulatino acceso a los diferentes niveles de la educación no sólo de las mujeres sino de todo el pueblo. ${ }^{59}$

Dentro y fuera de la isla existe un complejo debate en torno a la concreción (o no) de las medidas políticas tomadas por el gobierno revolucionario respecto de la igualdad de género. ${ }^{60}$ Aunque con matices, entre quienes consideran que el proyecto se concretó, se

58 Para comprender el proceso cubano resulta esclarecedor el artículo "Las mujeres y los cambios sociales" (1973) de la argentina Mirta Henault. Allí analiza qué sucede con las mujeres en un momento de cambio social, específicamente, durante la Revolución Rusa. Critica el marxismo por los límites implícitos en la emancipación de las mujeres, porque "para gran parte del marxismo la liberación de la mujer debería ser un corolario inevitable de la dictadura del proletariado. Esto no fue así en Rusia y tampoco lo es en Cuba" (Henault, 1973: 35-36). Cuando dedica una aparto al análisis de la situación de la mujer en Cuba, Henault recurre a las palabras de Ann Z. Partisans para adelantar que "la liberación de las mujeres no es un corolario inevitable de la dictadura del proletariado. Allí donde ella fracasa, la revolución también ha fracasado. El socialismo cubano continúa siendo una esperanza porque es original y porque todavía es joven" (Henault, 1973: 35).

59 Para acceder a estadísticas en cuanto a la distribución del ingreso, los niveles de alfabetización, la cobertura del sistema de salud, el acceso a la alimentación básica y la vivienda (entre otros índices), véase Valdés Fernández (1996).

${ }^{60}$ Resulta ilustrativo señalar algunas estadísticas que ponen en evidencia la situación de la mujer cubana en la actualidad. Hoy representan el 49,9\% de la población total, con una esperanza de vida de 77,6 años. Los avances alcanzados con la campaña de alfabetización han provocado que, en la actualidad, el 58\% de los graduados universitarios sean mujeres. En 1997, la participación de las mujeres en el sector estatal civil era de $42.5 \%$ y en el sector privado de $22,9 \%$; el $66,6 \%$ de los técnicos y profesionales del país son mujeres, ocupa el $31 \%$ en cargos de dirección en la economía estatal, el 27,6\% de parlamentarias, el 34,6\% de los dirigentes del sistema jurídico, el $61 \%$ de los fiscales, el $49 \%$ de los jueces profesionales y el $47 \%$ de los magistrados del Tribunal Supremo Popular (Lourdes Fernández Ruis, s/d). En cuanto a las reformas jurídicas se encuentran 
encuentran las cubanas Graziella Pogolotti (1991), Luisa Campuzano (1996), Lourdes Fernández Rius (2000) y Norma Vasallo Barrueta (2001, 2002 y 2004). Aunque reconocen avances en los ámbitos jurídico y político, no dudan en señalar que en la práctica y en la conciencia cotidiana, Cuba sigue siendo fuertemente patriarcal. ${ }^{61}$ También aducen que en la isla, a diferencia de otros países, la progresiva transformación de la mujer se produjo en el contexto de un cambio revolucionario que nunca tuvo como objetivo prioritario a las mujeres, sino la modificación radical de la estructura política y económica del país para lo cual la categoría operativa fundamental era la de clase y no la de género. ${ }^{62}$ Para la cubana Norma Vasallo Barrueta, el año 1959

... significó para las mujeres cubanas el inicio de un proceso gradual; pero sostenido, de grandes transformaciones sociales, aquello que el movimiento feminista se propuso después de tomar conciencia de que el derecho al voto por sí solo no produciría las transformaciones necesarias en la vida de las mujeres (Vasallo Barrueta, 2002: 19)

Advierte que, a diferencia de lo que ocurre en otros países, este proceso no surge como resultado directo de luchas feministas, sino que es consecuencia de un movimiento de grandes transformaciones sociales ligadas al "Proyecto Social de la Revolución Cubana" (Vasallo Barrueta, 2002: 19) en cuyo marco ideológico se establecía la lucha contra toda forma de discriminación y desigualdad entre las personas, sin importar su condición de sexo, clase o etnia. Considera que este proceso fue muy importante porque permitió la

la Ley de Maternidad (1974), el Código de la Familia (1975), la Ley de Protección e Higiene del trabajo (1977) y la de Seguridad Social y Código Penal (1979). En cuanto a los espacios sociales, se creó la Comisión de Atención a la Niñez, la Juventud y la Igualdad de Derechos de la Mujer, el Centro Nacional de Educación Sexual, las Comisiones de Prevención y Atención Social y la Comisión de Empleo Femenino.

${ }^{61}$ Para un extenso desarrollo de esta problemática, véase González Pagés (2002); Campuzano (1995 y 1996); Vasallo Barrueta (2001 y 2002); Holgado Fernández (2000). Con respecto a la situación de la mujer durante los últimos años, también resulta interesante el análisis semiológico que Verity Smith (1995) realiza en las revistas Mujeres y Muchachas. El artículo se centra en el lugar de la mujer en el período post-revolucionario (acota el período a la década de 1980) y la propuesta consiste en analizar los tópicos de mayor prominencia en dos revistas dirigidas al público femenino: la familia y las relaciones personales, los usos de la mujer y la moda. El análisis realizado por la autora le permite mostrar el desigual desarrollo de Cuba post-revolucionaria

${ }^{6}$ Para profundizar en la situación de la mujer en la actual coyuntura política, véase el artículo de Jennissen y Lundy (2001). Las autoras realizan una explicación, apoyada con datos estadísticos, de cuestiones como el trabajo en sectores privados, la prostitución, la violencia familiar, etc. Para ejemplificar las tensiones, recurren a experiencias vivenciadas durante su estadía en el país. 
independencia económica de la mujer, su reconocimiento social y su amplia participación en el ámbito público. ${ }^{63}$ En este proceso, el Ministerio del Trabajo suprimió todas las restricciones en el acceso de la mujer a empleos tradicionalmente masculinos y estableció leyes que protegieran sus derechos y garantizaran la igualdad de oportunidades y de remuneración. Para Vasallo Barrueta (2004) dos son los factores que retrasaron los estudios en Cuba respecto del resto de América Latina. En primer lugar, el Proyecto de Igualdad y Justicia Social de la Revolución porque significó un cambio en la situación de la mujer cubana que comenzó a ganar, en poco tiempo, la mayoría de las reivindicaciones por las que se había luchado durante la guerra por la independencia de España. Este hecho hizo que estuvieran en una situación favorable respecto de sus pares latinoamericanas. ${ }^{64} \mathrm{El}$ segundo factor fue la masiva campaña de alfabetización a la que accedió la mujer. Así, para Barrueta fueron estos hechos los que retrasaron, hasta fines de 1980, el proceso de reflexión y toma de conciencia de que el conjunto de las mujeres no ejercía la totalidad de sus derechos, ni hacía uso de las políticas que las beneficiaban. A partir de este momento comienzan a surgir algunas instituciones que garantizan la reflexión académica sobre aquellos elementos de la cultura y de la subjetividad social e individual que funcionan como un freno para el desarrollo de la mujer y para el cambio social. Además de la Federación de

${ }^{63}$ En "Ecos del pasado, voces del presente (Un acercamiento a ideas y objetivos feministas de las cubanas)", Norma Vasallo Barrueta (2002) realiza un recorrido histórico por las luchas llevadas adelante por mujeres cubanas. Si comparamos con otros países latinoamericanos, resultan llamativas algunas fechas, por ejemplo, la Ley de Divorcio fue una conquista del año 1918 (recordemos que en Argentina recién se dictó en 1987).

${ }^{64}$ Similares razones alega Lourdes Fernández Ruis (s/d) para explicar porqué los estudios de género recién surgen entre 1980 y 1990. Sin embargo, también aduce desconocimientos, confusión, prejuicio y resistencia con respecto al feminismo, las teorías feministas y la perspectiva de género. Señala que es durante la década de 1970 cuando se realizaron grandes reformas jurídicas destinadas a eliminar las injusticias derivadas de la cuestión de género: Ley de Maternidad (1974), Código de la Familia (1975), Ley de Protección e higiene del trabajo (1977), Ley de Seguridad Social y Código Penal (1979). También considera que otro avance en la situación de la mujer fue la creación de mecanismos sociales que impulsaron cambios en la vida social: la Comisión de Atención a la Niñez, la Juventud y la Igualdad de Derechos de la Mujer, el Centro Nacional de Educación Sexual, las Comisiones de Prevención y Atención Social y la Comisión de Empleo Femenino. 
Mujeres Cubanas que ya existía desde $1960,{ }^{65}$ Vasallo Barrueta menciona la creación de catorce cátedras en la Educación Superior que tienen como objetivo estimular los estudios de la mujer mediante la realización de congresos, encuentros y revistas que promueven un continuo debate sobre el tema. Un hito importante es la sanción, en 1992, de la Constitución de la República, porque establece la igualdad de género, prohibe la discriminación de la mujer y las restricciones en su condición civil. En el artículo 44 del capítulo VI sobre Igualdad, expresa: "El Estado garantiza que se ofrezcan a la mujer las mismas oportunidades y posibilidades que al hombre, a fin de lograr su plena participación en el desarrollo del país". También enuncia que "La mujer y el hombre gozan de iguales derechos en lo económico, político, social y familiar (...). El Estado se esfuerza por crear las condiciones que propicien la realización del principio de igualdad" (Constitución, 1992). ${ }^{66}$ En 1994, la creación del Programa de Estudios de la Mujer en Casa de las Américas significa un hito en el debate y sistematización de los estudios de la mujer, ya que su objetivo es promover un acercamiento crítico a la historia y la cultura de las mujeres latinoamericanas y caribeñas desde el siglo XVI hasta el presente. Al igual que Vasallo Barrueta, para la cubana Helen Hernández Hormilla (2011) la incorporación de la perspectiva de género en las ciencias sociales cubanas se produce a partir de la segunda mitad de la década del ochenta y de manera gradual, a partir de diferentes hechos como

... la relevancia alcanzada por las mujeres en todos los sectores sociales, la recepción de nuevos textos y teorías, la apertura del país a las tecnologías de la información, las visitas de profesionales extranjeras y la participación de especialistas cubanas en eventos internacionales dedicados a la mujer (Hernández Hormilla, 2011: 25).

${ }^{65}$ La Federación de Mujeres Cubanas (FMC) se funda el 23 de agosto de 1960 con la presidencia de Vilma Espín. El ideario no es netamente feminista sino que sus objetivos están interrelacionados con los de la Revolución. Véase Hernández Hormilla (2011).

${ }^{66}$ Para un análisis del Código de Familia y otros documentos oficiales sobre la mujer en Cuba, ver Stone (1981). 
Entre quienes desestiman las medidas tomadas por el gobierno se encuentran la colombiana Patricia de Miranda Parrondo (2002) y Madeline Cámara (2000), cubana que reside en EE.UU. Sostienen que para la mujer cubana los cambios no fueron radicales, ya que un proyecto en que se formule su libertad es incompatible con la falta de democracia en Cuba. Miranda Parrondo rechaza las políticas estatales y señala como un grave problema la situación de la familia cubana. Mientras las autoras antes referidas consideran que los espacios para los niños y los jóvenes significan un logro para el desarrollo de la vida laboral de las mujeres, Miranda Parrondo considera que hoy

...la educación familiar no es efectiva a distancia, pues la ausencia del contacto directo puede estimular desajustes e incomprensiones y desconoce la riqueza y dinamismo de los aportes que brinda un vínculo filial estrecho en la integridad del hombre como ser social. Mas, en Cuba ello ha sido ignorado por el gobierno que ha colocado como prioridad la participación del individuo en múltiples tareas sociales, muchas de las cuales tuvieron un carácter circunstancial y no arrojaron resultados positivos para el desarrollo del país, ni beneficios para sus pobladores, sino que contrariamente -fueron corrosivas para la unidad familiar e influyeron negativamente sobre el ordenamiento social (Parrondo, 2002: 14).

Demuestra sus afirmaciones a través de cuadros estadísticos que cuantifican una marcada disminución en las tasas de nupcialidad, de crecimiento de la población y de la tasa de natalidad, frente a un aumento del número de divorcios.

Madeline Cámara (2000) sostiene que la Revolución Cubana sólo liberó formalmente a la mujer del yugo de la servidumbre doméstica y sexual, así como de la dependencia económica de padres y esposos porque, en la práctica, no ha sido capaz de organizar la sociedad de modo que las mujeres accedan a puestos de decisión y mando en la vida nacional. ${ }^{67}$ Con respecto al feminismo, sostiene que fracasó en Cuba debido a la incompatibilidad entre este pensamiento y la existencia de un partido único como rector de una sociedad, porque la práctica del feminismo presupone la posibilidad de un discurso en

\footnotetext{
${ }^{67}$ Para comprender la posición ideológica de la autora basta la siguiente frase "He aquí un índice evidente de la falta de democracia que existe en Cuba: el hecho de que la emancipación de la mujer siga siendo una promesa incumplida" (Cámara, 2000: 213).
} 
el que las mujeres "considerando sus puntos de interés común, así como sus diferencias como grupo humano, sean el núcleo generador y ejecutor de proyectos que desarrollen y respeten estas afinidades y divergencias" (Cámara, 2000: 213). ${ }^{68}$

Graziella Pogolotti (1991) considera que Cuba es un caso excepcional porque, al hacer una revolución socialista que ha dado voz a "las silenciosas", ha suprimido los obstáculos que interferían con la plena integración laboral y con la participación social y política. La posición de esta cubana reivindica los logros alcanzados por la mujer: un lugar fundamental en la fuerza laboral y sobre todo en la fuerza laboral calificada. Aunque advierte que en el plano conceptual también se ha producido una transformación radical, reconoce que en la conciencia cotidiana muchas antiguas nociones no se han desarraigado.

Por su parte, la cubana Luisa Campuzano (1996) sostiene que las promesas fueron cumplidas parcialmente. Para demostrar su afirmación señala que, a pesar de la demostrada capacidad de la mujer en diferentes ámbitos de trabajo, en la actualidad los puestos de conducción siguen ocupados por el sexo masculino. De todos modos, señala que Cuba ha realizado un avance en este sentido debido a que, desde 1975, la mujer ha obtenido reconocimiento político (Tesis III del Primer Congreso del Partido "Sobre el pleno ejercicio de la igualdad de la mujer”) y jurídico (nuevo juramento nupcial y Código de la Familia). Esto implica un avance de gran magnitud porque el trabajo doméstico deja de ser invisible. El cubano Julio César González Pagés (2002) considera que en Cuba el machismo

\footnotetext{
${ }^{68}$ Resulta ilustrativo señalar algunas estadísticas que ponen en evidencia la situación de la mujer cubana en la actualidad, la información fue extraída de Lourdes Fernández Ruis (s/d). Hoy representan el 49,9\% de la población total, con una esperanza de vida de 77,6 años. Los avances alcanzados con la campaña de alfabetización han provocado que, en la actualidad, el 58\% de los graduados universitarios sean mujeres. En 1997, la participación de las mujeres en el sector estatal civil era de $42.5 \%$ y en el sector privado de $22,9 \%$; el $66,6 \%$ de los técnicos y profesionales del país son mujeres, ocupa el $31 \%$ en cargos de dirección en la economía estatal, el 27,6\% de parlamentarias, el 34,6\% de los dirigentes del sistema jurídico, el 61\% de los fiscales, el $49 \%$ de los jueces profesionales y el $47 \%$ de los magistrados del Tribunal Supremo Popular. A pesar de todos estos cambios, Fernández Ruiz señala que aún quedan transformaciones por realizar: las inequidades se evidencian más en el ámbito privado familiar y en el acceso a puestos de toma de decisiones. Lo mismo sostienen las canadienses Jennissen y Lundy (2001) al señalar que, aunque el artículo 26 del Código de Familia establece igualdad de responsabilidades del hombre y la mujer para la crianza de los niños, en la práctica son las mujeres quienes mayoritariamente siguen realizando esta labor.
} 
(término con el que se acuña la hiperbolización de la masculinidad y, por lo tanto, pone al macho-hombre como centro del universo) como conjunto de ideas socio-ideológicoculturales se ha encargado de preservar la hegemonía masculina como centro del poder. Señala que el machismo ha sido validado en Cuba como una forma de la cultura y, a pesar de ser muy criticado en las dos últimas décadas, aún goza de gran arraigo en los diferentes grupos sociales, tanto de la Isla como de la diáspora cubana. ${ }^{69}$

Como ya se señaló, los sucesos acaecidos a fines de la década de 1990 y la consecuente disminución de importaciones y exportaciones, afectaron a la economía cubana que tuvo que realizar un importante viraje desde una economía socialista hacia la economía de mercado, una situación de incertidumbre que ha generado diferentes reacciones dentro y fuera de Cuba. Sobre estos cambios se centra el artículo de las canadienses Therese Jennissen y Colleen Lundy (2001) en el que se examina el impacto que provocaron en la mujer y se pregunta si ésta podría mejorar su situación con la incorporación a la economía de mercado. Según las autoras, este hecho generó en las mujeres fuertes contradicciones, es decir, desató en ellas una denodada lucha entre los deseos de retener una sociedad socialista basada en los principios de la igualdad y los avatares de la incorporación de Cuba a otro modelo económico. ${ }^{70}$

En el campo literario, es a partir de fines de los ochenta cuando adquieren visibilidad y se acrecientan las producciones de escritoras cubanas. ${ }^{71}$ En ese momento,

${ }^{69}$ González Pagés (2002) recupera viejos debates sobre machismo, travestismo, homosexualidad y feminismo para abrir nuevas perspectivas que permitan discutir sobre los modelos de masculinidad que se han desarrollado históricamente en Cuba.

${ }^{70}$ Las autoras realizan una explicación, apoyada con datos estadísticos, de cuestiones como el trabajo en sectores privados, la prostitución, la violencia familiar, etc. Para ejemplificar las tensiones, recurren a experiencias vivenciadas durante su estadía en el país.

${ }^{71}$ En las representaciones de la mujer que aparecen en la cinematografía cubana, el film de Pastor Vega Retrato de Teresa (1979) significó un hito. Brígida Pastor considera que contribuye a deserotizar a la protagonista femenina y a revaluar los falsos modelos de feminidad tal como han sido perpetuados por los medios de comunicación de masas: "Este documental fílmico constituye una ruptura con las estructuras socialistas-tradicionalistas de género y, como artefacto cinematográfico incorpora signos del cine clásico 
grupos de académicas, escritoras y artistas, con o sin apoyo institucional (en 1994, Casa de las Américas crea el Programa de Estudios de la Mujer) comienzan a organizarse y a programar acciones para promover la asunción de una conciencia de género, otorgar mayor visibilidad a su historia y a sus realizaciones culturales. En 1989 Susana Montero publica La narrativa femenina cubana 1923-1958. En 1990 se realiza en Cuba el Primer Encuentro Cubano-Mexicano "Mujer y literatura" con el auspicio de Casa de las Américas y el Programa Interdisciplinario de Estudios de la Mujer del Colegio de México (PIEM). Muchos de los trabajos presentados se publicaron en una sección del número 183 (1991) de la revista Casa de las Américas. Al año siguiente se realizó el segundo congreso, esta vez con sede en México y estuvo dedicado a la obra de escritoras cubanas. En 1991 se funda la Cátedra de la Mujer en la Universidad de La Habana. Entre 1993 y 1994 Nara Araújo dicta el primer curso sobre "discurso literario femenino" (Campuzano, 2004: 214) en la Licenciatura en Letras de la Universidad de La Habana. En 1994, año del centenario del nacimiento de Camila Henríquez Ureña, se inicia el Programa de Estudios de la Mujer en Casa de las Américas y se convoca al Premio Extraordinario de Ensayo sobre Estudios de la Mujer, otorgado a Lucía Guerra por La mujer fragmentada: historias de un signo (1994). También en la década del noventa se crea la cátedra "Gertrudis Gómez de Avellaneda" en el Instituto Cubano de Literatura y Lingüística dirigida por Susana Montero y luego por Zaida Capote Cruz.

Es en este marco que en 1996 se publica Estatuas de sal. Cuentistas cubanas contemporáneas, primera recopilación antológica de textos narrativos de escritoras cubanas,

hollywoodense, en el que los signos transmiten la ideología patriarcal que subyace en nuestras estructuras sociales y que modela a las mujeres de formas muy específicas, formas que reflejan las necesidades y el subconciente del patriarcado" (Pastor, 2005: 297; itálica en el original). 
preparada por las críticas y escritoras Mirta Yáñez y por Marilyn Bobes. ${ }^{72}$ Este libro funda un corpus al presentar un amplio panorama de una larga tradición que se inicia en el siglo XIX (con Gertrudis Gómez de Avellaneda y la Condesa de Merlín) y continúa durante el siglo XX (con Lydia Cabrera, Renée Méndez Capote y Dulce María Loynaz, entre otras). Poco después, dos importantes revistas dedicaron sendas entregas a las mujeres cubanas y a la producción cultural femenina: Temas (n 6 de 1996) y Unión ( $\mathrm{n}^{\circ} 1$ de 1997). A partir de este momento, un grupo de jóvenes narradoras comenzó a obtener los más reconocidos premios nacionales: Ena Lucía Portela, el "UNEAC" de novela en 1997; Adelaida Fernández de Juan, el "UNEAC" de cuento en 1998; Anna Lidia Vega Serova y Mylene Fernández Pintado, el "David" de cuento en 1997 y 1998, respectivamente, entre otros.

Durante los últimos años se han comenzado a producir estudios críticos sobre las obras de escritoras cubanas. Entre la producción realizada desde el ámbito cubano, sobresalen, además de los mencionados en los párrafos precedentes, los trabajos de Diony Durán (2000), Zaida Capote Cruz (2002 y 2008), Helen Hernández Hormilla (2011), Víctor Fowler (1998) y Mabel Cuesta (2012). Fuera de Cuba, son importantes las contribuciones de Catherine Davies (1997), Alessandra Riccio (2002), María del Mar López Cabrales (2007 y 2008), Catharina Vallejo (2009 y 2012), entre otras. En relación con este proceso, las revistas literarias y culturales cubanas impresas y electrónicas así como la profusa circulación de papeles alternativos han jugado un papel central en la dinámica del funcionamiento de inclusiones y exclusiones, y han marcado una apertura en las ideas y en los nuevos temas que abordan, con lo cual han ido ganando espacio allí los textos escritos por mujeres (Valle, 2001). ${ }^{73}$

\footnotetext{
$72 \mathrm{El}$ mismo año que se publica Estatuas de sal, Luisa Campuzano publica "Ser cubanas y no morir en el intento. Estrategias culturales para sortear la crisis", en la revista Temas, no 5 (enero-marzo 1996).

${ }^{73}$ No resulta novedoso señalar que, durante los últimos años, en todo el mundo se ha producido una explosión de los medios electrónicos de comunicación. Sin embargo, en Cuba el fenómeno ha adquirido
} 
tintes interesantes porque se ha convertido en uno de los pocos medios de comunicación y/o difusión de cultura. En la circulación de su producción también influyó la necesidad de comercialización del producto cultural, y por eso, cada vez más libros de autores cubanos residentes en Cuba aparecen bajo sellos editoriales extranjeros (Planeta, Alfaguara, Bruguera, Tusquets y Mondadori) incluso antes de ser publicados en la isla. Este proceso también ha generado una selectiva inserción de la literatura cubana en el mercado editorial con cierta reconstrucción de estereotipos como la isla paradisíaca, fantasía erótica y política de la imaginación occidental. En este sentido, Zaída Capote Cruz agudamente señala que "amén de la literatura del exilio, a veces haya que pensar en el exilio de la literatura" (citado en Hernández Hormilla, 2011: 118). Hay quienes hablan de la mercantilización de la literatura cubana en estos años. Al respecto, señala Jorge Fornet que en poco tiempo se consolidaron dos tendencias que hasta entonces habían tenido una pálida presencia entre los cubanos: "confluyeron el interés de los editores extranjeros por la producción cubana, y el de los escritores cubanos por ser editados fuera de nuestras fronteras" (Fornet, 2006: 98). 


\title{
I. Empezar no es partir de cero
}

\section{Un análisis de Estatuas de sal. Cuentistas cubanas contemporáneas}

\author{
¿Qué significa pertenecer a una tradición? \\ ¿Cuál será el punto de apoyo para sostener su autoridad? \\ Arcadio Díaz Quiñones, Sobre los principios.
}

El título de este primer capítulo remite al inicio de Sobre los principios. Los intelectuales caribeños y la tradición, el sugestivo libro en el que Arcadio Díaz Quiñones retoma la noción de "beginnings" (Said, 1985) para estudiar las relaciones de los escritores e intelectuales con la tradición, cómo la han imaginado, cómo hablan de ella y cómo, en el campo literario moderno, se producen tradiciones múltiples que giran sobre dos polos: conservar la tradición o liberarse de su peso. ${ }^{1}$ El crítico puertorriqueño centra su análisis en el Caribe hispano, un espacio heterogéneo donde

la pertenencia se convierte en un dilema y pone en marcha el imaginario de los comienzos. La tradición no se posee ni se hereda tranquilamente; es necesario ir siempre a su búsqueda. Construirla obliga a reinventarse mediante un trabajo poético e intelectual y lleva a constantes revisiones historiográficas y conceptuales llenas de tensiones subterráneas (Díaz Quiñones 2006: 23).

\footnotetext{
${ }^{1}$ En Beginnings Edward Said (1985) postula el comienzo como el primer paso en la producción intencional de sentido que puede recorrer toda o parte de la obra de un autor; en este sentido, la noción de "comienzos" supone un proyecto subyacente. Said desarrolla la noción de comienzo y sus variaciones: un momento en el tiempo, un lugar, un principio o una acción, también en el sentido de origen. Arcadio Díaz Quiñones hace funcionar esa noción para pensar la configuración de la tradición en el Caribe Hispano a partir del análisis de las relaciones de los escritores y pensadores -Pedro Henríquez Ureña, Tomás Blanco, Fernando Ortiz, José Martí, Ramiro Guerra y Sánchez, Antonio S. Pedreira y Marcelino Menéndez y Pelayo- con la tradición. Las situaciones históricas y sociales compartidas por esta zona caribeña (largas experiencias coloniales, modernidades contradictorias generadas por la coexistencia de la esclavitud y el capitalismo, sucesivas y masivas emigraciones a las metrópolis europeas y norteamericanas) le permiten a Díaz Quiñones plantear un doble dilema: en tal contexto, el sentido de pertenencia a una tradición se ve acechado por la amenaza de su constante disolución y, ante ese riesgo, los intelectuales se ven obligados a reinventar sus tradiciones, a través de constantes revisiones historiográficas y conceptuales que los lleva a repensar la cuestión de los comienzos.
} 
Apelo a la obra de Díaz Quiñones como anclaje para iluminar la lectura crítica de Estatuas de sal. Cuentistas cubanas contemporáneas, antología compilada en 1996 por Mirta Yáñez y Marilyn Bobes, porque el análisis de este capítulo parte de considerar que la publicación de este controvertido libro constituyó en sí misma una operación que buscó construir una tradición y, en este sentido, se inscribe en los supuestos que subyacen en los polos contemplados por Díaz Quiñones, ya que se propone ocupar un vacío o, en otras palabras, fundar una tradición de escritoras. ${ }^{2}$ La operación radica en crear un origen, por eso resulta importante examinar cómo ha sido concebido ese linaje.

Cuando la que contribuye al ejercicio de crear una tradición es una compilación, resulta imprescindible pensar las tensiones subterráneas que sostienen sus cimientos. Estatuas de sal busca intervenir en el combate por insertarse en el ámbito literario cubano; para ello propone rupturas y desvíos, y para intentar ampliar el canon, construye una genealogía paralela o por fuera de la canónica. ${ }^{3}$ Por otra parte, la misma operación coloca en la palestra a un grupo de escritoras contemporáneas a la publicación del libro y proyecta el porvenir de la narrativa escrita por mujeres.

Estatuas de sal cubre un vacío porque en Cuba es la primera recopilación de narradoras y, según desarrollo en el apartado siguiente, porque ya desde la introducción se intenta fundamentar la publicación en la exclusión a la que han sido sometidas las mujeres escritoras en el ámbito literario cubano. ${ }^{4} \mathrm{El}$ único antecedente pertenece al género poético: el valioso Álbum poético-fotográfico de las escritoras cubanas publicado en 1868 por Domitila

\footnotetext{
2 Primera edición: La Habana, Unión.

${ }^{3}$ En Un banquete canónico (2000), Rafael Rojas señala que frente a todo canon cultural moderno (como el de Harold Bloom en El canon occidental o el de Roberto Fernández Retamar en Calibán. Apuntes sobre la cultura en nuestra América) se movilizan dos reacciones: "la de la apertura del canon y la del contracanon" (Rojas 2000: 26), la segunda en alusión a los Estudios Culturales que Bloom denomina la "Escuela del Resentimiento". Otra opción se presentaría desde una perspectiva posmoderna: "el desvío, la fuga, el abandono de toda racionalidad canónica” (Rojas, 2000: 26).

${ }^{4}$ En el Apéndice 1 realizo un recorrido por antologías del siglo XX y detallo a las escritoras incluidas en cada una.
} 
García de Coronado. ${ }^{5}$ El acto de publicar es una forma de intervención fuerte en el espacio público; esta toma de la palabra es una forma de empezar (retomando el concepto de Díaz Quiñones), de inaugurar un lugar, un espacio y, ante todo, de crear una genealogía legitimadora. En esta dirección me pregunto por qué se publica en ese momento; si es el resultado de una presión del campo cultural o si responde a un encargo oficial convergente con una preocupación estatal que impulsa atender cuestiones de género. ${ }^{6}$

\section{Sobre el acto de compilar}

Para ingresar en los entramados de este libro resulta insoslayable conocer algunos datos de las compiladoras. Mirta Yáñez nació en La Habana en 1947 y se dedicó desde muy joven a la escritura de poesía y de cuentos. Luego estudió Licenciatura en Lengua y Literaturas Hispánicas en la Escuela de Letras y Arte de la Universidad de La Habana (1965-1970). En la misma Universidad obtuvo el título de Doctora en Ciencias Filológicas (1992). En diversas entrevistas, entre ellas la que realicé en el 2011, señala la marca que dejaron en su formación docentes como Camila H. Ureña, Rosario Novoa y Ezequiel Vieta. Trabajó en la Universidad hasta que, con el propósito de consagrarse al ejercicio de las letras, renunció en 1987. Cuando publica esta antología, Mirta Yáñez se dedicaba a la crítica literaria y a la escritura de ficción; además era miembro de la Unión de Escritores y Artistas Cubanos (UNEAC); integraba, desde 1986, el Consejo Asesor de la Editorial Gente Nueva y

\footnotetext{
${ }^{5}$ Domitila García Coronado dedica este libro a Gertrudis Gómez de Avellaneda. La autora presenta una galería de catorce retratos: Gertrudis Gómez de Avellaneda, Luisa Pérez de Zambrana, Úrsula Céspedes de Escanaverino, Martina Pierra de Poo, Catalina Rodríguez, Julia Pérez y Montesdeoca, María Santa Cruz, Pamela Fernández de Laude, Mercedes Valdés Mendoza, Brígida Agüero y Agüero, Emelina Peyrellade, Clotilde del C. Rodríguez, Manuela Agromonte de Agromonte, Francisca Rus de Montoro.

${ }^{6}$ Sobre algunas aristas de esta situación, consulté a la propia Mirta Yáñez (ver el Apéndice 3). Estas preguntas recorren subterráneamente el análisis de este libro aunque no son respondidas en su totalidad ya que son distintos factores los que confluyen e intuyo que en el trasfondo hay una polémica, no siempre explícita, que gira en torno al rol del intelectual y que en Cuba alcanza un punto álgido en los sesenta, pero aún hoy impregna los debates del ámbito cultural.
} 
colaboraba como lectora especializada en la Editorial Letras Cubanas. ${ }^{7}$ Marilyn Bobes (La Habana, 1955) estudió Licenciatura en Historia en la Universidad de La Habana (19741978) mientras inició su labor como correctora y luego como redactora de cultura. En 1989 comenzó a trabajar a la Editorial Letras Cubanas como editora y a partir del IV Congreso de la UNEAC se desempeñó como cuadro profesional de la organización, de cuya Asociación de Escritores fue vicepresidenta durante algún tiempo. Hasta 1996 era conocida, principalmente, por su obra poética - Alguien está escribiendo su ternura (1978) y La aguja en el pajar (1979) —, género en el que obtuvo numerosos premios. ${ }^{8}$

Cuando en la entrevista que realicé en 2011 (Apéndice 3) le pregunto a Mirta Yáñez por el origen de este proyecto, según su relato, Estatuas de sal surge de una motivación personal para demostrar la existencia de producción de escritoras cubanas. ${ }^{9}$ Y agrega que convoca a Marilyn Bobes para realizar el proyecto y que recibieron el apoyo de Abel Prieto, en ese entonces Presidente de la UNEAC. En esta instancia también explica por qué opta por el término panorama:

porque no había ningún antecedente de una selección de escritura femenina en Cuba, y yo quería 'historiar' el proceso. El acuerdo fue poner una muestra de las narradoras que tuvieran publicado al menos un libro en esa fecha. Hubo ausentes por problemas técnicos, como Ana Luz García Calzada que nunca llegó a tiempo su colaboración por vivir en provincia. Se trataba de dejar establecida una trayectoria ante la repetida falacia de que en Cuba no había narradoras (Apéndice 3).

A pesar de su advertencia respecto de que Estatuas de sal responde a un criterio panorámico antes que antológico, considero que el análisis minucioso de la obra admite una lectura desde la segunda opción, por las razones que paso a detallar. En primer lugar, recordemos

\footnotetext{
${ }^{7}$ Sobre las publicaciones de Mirta Yáñez consultar el Apéndice 2.

${ }^{8}$ Sobre las publicaciones de Marilyn Bobes consultar el Apéndice 2.

${ }^{9}$ En mayo del 2011, tuve la posibilidad de conocer a Mirta Yáñez durante su participación en la Feria del Libro en Buenos Aires, instancia en la que presentó su última novela, Sangra por la herida (2010). En ese momento, realicé una entrevista (consultar en el Apéndice 3) que me resultó muy útil para saldar algunas dudas sobre su mirada respecto del campo cultural cubano y, en particular, sobre la antología analizada y la producción literaria de esta escritora.
} 
que "panorama" deriva del griego $\pi \alpha \eta$ (todo) y ǒ $\varrho \mu \alpha$ (vista) que significa "todo lo que se ve" (Real Academia Española) y que, por lo tanto, resulta imposible que este libro (ni ninguno) pueda abarcar la totalidad de lo escrito hasta el momento de publicación. Por el contrario, se aproxima a las obras de carácter antológico porque estas organizan una muestra de la producción de un período determinado. Puede ser la muestra de un autor, una generación o un movimiento literario; otras se centran en la producción de una década o pretenden abarcar las modificaciones de un género. En este sentido, la antología es una postura crítica respecto de la producción del período al cual se limita, pues el hecho de elegir ciertas obras y descartar otras implica un ejercicio crítico y canonizador.

En toda definición de antología hay tres elementos claves: colección, selección y preexistencia de los textos que la conforman. ${ }^{10}$ De acuerdo con estos aspectos, Ana María Agudelo Ochoa (2006) esboza una definición que reúne los rasgos mencionados y recoge lo que diversos autores han afirmado al respecto:

una antología es un conjunto de textos y/o fragmentos de textos que se agrupan a partir de ciertas características determinadas por un seleccionador, aunque no siempre argumentadas por el mismo, y una de cuyas finalidades principales es divulgar las obras más representativas de un autor, género, tema, tendencia, movimiento o región (Agudelo Ochoa, 2006: 141-142).

En un ensayo ya clásico, Alfonso Reyes señaló que hay dos tipos de antología según prime el gusto personal del coleccionista o el sentido histórico “objetivo” (Reyes, 1952: 131). A

\footnotetext{
10 Otras definiciones de antología son, por ejemplo, la de Estuardo Núñez, para quien es una "colección seleccionada de breves composiciones o de fragmentos literarios" (Nuñez, 1959: 257) y la de Demetrio Estébanez Calderón quien define la antología como "una colección de textos o fragmentos vinculados por alguna característica común (pertenecer al mismo autor, género, tema, estilo, movimiento literario, etc.) y que han sido escogidos de acuerdo con determinados criterios" (Calderón, 1996: 44). Hay quienes otorgan el estatuto de creación a las antologías; incluso consideran que son un género literario, asunto definitivamente polémico que no se abordará aquí pues es otra la dirección del análisis. Por ejemplo, Alfonso Reyes en Teoría de la antología (1952) propone una categoría de antologías en las que rige el gusto del seleccionador, las cuales, según el ensayista mexicano, pueden alcanzar la temperatura de creación. Juan Domingo Vera (2005) en su artículo "Sobre la forma antológica y el canon literario" propone que es una forma discursiva con sus propias reglas y fines, y con una propuesta creativa y estética.
} 
estas últimas atribuye la característica de ser creaciones críticas y, por eso mismo, las considera fundamentales para un proyecto histórico, mientras que a las primeras les concede una función accesoria, meramente ilustrativa.

En un trabajo sobre vanguardia y nacionalismo en Cuba, Celina Manzoni advierte que "las antologías han sido, son y serán siempre criticadas; como las traducciones, implican elecciones entre variantes. Todas se disculpan del pecado de subjetividad pero todas tienen justificaciones dignas y verosímiles para ella" (Manzoni, 2001: 101). ${ }^{11}$ Podríamos preguntarnos cómo determinar claramente el sentido de una antología si tenemos en cuenta que no siempre el seleccionador aclara el objetivo en el texto introductorio o, en el caso de hacerlo como en Estatuas de sal, el propósito puede no coincidir con lo efectivamente hecho.

Como señalé, en parte la publicación de Estatuas de sal se fundamenta en la necesidad de llenar un vacío: la neutralización y/o silenciamiento de su escritura y el espacio cuasi nulo otorgado a las escritoras en las antologías cubanas publicadas hasta 1996. ${ }^{12}$ Entonces, la situación de marginación pareciera justificar la publicación de un libro reservado a la producción femenina. El título circunscribe la selección a las cuentistas cubanas contemporáneas. Recién en la portada se especifica que es un "panorama" y se delimita temporalmente: Panorama crítico (1959-1995). En este umbral del texto se aclara que la compilación y las notas están a cargo de Mirta Yáñez y Marilyn Bobes, mientras que el

11 En Un dilema cubano. Nacionalismo y vanguardia, Manzoni reflexiona en torno al fenómeno de las antologías y revisa posibles modos de abordaje. Su corpus es la revista de avance. Propone pensar la(s) revista(s) como antologías: "Si se lee la revista como texto múltiple que se desarrolla en las condiciones de un espacio político y cultural, con su propia historia y sus conflictos internos, se posibilita la identificación de nexos y la elaboración de un cierto orden que, en ese sentido, resulta 'antológico', evitando, por una parte, la caída en la sumatoria y, por otra, permitiendo la percepción de tendencias fuertes que, en el caso de la revista de avance, me llevaron a considerar el eje "vanguardismo-nacionalismo"' (Manzoni, 2001: 59).

12 Un detalle del lugar de las escritoras en las antologías se puede consultar en el Apéndice 1. Respecto de la neutralización o el silenciamiento de su escritura hay que tener en cuenta que casi nunca se formula directamente (desde los enunciados de género), sino que el discurso crítico o historiográfico recurre a mecanismos de inscripción del poder que ocultan la identidad del sujeto bajo enunciados estéticos o estilísticos. Una interesante muestra de estos mecanismos es realizada por Rojas (2000) en el apartado "Cuatro técnicas de canonización". 
prólogo es de autoría de la primera. El cuerpo del libro está formado por cuatro partes antecedidas por una "Nota a la edición": ${ }^{13}$ la primera, "Y entonces la mujer de Lot miró..." es la introducción a cargo de Mirta Yáñez; en la segunda, “Antepasadas y...todavía vivas" se recuperan cuentos o fragmentos narrativos de trece escritoras; luego, "Cuentistas cubanas contemporáneas", que reitera el subtítulo del libro, incluye a treinta escritoras, por último, el "Apéndice” incorpora dos trabajos críticos de Luisa Campuzano y Nara Araújo.

En la descripción anterior se advierten dos detalles significativos: el uso del término "panorama" y el desfasaje entre el recorte temporal explicitado en la portada y la segunda parte del libro que recupera a escritoras del siglo XIX y mitad del XX. Con respecto al desfasaje, no se observa ninguna explicación de qué se entiende por "contemporáneo", a pesar de que el término es central para la significación del libro (forma parte del título y una de las partes). Este gesto adelanta la puesta en duda sobre el uso del término "panorama" como inclusivo: si, por un lado, se intenta realizar un acto de justicia histórico (y, para esto, se busca incorporar a todas las escritoras cubanas hasta la actualidad), por otro se excluye del subtítulo a las precedentes (aquellas escritoras que conforman la genealogía legitimadora y cuya incorporación en el cuerpo del libro otorga densidad histórica a las producciones de mujeres y que permiten configurar una legitimación diacrónica).

Del primer problema se desprenden las siguientes preguntas: ¿Existe una diferencia entre el panorama y la antología, tal como se la conoce históricamente ${ }^{14}$, ¿Qué quiere decir que un panorama es "crítico"? Aunque el objetivo de estas páginas no consiste en deslindar teóricamente los conceptos de panorama y antología, resulta ineludible analizar cómo

\footnotetext{
${ }^{13}$ La nota a la edición aparece en la reimpresión de 1998 que es la utilizada aquí. La mayoría de este texto aparece incluido en la "Nota a la nueva edición" de 2008.

${ }^{14}$ La palabra panorama viene del griego "pan=todo" y" horama= vista", lo que puede traducirse como “todo lo que se ve" o "visión global o total". Según la primera acepción del Diccionario de la Real Academia Española, panorama es un "Paisaje muy dilatado que se contempla desde un punto de observación" (RAE en web). En este sentido, un panorama literario se podría pensar como todo lo que se ve (obras) desde un punto de observación que estaría anclado en la mirada subjetiva de las seleccionadoras.
} 
funcionan en este libro. En principio, Estatuas de sal apunta a recortar un nuevo espacio, ofreciendo un enfoque panorámico que se aparta del carácter selectivo propio de una antología. En la "Nota a la edición”, Mirta Yáñez señala que

Un PANORAMA no es una antología, aunque son parientes cercanos. En una antología hay -o debe haber-un criterio de selección excluyente. En este PANORAMA, la intencionalidad ha sido reconstruir el proceso de la voz narrativa femenina cubana, con la mayor inclusividad posible, que permita seguir el discurso en su desarrollo histórico. Por supuesto, en un PANORAMA también hay elecciones (libres) (Yáñez, 1998: 7-8; itálica y mayúsculas en el original).

Este comentario sobre el uso de los términos en juego, aunque apunta a la idea de reconstrucción histórica de la narrativa, no esclarece las diferencias entre ambos ya que se adelanta que en este libro, aunque "panorama", también hubo "elecciones (libres)". Esta nota se incorpora en la primera reimpresión de Estatuas de sal; recién en esta segunda instancia se explicitan algunas decisiones tomadas respecto de la selección. Probablemente se trata entonces de una respuesta a los cuestionamientos que recibe el libro. La ambigüedad en el uso de los vocablos "antología” y "panorama” vuelve a aparecer cuando, para finalizar la nota, se mencionan ambos términos:

La primera tarea después de tomar conciencia de la existencia de un cuerpo literario es mostrarlo. De esta manera, la intención de ESTATUAS DE SAL, como se ha dicho, ha sido de exposición panorámica y no antológica. Aún cuando se ha querido ser exhaustivo, seguramente habrá ausencias como en toda selección personal (Yáñez, 1998: 8).

Estas palabras ponen especial énfasis en la necesidad de la publicación para que el "cuerpo literario" (femenino) adquiera visibilidad; es decir, lo que, desde una perspectiva marxista, se resumiría en el pasaje de la "conciencia en sî" a la "conciencia para sí”. Simbólicamente, el libro se postularía entonces como un acto de justicia histórica al mismo tiempo que construye una genealogía de mujeres escritoras. Sin embargo, esta operación también implica una selección, como se advierte en la última frase, por cierto, ambigua debido a que la proposición adversativa ("aún cuando") es desdicha por el uso del adverbio 
("seguramente") que encabeza la segunda parte de la frase. Algunos de los criterios son explicitados: las escritoras deben tener al menos un libro publicado, "con la excepción de autoras que recientemente han obtenido algún premio importante en el propio género de cuento, o la más joven de la selección en representación de una promoción todavía en fase de promesa" (Yáñez, 1998: 8).

Por otra parte, el subtítulo incluido en la portada del libro -Estatuas de sal. Cuentistas cubanas contemporáneas. Panorama crítico (1959-1995) — especifica que el panorama es "crítico". Este adjetivo no es explicado ni en el apéndice ni en la introducción; probablemente alude a que la "selección personal" está acompañada por estudios críticos que ayudan a delimitar el corpus; además, cada cuento está acompañado por una ficha bibliográfica que presenta a cada una de las escritoras. Esta "selección personal", entonces, no difiere en sus rasgos de las operaciones realizadas por cualquier obra antológica.

A menudo la crítica literaria ha considerado las antologías en función de una cierta "visión porvenirista" (en este sentido, se caracteriza al seleccionador como "un individuo con el poder de ahormar prematuramente la posteridad literaria"; Agudelo Ochoa 2006). ${ }^{15}$ La forma antológica tiene, entonces, una función depuradora vinculada con la etimología del término que alude a la selección de lo más bello; ${ }^{16}$ esta denominación hace pensar en que el carácter de antologizable confiere una validación que supone una discriminación cualitativa (Verdecio Carlunga, 2006). Esta función separaría el "panorama literario" (en términos de Yáñez y Bobes) de la "antología” (aunque, como vimos, los límites se vuelven lábiles y dificultan el deslinde entre ambas categorías). Como todo hecho cultural, la puesta en circulación de una selección de cuentos se proyecta y condiciona interactuando con el

\footnotetext{
15 Agudelo Ochoa retoma estos conceptos de Estuardo Nuñez (1959). "Teoría y proceso de la antología”, Cuadernos Americanos, México, XVIII, (106), 5: 257-267.

16 "Antología" proviene del griego y significa "selección de flores" y de este vocablo se derivó a su vez el término latino florilegium.
} 
momento concreto en que esta aparece. Como toda antología, Estatuas de sal es una muestra de lo que se desea presentar a los lectores en un determinado marco histórico-literario.

Tanto la nota a la edición, como el texto introductorio, otorgan elementos para reconstruir, en parte, cómo se posicionan Yáñez y Bobes en el ámbito literario y percibir la fuerte inscripción de género sexual en que se enmarca este proyecto. La lectura minuciosa del aparato discursivo que sustenta la selección confiere un espacio donde leer los argumentos explícitos y los silencios respecto de las decisiones tomadas por las compiladoras. Ambas escriben crítica, pertenecen al medio académico e incluso son escritoras (un cuento de cada una de ellas integra el libro).

El tema central de la introducción escrita por Mirta Yáñez, "Y entonces la mujer de Lot miró...", es la marginalidad a la que históricamente han sido sometidas las mujeres. Este escenario se desglosa en cuatro partes que realizan un recorrido desde lo general a lo particular. El primer apartado está centrado en el contexto histórico, lo que permite identificar las trabas que han tenido las mujeres para el acceso al saber (y por ende, a la escritura de ficción). El recorrido va desde una "historia de la humanidad" (Yáñez, 1998, 11) que pasa revista por casos particulares que han logrado transgredir los "sólidos preceptos de superioridad masculina" (Yáñez, 1998, 11) -como el de la reina Cristina de Suecia, Catalina la Grande, Sor Juana Inés de la Cruz, María Luisa de Habsburgo, Virginia Woolf - hasta la actualidad en la que ancla este problema. Hace uso de la perspectiva de clase para pensar el género sexual (pues deslinda la problemática cultural de las mujeres en los países desarrollados de la situación de la "indígena latinoamericana o esa habitante africana que tiene muchas bocas que alimentar y ve morir a sus hijos, año tras año, de enfermedades y falta de comida" (Yáñez, 1998, 13). De este modo, Yáñez desglosa las diversas problemáticas de género y señala la necesidad prioritaria de solucionar la 
explotación de clase para luego abordar cuestiones de género. ${ }^{17}$ Por momentos Yáñez cruza

las variables de género y clase (por ejemplo, cuando incluye a la mujer en el grupo de los oprimidos); en otros casos, la perspectiva materialista está teñida de cierto esencialismo: ${ }^{18}$

La mujer, dentro de un determinado conglomerado humano, tanto familiar, como productivo, como intelectual, en un contexto histórico dado, manifiesta rasgos particulares que provienen de un sedimento de su evolución, así como por su naturaleza concreta. Negar la perspectiva específica de la mujer y los rasgos que la signan en el terreno de la creación literaria -aun cuando su registro se incorpore a la tendencia dominante de una época - es ignorar que la literatura es reflejo de la vivencia singular que ha pasado por el cedazo de la imaginación (Yáñez, 1998: 13-14).

Este esencialismo emerge de la alusión al cuerpo sexuado ("naturaleza concreta") como uno de los rasgos determinantes de la escritura de ficción. ${ }^{19}$ En este sentido, si retomamos la teoría desarrollada en la introducción, advertimos que el planteo de Yáñez respecto de

17 La variable que se pone en juego es, principalmente, de clase aunque también se observa cierto funcionamiento de la cuestión étnica al ejemplificar con la situación de mujeres indígenas y africanas. Al cruzar las variables de clase y género, se podría hipotetizar una cercanía con el feminismo de la igualdad cuyo principal referente es Simone de Beauvoir quien, en El segundo sexo, demostró que la inferioridad femenina debe atribuirse no a la singularidad intrínseca de las mujeres sino a las condiciones adversas a las que siglos de ideología y prácticas patriarcales las han sometido y que han invisibilizado o destruido obras capitales del patrimonio de la Humanidad; por lo tanto, la inferioridad del sexo femenino es el producto de una situación de opresión historizable y sujeta a revisión y cambio. Sin embargo, como ejemplifico a lo largo de este capítulo, en Estatuas de sal la perspectiva feminista no es clara sino que se observan llamativas oscilaciones. En este sentido, como señalé, un problema importante a estudiar pero que excede los límites de esta tesis es investigar cómo ha sido leído el feminismo de la igualdad en Cuba debido a la influencia que tuvo tanto Beauvoir como Sartre durante los primeros años de la Revolución Cubana.

18 En la entrevista (Apéndice 3) que realicé a Mirta Yáñez le comenté que en el trabajo introductorio se observa cierta alternancia entre las posiciones respecto a la teoría de género (por ejemplo, se usa indistintamente: discurso femenino, intelectuales o narradoras cubanas, voz de la mujer entre otras). Ante la pregunta acerca de cómo evalúa estas decisiones a casi quince años de la primera edición, respondió: "Es cierto, yo no soy una especialista teórica sobre el tema del género, y en aquel momento había en Cuba un desconocimiento casi total. La cuestión ha cambiado radicalmente y hay numerosas estudiosas del tema. Aunque, en mi caso, seguiría usando, no indistintamente, pero si en su lugar, esa misma terminología porque, ya te dije, no soy una teórica dedicada al género, sino una narradora. Y creo que esos términos pueden usarse, siempre explicando sus contextos" (Apéndice 3).

19 Recordemos que, tal como se aclara en la introducción, es posible advertir que, con respecto a la cuestión de si el sexo biológico determina un modo de escritura, en 1949 Simone de Beauvoir se opuso al determinismo predominante en las teorías biológicas y antropológicas de los siglos XIX y XX, al señalar que "no se nace mujer, se llega a serlo" (Beauvoir, 2007: 207). Así puso en evidencia cómo cada sociedad construye una esencia "mujer" que le es propia; por eso, comienza a indagar en la condición femenina como condición de género. A partir de Beauvoir se señala que las actitudes de las mujeres, sus temas y sus hábitos no son dictados por las hormonas ni están prefigurados en los compartimentos del cerebro sino que están regidos por su "situación". De esta forma Beauvoir advirtió que el "eterno femenino" responde, en realidad, a un conjunto de condicionamientos económicos, sociales e históricos. 
que las diferencias biológicas se traducirían en diferencias en la forma de escribir soslaya los aportes de Beauvoir, quien varias décadas antes había establecido una diferencia clara entre el orden biológico y la construcción social de la mujer: la sexualidad “jamás se nos ha presentado como definidora de un destino, como portadora de la clave de las actitudes humanas, sino como expresión de la totalidad de una situación que contribuye a definir" (Beauvoir, 2007: 711).

Por otra parte, la historización del "ser escritora" que realiza Yáñez se inscribe en una perspectiva evolucionista de la historia literaria —más adelante habla de la "evolución de este discurso narrativo femenino" (Yáñez, 1998: 28)— y desde una concepción de la literatura como reflejo de la realidad. Hacia el final de este apartado cita fragmentos de unas conferencias leídas por Camila Henríquez Ureña en 1939 en el acto de publicidad por el Congreso Nacional Femenino. Esas palabras le permiten denunciar la permanencia de la difícil situación de la mujer en todos los ámbitos -y en la cultura, en particular-, setenta años después de haber sido pronunciadas y también rescatar la existencia de una “especificidad de su discurso" (ya que "muchos de los puntos analizados en las actuales corrientes afirmadoras del género y del lenguaje femenino, tienen un válido antecedente en los distintos textos de Camila Henríquez Ureña"; Yáñez, 1998: 15). Este apartado se cierra con la enumeración de algunas escritoras latinoamericanas que ocuparon posiciones marginales, como la misma Camila Henríquez Ureña, Gertrudis Gómez de Avellaneda, Sor Juana Inés de la Cruz, Delmira Agustini y Mirta Aguirre. Las siguientes palabras operan como corolario de la enumeración anterior: "y como seguimos siendo, de una u otra manera, marginales todas, y a mucha honra" (Yáñez, 1998, 17); de este modo, el uso de la primera persona del plural para incluir a todas las mujeres en el margen, le permite incluir(se) y afirmar(se) (en) dicha posición. Noé Jitrik advierte que la sola mención de la palabra canon arrastra consigo la de marginalidad: "El canon, lo canónico, sería lo regular, lo 
establecido, lo admitido como garantía de un sistema mientras que la marginalidad es lo que se aparta voluntariamente o lo que resulta apartado porque, precisamente, no admite o no entiende las exigencias canónicas" (Jitrik, 1996: 156). Respecto de lo marginal, especifica que puede entenderse "una manifestación que, deliberadamente o no, se sitúa fuera de las ordenanzas canónicas" (Jitrik, 1996: 157). En el prólogo a Estatuas de sal se elige la marginalidad como una forma de autoafirmación pero, al mismo tiempo, como un reclamo por el lugar al que han sido históricamente relegadas sus producciones; por eso, no necesariamente este movimiento puede pensarse a partir de las opciones propuestas por Jitrik.

En el segundo apartado, Mirta Yáñez realiza un sondeo histórico de la participación política, social y cultural de la mujer en general y particulariza con el caso de la cubana. Después de contraponer dos culturas arcaicas en que las mujeres han ocupado espacios diferentes - un lugar predominante en la cultura taína frente a la proscripción en el ámbito cerrado de lo familiar, en la cultura azteca - pasa revista a la situación de la mujer en el siglo diecinueve, prestando especial atención a la literatura del romanticismo, en la que la proyección de "lo femenino" como algo inferior y dependiente tenía su correlato en la necesidad social de recluir a la mujer a la propiedad exclusiva de un individuo que decidía sobre sus bienes, su cuerpo y su pensamiento. ${ }^{20}$ En este contexto rescata la figura de Gertrudis Gómez de Avellaneda, quien “con su novela Sab rompió la norma de su tiempo y abrió el camino a la narrativa social latinoamericana" (Yáñez, 1998: 20). Luego realiza un recorrido por la participación de las mujeres cubanas en las distintas luchas sociales del

\footnotetext{
${ }^{20} \mathrm{El}$ exceso de atención (en extensión) a la situación de la mujer en el romanticismo, así como en el contexto en que se inserta este movimiento, se debe al conocimiento que Mirta Yáñez tiene del tema, ya que en 1990 había publicado La novela romántica en Latinoamérica. Un año antes había presentado una tesis doctoral sobre El matadero de Esteban Echeverría que, en 2004, se publicó bajo el título de El matadero. Un modelo para desarmar.
} 
siglo XX, comenzando por los inicios de la República (1902-1959)21. Esta lectura vuelve a anclar la acción de las mujeres cubanas, en las primeras décadas del siglo XX, en el marco general de las luchas políticas (y de clases). Así, contextualiza el caso de la lucha de género en torno de lo que denomina "las pugnas por el progreso social":

Las mujeres intelectuales de la época defendieron el ideario del feminismo, sin enajenarlos [sic] de la aspiración mayor hacia un mundo sin opresores ni oprimidos. Esta proyección abonó la reflexión y la conducta de la mujer cubana que, a diferencia de otros países, tenía una actitud más combativa y menos sumisa, a pesar de los obstáculos que le imponían los prejuicios (Yáñez, 1998: 20).

Este énfasis en la excepcionalidad del caso cubano, así como en resaltar el vínculo entre las variables de género y clase, es necesario leerlo en el marco del marxismo que sustenta el ideario revolucionario, pero también en el contexto en que se inscribe este libro: para 1996 el movimiento feminista, a nivel continental, estaba avanzado en sus reivindicaciones respecto de los estudios y luchas llevadas adelante en Cuba. Por lo tanto, puede leerse como una justificación del desfasaje de la isla respecto del resto de "Nuestra América". ${ }^{22}$ Sólo cuatro años antes de la publicación de este libro se había producido un hito importante: la sanción en 1992 de la Constitución de la República, que estableció la igualdad de género, prohibió la discriminación de la mujer y las restricciones en su condición civil. ${ }^{23}$ Como se desarrolló en la introducción, con respecto a este desfasaje temporal, gran parte de los estudios sobre el tema, aunque reconocen avances en los

\footnotetext{
${ }^{21}$ En 1902 es electo Tomás Estrada Palma como primer presidente de la República; se adopta el régimen presidencialista, y se establece un período de cuatro años y una reelección.

22 En 1980 comienzan a fundarse, en América Latina, instituciones de carácter académico en torno al tema de los Estudios de Mujeres o de Género, según denominaciones adoptadas en diferentes países. En Cuba este proceso se inicia más tarde. Una de las antecesoras en los estudios del género es Camila Henríquez Ureña, a la que ya hicimos referencia, quien en 1939 denunciaba la marginalidad de la mujer en la cultura y que los problemas de la mujer no eran sólo de sexo sino de clase social. Al respecto es muy importante la conferencia que pronunció en el Lyceum en marzo de 1939, en el acto de propaganda del Congreso Nacional Femenino. Véase Henríquez Ureña (1982 y 1985).

${ }^{23}$ En el Apéndice 4 se detalla información numérica respecto del debate sobre la concreción (o no) de las políticas de igualdad de género en Cuba.
} 
ámbitos jurídico y político, no dudan en señalar que, en la práctica y en la conciencia cotidiana, Cuba sigue siendo fuertemente patriarcal (Pogolotti, 1991; Campuzano, 1996; Fernández Rius, 2000; González Pagés, 2002; Vasallo Barrueta, 2001 y 2004). También aducen que en la isla, a diferencia de otros países, la progresiva transformación de la mujer se produjo en el contexto de un cambio revolucionario que nunca tuvo como objetivo prioritario a las mujeres, sino la modificación radical de la estructura política y económica del país y, en consecuencia, la categoría operativa fundamental era la de clase y no la de género.

A partir de estos elementos, retomo el análisis de Yáñez para advertir que su estrategia consiste en situar la opresión de la mujer en un contexto social más amplio, lo que coloca la situación marginal de las mujeres cubanas por fuera de los programas que circunscribían este problema a una cuestión de género. Para marcar el quiebre que significaron los cambios socio-estructurales ocurridos a partir de 1959, Yáñez realiza una contextualización de las características machistas de la sociedad cubana en la que, antes de esa fecha, subsistían hábitos patriarcales y costumbres de "severa tradición hispánica" junto a la "neocolonización occidental con la avalancha propagandística acerca de la 'eficacia' del ama de casa y la imposición de cánones consumistas a favor de un mercado de la moda" (Yáñez, 1998: 21). Estos prejuicios se suman a los de raíz católica y a "las conductas tribales y mitos heredados de la emigración negra esclava" (Yáñez, 1998: 21). De este modo, se configura una mentalidad masculina prepotente y que subestima a la mujer, así como una proyección sumisa y pasiva de ésta. El marco que construye de la realidad cubana antes de 1959 le permite justificar la perduración de esta concepción aún después de la revolución:

Ha subsistido, sobre todo, en el plano de la relación familiar o íntima de la pareja, en los prejuicios acerca de la virginidad o en la diferente apreciación de la infidelidad conyugal, en la distribución de las tareas domésticas, en la educación de los niños y, también en algunos planos de la vida laboral, profesional, política, social, incluso de proyección masiva de divulgación" (Yáñez, 1998: 22). 
La ambigüedad en el uso de las perspectivas tanto esencialista como materialista del género vuelve a hacerse presente en el tercer apartado. Allí, luego de incluir la literatura escrita por mujeres en un espacio de "frontera" ligado a la marginalidad, (especialmente la narrativa, porque considera que en este género las leyes de apropiación del mundo han sido más susceptibles de confinación, expulsión y limitación), señala que "la literatura -la narrativaescrita por mujeres comparte la misma sustancia que la de los hombres, más [sic] con el empleo de su propio lenguaje" (Yáñez, 1998: 24; itálica en el original). Pero más adelante, menciona la imposibilidad de seguir eludiendo el "análisis de la escritura femenina” (Yáñez, 1998: 25). Esta ambigüedad se hace visible cuando, en una nota al pie, especifica qué se entiende por "estudios de género", y detalla el trabajo que la crítica literaria feminista ha realizado en el ámbito de las ciencias humanas "para demostrar la peculiaridad del discurso femenino sin que ello implique limitaciones" (Yáñez, 1998: 39). Para esto se apoya en un fragmento de un artículo de Márgara Rusotto (aparecido en septiembre de 1994, en la revista Casa de las Américas) en el que se especifican las acciones llevadas adelante por la crítica feminista, pese a que en ninguna parte de dicho fragmento se alude a la especificidad del discurso femenino sino que, por el contrario, se rechazan las "nociones esencialistas o 'universales' sobre la mujer (o sobre cualquier otro objeto de estudio)" (Russotto, citada en Yáñez, 1998: 39). ${ }^{24}$ Luego, en el cuerpo del texto, Yáñez vuelve a retomar cuestiones materiales que ponen en evidencia el lugar marginal al que ha sido confinada la producción de las mujeres. Para esto, aunque reconoce la funcionalidad de la categoría de frontera, señala los riesgos y abusos que ésta conlleva, ya que supone la división entre un "presunto

\footnotetext{
${ }^{24}$ A pesar de esta desavenencia que observo en la lectura que Yáñez hace del fragmento de Rusotto, la cita le sirve de sustento teórico porque menciona el trabajo de la crítica feminista para realizar una arqueología legitimadora de las obras escritas por mujeres. De esta forma, busca "desconstruir la serie de imitaciones, desvíos y oblicuidades, pactos y rebeliones, en la constitución - real y simbólica- del sujeto femenino" (Rusotto, citada en Yáñez, 1998: 39).
} 
canon" (Yáñez, 1998: 25) y "lo femenino" (Yáñez, 1998: 25), de segundo rango. En el mismo apartado retoma argumentos de otras dos estudiosas de las cuestiones de género: Helena Araújo en su artículo "Narrativa femenina latinoamericana” y Jean Franco quien, en "Apuntes sobre la crítica feminista y la literatura hispanoamericana", propone pensar las cuestiones materiales que han provocado la marginación de la narrativa escrita por mujeres, es decir, las relaciones de poder. ${ }^{25}$ Dice el fragmento de Franco:

...no se trata de averiguar si las escritoras tienen temas específicos o un estilo diferente a los hombres, sino explorar las relaciones del poder. Todo escritor, tanto hombre como mujer, enfrenta el problema de la autoridad textual o de la voz poética ya que, desde el momento en que empieza a escribir, establece relaciones de afiliación o de diferencia para con los 'maestros' del pasado (Franco, citado en Yáñez, 1998: 27).

Esta perspectiva pone en igualdad de condiciones a los escritores y a las escritoras respecto de su relación con la tradición, vínculos que Franco coloca en el plano de lo estético y de lo político. Luego Yáñez enumera a las escritoras que lograron sortear la frontera "intimista" a la que habían sido confinadas sus producciones: Sor Juana Inés de la Cruz, Gertrudis Gómez de Avellaneda, Clorinda Matto de Turner, Juana Manuela Gorriti. Y señala cómo estos casos no podían ser explicados y por eso se los consideraba como la "excepción de la regla" (Yáñez, 1998: 28). El problema que se observa aquí es que la reivindicación de los casos excepcionales invierte las connotaciones tradicionalmente asignadas a ese espacio de transgresión pero no desarticula las categorías con las cuales se juzgó la literatura escrita por mujeres en el pasado, desde el punto de vista del patrón hegemónico. Es decir, aunque por un lado se señala la mirada reduccionista de la crítica que catalogaba estas obras como "excepción de la regla", al mismo tiempo se utilizan esos mismos criterios -criticar a las obras porque son confesionales y subjetivas, por ejemplo- para desacreditar o poner en una escala inferior los textos y, por el contrario, ensalzar sólo a quienes han roto esos

\footnotetext{
${ }^{25}$ Ambos artículos fueron publicados por Hispamérica en 1982 y 1986, respectivamente
} 
parámetros a los que había sido confinada la escritura de mujeres. No obstante, unas líneas después retoma una perspectiva que supera el esencialismo:

Las narradoras han tenido que enfrentar a los múltiples jinetes del Apocalipsis de la frontera entre los géneros: el canon hegemónico y su aparato crítico; la vulnerabilidad, el aislamiento, los roles sexuales, el espacio tradicional, la censura del cuerpo, la falsa atribución de subjetividad y la invisibilidad. Y el peor: la autocensura (Yáñez, 1998: 29).

Este análisis, que cruza las cuestiones de género con las condiciones materiales explicitando las relaciones de poder—, se desmantela en el párrafo siguiente cuando concluye: "Es cierto que en la narrativa escrita por mujeres, las grandes figuras han sido las excepciones" (Yáñez, 1998: 29), afirmación fuerte que retoma el discurso hegemónico (es decir: las buenas escritoras son la "excepción de la regla"). Son esas escritoras las que pudieron rebasar las fronteras y escapar a la marginalidad, las que se erigen en la tradición: "a las antepasadas, algunas todavía vivas, que traspasaron, a todo riesgo, la frontera" (Yáñez, 1998: 29). Entonces, según lo planteado aquí, esas antepasadas, que ocupan el lugar de la genealogía legitimadora, parecerían responder a criterios, estéticas y cánones hegemónicos.

La última parte de la introducción está dedicada a esas "antepasadas", aquellas escritoras cubanas que, según Yáñez, se atrevieron a mirar. En esta operación crea un linaje en el que se reconoce a sí misma (y/o desea verse identificada). Según esta lectura, la acción de "mirar" se vincula con el acto de escribir, pero al mismo tiempo, esa escritura está signada por la prohibición: prohibición de mirar y de contar mediante la escritura. Por eso se pregunta "Mirar y contar, la sencilla fórmula de la narrativa... ¿Será por aquella vieja sanción bíblica que la narrativa ha sido poco frecuentada por las mujeres?” (Yáñez, 1998: 30). La afirmación deja entrever una concepción de la literatura como reflejo de la realidad porque no plantea ningún tipo de mediación, aunque después aclara que los escritos han 
cubierto un "amplio registro de propuestas temáticas y estéticas” (Yáñez, 1998: 30). Esta concepción puede vincularse con su perspectiva evolucionista de la literatura (visible, por ejemplo, cuando advierte que estas antepasadas "han ido fundando un corpus del discurso femenino dentro del proceso literario cubano"; Yáñez, 1998: 30).

Aquí nuevamente se observa alternancia (que podría suponer vacilación) en los términos utilizados para referirse a las cuestiones de género. En una primera oración la afirmación parece atenerse a dificultades materiales y sociales para acceder a los espacios restringidos: "Como tantas veces se ha dicho, el arte, la literatura, el lenguaje, no tienen sexo, pero la experiencia vital sí, y quien la transmite también” (Yáñez, 1998: 30). Pero recurre a expresiones como "perspectiva desde la mujer" (Yáñez, 1998: 30; itálica en el original $)^{26}$ que parece atenerse a cuestiones de transgresión: “aún cuando en algunos casos reprodujeran los códigos del discurso hegemónico masculino, de alguna manera u otra se pueden rastrear indicios vulneradores, intencionales o no” (Yáñez, 1998: 30) y sólo unas líneas después señala que en las primeras décadas del siglo XX "existieron algunos pocos textos de cierto enfoque "feminista", aquellos que "tomaron a la mujer por asunto, insistiendo sobre todo en sus reivindicaciones sociales" (Yáñez, 1998: 31). En una nota al pie remite a un estudio de Susana Montero, que en una clasificación de la narrativa escrita por mujeres, propone un grupo integrado por "narraciones de tendencia feminista" (Yáñez, 1998: 40) en el que incluye a Lesbia Soravilla, Flora Díaz Parrado, Irma Pedroso, Surama Ferrer, Graziella Garbalosa, Ofelia Rodríguez Acosta y Dulce María Loynaz. Sin embargo, en el cuerpo del texto toma distancia de esta producción que por "sus ineficacias formales y

\footnotetext{
26 Estas referencias esencialistas se pueden vincular los postulados del feminismo de la diferencia desarrollado en la introducción.
} 
su leve trascendencia dentro del conjunto, hacen que apenas nos sirvan para armar esa 'arqueología' de que se habla, certificadora del quehacer continuado y de la representación femenina (...), fueron las golondrinas que no pudieron hacer el verano” (Yáñez, 1998: 31). Este señalamiento no sólo descalifica las producciones de las escritoras mencionadas en ese comentario, sino que parece entrar en contradicción con el propio proyecto (o por lo menos, desvalorizarlo) ya que, como vimos, páginas antes se justifica la publicación de este panorama en la necesidad de realizar una tarea de justicia histórica que demuestre la continuidad de su producción. Esta valoración se debe a la perspectiva ideológica que Yáñez adopta en la introducción, ya que los verdaderos cambios en la narrativa escrita por mujeres son ubicados en el período posterior a 1959, valoración que anticipa cuando señala:

presencia femenina no es conciencia femenina. La conciencia del ser femenino que intenta apropiarse del mundo de manera propia, con conocimiento, sin cólera, ni sentimiento de inferioridad o de culpa, y contar la realidad o la fantasía sin cortapisas o linderos de 'mundo exterior' y 'mundo interior', es una conquista reciente (Yáñez, 1998: 31).

Es decir, el léxico utilizado remite al marxismo que diferencia entre "conciencia de sí" y “conciencia para sî” que, sugiere, emerge con la Revolución Cubana. Desde ese año inaugural, 1959, hasta 1966, cuando se inician “los años duros” (Yáñez, 1998: 32; itálica en el original) ${ }^{27}$, estos cambios se centran en el debate sobre la estética que debe regir la cultura durante una Revolución y que aquí es simplificada en la oposición entre ‘lo fantástico’ y ‘lo

\footnotetext{
${ }^{27}$ La expresión utilizada por Yáñez es el título del primer libro de Jesús Díaz que se llama precisamente Los años duros. La serie de cuentos de corte realista que integra el libro da cuenta de las luchas insurreccionales y de los primeros años de la revolución. El libro fue publicado en 1966 y ese mismo año recibió el Premio Casa de las Américas. Forma parte de la serie conocida como "la narrativa de la violencia", término que Arturo Arango incluyó en un artículo de 1978. Para más información, consultar: Garrandés (2001) y Capote Cruz (2008).
} 
real concreto' (aunque, como ha demostrado la crítica, se trata de categorías particularmente complejas). ${ }^{28}$

Cuando Yáñez examina la situación de las narradoras a partir de la década del sesenta, constata la casi inexistencia de publicaciones de sus obras. Apela a la "abigarrada problemática social y estética" (Yáñez, 1998: 32) para explicar este hecho desde razones literarias y extraliterarias. Luego especifica:

Las autoras femeninas aspiraron a poner su pica en el Flandes de la narrativa desde los mismos principios de los años sesenta, pero no sólo por razones de 'invisibilidad' sexista, sino por la propia inclinación salvaje de la balanza temática hacia los temas de la 'dureza', las narradoras se convirtieron con rapidez en estatuas de sal (Yáñez, 1998: 32).

En esta cita se observa, nuevamente, la ambigüedad conceptual con respecto a la teoría de género subyacente. Por un lado, las "autoras femeninas", ¿son todas las escritoras o sólo aquellas que escriben con "conciencia de sî" o desde una perspectiva de género? Por otro, ¿hay temas según el sexo? Es decir, las escritoras ¿̇e convirtieron en “estatuas de sal” por la imposición de un tema -y una forma-, o porque no es un tema que les corresponda por “naturaleza”? ${ }^{29}$ La ambigüedad del texto se debe no sólo a la imprecisión de la terminología utilizada, sino también al abuso de los rodeos, eufemismos y sobreentendidos cuando se realiza un recorrido por las problemáticas suscitadas en el ámbito cultural cubano a partir de 1959. Es probable que se trate de una estrategia de escritura que probablemente dé cuenta de las censuras y batallas de ideas en el contexto de enunciación.

\footnotetext{
28 Para tener una visión de la complejidad que reviste este debate en el caso cubano, remitimos al contexto cultural desarrollado en la introducción. Consultar: Quintero Herencia (2002); Gilman (2003); Rojas (2006), entre otros.

${ }^{29}$ En una nota al pie cita otro trabajo de su autoría, Poetisas sí. Panorama crítico de la poesía cubana escrita por mujeres, y allí se vuelve a visibilizar este problema cuando dice "La poesía escrita por las poetisas de las generaciones recientes se ocupa de los mismos grandes temas - los tradicionales y los nuevos - por la razón de participar al mismo nivel en los acontecimientos sociales capitales. Ello no quiere decir, ni mucho menos, que su condición de mujer no trascienda dentro del acto creador como parte de sus esencias" (Yáñez, 1998: 42). No toma distancia de los "grandes temas" que constituyen una construcción social (que históricamente ha ubicado a las mujeres en los temas menores) y parte de una perspectiva esencialista del género.
} 
En este sentido, por ejemplo, la apelación a lo conocido y la elipsis le permiten no detenerse en el caso Padilla (sólo dice que "a principios de los setenta, la oposición entre las tendencias se exasperaría hasta extremos tales que llegarían a desencadenar, como es de sobra sabido, crisis extraliterarias"; Yáñez, 1998: 34). Sin embargo, sí toma partido por el alejamiento del "realismo primario", explicitando que, a partir del apoyo oficial a este último, desaparecieron las antologías de cuentos fantásticos y se borraron nombres de diccionarios y de cursos académicos. En otro caso, no se mencionan nombres de escritores o de obras literarias sino genéricos: así, para referirse a los debates ideológicos sobre la forma apropiada para la escritura de ficción en un campo revolucionario, señala que "los grupos tradicionalmente marginados -como los gays o las mujeres- llevaron el fardo más pesado, por decirlo de una forma eufemística. Perdón no quiere decir olvido" (Yáñez, 1998: 33; itálica en el original). Esta síntesis remite a la marginación y, en ciertos casos, al exilio que sufrieron algunos escritores y, en esta operación, entronca a las mujeres en la historia de un grupo de escritores marginados debido a su elección sexual y textual (en muchos casos sus elecciones formales tampoco respondían a los requerimientos del realismo socialista).

Cuando realiza un recorrido por las diferentes promociones de escritores y, con especial detenimiento, de escritoras que comenzaron a publicar después de 1959, las menciones a varones se deben al ejercicio de cierta transgresión que los vincula con las mujeres (por ejemplo, quienes "desde la esquina de lo experimental y lo fantástico, hicieron obras que no fueron aceptadas por los cánones preponderantes. Algunos publicaron sus libros en la polémica editorial 'El puente' o en arguciosos proyectos se escapaban por la tangente como la colección 'Dragón”' (Yáñez, 1998: 33-34). ${ }^{30}$ Las afiliaciones, entonces, se

\footnotetext{
${ }^{30}$ La editorial El Puente (1961-1965) fue un proyecto editorial de escritores jóvenes dirigido por José Mario Rodríguez y Ana María Simo. Lanzaron un manifiesto en octubre de 1960, donde se adscribieron al
} 
establecen en términos de transgresión sexual y estética en un período en que ambas fueron perseguidas.

\section{Desde los umbrales: la apoyatura crítica}

Cualquier trabajo antológico implica decisiones que a veces intentan ser explicadas por el antólogo -el gusto, el espacio editorial, etcétera.- y otras, pueden leerse en los silencios que se desprenden de la lectura del aparato discursivo que sustenta dicha antología. La última nota al pie de la introducción de Estatuas de sal establece vínculos con el apéndice del texto ya que se explicita, una vez más, que no es un panorama exhaustivo y se nombran otros trabajos que pueden completar la lista de narradoras incluidas allí. Uno de los estudios que se mencionan es el de Luisa Campuzano que aparece en el apéndice y el gesto abraza la selección que está en el medio de las partes que inician y cierran el libro. Entonces, el aparato discursivo también está integrado por dos trabajos críticos incluidos al final del libro: "La mujer en la narrativa de la revolución: ponencia sobre una carencia" de Luisa Campuzano y "La escritura femenina y la crítica feminista en el Caribe: otro espacio

proceso revolucionario. A partir de 1961, comienzan a aparecer los más de cuarenta títulos que publicaron hasta principios de 1965. Como rasgos distintivos hay que señalar que allí fueron publicadas muchas escritoras (Nancy Morejón, Ana María Simo, Ana Justina Cabrera, Ada Abdo, Évora Tamayo) así como escritores y escritoras mulatos o negros. Este proyecto editorial no constituyó un grupo coherente en términos estéticos e ideológicos y una de las características era la homosexualidad de varios de sus integrantes, hecho que influyó en el cierre de la editorial (en particular, esto se lee así a partir de que José Mario fuera enviado a las Unidades Militares de Ayuda a la Producción, UMAP, después de la cancelación de las Ediciones en 1965, es decir, este hecho es leído como síntoma de la incomodidad que las preferencias sexuales de esos iconoclastas deben haber causado). Aunque se constata la presencia de mujeres y negros entre los autores publicados, diversos trabajos testimoniales han demostrado que el tema racial o de género no era parte de la agenda de la editorial. El Puente se oponía a las generaciones previas (Lunes de Revolución, dirigida por Cabrera Infante, por ejemplo) a las que consideraban elitistas y que no otorgaban lugar a las generaciones jóvenes. En este sentido, en 1966, mantuvieron un enfrentamiento con Jesús Díaz, en ese momento editor de El Caimán Barbudo. Díaz llegó a decir que los miembros de El Puente eran "generalmente artistas malos" y que constituían el "segmento más disoluto y negativo de su generación (...) un fenómeno política y estéticamente erróneo"). Una versión digital de La Gaceta de Cuba (abril-septiembre de 1966) se encuentra en el archivo del sitio: www.archivodeconnie.annaillustration.com/?p=104. Allí se encuentra la nota publicada por Ana María Simo a propósito de las expresiones de Jesús Díaz así como la respuesta de este. En los últimos años, varios trabajos críticos han rescatado del olvido el trabajo realizado por esta editorial, por ejemplo, el dossier preparado por Roberto Zurbano (2005) para La Gaceta de Cuba y Alfonso (2012).

Oscar Hurtado (1919-1977) dirigió la colección Dragón que difundió literatura policial, fantástica y de ciencia ficción y difundió en la isla a Ray Bradbury, Isaac Asimov, Arthur Conan Doyle, entre otros. 
de identidad" de Nara Araújo. Ya desde el título se puede observar que los textos responden a diferentes perspectivas de los estudios de género: el primero parecería atender a un trabajo arqueológico de rastreo histórico mientras que el segundo adelantaría una mirada centrada en la diferencia ya que parte de la noción de "escritura femenina". ${ }^{11}$

El artículo de Luisa Campuzano (La Habana, 1943-) no fue pensado a los efectos de Estatuas de sal aunque al incluirlo, evidentemente, las compiladoras consideran que sus ideas iluminan o permiten pensar el conjunto de textos incluidos en Estatuas. ${ }^{32}$ El origen de este texto fue una ponencia que Campuzano presentó en 1984, en el "Primer Forum de Literatura Cubana"; es decir, la escritura de este texto se enmarca en un encargo (estatal), por lo que permite reconstruir un clima de época en que, por diferente razones (esbozadas en la introducción), la problemática de la mujer se convierte en un tema que comienza a requerir diversos abordajes. ${ }^{33}$ En ese contexto causó debates y hasta se intentó eliminar el

\footnotetext{
${ }^{31}$ En una entrevista que María del Mar López Cabrales (2007a) realiza tanto a Luisa Campuzano como a Nara Araújo, las ensayistas aluden, por distintas razones, a Estatuas de sal. Respecto del lugar que tuvo esta compilación en la conformación de un espacio dedicado a los estudios de género en Cuba, Nara Araújo señala: "estuvo muy bien y fue muy necesario en su momento, es un volumen interesante, pero el libro tiene irregularidades. Hay unas fichas que son mejores que otras. No es una antología que viene de la crítica o de la academia" (López Cabrales 2007a: 52). Araújo reconoce el papel que tuvo Estatuas de sal aunque señala algunos defectos que, llamativamente, atribuye a que la compilación no se realiza desde el ámbito académico cuando, en realidad, tanto Mirta Yáñez como Marilyn Bobes son profesionales que ya en ese entonces escribían crítica literaria. Este mismo argumento esgrime Yáñez en la entrevista que le realicé (Apéndice 3) cuando señala que las alternancias en el uso de la teoría de género se deben a que "no soy una especialista teórica en teoría de género" (consultar el comentario realizado en la nota 89 del primer capítulo). Por su parte, Luisa Campuzano alude a la publicación de su artículo en el cuerpo de la compilación: "Sólo incluyeron la sección final, las dos últimas partes: 'la mujer tematizada y tratada por los hombres y la mujer como escritora'. No apareció en Estatuas de sal la parte sobre cómo viven las mujeres en la sociedad cubana, que era lo que realmente llamaba la atención” (López Cabrales, 2007a: 100-101). En estas palabras no queda claro qué y a quién le "llamaba la atención

32 Campuzano lo publica en Quirón o del ensayo y otros eventos (1988). Doctora en Letras Clásicas, Luisa Campuzano (La Habana, 1943) es miembro de la Academia Cubana de la Lengua, directora del Programa de Estudios de la Mujer de Casa de las Américas y de la revista Revolución y Cultura El Programa de Estudios de la Mujer (PEM) se ocupa de la cultura y la historia de las mujeres latinoamericanas y caribeñas. Se fundó en 1994 con el objetivo de recuperar y rescatar el pasado de las mujeres, promover el trabajo de las artistas y escritoras contemporáneas de la región, así como de discutir los temas teóricos y las estrategias políticas correspondientes. Con ese fin, todos los años se realiza un coloquio internacional en Casa de las Américas. El Programa de Estudios de la Mujer ha creado "Mujeres en Líne@”, (debe el nombre a que su sede está en las calles Línea y G), un espacio de debate que promueve un diálogo interdisciplinario de estudios de la mujer.
}

33 Ver la entrevista que María Grant (2002) realiza a Luisa Campuzano en la que la ensayista realiza un recorrido por su trayectoria académica y señala el momento en que, por encargo para un Foro sobre narrativa de la Revolución, comenzó a investigar sobre la producción narrativa de mujeres cubanas. 
subtítulo elegido para la exposición — "Ponencia sobre una carencia" — a pesar de que el tema había sido solicitado por los organizadores de foro. El pedido es utilizado por Campuzano como punto de partida para establecer una analogía con la situación que gestó la escritura del ensayo Un cuarto propio de Virginia Woolf:

la perplejidad que embargó a su excepcional autora cuando se la invitó a que hablara sobre las mujeres y la novela es, salvando insalvables distancias, la misma que me ha embargado a mí, pobre sardina del cardumen profesoral, al pedírseme que me ocupara de la mujer en la narrativa de la Revolución (Campuzano, 1998: $352)$.

Vale la pena detenerse en esta analogía porque permite vislumbrar los entretelones del contexto de enunciación: que sea Virginia Woolf -perteneciente a la clase alta de Inglaterra - el sustento teórico (y/o el pretexto distinguido) que avala la reflexión, es una estrategia para interpelar a un público culto y/o específicamente dedicado a la crítica literaria (es una ponencia leída en un foro) utilizando un pretexto distinguido. Este extraño (desde el punto de vista ideológico pero también estético) parangón se amplía cuando también retoma los problemas que se plantea Woolf al inicio de su ensayo (sólo que transpuesto al contexto de la Revolución) y que definen los objetivos a abordar a lo largo de su trabajo: las mujeres en la Revolución, la mujer como sujeto (creadora de la narración) y la mujer como objeto (tema del cuento y de la novela).

La primera parte de "La mujer en la narrativa de la revolución: ponencia sobre una carencia" aborda la transformación de las mujeres cubanas a partir del proceso iniciado en 1959. Pero para centrarse en estos aspectos, primero pasa revista a la situación de la mujer cubana antes del período revolucionario, analizando la situación laboral de la mujer (el trabajo visible e invisible) y su participación activa en las luchas políticas y sociales durante las guerras de independencia y durante toda la República. En este marco retoma como apoyo teórico "Feminismo" escrito para la Asamblea Constituyente de 1940 por la cubana 
Camila Henríquez Ureña, ensayo que cruza las cuestiones de género con la variable de clase y que le permite entroncar con su análisis de la situación de la mujer en la Revolución: "De entrada, como Sofía, la más hermosa de sus precursoras, se lanzó a la calle a ‘hacer algo' y ese algo fue convirtiéndose poco a poco en un todo unánime: la Revolución" (Campuzano, 1998: 355). ${ }^{34}$ Campuzano pasa revista a los cambios laborales, educativos y sexuales implementados en este contexto y que modificaron la situación de las mujeres aunque respecto del ámbito doméstico, aclara que recién en 1975 se explicita política y jurídicamente que los dos integrantes de la pareja deben compartir las tareas del hogar: en ese momento se implementó la Tesis III del Primer Congreso del Partido ("Sobre el pleno ejercicio de la igualdad de la mujer”) y el nuevo Código de la Familia. Campuzano demuestra cómo, a pesar de tantos cambios a nivel social, siguen existiendo determinadas barreras que hasta entonces no se había logrado vencer: por ejemplo, el acceso a ámbitos jerárquicos o de decisión ya sea en el Partido, los sindicatos o el Estado. En este recorrido se apoya en dos discursos diversos: por un lado en las palabras pronunciadas por Fidel Castro (que según la autora, parecen avizorar un futuro de igualdad o, en otros casos, reconocer los logros de las mujeres); por otro, en estudios liminares del campo académico como Hacia una concepción cientifica de la emancipación de la mujer de Isabel Larguía y John Dumoulin (publicado en La Habana en 1983). ${ }^{35}$

En las otras dos partes de su ensayo, Campuzano explica que, a pesar de los avances en el ámbito jurídico y social, no sucede lo mismo en el ámbito literario. Recurre a datos estadísticos que le permiten demostrar su hipótesis. Así por ejemplo, constata que, durante los primeros veinticinco años de la Revolución, se publicaron cerca de doscientas

\footnotetext{
${ }^{34}$ La alusión remite a la situación de Sofía, en el final de la novela El siglo de las luces (1962) de Alejo Carpentier.

${ }^{35}$ En la nota al pie 57 de la introducción se proporcionó información sobre los autores de este artículo.
} 
novelas escritas por hombres y sólo doce por mujeres. ${ }^{36}$ De este grupo elimina los testimonios y memorias, reducidos a un "cuasigénero de aliento narrativo" en el que "las mujeres han hallado un vehículo expresivo muy eficaz y poco complejo" (Campuzano, 1998: 359) $\cdot{ }^{37}$ De este modo descalifica el resto de los libros publicados y redime sólo dos: Tierra inerme de Dora Alonso y La hora de los mameyes de Mirta Yáñez.

A diferencia de la introducción de Yáñez a Estatuas de sal, las valoraciones de Campuzano son más explícitas. Sus operaciones valorativas tienden a configurar un canon, sobre todo porque escribe desde un espacio de autoridad: el apéndice de Estatuas de sal dedicado a ensayos que sustentan teóricamente el panorama. Así como desacredita el valor literario de los textos testimoniales, cuando comenta las novelas y cuentos de las escritoras no se priva de expresar su valoración negativa, aún cuando varias de las mencionadas han sido incluidas en la antología (así por ejemplo, cuando analiza cómo aparece tratado el tema de la mujer en estas obras -objetivo de su ensayo - señala que el libro de cuentos Las protagonistas de Nora Maciá Ferrer "constituye un primer intento por introducir en la narrativa revolucionaria un tema de gran trascendencia: la mujer actual; pero los cinco breves relatos de este libro no pasan de ser un frágil esbozo, un inseguro ensayo". Otro caso, para referirse a Cuentos de fantasmas de Josefina Toledo: "libro con el que se empeña en dar a conocer toda su cuentística y, por tanto, libro poco orgánico y harto apresurado, desmiente el entusiasmo inexplicable con que sus editores lo presentan" (Campuzano, 1998: 363).

\footnotetext{
${ }^{36}$ Reduce aún más el número de publicaciones de escritoras cuando afirma que "de estas novelas femeninas hay dos que ni recuerdo merecen porque fueron escritas por quienes prefirieron abandonar su tierra por la ajena: que allá las cuenten” (Yáñez, 1998: 359; la itálica me pertenece). Obsérvese en esta afirmación, el problema que suscita el uso de la expresión "novelas femeninas", al reponer una esencialización que no había aparecido aún en este ensayo. Además, el rechazo de las exiliadas no se condice con el criterio de las compiladoras de Estatuas de sal (que las incorporan en la selección y en la introducción).

37 A pesar de estas valoraciones negativas, Campuzano salva Memorias de una cubanita que nació con el siglo (1963) de Renée Méndez Capote y dos libros de Dora Alonso: El año 61 y Agua pasada.
} 
Concluye el recorrido afirmando: “Apilados los frutos y sacadas las cuentas, se hace evidente que la cosecha es más bien pobre" (Campuzano, 1998: 363); a partir de allí intenta esbozar una explicación amparada en razones extraliterarias que vinculan estas líneas con la primera parte de su recorrido; es decir, el trabajo invisible de la mujer, sumado al "cúmulo infinito de restricciones, de represión, de apocamiento que ha fomentado la cárcel de silencio de la mujer" (Campuzano, 1998: 364).

Campuzano sugiere la falta de una tradición narrativa en la cual apoyarse. Esto se vincula con el último apartado en el que señala que la mujer, como sujeto, se ha desarrollado más en la poesía. Respecto de la mujer como objeto de la narración (es decir, como tema), considera que está muy bien trabajado en el cine y en el teatro, donde reconoce toda una tradición, pero que en la narrativa el resultado es aún muy pobre. En este recorrido cronológico rescata la construcción de algunos personajes femeninos en algunas obras de Senel Paz, Manuel Cofiño, José Solar Puig (El derrumbe y El caserón), Miguel Barnet (Canción de Rache), Jorge Calderón (Amparo, millo y aqucenas), Tomás Fernández Robaina (Recuerdos secretos de dos mujeres públicas), Alejo Carpentier (El siglo de las luces y La consagración de la primavera), Lisandro Otero (Temporada de ángeles), Cintio Vitier (De peña pobre) y Miguel Mejides (La habitación terrestre), entre otros. ${ }^{38}$

Resulta significativo que los últimos párrafos estén dedicados a "la realidad cotidiana de la Revolución” (Campuzano, 1998: 369), centrándose en aquellas novelas en las que la Revolución es el referente inmediato. Otorga un lugar destacado a la obra de David Buzzi por su indagación en la problemática femenina y en el proceso de

\footnotetext{
${ }^{38}$ No especifica las obras de los dos primeros escritores mencionados. Pero la valoración de Cofiño es taxativa: "Esa mirada es también la que Manuel Cofiño (1936) ha dirigido hacia la galería de mujeres que, en ocasiones como adorno más o menos gratuito y a veces como centro y sostén del relato, constituye uno de los mayores aciertos de su narrativa" (Campuzano, 1998: 368). Quiero señalar que no acuerdo con esta lectura que Campuzano realiza de la obra Manuel Cofiño. Sospecho que se está refiriendo a La última mujer y el próximo combate (1971); según mi lectura, en esta novela se esterotipa la figura de la mujer abnegada al mismo tiempo que se la coloca en posición de objeto.
} 
emancipación de la mujer. ${ }^{39}$ La mención de la obra de este escritor le sirve de excusa para explicitar las dos posturas adoptadas por los hombres en Cuba ante el proceso de emancipación de las mujeres: el machismo, "esa estentórea, polícroma y chabacana vulgaridad espiritual", y el paternalismo untuoso, "mucho más difícil de remover por lo que tiene de presunta bondad, de hipócrita condescendencia, de sublime conmiseración" (Campuzano, 1998: 370). Campuzano aboga por la presencia de escritores-cronistas de "la épica contemporánea de la emancipación femenina", reactualizando así la noción de la literatura como reflejo de la realidad, tan presente en Cuba en las décadas previas.

En el cierre de su trabajo recupera el análisis de la situación de la mujer realizado por Camila Henríquez Ureña en los años cuarenta. Desde allí señala la presencia aún minoritaria de mujeres escritorasy, en cambio, el lugar predominante que ocupan dentro del público lector y su papel central en la concreción y circulación de la cultura y la literatura. ${ }^{40}$

El artículo de la ensayista Nara Araújo (1945-2009) tampoco fue pensado a los efectos de Estatuas de sal sino que ya había sido publicado en 1993, en la revista UNIÓN. Por lo tanto, como en el caso anterior, se insertan en este nuevo espacio discursivo por la voluntad interpretativa de las compiladoras quienes, con este gesto, consideran que sirve de autoridad crítica para ingresar al corpus seleccionado en Estatuas de sal. En "La escritura

39 David Buzzi (1932-2004) se graduó de abogado en la Universidad de La Habana y en la década del sesenta comenzó su carrera de escritor. Por Los Desnudos (1966) recibió mención de honor en el concurso literario de Casa de las Américas. Posteriormente, en 1968, fue galardonado con el Premio de Novela de la Unión de Escritores y Artistas de Cuba (UNEAC) por La religión de los elefantes. En ese concurso también fueron seleccionados Los siete contra Tebas, de Antón Arrufat y Fuera de juego de Heberto Padilla. Entre sus obras posteriores se destacan Mariana (1970), Caudillo de Difuntos (1975), Cuando todo cae del cielo (1978) y Un amor en La Habana (1983). Durante muchos años fue Asesor Nacional de literatura del Ministerio de Cultura de Cuba, colaborador de las revistas Unión y La Gaceta Literaria y, por último, en Cuba redactor de la revista Revolución y Cultura. A finales de los años ochenta comenzó a participar de manera activa en el movimiento disidente cubano, por lo que fue arrestado en varias ocasiones. Abandonó Cuba en agosto de 1994 durante el éxodo de los balseros y tras ser rescatado en el Estrecho de la Florida fue llevado a la base naval de Guantánamo. Cuatro meses después, por motivos de enfermedad, fue enviado a Estados Unidos.

40 Deliberadamente, para poner en evidencia el carácter incumplido de la emancipación femenina, al comparar la situación de la mujer en la cultura en los años cuarenta y en su presente de enunciación, Campuzano homologa cincuenta años, con sus consecuentes cambios socio-históricos (incluida la Revolución). 
femenina y la crítica feminista en el Caribe: otro espacio de la identidad" Nara Araújo inserta en un contexto mayor la problemática de la narrativa escrita por mujeres cubanas: la eclosión de producción narrativa y de crítica en todo el Caribe. ${ }^{41}$ Menciona tres antecedentes: la antología de "narrativa femenina" en el Caribe: Her true-true name, editado por Pamela Mordezai y Betty Wilson en 1989 (publicado en inglés, en Inglaterra); la recopilación de ensayos sobre "literatura femenina caribeña" Out of the Kumbla Caribbean Women and Literature, publicado en 1990 por Carole Boyce Davies y Elaine Savory Fido (en inglés, en Estados Unidos) y la memoria de la Primera Conferencia Internacional de Escritoras Caribeñas, Caribbean Women Writters. Para Araújo el "acto fundacional” (Araújo en Yáñez 1998, 373) de la "escritura femenina” en el Caribe es la conferencia internacional convocada en 1988 por el Departamento de Estudios Negros de Wellesley College en la que participaron, principalmente, escritoras y críticas del Caribe anglófono. Señala también que dos años más tarde, convocadas por la Universidad de West-Indies, en Trinidad y Tobago, se reunieron representantes de las distintas áreas caribeñas. Evidentemente Araújo se esfuerza por insertar a Cuba no sólo en las Antillas hispánicas (donde el eje lingüístico permite que se conecte con el corpus mayor de la literatura latinoamericana), sino también con el resto del Caribe, por eso augura: "La inserción de la escritura femenina cubana en el concierto caribeño tendría que sobrepasar su tímida presencia" (Araújo 1998: 377).

Para Araújo el auge de esta narrativa así como las crecientes indagaciones de la crítica se deben a la confluencia de distintos factores: "la consistencia de un corpus literario, la impronta de las corrientes feministas del mundo occidental, la irrupción de una teoría y crítica feminista" (Araújo, 1998: 373-374). Esta supuesta circulación de los estudios de

\footnotetext{
${ }^{41}$ Nara Araújo es doctora en Ciencias Filológicas y profesora titular de la Facultad de Artes y Letras de la Universidad de La Habana, antes de publicar este artículo Araújo ya era conocida por Viajeras al Caribe (1983), volumen que reúne textos de viajeras, europeas y estadounidenses, que habían visitado los territorios del Caribe en el siglo XIX. Luego publica Visión romántica del otro (1993), los ensayos El alfiler y la mariposa: género, vozy escritura en Cuba y el Caribe (1997) y Diálogos en el umbral (2003).
} 
género es, por lo menos, llamativa si se tienen en cuenta las ambigüedades constatadas en los textos precedentes (y, como se verá, también en el de la propia Araújo). ${ }^{42}$

Su texto está marcado por referencias a investigaciones realizadas en el Caribe francófono e inglés, sobre narrativa escrita por mujeres, en contraste con las escasas menciones referidas a Cuba, ${ }^{43}$ lo que da cuenta de la escasez de estos estudios en la isla frente al desarrollo en otros lugares del Caribe. Araújo apunta cuáles deberían ser las tareas de la crítica feminista:

la arqueología literaria de textos marginados y el establecimiento de los perfiles de la tradición literaria femenina cubana. Igualmente, el estudio de la imagen de la mujer, la voz femenina y su diálogo con el discurso dominante/masculino y el canon, así como el papel renovador o transgresor de esta escritura, sus particularidades ideotemáticas y lingüísticas, los géneros de discursos, etc." (Araújo, 1998: 376).

En esta enumeración de las tareas que debería plantarse la crítica en Cuba se observa cómo la ambigüedad de la terminología empleada se traslada a las posibles acciones a desarrollar. Por ejemplo, las primeras acciones se pueden enmarcar dentro de los estudios que abordan la narrativa escrita por mujeres como un texto literario (aunque atendiendo a los distintos determinantes socio-históricos), mientras que las "particularidades ideotemáticas y lingüísticas" se vinculan con los estudios de género desde las teorías de la diferencia. Esta vaguedad terminológica también se vislumbra cuando se menciona en forma indistinta la escritura con "mirada de mujer" (Araújo, 1998: 379) y/o la "escritura femenina” (Araújo, 1998: 381), "discurso femenino y feminista" (Araújo, 1998: 379) (expresiones que poseen

\footnotetext{
42 En entrevistas posteriores, esta investigadora reconoce la falta de sustento teórico (de género) en sus trabajos iniciales debido a la escasez de bibliografía. Ver, por ejemplo, la entrevista "Mi huella en la huella" publicada en 2008 en http:/ /www.habananuestra.cu

43 Para el caso de Cuba, Araújo sólo menciona dos trabajos: el estudio de Susana Montero (también referido en la introducción) sobre narrativa femenina cubana (1923-58), publicado en 1989 y el de Luisa Campuzano incluido en Estatuas. Aquí menciona la cita original (en Quirón y otros ensayos), dato que permite probar la inserción sin correcciones ni adecuaciones del texto de Araújo.
} 
una fuerte carga esencialista) con especificaciones como "el género, como una construcción socio-histórica” (Araújo, 1998: 382).

En su recorrido por las figuras sobresalientes de la literatura escrita por mujeres, esta autora advierte que la tendencia principal ha sido la poesía. En cuanto a la novela y el cuento, sólo rescata la obra de Gertrudis Gómez de Avellaneda y de Dulce María Loynaz, siendo incisiva con el resto de la producción al afirmar que "entre intentos por novelar un testimonio, o el 'conflicto de la tierra' (a la manera de los consagrados escritores continentales), la escritora cubana ha querido dominar el espacio novelesco, sin mucho éxito" (Araújo, 1998: 379). Pese a esto, redime La hora de los mameyes (1983) de Mirta Yáñez por su intento de superar "los tradicionales registros sentimentales de la 'novela femenina', con un relato de cierta vocación histórica" (Araújo, 1998: 379). ${ }^{44}$ Otras novelas contemporáneas que rescata son Brujas (1990) de Chely Lima, Adolesciendo (1968) de Verónica Pérez Konina, y la producción de Dora Alonso y Lydia Cabrera.

\section{De la biblioteca heredada a la biblioteca creada}

Si consideramos los mecanismos de control del discurso y cómo éstos, de una u otra manera, pretenden dar coherencia a un discurso determinado, sustentar su veracidad y controlar quién lo emite (Foucault 1970), vemos cómo en Estatuas de sal, al igual que en cualquier antología, estos mecanismos funcionan iluminando determinadas obras o escritoras y omitiendo otras, sea por desconocimiento, razones ideológicas, causas editoriales, o por lo que Rafael Rojas llama "políticas de la amistad” (Rojas, 2000: 8) que

\footnotetext{
${ }^{44}$ La valoración resulta llamativa porque es una novela muy teñida por la influencia del realismo mágico imperante en la época. La misma Yáñez coincidió con esta valoración en una entrevista que le realicé en mayo del 2011, durante su participación en la Feria del Libro en Buenos Aires. Para acceder a la entrevista consultar el Apéndice 3.
} 
rigen la sociabilidad intelectual. ${ }^{45}$ Sin embargo, debido a las dificultades materiales que reviste este tipo de rastreo: acceso a bibliotecas y archivos de Cuba excepto los abundantes medios digitales; distancia de los conflictos inherentes al campo literario -que permitirían poner en evidencia exclusiones e inclusiones por parte de las seleccionadoras pero, también, considerar la posibilidad de la automarginalidad de la que habla Noé Jitrik (1996), las decisiones en torno al análisis de inclusiones y exclusiones en estas páginas se limita al plano de preguntas que buscan iluminar la investigación.

Estatuas de sal es un punto de inflexión que ofrece la posibilidad de revisar cómo, en un momento determinado del proceso literario cubano, se configura una herencia y una contemporaneidad que entran en diálogo (por momentos tenso) con otros discursos. Por eso, el arco temporal que recorre Estatuas de sal cubre dos lapsos: evalúa el pasado (y para eso recupera a las “Antepasadas... y todavía vivas") y mira el presente (“Cuentistas cubanas contemporáneas"). Ahora bien, ¿por qué el espacio temporal que queda desdibujado es el futuro, el espacio de las jóvenes (promesas) escritoras?

Como señalé, el primer recorte contemplado en el apartado "Antepasadas...y todavía vivas" configura la genealogía legitimadora, ya que visibiliza un linaje en el que se reconocen y en el que desean verse identificadas las antólogas (y, en consecuencia, su selección). Esta tradición resulta (cuanto menos) llamativa porque, como explicita el subtítulo, algunas estaban vivas en el momento de la edición de Estatuas. Entonces, ¿por qué no haberlas incluido en la segunda parte de la selección? ¿Cuál es el criterio de división?

\footnotetext{
45 Rojas toma este concepto a partir de las reflexiones de Carl Schmitt que también fueron utilizadas por Michael Foucault en Microfísica del poder y La hermenéutica del sujeto y por Jacques Derrida en Politicas de la amistad. En la última parte de Un banquete canónico, Rojas aborda las relaciones literarias entre los seis escritores cubanos incluidos por Harold Bloom en El canon occidental. La expresión "políticas de la amistad" refiere una de las formas de autorización que se practican dentro de un campo literario, pero también alude a la influencia de Roberto González Echevarría en la selección de escritores cubanos que realiza Bloom. También utiliza este concepto en "Memorias armadas", la última parte de Tumbas sin sosiego (2006) en el que propone detectar algunas políticas de la escritura que practican narradores de la isla y de la diáspora y que contribuyen a la integración simbólica de un campo intelectual fragmentado.
} 
Si nos atenemos a las fechas de nacimiento registradas en la organización cronológica de las escritoras, el punto de inflexión sería 1930, por lo tanto, el criterio temporal resulta arbitrario o, por lo menos, no justificado explícitamente en el cuerpo del texto.

En el momento de publicación de Estatuas, todas las escritoras seleccionadas para este apartado cuentan con varios libros en su haber. Las dos primeras escritoras cubren el espectro temporal que va de fines del siglo XVIII a fines del XIX, y son María de las Mercedes Santa Cruz y Montalvo y Gertrudis Gómez de Avellaneda. ${ }^{46}$ Aunque, como explicité, el objetivo no consiste en rastrear las exclusiones sino en describir y analizar los criterios de inclusión (así como generar preguntas e hipótesis de trabajo) cabe señalar que en esta brecha temporal se evidencia un llamativo vacío: la ausencia de Marquesa Beatriz de Jústiz y Zayas de Santa Ana (1733-1807) quien, junto a la Condesa de Merlín, es considerada entre las primeras escritoras cubanas. ${ }^{47}$

A diferencia de la sección "Cuentistas cubanas contemporáneas" que incluye una nota bio-bibliográfica de las escritoras, aquí sólo se consignan la fecha de nacimiento y los datos editoriales del texto seleccionado. Al recorrer los títulos incluidos se observar la variedad de géneros incluidos: memorias, cuentos, textos infantiles, fragmentos de novelas. De estas últimas se selecciona un segmento al que se le adjudica un título y en las notas a pie de página se aclara que el título es "ocasional para el fragmento seleccionado", gesto que permite deducir la arbitrariedad de las seleccionadoras. Por ejemplo, es lo que sucede con el título "Martina y Sab” inventado para el fragmento de la novela de Gertrudis Gómez

\footnotetext{
${ }^{46}$ En el Apéndice 2 detallo las escritoras y obras incluidas en Estatuas de sal. Cuentistas cubanas contemporáneas. También consigno los datos bio-bibliográficas de estas escritoras y de las del corpus de mi investigación.

${ }^{47}$ En Las muchachas de La Habana..., Luisa Campuzano señala que, a propósito del bloqueo inglés que se prolongó durante once meses a mediados del siglo XVIII, se produjeron escritos, algunos de los cuales pueden ser atribuidos a la marquesa Jústiz de Santa Ana, como el "Memorial dirigido a Carlos III por las señoras de La Habana" y un largo poema "Dolorosa métrica espresión del Sitio, y entrega de la Havana, dirigida a N.C. Monarca el Sr. Dr. Carlos Terce[ro]". Estos textos tienen autoría de carácter corporativo y no llevan firma por lo que la atribución se ha basado en dos fuentes secundarias que Campuzano retoma en su artículo.
} 
de Avellaneda; del "Capítulo VII. La historia de Pepe" para el fragmento de las memorias de Renée Méndez Capote, o de "Para hacer El Retiro" de la novela de Loló de la Torriente. Este gesto es una muestra de la intervención de las compiladoras: el título elegido no forma parte de las obras de ficción sino que es una elaboración externa, para insertarlas, como fragmento, en Estatuas de sal. Además, la inclusión de fragmentos permite hipotetizar que la publicación apunta a un público no especializado, para fundar un objeto de lectura y estudio hasta ese entonces silenciado.

En esta primera selección también resulta llamativo que el cuento de Lydia Cabrera incluido en Estatuas haya sido extraído de Antología del cuento en Cuba (1902-1952) de Salvador Bueno, detalle no menor si tenemos en cuenta que la única obra póstuma -Páginas sueltas — data de 1994. Es decir, que para el año en que se publica Estatuas de sal Lydia Cabrera ya había publicado toda su vasta producción, por lo tanto, la operación de selección reproduce el gesto de lo que venía sucediendo con las escritoras que aparecían en otras compilaciones previas.

"Cuentistas cubanas contemporáneas" congrega textos de treinta escritoras manteniendo un orden cronológico (según la fecha de nacimiento) que abarca desde 1930 a 1972. Cada cuento o fragmento de novela seleccionado va acompañado de una breve nota bio-bibliográfica que describe la trayectoria profesional, algún juicio valorativo (muchas veces se retoman comentarios de otros críticos o escritores) y un apartado dedicado a las publicaciones y premios recibidos. Respecto de las escritoras y obras incluidas en este apartado (que describo minuciosamente en el Apéndice 2) deseo llamar la atención sobre dos aspectos. En primer lugar, hay que tener en cuenta que para 1996, año en que se publica Estatuas de sal, ya estaban fuera de Cuba, por diferentes razones, Sonia RiveraValdés, Ana María Simo, Uva Clavijo, Achy Obejas, Mayra Montero, Ruth Behar y Zoé Valdés. Incorporarlas en la compilación resulta, para ese entonces, un gesto inclusivo: en 
Estatuas dialogan escritoras que producen fuera o dentro de la isla. Recordemos que fue muy lento el proceso de incorporación de los que se fueron: recién en 1981 se produce un punto de inflexión con la publicación de Los dispositivos en la flor. Cuba: literatura desde la Revolución (1981) en la que Edmundo Desnoes reúne fragmentos de discursos políticos, cuentos, poemas y canciones tanto de escritores residentes en la isla como de exiliados. Luego aparecen una serie de antologías integradas por escritores/as que residían en la isla o estaban en el exilio, por nombrar algunas, un año antes de la publicación de Estatuas de sal, Iván de la Nuez compila en Barcelona Cuba: La isla posible y, también en 1995, Ruth Behar publica Bridges to Cuba/Puentes a Cuba, un libro que compendia testimonios, fotografías, poemas, etcétera, de cubanos que viven dentro y fuera de la isla.

Por otra parte, la inserción, en términos cronológicos, de las escritoras más jóvenes suscita algunas reflexiones. En la introducción hay una nota al pie que define la posición de las compiladoras respecto de las escritoras más jóvenes como "todavía sin madurar estéticamente". Esa mirada, teñida por una distancia generacional, pone en duda "lo nuevo":

atraviesan por el sarampión de querer romper a toda costa las estructuras con desmontajes a veces no justificados del todo, uso reiterado de claves semiocultas, supercultismos y en muchos casos con un tono de brutalidad intencional que tiene mucho sabor todavía a adolescencia rebelde (Yáñez, 1998: 43).

A la vez, las compiladoras anticipan (o justifican) algo que sólo será una promesa incumplida: "Pero, sin lugar a dudas, algunas de ellas tendrán asegurado su puesto en una supuesta reedición ampliada (jSocorro!) de este PANORAMA” (Yáñez, 1998: 43). Las escritoras incluidas parecen cubrir el lapso (difuso) del futuro, de las promesas a cumplir, aunque formalmente quedan desdibujadas del cuerpo del texto porque no pertenecen al pasado ("Las antepasadas") ni al presente "(“Cuentistas contemporáneas”) sino que su configuración está supeditada al impreciso espacio en ciernes. Y son las mismas notas de 
las compiladoras las que delinean este futuro en el que se incluye a las últimas cuatro escritoras. Ya Adelaida Fernández de Juan es posicionada como una “joven autora” que pertenece a "la más reciente promoción de narradoras cubanas" (Yáñez 1998: 318). ${ }^{48}$ En forma consecuente incluyen a Mylene Fernández Pintado, cuando sólo tiene un cuento publicado y premiado (en este sentido, están apostando a su proyecto literario más que a lo efectivamente realizado). ${ }^{49}$

Verónica Pérez Konina, que no recibe tan explícitas valoraciones positivas, sí contaba con un libro publicado; tal vez este hecho respalde su inclusión sin tener que apelar a la justificación de las seleccionadoras. Por último, incluyen a Ena Lucía Portela, nacida en la década del setenta y que, cuando se publica Estatuas de sal, cuenta con apenas veinticuatro años y un cuento publicado en la antología de Salvador Redonet Cook. Sin embargo, en una nota al pie las compiladoras dejan entrever que ya circulaban otros textos de su autoría:

Sus cuentos constituyen una muestra de la rebeldía en cuanto a la aceptación de los patrones y tópicos tradicionales del género. El lenguaje procaz, la desarticulación del discurso y la preocupación por temas poco frecuentes dentro de la literatura cubana de promociones anteriores, confieren a su obra incipiente un interés particular (Yáñez 1998, 341).

Parece ser, entonces, que son criterios tanto temáticos como estéticos los que delinean, desde Estatuas de sal, ese futuro (prometedor) de la narrativa escrita por mujeres cubanas. Como en cualquier antología, de más está decir que son muchas las ausencias, vacíos o exclusiones. Aún teniendo en cuenta los criterios de selección explicitados en Estatuas (un

\footnotetext{
${ }^{48}$ Hay que notar que para cuando se publica Estatuas ya tenía 35 años y un libro en su haber.

${ }^{49}$ En la nota señalan que “obtuvo Mención en el Concurso para cuentos de 'La Gaceta de Cuba' de la UNEAC en 1994"; es decir, la sola "Mención" es enaltecida por la explicación de las seleccionadoras al decir que es un "galardón que prueba su mérito en la alta calidad de los concursantes y en el rigor selectivo" (Yáñez, 1998: 322). También enaltecen el cuento: "Pulcritud en el discurso, profundidad en la dimensión temática, habilidad en la construcción de los caracteres de los personajes y con una excelente elaboración, es un cuento de primera línea que da fe de esta nueva voz entre las narradoras” (Yáñez, 1998: 322).
} 
cuento publicado, algún premio recibido), ya circulaban otras (jóvenes) escritoras como Karla Suárez (1969) y Wendy Guerra (1970), por nombrar a dos de las que luego han tenido mayor visibilidad y producción. Para 1994, la primera había publicado un cuento, “Aniversario", en la Revista Revolución y Cultura, en La Habana. En cuanto a Wendy Guerra, en 1987 había publicado su libro de poesía Platea oscura y en 1996 aparece Cabeza rapada. Su producción narrativa es posterior o, por lo menos, no he podido rastrear cuentos publicados antes de 1996.

\section{Conclusiones parciales}

He dejado para el final lo que debería ser el incipit de este capítulo: reflexionar en torno al título del libro -Estatuas de sal. Cuentistas cubanas contemporáneas - nos retrotrae a lo esbozado sobre el recorte del corpus en lo "contemporáneo" y el enunciado también autoriza una interpretación para ingresar en el análisis porque otorga pautas de la idea que estructura la lógica del libro. La decisión de dejarlo para el cierre del capítulo reside en que el mismo título de la compilación condensa los riesgos que conlleva cualquier selección y más aún ésta en particular y este hecho nos permitiría esbozar una reflexión final al respecto. El epígrafe de la introducción remite a un episodio narrado en el Génesis, lo que refuerza la connotación del título elegido para la compilación: "Y entonces la mujer de Lot miró atrás, a espaldas de él y se volvió estatua de sal" (Yáñez, 1998: 11). ${ }^{50}$ Simbólicamente, debido a su anclaje en el pasado y a su incapacidad para mirar hacia el futuro, la mujer es convertida en estatua de sal. Se trata, entonces, de un castigo (al género) por transgredir las leyes

${ }^{50}$ El título alude al episodio bíblico en que la mujer de Lot, desobedeciendo el mandato de Yahvé, mira hacia atrás y, como castigo, queda convertida en estatua de sal. Lot, avisado por Yahvé, huye de Sodoma antes de que esta sea destruida. Este pasaje bíblico ha sido revisitado literariamente por ejemplo, en En busca del tiempo perdido (1913-1927) de Marcel Proust, por nombrar uno de los casos más renombrados, el volumen cuatro lleva por título "Sodoma y Gomorra” y se aborda tanto la homosexualidad masculina como la femenina. 
patriarcales. ${ }^{51}$ No podemos dejar de advertir el sentido de pertenencia que implica el uso de la preposición y la ausencia de nombre propio "la mujer de Lot". Este detalle conecta las lecturas propuestas al episodio porque lo que está implícito en el acto de esta mujer — sin nombre - es la transgresión de lo establecido y es este acto el que la individualiza y, por lo tanto, le otorga identidad. En este acto de transgresión también está implícito el hecho de que la mujer construye su historia mirando necesariamente hacia el pasado (operación que, por otra parte, realizan las compiladoras al recuperar a sus antecesoras). Sin embargo, en este libro -donde las mujeres sí poseen nombre y apellido-, el título se congela en un estado -el castigo- y, de esta forma, la misma operación que las coloca en la palestra pública, las congela (las silencia). Si se tiene que en cuenta que la tarea de selección contribuye, además de a promover obras y escritores, a conformar cánones en tanto las nuevas recopilaciones generalmente reproducen una porción de lo aparecido en las anteriores, el gesto adquiere otra densidad. ${ }^{52}$ La misma antología promueve esta operación ya que, por ejemplo, Estatuas de sal sirvió de base para una antología publicada en Estados Unidos: Cubana: Contemporary Fiction by Cuban Women (1998). Esta versión elimina el apéndice con artículos de Luisa Campuzano y Nara Araújo sobre la narrativa femenina contemporánea en Cuba y conserva el prólogo de Mirta Yáñez, antecedido de un prefacio de Ruth Behar. Dicha antología reúne dieciséis relatos escritos por mujeres de entre

51 Pero volvamos al título de la antología. Una referencia al título aparece en la cuarta parte de la introducción. Allí se menciona la intención aleccionadora que ha tenido la enseñanza de las historias bíblicas y cómo aparece castigada la desobediencia. "El segundo castigo lo recibió sólo una mujer por el mero delito de la curiosidad. La Mujer de Lot (ni siguiera conocemos su nombre) se atrevió a mirar, y por ello fue convertida en estatua de sal" (Yáñez, 1998: 30). El primer castigo señala que lo recibieron tanto el varón como la mujer y se vieron expulsados del paraíso. El problema aquí es que alega que el delito fue la curiosidad, una de las posibles lecturas de ese episodio del génesis. Y esa vuelta hacia atrás, según propone mi lectura, tiene que ver con reconocerse en el pasado.

${ }^{52}$ Recordemos que varios de los cuentos de Estatuas de sal fueron extraídos de otras antologías. Además del citado caso de Lydia Cabrera, se observan los de Esther Díaz Lanillo, Ana María Simo y María Elena Llana. Esta operación se puede comprender para el caso de Lanillo (sólo había publicado en antologías) pero tanto Cabrera como Llana y Simo contaban con una profusa producción en su haber. Entonces, lo cuestionable de este mecanismo es que reproduce el gesto de lo que venía sucediendo con las escritoras que aparecían en compilaciones y repiten el gesto del que intentan tomar distancia. 
veintisiete y sesenta y cinco años de edad y elimina la parte dedicada a las "Antepasadas". 53 Magalí Sánchez es la única incorporación diferente a Estatuas de sal. ${ }^{54}$

Si bien en estas reflexiones se tienen en cuenta los umbrales del texto, no puedo dejar de aludir a la imagen que ilustra la tapa de Estatuas, una obra de la pintora cubana Rocío García (1955), en la que se observa a una mujer desnuda tendida en un sillón y, a sus pies, un lobo (¿feroz?) que, con el hocico atado, la observa. La imagen seleccionada para la tapa se puede vincular con la metáfora que utiliza Mirta Yáñez en la introducción cuando dice "La colocación del mundo ficcional femenino del otro lado de una frontera imaginaria, trajo como resultado, entre otras cosas, que la narrativa escrita por mujeres, haya sido no sólo "la Cenicienta", sino además "la Caperucita Roja" siempre obligada a atravesar un enmarañado bosque donde la acechaba más de un lobo feroz" (Yáñez, 1998: 26). En la imagen, por el contrario, es una mujer (podría ser la misma Caperucita Roja) la que observa al lobo amordazado (¿por quién?) mientras ella, en una imagen medio diabólica, parece tener la voz y ejercer el poder de la palabra.

Esta imagen se puede repensar también a partir de los aportes de Michel Foucault (1970), quien señaló que la posesión del discurso implica poder y por eso, en toda sociedad, su producción está controlada, seleccionada y redistribuida por un cierto número de procedimientos que tienen por función conjurar los poderes y peligros, dominar el acontecimiento aleatorio y esquivar su pesada y temible materialidad. En este sentido, el discurso no es simplemente aquello que traduce las luchas o los sistemas de dominación, sino aquello por lo que, y por medio de lo cual se lucha, aquel poder del que quiere uno

\footnotetext{
53 No he podido acceder a esta antología. Pero en una reseña aparecida en la Revista Interamericana se consigna que "Mientras que algunas han publicado más de un libro de cuentos, otras, las más jóvenes, han hecho su 'debut' en Estatuas de sal'. Esta afirmación presente en un comentario del libro, contradice los argumentos esgrimidos en la introducción de Estatuas de sal. Ver: www.sg.inter.edu/revista-ciscla/volume30/ review.html

${ }^{54}$ Los otros nombres incluidos son: Mylene Fernández Pintado, Mirta Yáñez, Sonia Rivera-Valdés, Aida Bahr, Rosa Ileana Boudet, Marilyn Bobes, Achy Obejas, Josefina de Diego, María Elena Llana, Nancy Alonso, Adelaida Fernández de Juan, Ena Lucía Portela, Uva de Aragón.
} 
adueñarse. El acto de publicar se vincula con esta lucha para adquirir visibilidad en el ámbito cultural y es desde esta perspectiva que debe pensarse la estrategia implícita en la publicación de Estatuas de sal: el gesto antológico abre la posibilidad de mostrar textos que habían sido dejados afuera por las distintas operaciones de exclusión llevadas adelante por editoriales, la crítica, las publicaciones periódicas, por mencionar sólo algunos de los agentes que intervienen en el vasto campo cultural. Como sabemos, estas operaciones ejercen sobre los discursos un poder de coacción. Por eso, la visibilidad que adquiere la producción escrita por mujeres conlleva una paradoja: por un lado, forja la circulación de obras y autoras en una propuesta que, más que discriminar respecto de calidades, apunta a romper un silencio; pero en la misma operación coloca en el ruedo de la repetición (que se criticaba) e invisibiliza a otras escritoras.

Ahora bien, aún atendiendo a las limitaciones del género (antológico), en esta tarea de construir una genealogía es necesario reconocer que Estatuas de sal logra conformar un corpus por la cantidad de escritoras que incluye y, también, por la mostración de su extensa trayectoria en términos históricos. Por eso, la intención de estas páginas no fue determinar qué autoras y qué obras son incluidas y excluidas en el libro, sino pensar qué criterios se pusieron en juego y reflexionar sobre este otro implícito presente en toda obra antológica: la presentación de un corpus que aspira a la (utópica) unidad. La publicación de este libro en plena crisis del "Período especial" formaliza dos gestos relevantes: difunde obras que de otra manera no serían conocidas por la exclusión o por la invisibilización a la que han sido sometidas históricamente muchas de las escritoras cubanas y reúne producción producida dentro y fuera de la isla. Si Estatuas de sal procura dibujar en el campo cubano, una constelación de escritoras, esta operación ha generado reacciones al entrar en contacto con glorias reinantes y, por qué no, por visibilizar escritoras, muchas de ellas, de escasa participación en el circuito literario. Por eso, si bien, como demostró el análisis, la 
fundamentación de la selección es confusa y se le puede criticar que ponga en un mismo nivel de importancia obras que supuestamente no la tienen, la amplitud de la muestra la convierte en un material interesante, incluso por su mismo eclecticismo. 


\title{
II. Modos heterogéneos de construir la identidad y la genealogía literaria. Margarita Mateo Palmer
}

\author{
Para interpretar el mundo, todo ensayista emprenderá, \\ al mismo tiempo, una interpretación de la propia existencia. \\ Liliana Weinberg, El ensayo, entre el paraíso y el infierno

\begin{abstract}
La büsqueda de una identidad-quimérica que se escapa-diluye-escamotea ha sido una obsesión en el Caribe. Y en medio de ese caos -la isla que se repite, la isla que se repite, la isla que se repite-el espejismo de un centro omphálicamente estable que también tiende a diluirse aunque a veces se vislumbre la unidad en la diversidad. Nada, lo de siempre: de volvernos locos, la isla y la diáspora
\end{abstract} \\ la transculturación, el ajiaco y la nación. Y abora, además, como para acabar \\ Margarita Mateo Palmer, Ella escribia poscritica
}

La producción literaria escrita después de la caída del muro de Berlín se encuentra atravesada por las circunstancias del llamado por el discurso oficial "Período especial en tiempos de paz" que se materializó en una cotidianeidad signada por las carencias de todo tipo, desde escasez de combustible, de agua, de energía eléctrica (los “apagones" que establecieron una organización cotidiana regida por el imprevisto por ejemplo, en los horarios de trabajo, de la escuela), hasta retrocesos en sectores que habían sido prioritarios en el discurso revolucionario como la alimentación, el empleo, la salud y la educación (Vega Quintana 2000; Font 2004). En este contexto, el gobierno tomó algunas medidas de corte financiero como la despenalización del uso y tenencia de divisas, la apertura de los mercados agropecuarios y el fomento del turismo. Estas circunstancias han dado lugar a una nueva diferenciación social que hizo más complejo el escenario social. Diferentes investigaciones demostraron que, en este escenario, han sido las mujeres (en su condición de trabajadoras, ama de casa y madres) quienes más sufrieron los rigores de la crisis por la reducción de puestos laborales, las dificultades con el transporte, la complejidad de las 
labores debido a los cortes de luz, la escasez de alimentos y de medicamentos, la precarización habitacional, etcétera (Aguilar, 1996; Valdés Fernández, 1996; Vasallo Barrueta, 1997 y 1999; Holgado Fernández, 2000; Nuñez Sarmiento, 2001 y 2004).

La desaparición de la Unión Soviética y las consecuencias materiales mencionadas han tenido un peso político y moral que atraviesa la configuración del campo cultural (Vega Quintana, 2003, Fiallega, 2011; Costa, 2011). En tanto "estructura del sentir" (en términos de Williams), la literatura condensa tensiones sociales en las que es posible percibir cambios que aún no se han producido socialmente. A partir de la década del noventa, en el campo literario cubano se perciben huellas de modificaciones en la construcción identitaria de los sujetos femeninos que rompen cualquier intento de naturalización del género y, por el contrario, ponen en funcionamiento una perspectiva posicional (en términos de Alcoff). En este sentido, en este capítulo indago cómo ciertas operaciones discursivas puestas en juego en la narrativa de Margarita Mateo Palmer (La Habana, 1950-) constituyen marcas de esas modificaciones. En primer lugar analizo cómo en el ensayo Ella escribía poscrítica (1995) se desestabiliza la construcción de un sujeto femenino homogéneo. Aquí resulta transgresor que se plantee una mujer como sujeto que enuncia el ensayo a través de una compleja construcción de múltiples identidades posicionales del "yo". En segundo lugar, traslado estas indagaciones a Desde los blancos manicomios (2008), una novela en que la proliferación del sujeto se vuelve aún más problemática porque la protagonista bordea la marginalidad (en tanto, escritora encerrada en un manicomio). En esta novela analizo cómo se expanden y resignifican los sentidos del encierro que se pueden anclar en un primer espacio referencial (el manicomio) con sus múltiples implicancias, pero también en sus desplazamientos semánticos sobre la identidad.

Tanto en el ensayo como en la novela, resulta productivo pensar cómo funciona la intertextualidad en tanto mecanismo que configura una genealogía desde donde Mateo 
Palmer quiere ser leída. El funcionamiento de esta operación discursiva delinea lo caribeño como un espacio múltiple y complejo en el que este (nuevo) sujeto femenino se identifica, cuestión a la que dedico el último apartado.

\subsection{Ella escribía poscrítica : la construcción discursiva del sujeto escritora ${ }^{1}$}

Margarita Mateo Palmer estudió Licenciatura en Lengua y Literaturas Hispánicas en la Universidad de La Habana y, desde entonces, fue profesora de la Facultad de Artes y Letras de dicha institución hasta que en el año 2000 se trasladó a la Facultad de Artes Escénicas del Instituto Superior de Arte. Se ha especializado en narrativa latinoamericana contemporánea y en literatura caribeña, labor crítica por la que ha recibido numerosas distinciones. También, durante los últimos años ha incursionado en la escritura de ficción.

Publica Ella escribía poscrítica en el año 1995, en pleno "Período Especial en Tiempos de Paz". ${ }^{2}$ Los rasgos formales y estilísticos de este ensayo transitan por la ficción, el testimonio, la autobiografía y formas epistolares, géneros que apuntan a un tema central: la reflexión sobre la posmodernidad en el contexto latinoamericano, caribeño y cubano en particular. A lo largo de esas páginas, Mateo Palmer pone en evidencia que el fenómeno examinado no es tan "post" o que el "post" no está tan lejos de la modernidad. Aunque no desarrollaré las aristas del debate en torno a la posmodernidad ni la perspectiva adoptada por esta escritora, señalo que el abordaje de este tema implicó en Cuba poner en debate una problemática que, en la década anterior, fue censurada porque se asoció a corrientes como el "neoanexionismo" y el "neoliberalismo". Alfonso de Toro (2006) analiza desde

\footnotetext{
1 Unas reflexiones preliminares sobre este texto fueron publicadas con el título: "La transgresión del ensayo: Ella escribia poscrítica de Margarita Mateo Palmer" (2010).

2 Primera edición: La Habana, Abril.

${ }^{3}$ El posmodernismo fue impulsado hacia fines de la década del ochenta y principios de los noventa por pintores y artistas visuales reunidos en el grupo Paideia y movimientos como Arte Calle y Castillo de la Fuerza pero "esta insurgencia cultural fue sofocada por el poder" (Rojas, 2006: 452).
} 
qué perspectiva se utiliza la posmodernidad en el ensayo de Mateo Palmer y señala la originalidad de su planteo pese a la escasa bibliografía que cita, debido a la situación de la isla, que no le permitió acceder a publicaciones fundamentales. De Toro señala que la perspectiva utilizada logra sobrepasar “el binarismo de posiciones entre 'periferia y centro', 'lo propio y lo ajeno', 'el original y la copia"' (de Toro, 2006: 1) para proponer estrategias de recodificación y de reinvención de conceptos originados en otros lugares para emplearlos en el contexto del pensamiento y la cultura latinoamericana y del Caribe en una dialogicidad productiva. En este sentido, considero que Mateo Palmer recupera, reubica y recodifica la tradición latinoamericana y cubana en el debate de la postmodernidad, por ejemplo, con Fernando Ortiz (y los conceptos de transculturación y contrapunteo) y la alusión a la perspectiva posmoderna que adopta Antonio Benítez Rojo en La isla que se repite (1989) quien en la década del noventa ya no estaba en Cuba (ni circulaban sus libros). ${ }^{4}$

Mateo Palmer realiza una particular construcción del ensayo, apelando a rasgos típicos de este género (la hibridez y la heterogeneidad) pero la indagación teórica está puesta en la voz de un sujeto femenino que quiebra la unidad. El ensayo, que es un género de extensa trayectoria en América Latina, en la coyuntura de entresiglos, adquiere características que marcan continuidades y rupturas con sus predecesores de los siglos XIX y XX. Como señalan Antonio Urrello (1986) y muchos otros teóricos, el ensayo es un género híbrido que encierra una multiplicidad de componentes que han dado lugar, a su

\footnotetext{
${ }^{4}$ Señalo dos posibles hipótesis que a primera vista pueden parecen contrarias pero, en realidad, las pienso en sentido complementario: por un lado, en el ensayo de Mateo Palmer se produce una saturación de lo posmoderno que no es asumido acríticamente sino que, por el contrario, adquiere un tono irónico porque el contexto cubano que se describe dista de lo pos y se acerca a lo pre-moderno: una Habana sin luz, sin agua, sin papel, sin transporte, etc. La segunda hipótesis gira en torno al planteo de que Cuba (y toda América Latina) estaría marcada por una experiencia ad-hoc de la posmodernidad periférica por las obras literarias que aluden a ese fenómeno, por ejemplo, el choteo. Estas dos hipótesis se fundamentan por comentarios que realiza sobre cuestiones epistemológicas de la posmodernidad, por ejemplo, señala que América Latina, "no ha alcanzado aún un nivel de industrialización mínimamente decoroso", preguntando "¿cómo hacerse eco de un fenómeno que se ha caracterizado como propio de la llamada sociedad postindustrial?” (Mateo Palmer, 1995: 6-7); sin embargo señala que este fenómeno "se impone como tópico obligado de reflexión” (Mateo Palmer, 1995: 7).
} 
vez, a un gran número de definiciones y acercamientos críticos que varían según la fuente en que se originan. Desde la teoría, se ha abordado tanto la evolución del género, como los contenidos literarios, los político-económicos e histórico-filosóficos (Lukács, 1910; Adorno, 1954; Urrello 1986; Weinberg, 2001-2004; Grüner, 1996, entre otros). En Cuba existe una sólida y extensa trayectoria ensayística en la cual las mujeres fueron ubicadas en los márgenes de un espacio de escritura asociado, predominantemente, a los varones. ${ }^{5}$ Pese a esto, hubo quienes rompieron los cercos establecidos, como Camila Henríquez Ureña, Lydia Cabrera, Mirta Aguirre, Fina García Marruz y, más cerca en el tiempo, Luisa Campuzano, Graziella Pogolotti, Nara Araújo, Zaida Capote Cruz y Margarita Mateo Palmer. ${ }^{6}$ En este sentido, resulta interesante la lectura que realiza la investigadora Catharina Vallejo (2012) cuando analiza la relación que existe entre las ensayistas en Cuba (específicamente en sus ensayos de género) y la construcción de una voz femenina de conciencia autorreflexiva que a través de sus entrecruzamientos temáticos y temporales busca la expresión de una identidad femenina surgida de la colectividad nacional (espacio, territorio, etnia) y que lucha por indagar y clarificar la cubanía femenina, en particular después de la Revolución de 1959.7

\footnotetext{
5 Ver, por ejemplo Roberto González Echevarría (La voz de los maestros. Escritura y autoridad en la literatura latinoamericana moderna, 1985), donde analiza la tradición ensayística latinoamericana: José Enrique Rodó, Rómulo Gallegos, Fernando Ortiz, Alejo Carpentier, Carlos Fuentes, Julio Cortázar, Miguel Barnet, Guillermo Cabrera Infante.

${ }^{6}$ Excepto Zaida Capote, los nombres citados son los únicos textos ensayísticos escritos por mujeres que recoge la antología Ensayo cubano del siglo XX compilada por Rafael Hernández y Rafael Rojas. Es necesario advertir que, aunque sostienen que la intención de la antología no es clausurar el canon de la ensayística cubana sino esbozar un muestrario del género, de todos modos, el número de mujeres incluido es claramente inferior: ocho contra treinta y un ensayos escritos por varones.

7 Catharina Vallejo (2012) realiza un acercamiento al ensayo escrito por mujeres cubanas desde 1947 a 2007. Se propone señalar “el fenómeno dialógico (más que monológico), de una colectividad (más que de sujeto individualizado), voces múltiples que (se) comunican — se repiten, modifican, confirman- como los vasos comunicantes que se nutren entre sí, buscando un horizonte común, más elevado, cuando se les vierte nueva producción. Dentro de esa continuidad se hallarán rupturas — cambios, diversidad, innovaciones, revisiones - con las múltiples etapas del pasado reciente hacia un porvenir que se actualiza" (Vallejo, 2012: $522)$.
} 
En Ella escribía poscrítica, Margarita Mateo Palmer recurre a este género de un modo renovador y disruptivo por dos razones: por un lado, por el uso de una compleja trama escrituraria; por otro, por la construcción de un sujeto femenino (múltiple) atravesado por la materialidad de lo cotidiano (luchas por conseguir alimento, remedios, la maternidad, etcétera) y los avatares del mundo académico, es decir, un sujeto que no borra las problemáticas materiales. El ensayo intercala dos líneas discursivas: una académica y otra ficcional. Esta última recibe el mismo nombre que titula el libro: "Ella escribía poscrítica". El primer capítulo académico -"La literatura latinoamericana y el posmodernismo"cumple una función introductoria y se constituye en la base teórica del ensayo. El sujeto protagónico de la ficción es una profesora de literatura que está investigando o trabajando sobre los tópicos que en el apartado académico se discuten y, de este modo, ambos niveles quedan entrelazados. Debido a las características autorales, temporales y temáticas del texto seleccionado, tomo en consideración las advertencias de Georg Lukács (1910) y de Theodor Adorno (1954) quienes señalan que el ensayo es una escritura que emerge en situaciones de crisis y que realiza críticas a las condiciones de la cultura.

En este ensayo la escritura adquiere la forma de un cuerpo propio que va dibujando los contornos de sí misma como escritora, tanto en los capítulos académicos como a través de los personajes de los capítulos ficcionales. El título ya constituye una clave para ingresar en esta construcción. Una primera lectura, más detallada, permite advertir el diálogo intertextual con Tres Tristes Tigres de Guillermo Cabrera Infante: mientras que en "Los debutantes" se alternan dos espacios discursivos diferentes, y uno de ellos se coloca bajo el título de "Ella cantaba boleros", Mateo Palmer también alterna distintos fragmentos discursivos, uno con el título "Ella escribía poscrítica". Sin embargo, como advierte Nara

\footnotetext{
8 A su vez, Tres tristes tigres integra el corpus que Mateo Palmer analiza en el apartado "Ilustres Antecedentes II". Allí también aborda De donde son los cantantes de Severo Sarduy.
} 
Araújo (2006), mientras que en la novela del escritor cubano la mujer aparece como objeto, en el texto de Mateo Palmer se articula una relación con la mujer como sujeto, elección ya explicitada en el título del libro y en el vínculo entre sus partes. ${ }^{9}$ Otra lectura nos centra en las tres referencias inmediatas: género -"Ella"—, profesional -"escribía”- y temporal —la época de los "post". Resulta transgresor que ya desde el inicio se plantee una mujer como sujeto de la crítica que, además, escribe un ensayo, género habitualmente asignado a una tradición de varones a los que se les ha concedido el poder de argumentar en forma ensayística. Esta transgresión se refuerza por la elección de una tercera persona, "ella", que se opone a un "él" y que implica la elisión de un "yo" por el que pudo haber optado pero que, evidentemente, descartó. Sobre esto volveré más adelante.

Liliana Weinberg señala que el ensayo puede leerse como una dialéctica entre el “yo" y el nombre porque el que habla está adscrito a un orden determinado y tiene marcas de identidad social, nacional y regional: "El nombre reproduce de forma íntima e individualizada la historia de nuestra familia, el orden jerárquico de nuestra sociedad, nuestra propia posición en el mundo cultural que heredamos" (Weinberg, 2001: 40). En Ella escribia poscrítica ese "yo" es complejo al multiplicarse en identidades que, sin embargo, desembocan en una sola persona. Esa "toma de conciencia" (Weinberg, 2001: 43) entre el nombre y la firma a la que alude Weinberg, adquiere características particulares cuando lo que se asume y/o reconoce es el problema de género y es esto lo que sucede aquí, ya que la mujer aparece como voz dominante, como sujeto, no como objeto, y la escritura se erige

\footnotetext{
${ }^{9}$ Para mostrar este lugar de la mujer como objeto en la novela de Cabrera Infante, Nara Araújo analiza la construcción de la figura de Estrella como una masa corporal indetenible en su flujo sonoro y en su presencia estentórea, en su caracterización vulgar, cercana a lo animal. En cambio, en la caracterización del personaje de Surligneur-2 del ensayo de Mateo Palmer, se privilegia la conciencia y no el cuerpo (no aparece ninguna descripción física). Además, Estrella es el objeto dominado por las voces masculinas del fotógrafo y del locutor. Por el contrario, la voz dominante en el ensayo analizado es la del sujeto crítico femenino en el discurso académico y la de las voces del personaje femenino que se hacen escuchar a través de la mediación de una voz enunciativa que, desde la tercera persona, se coloca en el punto de vista del personaje protagónico.
} 
como el lugar de construcción de una identidad que lejos está de ser monolítica. Esto se observa tanto en la parte académica, donde la primera persona pertenece al sujeto crítico femenino, como en la ficcional, donde se narra el proceso de gestación de una clase sobre la posmodernidad que tiene que preparar Surligneur-2, profesora de literatura y alter ego de la autora. Aquí la protagonista se desdobla en múltiples identidades — Surligneur-2, Dulce Azucena, Siemprenvela, la Mitopoyética Intertextual, Lafeministadesatada y la Abanderada Roja- que plasman en la conciencia del personaje un debate sobre las diversas identidades (o máscaras) de Mateo Palmer, voces de la conciencia que dan cuenta de sus diversos roles como ama de casa, como madre, como profesora, como amante, etcétera. Con respecto a este juego especular, es necesario advertir que el texto de Palmer plantea una identidad múltiple pero desde una perspectiva moderna de preservación de la unidad en la diversidad, es decir, la unidad del sujeto no es cuestionada a pesar del juego que escinde en múltiples capas la identidad. ${ }^{10}$

Este “concierto de voces polifónicas” (Mateo Palmer, 1995: 89) pone en entredicho las diversas facetas en que se ha encorsetado la identidad "femenina". ${ }^{11}$ Surligneur-2 es el "yo" racional, pensante y con un fuerte amor propio. Constituye la memoria magisterial, la razón memoriosa llena de citas y referencias literarias, es el "yo" ligado al conocimiento y a la vida académica. Reiner Pérez-Hernández (2002) realiza una exégesis sobre ese nombre y explica que proviene de un "vocablo francés que articula por un lado dos palabras: 'sur' y 'ligneur' (entre líneas), y que alude al texto como mosaico de citas que se construye en un

\footnotetext{
${ }^{10}$ No es el juego especular de descentramiento de las teorías posmodernas como las de Gilles Deleuze y Félix Guattari en El Antiedipo (1973).

11 Araújo (2001) advierte que esta multiplicidad del sujeto femenino plantea y no resuelve el conflicto especular del libro: la vieja polémica entre el logos y el pathos. Efectivamente este conflicto se dirime durante todo el ensayo y adquiere ribetes melodramáticos cuando Dulce Azucena elige ir detrás de un posible amor que la invitó a un concierto, mientras que Surligneur-2 opta por correr detrás de Julio Ramos porque le puede acercar el artículo de Mempo Giardinelli sobre la posmodernidad. Parece que finalmente se produce la preeminencia del logos frente al pathos aunque el final queda abierto porque Surligneur-2 finaliza su discurso con una serie de preguntas retóricas que sintetizan el vacío y ascetismo de su vida sin la pasión y el encanto de Dulce Azucena.
} 
estar 'entre sus líneas o renglones', es decir, en múltiples dimensiones pero nunca visiblemente al centro y, por otro, al término 'intertextualidad' desde la lengua francesa". En contraposición, Dulce Azucena es el “yo" maternal, cándido, sensible, ingenuo, comprensivo y soñador. Es quien exacerba el discurso sensitivo y desbordado, la intuición y las experiencias del cuerpo llevada por una "visión compasivamente ingenua de la vida" (Mateo Palmer, 1995: 30). Según advierte Pérez-Hernández, este nombre es el equivalente sinonímico de redundancia, pasión, sentimiento y vitalidad. A veces aparece con el nombre de "Duermevela" en contraste con la "Siemprenvela" de Surligneur-2. Estas dos facetas son las que adquieren mayor presencia a lo largo de los capítulos ficcionales, pero es Surligneur-2 la que tiene el lugar protagónico, porque es en ella en quien se centra la voz en tercera persona que narra la historia. Las otras facetas están construidas por "Lafeministadesatada" que aparece en reiteradas oportunidades deliberando sobre el machismo instaurado en Cuba, pero que no logra ningún cambio en los actos de Surligneur-2; "La Abanderada Roja", exponente de los mayores sacrificios en pos de la Revolución y, por último, la "Mitopoyética": el "yo" que escribe o desea escribir. ${ }^{12}$ Resulta interesante analizar la construcción de esta voz que es, además, la más postergada. La Mitopoyética se hace presente cuando Surligneur-2 duerme; por lo tanto, resulta posible pensar que representa el sueño pero también la inspiración poética. En el cuarto capítulo ficcional, la narradora cuenta que

La Mitopoyética decide, en efecto, escribir ahora su posmito. Se siente como Lezama concibiendo «Las eras imaginarias», creando un sistema poético del universo. Se

\footnotetext{
${ }^{12}$ Un ejemplo de las discusiones entre tres de sus facetas es la narración de la inundación de su casa y el trabajo de sacar el agua a baldazos, actividad que acompaña con su canto hasta que "Abejorro la mandó a callar. Diz que hacía mucho ruido, que molestaba a los vecinos y que, definitivamente, no sabía cantar. Lastimada en lo más profundo de su amor propio, Surligneur-2 se detuvo y contó hasta tres, mientras Dulce Azucena invocaba a María Teresa Vera, su larga espera de veinte años, Penélope tropical santificada para que sus devotas no perdieran la paciencia: oh, santa Teresa, asístela en este trance. Mas Lafeministadesatada siempre al acecho—no dejó escapar la oportunidad que se le ofrecía: tienes que ponerlo a limpiar a él ahora mismo, gritó en el oído de Surligneur-2. si no lo haces por ti -ya que has llegado a tan bajo nivel de autoestima genérica-hazlo por tu futura nuera, a quien le corresponderá enfrentar en su momento las embestidas, ya no del dulce Abejorro, sino del mismísimo Minotauro" (Mateo Palmer, 1995: 78).
} 
siente como Carlos Marx escribiendo El Capital. Se siente como Martí fijando las bases del Partido Revolucionario cubano ¿Por qué no se siente como la niña de Guatemala, ya que no María Mantilla? ¿Por qué no se siente como Jenny? ¿Por qué no se siente como María Zambrano, o mejor aún, como Rosa Lima de Lezama? ¿O como Rialta, para estar en un plano más claramente ficcional? Y ya que está ficcionando ¿por qué no como Ynaca Eco? Pero lo decisivo realmente es que la Mitopoyética se siente importante (Mateo Palmer, 1995: 83).

Estos comentarios hacen evidente aspectos de la problemática de la escritura para la mujer. Aunque en el momento de escribir las identificaciones se realizan con figuras masculinas y de fuerte tradición en la isla, la narradora enumera una serie de personajes femeninos reales o de ficción que ponen en entredicho la identificación primera. Ese "sentirse importante" la lleva a buscar parangones masculinos pero, finalmente, la inspiración no termina en la escritura sino que es cortada por un hecho cotidiano: los gritos de "Abejorro" pidiendo su comida.

El hijo se hace presente desde la dedicatoria: "Para Alejandro Escobar, mi hijo" (Mateo Palmer, 1995: 4). Como ha señalado la crítica, las dedicatorias conforman un mapa o topografía de recepción y circulación del texto, porque marcan un espacio de reserva textual y de clase (Weinberg, 2001). En este caso, la dedicatoria marca una filiación que complejiza el mero vínculo maternal a partir del recuerdo intertextual de la dedicatoria martiana del Ismaelillo (1882). ${ }^{13}$ Este nexo genealógico funciona como un doble articulador textual. Por un lado, autoriza la voz maternal de "Dulce Azucena" al enraizarla, no sin ironía, en el linaje patriarcal de Martí. Por otro, establece una neta diferencia con otra tradición de dedicatorias masculinas que, generalmente, aluden a otros escritores con los

${ }^{13}$ La filiación martiana de esta dedicatoria me fue sugerida por María del Pilar Vila en una versión preliminar de este trabajo. En Ismaelillo (1882) escribe Martí: "Hijo: Espantado de todo, me refugio en ti. Tengo fe en el mejoramiento humano, en la vida futura, en la utilidad de la virtud, y en ti. Si alguien te dice que estas páginas se parecen a otras páginas, diles que te amo demasiado para profanarte así. Tal como aquí te pinto, tal te han visto mis ojos. Con esos arreos de gala te me has aparecido. Cuando he cesado de verte en una forma, he cesado de pintarte. Esos riachuelos han pasado por mi corazón. ¡Lleguen al tuyo!”. Aunque Martí escribe su libro en el exilio, alejado de sus afectos, incluido su hijo, considero que, si se vincula la dedicatoria con el libro completo, es posible advertir en la elección de Mateo Palmer esta apuesta por la futuridad, es decir, apelar al hijo, a su descendencia (y por sinécdoque, a todos los niños), como un refugio y también como una razón por la cual apostar al futuro. 
que se desea entroncar y evitan toda referencia al mundo de los afectos. Además, su hijo se convierte en una referencia constante a lo largo del libro, tanto para aludir a las dificultades de criarlo, sola, en el contexto de las penurias económicas de los noventa en Cuba, así como también para mencionar las pequeñas alegrías cotidianas. De este modo, las referencias a su hijo y las instancias donde se narran hechos de la vida familiar permiten percibir uno de los roles que construyen su múltiple personalidad, aquí en su rol de madre. Esta construcción se complejiza a lo largo del ensayo, porque aunque en la dedicatoria aparece el nombre y apellido -“Alejandro Escobar”-, en los capítulos ficcionales sus referencias fluctúan entre el cariñoso "Abejorro", el futuro "Minotauro" para referir su conversión en varón machista, o la dupla “Abejorro-Minotauro" para referirse a la tiranía que ejerce ya desde niño. Estas fluctuaciones ponen en evidencia la alternancia entre un “yo" más tradicional -Dulce Azucena_ que remite a la madre abnegada en la crianza de su hijo, humillada y sublimada (por el mismo acto), con otra faceta de su "yo" Lafeministadesatada-, que una y otra vez lucha por imponer su opinión en la crianza del niño pero siempre resulta marginada, es decir, se convierte en un "yo" que "dice" en el inconsciente (y en el texto) pero que no pasa a la acción. Un ejemplo paradigmático de lo expresado se puede observar en el siguiente fragmento:

Salta de la cama Surligneur-2, sorprendida por sus sueños, aturdida por los gritos del Minotauro -ya no dulces requiebros del Abejorrro- exigiendo su comida; corre Dulce Azucena hacia el fogón para alimentar a su hijo -recetas de Laura Esquivel en la mente de la Intertextual, inventiva de la escasez en la imaginación desatada de la Abanderada Roja- mientras la Siempreenvela aprovecha la confusión para gritar que todo este descalabro del ámbito doméstico se veía venir, frase desafortunada que desata las agresivas réplicas de la Feminista desatada: los hijos varones son como vampiros en La Habana abusando de las buenas intenciones maternales. Mientras tanto el Abejorro, ajeno al concierto de voces polifónicas, apaciguado en el centro del cuarto ahora que escucha a su madre dirigir la alegre contradanza de las cazuelas en la cocina, comienza a recoger las plumas blancas aún diseminadas por el aire para rellenar el casco -travestido yelmo de Mambrino en este tiempo de pobreza irradiante-mágico resguardo que protegerá sus huesos parietales y frontales en los entrenamientos para la próxima nacional (Mateo Palmer, 1995: 88-89).14

\footnotetext{
${ }^{14}$ Otro ejemplo similar se observa en Mateo Palmer (1995: 78).
} 
En la cita se observa que el sujeto femenino que alude a la voz del discurso académico de manera oblicua está escindido en varias identidades pero todas viven la experiencia de la crisis cubana durante los años del "Período Especial". ${ }^{15}$ Por otra parte, es posible advertir que en la construcción de Dulce Azucena, la autora tiende a esencializar el género, ya que sus características se asientan en el estereotipo "mujer" (madre, ama de casa) frente al "varón" (Minotauro). Esta sería una forma de denunciar el machismo predominante en Cuba (que adquiere espesor en la operación de hacer trizas el estereotipo de género). ${ }^{16}$

En los capítulos ficcionales también es posible analizar cómo construye la imagen de intelectual marginal. Es en el personaje de Surligneur-2 donde es posible advertir esto desde diversos aspectos: tanto por el hecho de ejercer su trabajo en un país como Cuba y en plena crisis económica - cuestión sobre la que volveremos en otro apartado- con limitado acceso a la bibliografía (en el primer capítulo ficcional se pasa revista por los libros que buscó en la biblioteca y que estaban prestados/inexistentes/robados), como por el lugar marginal que ocupa dentro de la misma institución en la que trabaja, no sólo debido a los temas que aborda sino también a la forma en que dicta sus clases y a la relación que establece con sus estudiantes. Esto último queda entredicho en el quinto apartado ficcional donde, además, reflexiona sobre el proceso de escritura, y toma distancia de la academia y

$15 \mathrm{Al}$ respecto, en una entrevista Mateo Palmer señala que "Para mí fue una manera de continuar mi trabajo intelectual, contra viento y marea, aunque las condiciones de la vida cotidiana atentaran contra ello en más de un sentido: desde los apagones hasta la falta de papel para escribir, pasando por la escasez de medicamentos — vivo con mi madre y mi hijo, ambos asmáticos_ y la tragedia cotidiana de la comida y el transporte" (Puyol, 2007).

${ }^{16}$ Esta cuestión de la explosión de los clichés constitutivos de la identidad también se realiza desde otras variables como la "raza". Por ejemplo, Silvia Valero (2011) señala el proceso de re-etnización que se manifestó en ámbitos culturales, intelectuales y de activismo político en Cuba a partir de la década del noventa. Advierte que como todo movimiento social, éste es heterogéneo y presenta resultados disímiles con respecto a las autodefiniciones y las reflexiones teóricas. Advierte que algunas expresiones se vuelven controvertidas al ignorar el carácter relacional e histórico de toda etnización y al adjudicarle carácter real a las "razas". Analiza cómo se procesan estos debates en las ciencias sociales y en manifestaciones musicales, literarias y en las artes plásticas. 
de sus valores y, en cambio, opta por la valoración de sus estudiantes y por cuestiones cotidianas como bañarse con su hijo en el mar.

En el tercer apartado ficcional Surligneur-2, en el rol de profesora que prepara la clase sobre posmodernidad, revisa diversos autores que abordan la compleja dinámica Modernidad/Posmodernidad. Esta síntesis teórica le permite poner en cuestión la identidad monolítica de la modernidad sintetizada en el "yo soy yo", y reflexionar sobre las posibilidades de la propuesta posmoderna de descomponer el "yo":

Leído al derecho: yo soy yo. Lección primaria de identidad. El ego recoge, clasifica y archiva: tengo un Nombre. Una Mamá. Un Papá (¿Un Papá?). Un lenguaje. Un Género. Un Sexo. Una Raza. Un País. Una Cocina (¿Una Cocina?). Una Cultura. Un Clima. Un Ritmo. Una Nación. Un Origen. Un Ancestro. Un Etcétera casi infinito" (Mateo Palmer, 1995: 43).

Finalmente opta por darlo vuelta en un "Hoy soy yo. Ya es bastante" (Mateo Palmer 1995: 44), un "yo" variable que cambia todos los días y que, como señala Alfredo de Toro (2006), tiene consecuencias para la concepción de una identidad cultural nacional determinada y para los roles sociales. Para ejemplificar la identidad en la posmodernidad, Surligneur-2 alude a su propia situación e, indirectamente, al "yo" autoral:

Hoy soy yo. Ya es bastante. Mañana también seré, probablemente, pero no sé cómo. No tengo por qué ser quien fui hoy, no tienen por qué coincidir las identidades. Y ahí entraría lo de la máscara, el teatro, el espectáculo y hasta los disfraces de todos los días. La interpretación de los roles, añadió Dulce Azucena, que en el caso de las mujeres de la isla, son muy complejos. De doctora en Ciencias Filológicas, que irrumpe como ciclista desesperada en la reunión del núcleo - de donde ya sale dialogando con la escoba y la frazada--, hasta madre hay una sola con el Abejorro a cuestas por la loma de la calle 8 o mujer apabullada por las holoturias machistas que gozan de tanta salud en los climas tropicales, por no hablar de los papeles secundarios de alquimista del picadillo de soya o del último cubo en la cola para el agua de la pilita de la esquina. Y de ahí, sin transiciones, —se desbordaba Dulce Azucena—nuevamente la toga y el birrete, confundidos ya con el delantal y la espumadera y hasta con la capa de agua y la sombrilla por aquello de las ventanas que no cierran cuando llueve y mucho menos cuando los efluvios del Niño azotan la ciudad. Del encausto a la sangre, hubiera dicho Mirta Aguirre, como quien habla de sor Juana; del azafrán al lirio, Ballagas (Mateo Palmer, 1995: 44). 
Al pasar revista por el uso de los deícticos podemos observar cómo la ensayista reflexiona sobre su propia situación para analizarse e interpretarse. Como todo ensayo, éste no elude el momento de la deixis y el movimiento por el cual ese sujeto femenino que pronuncia yo/aquí/ahora da pie a la posibilidad de describir y descubrir la realidad. Un claro ejemplo de esta estrategia es, por ejemplo, la nota al pie número veintitrés donde se explicita el presente de unos comentarios hechos en una carta a John Beverley que aparece citada en el cuerpo del texto: "Los mencionados ensayos, desde luego, no se terminaron ese mes, ni aun el siguiente. Todavía hoy, más de un año después, están sin terminar, pero —abora sí, a punto de" (Mateo Palmer, 1995: 33). ${ }^{17}$ Este discurso autorreferencial también se observa en las cartas y en el postprólogo, donde en un juego de dualidad autoral se narra en tercera persona cómo la escritora, "que había estado escribiendo una crítica de la crítica sobre una novela", termina la escritura porque no encuentra la pluma con la que había estado escribiendo.

\subsubsection{De los muros y la escritura o la puesta en acto del cruce de géneros}

La plurivocidad de este ensayo se combina con la multiplicidad de materiales que lo construyen. Como se señaló, el tema central es la posmodernidad y, según se desarrolló en el apartado anterior, la construcción del texto en sí mismo podría ser considerada posmoderna. Es sabido que la posmodernidad apela al tópico de lo marginal, de la diferencia, de la ruptura y en Ella escribia poscrítica, la construcción del libro recurre a estas rupturas tanto en el título como en la fragmentación de los capítulos en dos niveles discursivos: uno académico y otro ficcional. El capítulo que más se ajusta a la denominación de "académico" es el primero -"La literatura latinoamericana y el

\footnotetext{
${ }^{17}$ La itálica pertenece al original.
} 
posmodernismo" - que, además, elabora la base teórica del ensayo sobre la posmodernidad, mientras que en los otros capítulos se analizan diferentes corpus que se inscriben en lo que se considera "posmoderno" en el estado de la cuestión. En efecto, el primer capítulo no transgrede ninguna de las características del discurso formal: uso de la tercera persona, citas textuales que le permiten desarrollar el tema y sus respectivas notas al pie con la bibliografía consultada y el despliegue de lecturas, etcétera. Sin embargo, ya en el segundo capítulo, la transgresión se establece en la elección del corpus para analizar la inscripción de la memoria: primero los graffitis plasmados en una calle de La Habana y, más adelante, el estudio de los tatuajes en la piel.

Mateo Palmer da cuenta de esto en el capítulo "De los muros y la escritura" cuando realiza un recorrido por la calle $\mathrm{G}$ - o Avenida de los Presidentes— de La Habana leyendo los graffitis que parodian las estatuas en las que se plasman, dialogan entre sí y leen la realidad cubana. Es una búsqueda de la memoria latente, inscripta en las paredes. Estos signos marginales, pequeños, ocultos, son el eco de la voz de las personas comunes expresiones de amor desesperado, de amor casual, el humor o ya la más compleja intertexualidad graffitera- y contrastan con las estatuas de bronce y con la descripción de los edificios en que culmina la calle G: por un lado, Casa de las Américas, por otro, la Universidad de La Habana, "los templos del saber de la ciudad letrada" (Mateo Palmer, 1995: 23). De esta forma, Mateo Palmer pone en evidencia cómo estos signos de la cultura popular polemizan y/o desacralizan la ciudad letrada y su historia. El texto establece los graffitis como un sistema de "escritura sobre la escritura, reduplicación de palabras y textos, palimpsestos de infinitas superposiciones" (Mateo Palmer, 1995: 22) que retoman el debate de la historia con la actualidad.

El tercer fragmento académico se inicia en la línea de ensayo más tradicional, cercano al trabajo crítico universitario; pero poco a poco se producen transgresiones 
porque, al mismo tiempo, se incorporan en las notas al pie y en el mismo cuerpo del texto cartas a John Beverley, a Salvador Redonet Cook y al editor de Mateo Palmer, entre otros. Como señala Araújo (2001), mediante esta operación realiza un proceso autorreflexivo y autorreferencial (la emisora o destinataria, según correspondiere, es Mateo Palmer y firma como tal) que parodia el discurso académico, porque pone de manifiesto el proceso de gestación — solicitud de John Beverley en un encuentro en La Habana—y de esta forma el discurso combina la voz en tercera de la enunciación académica, con la primera de los discursos epistolares con los que se establece un diálogo. ${ }^{18}$ La relevancia de la información que se incorpora hace que el paratexto adquiera el mismo valor que el texto, ya que otorga elementos del desarrollo teórico puesto en el cuerpo principal y porque desoculta el origen y el proceso de gestación del texto.

En "De la piel y la memoria", las transgresiones genéricas se profundizan porque, en la construcción de los primeros tres párrafos se observa una cadencia que lo liga fuertemente a la poesía. ${ }^{19} \mathrm{El}$ tono y los recursos poéticos nos ubican como espectadores de una procesión de personas que llevan a flor de piel las inscripciones sobre su cuerpo. De este modo, poético al inicio, luego descriptivo, Mateo Palmer transcribe entrevistas con diferentes clases de tatuadores (y tatuados) de La Habana, y esto le permite demostrar cómo en Cuba el tatuaje se inscribe en el ámbito de lo sagrado, de la perdurabilidad, porque está "integrado a la carne para siempre” (Mateo Palmer, 1995: 11).

$\mathrm{Al}$ incorporar la cultura popular -representada por los graffitis, los tatuajes, las citas apócrifas, las canciones, los epitafios - y al colocarla en el mismo nivel que el discurso literario, Mateo Palmer intenta abrir (y, al mismo tiempo, cuestionar) los límites del canon

\footnotetext{
18 Específicamente, se cita el encuentro "Modernismo y Posmodernismo en la literatura de América Latina: perspectivas cubanas y norteamericanas", auspiciado por LASA y Casa de las Américas.

${ }^{19}$ Ya desde el epígrafe, este capítulo establece un diálogo con el ensayo Escrito sobre un cuerpo de Severo Sarduy, cuestión que es analizada por Araújo (2001). Por otra parte, "De la piel y la memoria" también es un video realizado por Mateo Palmer en 1995, con el Grupo Videocamello.
} 
académico. Además, la incorporación de los tatuajes permite el ingreso del cuerpo, en la tradición de Severo Sarduy, Michael Foucault y Gilles Deleuze (De Toro, 2006). Así, establece una distancia con el discurso que intenta imitar, porque se tratan en el mismo nivel lo literario tradicional -por ejemplo, el análisis de textos de Virgilio Piñera, José Lezama Lima, Alejo Carpentier, Severo Sarduy y varios cuentos de los novísimos- y los discursos de la cultura popular.

La transgresión adquiere mayor densidad cuando, a lo largo de los capítulos "serios", se citan frases en latín junto a frases coloquiales, se incorporan versos que circularon entre los asistentes al "I Encuentro Internacional de Criterios", ${ }^{20}$ se citan epitafios ilustres junto a otros creados para realizar chanzas, se inventan citas, etcétera. Este procedimiento ya queda plasmado en el primer capítulo ficcional cuando se transcribe el resultado de una pesquisa bibliográfica en una biblioteca y los resultados fueron: prestado/ robado/ extraviado/ inexistente. Y como es evidente el vínculo entre los capítulos intercalados, es posible leer en esta primera presentación, uno de los desencadenantes de las transgresiones posteriores. Además, en esta historia se narra utilizando todas las transgresiones explicitadas a nivel teórico en la parte académica (por ejemplo, Surligneur-2 construye sus clases en base a apuntes, manuscritos y fragmentos). Esta operación adquiere tintes autobiográficos cuando, en el capítulo dedicado a los novísimos, en primer lugar realiza una aproximación a la obra de los narradores, cita la bibliografía que ha tratado el tema y transcribe un (¿real? ¿supuesto?) artículo publicado en Juventud Rebelde sobre un encuentro de escritores realizado en Cárdenas. En homenaje a ese encuentro, propone mostrar textos periféricos que circularon allí y que fueron marginados por la "historiografía y la crítica literaria" (Mateo Palmer, 1995: 140). Para esto introduce una serie de herméticas

\footnotetext{
20 Transcribo los versos porque son ocurrentes y son una muestra del humor cubano aún en los ámbitos académicos: "Cuando llego a tu forum desatado/ y me toca con la punta de un Criterios/ me desiderio amor, me desiderio" (Mateo Palmer, 1995: 56).
} 
cartas íntimas, sentimentales, escritas por una mujer (¿alter ego de la autora?) a un hombre que la abandonó y, luego, a un posible nuevo amor. Pero la transgresión se duplica cuando la última carta de amor con, excesivas referencias literarias -ya presentes en las anteriores-, aparece acompañada por diez notas al pie explicando (o ironizando) términos utilizados en el cuerpo de las epístolas. Aquí son los recursos críticos los que contaminan el discurso íntimo o confesional.

De este modo, es posible observar cómo se produce un borramiento de los límites y contornos de los géneros literarios: el ensayo se conjuga con las cartas, las entrevistas, el diario íntimo, las citas eruditas y las apócrifas, canciones populares, etcétera. ${ }^{21} \mathrm{El}$ apartado "Post-epistola ad editorem o lo que quedó quedó" es un claro ejemplo de la transgresión genérica planteada ya en el título que conjuga la tradición clásica con la coloquialidad de la oralidad. El cuerpo de este apartado está constituido por una carta a Jorge Ángel (Pérez), el editor de la autora, donde explica los hechos cotidianos que retrasaron la escritura de (este) ensayo y detalla todo lo que le faltará desarrollar y, por lo tanto, lo reserva para otro libro. Con este procedimiento, desoculta el proceso de creación del ensayo, acción que se conjuga con el último capítulo ficcional, donde se relata cómo Surligneur-2 lucha desesperada por terminar su libro ante la insistencia del editor. ${ }^{22}$

\subsubsection{Los embates de escribir en Cuba en los noventa}

Ella escribia poscrítica se presenta como una estrategia de supervivencia de una mujer escritora y profesora- ante las situaciones dramáticas que desencadena la crisis.

\footnotetext{
21 Acuerdo con Araújo (2001) cuando considera que esta crítica paródica de la crítica tiene una carga desestabilizadora que, a partir de los marcos que el libro establece -un sujeto femenino es portador de la transgresión de los géneros-tiene una indudable relación con la posicionalidad de lo femenino.

${ }^{22}$ No he podido constatar si Mateo Palmer leyó o no a Jacques Derrida. Sin embargo, resulta necesario advertir que la tendencia de la poscrítica, planteada en el ensayo analizado, ya fue puesto en juego por Derrida en Glas (1974). Sobre la escasa y zigzagueante circulación de los teóricos franceses en Cuba, véanse los comentarios de Navarro (1997).
} 
Recurriendo al humor, el ensayo pone en evidencia cómo Mateo Palmer se aferró a la escritura en momentos en que todo parecía desmoronarse y en los que hasta escribir resultaba materialmente difícil, debido a la escasez de papel. La escritora presenta esta experiencia como colectiva (aunque el colectivo incluye sólo al grupo intelectual), porque a lo largo de las páginas menciona el surgimiento de diferentes movimientos culturales que padecían esta situación y expresaban e interpretaban este clima, en algunos casos, llamado posmoderno.

Es a través de las vicisitudes por las que atraviesa Surligneur-2 en los capítulos ficcionales donde se plantean con mayor intensidad los problemas de la vida cotidiana:

Ella escribía poscrítica e iba al estadio a ver el play-off de Industriales y Pinar del Río (...), luego caminaba los dos kilómetros de regreso a su casa, como correspondía a todo crítico aficionado al béisbol en una época y un país en que el transporte era sólo una quimera (...).

Ella escribía poscrítica y arreglaba la bicicleta, hacía la cola del agro y redactaba cuestionarios de exámenes. Le tiraba el tarot a los vecinos, fichaba un artículo de Iuri Lotman, baldeaba el portal y cosía el uniforme de tae-kwan-do de su hijo. Revisaba el proyecto de la beca de Loyola en Sao Paulo, hacía tortas de pasta de oca mientras ó́a a The Mamas and the Papas, iba a las reunión de departamento, alimentaba con humo de tabaco su talismán, mataba cucarachas de madrugada y le daba consejos espirituales a sus sobrinos (Mateo Palmer, 1995: 36-37).

En el fragmento seleccionado (como en la mayoría del ensayo) la crisis que atraviesa la isla cruza el espacio de lo privado, de su vida familiar y el espacio de lo público, de su vida como investigadora y profesora, situación que se plasma cuando Surligneur-2 relata las artimañas a las que recurre para preparar la clase: la necesidad de apelar a las fichas ante la imposibilidad de acceder a los libros o las dificultades aún en las bibliotecas ("prestado", "no lo posee la biblioteca", "no hay luz", "no aparece", "no existe", "se robaron la revista"), el acceso a autores sólo por referencias de otros textos, por ejemplo, llegar a Jean François Lyotard a través de Fredric Jameson por la ausencia de los originales, etc. Por esto, es posible decir que la actividad de Surligneur-2, personaje de ficción, se imbrica con la de Mateo Palmer: ambas son ensayistas y, como sintetiza Eduardo Grüner, son aquellos 
que saben que nunca escriben solos (y su soledad consiste en saber eso) porque "su escritura es también la que permite que se escriba -que se inscriba- el autor con el cual "ensaya"; para un ensayista, leer no es escribir de nuevo un libro: es hacer que el libro sea escrito, “aparezca” (Grüner, 1996: 16; itálica en el original).

La extensa lista de actividades superpuestas que realiza Surligneur-2 pone en evidencia la desjerarquización de los saberes académicos frente a los cotidianos. Este sujeto que sigue siendo uno en su multiplicidad y/o pluralidad, adquiere espesor político en el gesto de visibilizar sus diferentes posiciones en la sociedad y la construcción de saberes en estos espacios. En esta desjerarquización se combina el legado ideológico de la Revolución y la crítica al patriarcalismo anclado en el campo intelectual.

Como advierte Weinberg (2001), el ensayista se preocupa por insertar su discurso en condiciones de inteligibilidad articuladas en tres espacios: el campo literario específico, el de la cultura en general, y el de las condiciones exteriores ligadas a la "cultura occidental". Este es un problema para los escritores en América Latina, porque las condiciones de inteligibilidad están regidas extraterritorialmente. Esta también es la discusión teórica que plantea Mateo Palmer en este ensayo cuando hace referencia al proceso de gestación del ensayo y cuestiona, desde la periferia (que implica América Latina, Caribe, Cuba), la visión normativa de la posmodernidad impuesta por los centros académicos (EE.UU., principalmente, y Europa) y señala, al mismo tiempo, la paradoja de un discurso que se plantea como antinormativo pero que pretende erigirse como modelo a seguir. En este sentido, el/la sujeto de Ella escribia poscrítica habla en cuanto artista e intelectual y en cuanto miembro de una comunidad cultural delimitada por la nación (Cuba), la región (Caribe) y el continente (América Latina o Nuestra América) y, a su vez, contrapuesta al primer mundo. A lo largo de las páginas del texto se puede observar que existe una concepción de 
"Nuestra América" como una unidad regional y, más aún, una identificación de Cuba con el Caribe por las problemáticas y la historia en común.

\subsubsection{Reflexiones preliminares}

La perspectiva respecto de la/el ensayista propuesta en el epígrafe de este capítulo supone una multiplicidad de vías de acceso al objeto de reflexión, en este caso la posmodernidad, y admite la reunión de un número considerable de materiales pertenecientes a varias ramas del conocimiento humano — la economía, la política, la literatura, etcétera- presentes en Ella escribia poscrítica, texto que se inscribe en una poética transgresora y desestabilizadora. A partir de lo expuesto, coincido con Weinberg (2001) cuando señala que al ensayo no se lo puede definir sólo por sus temas o su estilo, sino por esta tarea a un tiempo creativa, crítica e interpretativa que su autor/a lleva a cabo y por la cual el ensayo entra a su vez en diálogo con un sistema y tradiciones literarias específicas y con un campo cultural mayor, cuyos límites él mismo descubre y delinea. El análisis desarrollado permite entrever la situación de crisis en que emerge Ella escribía poscritica y también intenta convertirse en un disparador para, en una investigación posterior, indagar cómo se inscribe en la línea de ensayos cubanos y latinoamericanos, qué continuidades y qué rupturas se pueden observar. ${ }^{23}$ Con respecto a esto, Rafael Hernández y Rafael Rojas (2002) advierten que en la ensayística cubana de las últimas décadas del siglo XX sobresalen tópicos antes soslayados, como la cuestión de la identidad, la recuperación de obras del pensamiento confinadas u olvidadas, la emergencia de tópicos como la etnicidad, la sexualidad y la marginalidad, el análisis cultural de la política, la nueva emigración y la cultura de la diáspora. Aunque es cuestionable la originalidad de los tópicos mencionados (por ejemplo, la problemática de la

\footnotetext{
23 Por ejemplo, Ella escribía poscrítica retoma algunas cuestiones de la ensayística del XIX, como la problemática de lo regional, lo nacional y las preocupaciones por la estética, pero también tiene otras características, como el tema elegido y la introducción de los capítulos ficcionales que tienden volver lábiles las fronteras de la ficción pura o del pensamiento puro.
} 
identidad), sí es cierto que en este contexto de crisis muchos de ellos se reactualizan. En este sentido, la obra de Mateo Palmer se vincula con otras revisiones críticas del canon narrativo cubano y americano realizadas por escritores como Roberto González Echevarría, Luisa Campuzano, Rafael Rojas, Nara Araújo así como con las relecturas sobre la cultura cubana, latinoamericana y caribeña que realiza Antonio Benítez Rojo en el ensayo La isla que se repite (1989).

En este apartado, además, revisé las figuraciones como escritora y la búsqueda de una opción escrituraria a través de la compleja construcción de las múltiples identidades posicionales del "yo". En el caso de Mateo Palmer, ser mujer ensayista supone una trasgresión que se plantea ya desde el título con el uso del pronombre "ella" que marca la cuestión de género y, al mismo tiempo, la distancia del "yo" que presumiblemente no puede asumir en esta instancia de escritura. En el recorrido de estas páginas reflexioné sobre la forma en que el texto ha retado o reelaborado la configuración patriarcal presente en el ensayo, en general, y en la cultura cubana, en particular; esto se observa, entre otras estrategias, en la necesidad de armar genealogías que permiten leer el texto desde una óptica diferente a aquella en que fueron leídos sus predecesores.

Debido al carácter "abierto" del texto ensayístico, no sería posible considerar esta lectura como la única posible de Ella escribía poscrítica, también porque es un texto híbrido que rebasa cualquier intento de clasificación genérica. En este sentido, Mateo Palmer realiza la misma operación que advierte en el análisis del "Impromptu en Fa de Federico Chopin" incluido en Muecas para escribientes (1987): “[Virgilio Piñera] realiza una audaz síntesis de diferentes tradiciones que borra las fronteras entre géneros, procedencias y niveles de cultura" (Mateo Palmer, 1995: 95). De este modo, el discurso interpela (y es interpelado por) los textos literarios y no literarios que analiza y, en el mismo gesto, está desafiando a la comunidad académica y a los modos de pensamiento que circulan en el ámbito en que 
emerge el texto. Por eso, el análisis pone en evidencia que la escritura es un campo de batalla porque, como señala acertadamente Grüner (2006), en todo ensayo hay una política, en el sentido de que se juega el conflicto de las miradas que se proyectan sobre la cultura, en el caso que nos ocupa, la cultura cubana durante los críticos años del "Período Especial".

\subsection{Desde los blancos manicomios: devorar (para homenajear) la literatura}

La modulación ensayística de Mateo Palmer, el juego con los límites entre la ficción y la realidad, las duplicaciones (a veces deformantes) de los personajes, sus flirteos con la construcción del alter ego de la autora y, sobre todo, la proliferación intertextual, alcanzan el punto álgido en Desde los blancos manicomios (2008). ${ }^{24}$ En esta novela me interesa detenerme en analizar cómo se expanden y resignifican los sentidos del encierro que se pueden anclar en un primer espacio referencial (el manicomio) con sus múltiples implicancias, pero también con sus desplazamientos semánticos: la identidad (de la protagonista) -cuya construcción en la novela pone en tensión la imagen de mujer asociada a la locura, así como también los estereotipos que ligan lo femenino a la reclusión doméstica (Beauvoir 1949) y al silencio-, la isla e incluso el Caribe -espacios que adquieren espesor, principalmente, a partir del uso de los epígrafes que hacen proliferar las múltiples posibilidades de encierro. ${ }^{25}$

La proliferación intertextual se convierte en una de las claves de lectura vislumbrada no sólo en el título, que puede aludir a unos versos de Ángel Escobar (1957-1997), o al libro de poemas - Los altos manicomios - publicado por el cubano Pedro Marqués de Armas

\footnotetext{
24 Primera edición: La Habana, Letras Cubanas. Esta novela obtuvo el Premio Alejo Carpentier 2008 y el premio de la Crítica 2009. Las citas pertenecen a la segunda edición realizada en 2010.

25 Aunque no lo desarrollo aquí, también resulta factible pensar la ciudad (La Habana) como un posible espacio al que se desplaza el encierro.
} 
en 1993, sino también en los epígrafes de apertura y cierre de la novela, fragmentos de poemas de dos poetas cubanos que se suicidaron. ${ }^{26}$ Por esos motivos presentes en los umbrales del texto, por la expansión intertextual, el libro puede pensarse como un homenaje aunque también como configuración de un homenaje mayor: a José Lezama Lima y su novela Paradiso (1966) que, presentes en las historias y en la voz de Gelsomina entablan un recurrente ejercicio intertextual con el universo lezamiano. ${ }^{27}$ Aunque las citas, alusiones y menciones también proliferan en relación con otros referentes: Virgilio Piñera, Nicolás Guillén, Alejo Carpentier, Miguel Matamoros, Gertrudis Gómez de Avellaneda, Fernando Ortiz, Lydia Cabrera, Jacques Roumain, Aimé Cesaire, John Lennon, la Condesa de Merlín, Julia de Burgos, Saint-John Perse, Plácido, Salvador Redonet Cook, Sor Juana Inés de la Cruz, por nombrar sólo algunos.

El primer capítulo, "Gelsomina en los altos manicomios blancos", comienza con unos versos de "Promesa", de Cuando sali de La Habana (Zaragoza 1997) del poeta cubano Ángel Escobar (1957-2002):

¿por qué me desplazan, me sacan de mi centro, me ofrecen los altos manicomios blancos, y ante el muro me veo así y me aterro, alto el muro y alta la sola poquedad de mis cuidados... (Mateo Palmer, 2010: 7).28

26 La tasa de suicidio en Cuba es una de las más altas del mundo. Varios miembros de la élite político/intelectual se han suicidado. Sobre esta controvertida problemática consultar http:// cubaunderground.com/cuba-underground/ensayos/el-bello-pais-de-la-muerte

${ }^{27}$ En 2002, Mateo Palmer publica Paradiso: la aventura mítica, ensayo que ganó el Premio Alejo Carpentier ese mismo año. En la nota al pie número 2 de la introducción aludí a la operación institucional de canonización de este escritor. Otra cuestión es la influencia que ejerce en los escritores y escritoras, fundamentalmente, a partir de la década del noventa. Tal vez más que influencia debería hablar de presencia insoslayable (como alguna vez mencionó Guadalupe Silva en una conversación informal sobre este tema) porque más que utilizar estrategias lezamianas o entablar relaciones intertextuales, entre otras operaciones, simplemente alude a su obra. Creo que esta es una línea que ameritaría una investigación. Agradezco a Guadalupe su paciencia y generosidad para transmitirme sus opiniones y sugerirme bibliografía que me permitiera indagar en el universo lezamiano.

28 “Oh, estrella del sur, qué quiere decirme/ tu silencio. Estas palabras traicionan mi mudez-/anhelan tu fijeza, hacen señales. Mueve/algo en mí, que no puedo pararme así y correr/Quieren ponerme vicaria blanca en las ojeras/Alguien habrá que yo pueda mirar como te miro/a ti. Por qué me desplazan, me sacan de mi centro,/me ofrecen altos manicomios blancos, y ante el muro/me veo así y me aterro, alto el muro y alta/la sola poquedad de mis cuidados. Ando/como sobre ascuas, sobre sierpes sanguinolentas, torpes-/el día y la noche abusan, rompen, llegan./Sólo alcanzo un atroz significado en vilo-/tú brillando. Déjame esa ilusión; no esperes/cantos. Me someto a tu don sin parabienes". En: http://www.olifante.com/poemas.php?id=54 
Mientras que el capítulo final, "Gelsomina frente al mar", se abre con versos del soneto "Me ha dado diez mil liras" del poemario Sonetos a Gelsomina de Raúl Hernández Novás (1948-1993):

Ma, dove vai?, ¿adónde? Gelsomina

¿Por qué estás frente al mar arrodillada? (Mateo Palmer, 2010: 233).

Los nombres que elige para iniciar y cerrar la novela así como para el intertexto del título y para el nombre del personaje principal -Gelsomina- corresponden a los de dos poetas que se suicidaron. Poetas que tal vez fueron sus amigos, sus lectores o ella su lectora (después de todo no es difícil pensarlo en un ambiente literario como el habanero). Y no es casualidad, entonces, que la locura y sus bordes -la pérdida de la identidad y del sentido de la vida - se configuren en los ejes centrales de esta historia. Aquí la protagonista es Gelsomina, cuyo nombre es una clara alusión al inmortal personaje de La strada (1954) de Federico Fellini pero también refiere a los Sonetos a Gelsomina de Raúl Hernández Novás (obra que también entabla un diálogo con la película y cuya dedicatoria inicial está en clave con la película: “a M.E. En recuerdo de la tarde del 8 de noviembre de 1982, en que vimos juntos La strada, de Federico Fellini”; Hernández Novás, 2007: 404).

Dividida en cuarenta y un fragmentos (quizás mejor que capítulos), la estructura se ordena en una línea temporal cronológica que reconstruye el presente de la protagonista. Gelsomina o María Mercedes Pilar de la Concepción llega por voluntad propia a un manicomio y su historia se va construyendo a partir de su vOz y de las voces de otros personajes de su entorno, que dibujan los antecedentes de la enfermedad mental: su hijo, Clitoreo; su madre, la Marquesa Roja; su hermana, María Estela que escribe cartas desde Miami; el Poeta Suicida, quien en una de las partes connota como un narrador omnisciente que observa e interviene sobre el presente de la protagonista; y la paciente de 
la cama 23, que a veces aparece como una compañera de sala pero que también podría ser identificada como alter ego de la protagonista. El núcleo argumental, enmarcado en la difícil cotidianeidad del llamado "Período Especial", está configurado por las visiones de Gelsomina desde el manicomio y la lucha por reconstruir su identidad desde esta “institución total" (Goffman, 2001: 31). Esa identidad también se configura a partir de la estructura coral de los relatos de los demás personajes de la novela que se repiten en forma consecutiva, luego de las secciones dedicadas a los avatares de la protagonista en su llegada y estadía en el manicomio. La sección centrada en las peripecias de la protagonista narra reflexiones que se disparan a partir de los distintos espacios que su mente escoge: en los altos manicomios, en la costa, en el jardín de la ciudad, en el camino, con las brujas, en el mapa de Europa, en la Universidad Blaise Pascal. Los apartados que configuran esta estructura coral se intercalan, con un orden regular y no sólo aportan una visión de la alienada sino que también permiten reconstruir sus propias historias personales. Así, después del apartado en tercera persona dedicado a las vivencias de Gelsomina en el manicomio, el relato que sigue es "La carrera interminable" que se centra en su hijo, apasionado por el ejercicio de correr, y en el que una tercera persona reconstruye la relación madre/hijo desde la infancia y cuenta, al mismo tiempo, la manera en que Clitoreo (uno de los tantos sobrenombres) se desenvuelve ante la ley que rige la calle, los problemas amorosos y las peleas que se desencadenan. Luego sigue una parte dedicada a la reflexión filosófica sobre lo insular desde la narración de una tercera persona que se centra en las lecturas, reflexiones y proyecciones que Gelsomina realiza durante su estadía en el manicomio. Continúan los monólogos en primera persona de la madre, la Marquesa Roja, quien se encuentra hablando con una doctora que la interroga sobre su hija. Pero sólo accedemos al relato en que narra anécdotas de la infancia de su hija, actitudes extrañas que delatarían más tarde su enfermedad, y a cómo, para ella, la locura está asociada a la lectura 
de determinados libros. En "Cartas a Gelsomina" aparece la correspondencia que le envía su hermana María Estela desde Estados Unidos dando cauce al recuerdo de la infancia juntas (para subrayar las diferencias entre ambas: lecturas, maldades de niños, etcétera) y los avatares de la vida en una ciudad en la que vive desde hace doce años y donde trabaja como docente, ciudad que admira pero a la que no termina de acomodar su propia identidad.

\subsubsection{Confinar la locura}

En Desde los blancos manicomios, la presencia de la locura, ya exhibida en el título, es el tema central que, a lo largo de las páginas, se convierte en una forma de introspección del sujeto mismo. Si tenemos en cuenta la producción ensayística de Mateo Palmer, no es casual que la protagonista de su ficción sea una enferma mental en la que la autora despliega sus conocimientos como investigadora y crítica a partir del dominio de fuentes literarias sobre la locura, como Erasmo de Rotterdam y Miguel de Cervantes. Sin embargo, aquí la locura toma cuerpo en la figura de una mujer, hecho que adquiere significanción si se piensa en un continum temporal en el que en su cuerpo se ha plasmado lo diferente como motivo de exclusión pero también como espacio desde donde es posible enunciar (la) verdad. Históricamente, los que eran catalogados por la razón como locos han sido excluidos, junto con el resto de las figuras de la sinrazón (el ladrón, el mendigo, la puta, la bruja). En su Historia de la locura en la época clásica, Michel Foucault analiza estas restricciones y parte de la articulación de prácticas del decir (los diferentes discursos sobre la locura a través de la historia), y del hacer (entendido como las distintas formas de internación) para analizar con qué criterios se ha ido delimitando la locura a lo largo de la historia (por ejemplo, el castigo, la moral, el pecado, la falta, la animalidad). De esta manera Foucault indaga en las cuestiones materiales que históricamente han configurado las causas de la locura a la que entiende como una construcción social y no una entidad natural. Realiza la arqueología de la psiquiatría, es decir, en qué condiciones y con qué intereses nace esta ciencia y, de esta 
forma, realiza una historia de los límites, de cómo una cultura rechaza algo convirtiéndolo en lo "otro" y encerrándolo.

El manicomio constituye uno de estos espacios en los que se encierra al que se ubica en los límites de la sinrazón. Erving Goffman incluye estos lugares dentro de lo que define como "instituciones totales", es decir, aquellos espacios "donde un gran número de individuos en igual situación, aislados de la sociedad por un período apreciable de tiempo, comparten en su encierro una rutina diaria administrada formalmente" (Goffman, 2001: 13). ${ }^{29}$ En su estudio, clasifica a las instituciones totales en cinco grupos: las encargadas de cuidado de las personas incapacitadas e inofensivas (hogares de ancianos, ciegos, huérfanos, etc.), las que se dedican al cuidado de personas que no pueden valerse por sí mismas y que además son consideradas una amenaza para la comunidad (hospitales de enfermos infecciosos, manicomios y leprosarios), las que protegen a la comunidad de personas que atentan deliberadamente contra ella (cárceles, presidios, campos de trabajo), las de carácter laboral (cuarteles, barcos, campos de trabajo, colonias, servicio en mansiones señoriales) y los espacios para formación de religiosos (abadías, monasterios, conventos). Este sociólogo define como instituciones totales aquellos espacios en los que se produce una ruptura de las barreras que separan los ámbitos de dormir, jugar y trabajar, es decir, donde se manipulan las necesidades de las personas mediante la organización burocrática de conglomerados humanos indivisibles y se establece una escisión básica entre internados (la gran mayoría) y supervisores. Los primeros tienen limitado el contacto con el exterior y se sienten inferiores, débiles, culpables, mientras que los supervisores se sienten por encima, dominando a los reclusos.

29 Goffman realiza su estudio a partir de un trabajo antropológico en el que se integra a las instituciones para observar minuciosamente los comportamientos sociales de interacción que se dan en una institución total como el manicomio desde dentro. A partir de esta experiencia describe los procesos de agresión al "yo" como identidad subjetiva, la pérdida injustificada de derechos para los internos, la dudosa efectividad terapéutica de los manicomios, las representaciones de reclusos y funcionarios en la escena social del internado, etc. 
Desde los blancos manicomios se inicia con el relato de la degradación del cuerpo de la protagonista y entabla una analogía con los perros que viven cerca de la puerta principal del manicomio; perros enfermos, llenos de sarna, lamiendo sus llagas, agonizando cerca del cuerpo de Gelsomina que se arrastra junto a los hocicos de los animales. En esta escena inicial, la protagonista se identifica con estos seres y, de esta forma, adquiere rasgos monstruosos al producirse una conjugación entre el reino animal y el humano. ${ }^{30} \mathrm{La}$ degradación física de los animales es su propia degradación. Los perros son los "tristes cancerberos" -Zoar, Baldovina y Truni, en clara alusión a personajes de Paradiso de José Lezama Lima - ${ }^{31}$ con quienes dialoga “en un lenguaje ajeno, olvidada, negada quizás la lengua materna" (Mateo Palmer, 2010: 7). Los perros ocupan el espacio fronterizo entre el afuera y el adentro de la locura; a ellos interroga y les plantea sus dudas sobre entrar o no al manicomio. Comienza así “el coloquio con los perros” (Mateo Palmer 2010: 8) en explícito intertexto con una de las novelas ejemplares de Miguel de Cervantes. ${ }^{32}$ La asunción de la propia locura al elegir el manicomio como espacio es evaluada por "el don de los ojos penetrantes" (Mateo Palmer, 2010: 8) de los perros, como una huida, pero también como "un exilio forzado de su propia mente" (Mateo Palmer, 2010: 8). Luego de escuchar los consejos de los perros sarnosos, Gelsomina consulta la opinión de otro ser marginal que habita el espacio fronterizo: el "anciano negro que sostenía el peso de sus carnes miserables y enfermas sobre un báculo mortencino" (Mateo Palmer, 2010: 11). La descripción de este

\footnotetext{
${ }^{30}$ En Los anormales, Foucault continúa sus estudios de las relaciones entre saber y poder. Esta vez se centra en los individuos considerados peligrosos a quienes, en el siglo XIX, se denomina "anormales". Define sus tres figuras principales: los monstruos, los incorregibles y los onanistas. La primera de estas figuras es la que permite pensar la configuración de Gelsomina en el inicio de la novela. las figuras de lo que Foucault llama "lo monstruoso" es una noción jurídica en tanto lo que define al monstruo es el hecho de que, en su existencia y su forma, no sólo viola el pacto cívico, sino también las leyes de la naturaleza (en el caso de la protagonista de la novela, es la identificación con el mundo animal).

31 Zoar es un criado de la familia de José Cemí. Truni es la mujer de Zoar, también empleada del padre de José Cemí. Baldovina es el aya del niño Cemí. Ambos conforman la Trinidad, y son quienes realizan un conjuro en el primer capítulo para salvar a Cemí de un ataque de asma.

${ }^{32} \mathrm{Su}$ título original es Novela, y coloquio, que pasó entre Cipión y Berganza, perros del Hospital de la Resurrección, que está en la ciudad de V alladolid, fuera de la puerta del Campo, a quien comúnmente llaman "Los perros de Mabudes"
} 
anciano, al que ella alude como "padre", tiene rasgos de Elegguá (uno de los Orishas de la religión yoruba). Se encuentra sentado en la entrada del manicomio en coincidencia con el rol del dios afrocubano, dueño de los caminos y el destino, por ser quien cierra o abre el astral para la felicidad o infelicidad de los seres humanos. ${ }^{33}$ Sus consejos encaminan al reencuentro de Gelsomina con la ciencia y con sus efluvios medicinales, como búsqueda de sanación.

Gelsomina, finalmente, elige ingresar al manicomio (a diferencia de lo habitual en que el ingreso a estas "instituciones totales" ocurre sin el consentimiento del sujeto). Esta decisión viene acompañada por sucesivas agresiones al "yo", semejantes a las descriptas por Goffman en su investigación: cómo se mortifica habitualmente y por distintos procedimientos la identidad subjetiva del interno (anulación del rol social, obediencia ciega, humillaciones en el trato con los superiores, desposeimiento de objetos personales, uniformización, control de movimientos, violaciones de la intimidad, castigos y amenazas, malos tratos). ${ }^{34}$ La elección del adentro significa la asunción de la locura pero también es un gesto de autodestrucción por la pérdida de la identidad y la enajenación del propio cuerpo que ya se percibe antes del ingreso:

Gelsomina recorría los espacios de la casa como un alma en pena, la mirada perdida, el pelo de medusa sobre la frente, los brazos colgando a ambos lados del cuerpo: ya de corcho, ya de aserrín, ya de trapo, marioneta de hilos cortados. Hilos cortados que ahora pendían de sus extremidades inertes y barrían el piso en un sonámbulo y domesticado itinerar, olvidados de la tensión espigada que antes les permitían formar el huevo luminoso que envolvía su silueta (Mateo Palmer, 2010: 90).

En el manicomio, este cuerpo disociado/monstruoso se convierte en objeto de análisis de los médicos que luchan contra la "desorbitada fuga” (Mateo Palmer, 2010: 24) provocando

\footnotetext{
33 Es el primero en ser llamado en todo acto religioso o festividad y el último en despedirse. Los adoradores lo consideran el inicio y el fin de todos los caminos, el nacimiento y la muerte, el bien y el mal. Dentro de las funciones más importantes que tiene esta deidad es la de ser mensajero de los dioses. Si él lo quiere, nada de lo que se le ofrenda a estos les llega. Consultado en: http://www.ecured.cu/index.php/ Eleggu $\%$ C3\%A1

${ }^{34}$ Goffman analiza los efectos devastadores que todos estos rituales de agresión tienen sobre el yo y, en el caso de los enfermos mentales, cómo estas estrategias son nocivas para la salud mental.
} 
desmayos, suministrando inyecciones tres veces por día, sujetando el cuerpo: "Las sombras de las rejas, que se reflejaban en los cristales de los amplios ventanales, no dejaban dudas acerca de su condición de reclusa, con una libertad tan restringida que apenas podía tomar alguna decisión por sencilla que fuera” (Mateo Palmer, 2010: 23).

Elegir el adentro también implica optar por la insularidad interior. Esto puede pensarse a partir de la identificación de Gelsomina con Bárbara (personaje de Jardín, novela de Dulce María Loynaz) cuando recuerda que este (auto) reconocimiento de la locura se inicia en los bordes entre el sueño y el despertar, es decir, cuando despierta de un sueño y aún siente que su cuerpo flotaba sobre azules y transparentes aguas y su cama era una balsa que le permitía deambular por su cuarto. En esta descripción del sueño/realidad, el agua (en diálogo intertextual con "Un son para niños antillanos" y "Agua del recuerdo" de Nicolás Guillén), ${ }^{35}$ es el medio para el recuerdo o reconstrucción de un pasado individual, pero también histórico, si se tiene en cuenta la asociación (y el desplazamiento) que a lo largo de las páginas se realiza entre el cuerpo, La Habana, Cuba y el Caribe. Al respecto, observa Gelsomina que

Se levantó del lecho, y al calzar las chancletas verdes tuvo la fuerte sensación de que el espacio había cambiado. No existían los límites. No había fronteras. Se asomó a la terraza. Supo entonces que su casa era parte del gran jardín de la ciudad. La puerta de su hogar no marcaba el tránsito de un espacio íntimo, doméstico, privado, cerrado, a otro público, colectivo, abierto, agórico. Ambas zonas, antes bien delimitadas, formaban parte de un continum sin oposiciones ni conflictos (Mateo Palmer, 2010: 12-13).

La casa/jardín marca el paso donde lo privado y lo público se tocan y, en este caso, se funden en un encuentro donde lo uno y lo otro se disuelven. Y donde además, el mar es un continuum de ese jardín --"El amplísimo vergel de la ciudad parecía extenderse hacia el infinito, continuar incluso más allá del muro que ahora la separaba del mar, a través de

\footnotetext{
35 “Agua del recuerdo, voy a navegar, pensó Gelsomina junto con el poeta, y continuó bogando en su balsa, barco de papel que andaba por el mar de las Antillas, sin capitán y sin timonel. Y así pasaron islas, islas, islas, muchas islas, siempre más, en un son para niños antillanos que volvía a adormecerla con el arrullo del mar, viaje al mundo de la infancia" (Mateo Palmer, 2010: 12).
} 
volutas de coral y arabescos de diente de perro que se confundían con las espumosas olas" (Mateo Palmer, 2010: 14) lo que permite identificar la isla en/como el Caribe, cuestión sobre la que volveré.

\subsubsection{Construir la identidad (múltiple)}

La elección de una protagonista insana que, en un espacio en conflicto (como es el manicomio), reconstruye desde la introspección y las heterogéneas lecturas sobre el Caribe una identidad múltiple, puede pensarse como una estrategia que persigue recrear (o por lo menos desestabilizar) los discursos de una Cuba en crisis donde conviven simultáneamente (y no sin conflicto) un canon establecido junto a una literatura que pugna por emerger y/o insertarse dentro del canon. El uso de los epígrafes, la prolífica intertextualidad, así como las lecturas de Gelsomina, pueden ser pensados como una forma de homenajear, de insertarse en una tradición literaria pero, al mismo tiempo, transformarla y crear una nueva tradición, al ponerla en juego y en tensión con una multiplicidad de citas.

En las páginas de la novela se realiza un doble movimiento en la construcción de la identidad de la protagonista. Por un lado, a partir del discurso de otros personajes cercanos a su vida (la madre, el hijo, la hermana) y, por otro, mediante la reconstrucción que realiza la propia Gelsomina: indagación sobre su pasado pero, también, volver a pensar (se) a partir de su presente límite en esta "institución total".

El discurso de su madre, presentada como la "Marquesa Roja", se realiza desde una primera persona que dialoga con una doctora del manicomio, pero como sólo accedemos a su voz, se puede considerar un monólogo. En una interpretación que recuerda a Cervantes, considera que fue la lectura (de determinados autores) el motivo de la sin-razón de Gelsomina.

Una vez traté de leerme un libro que a mi hija le encanta, de Lezama Lima. Ahí volví a ratificar lo que siempre he pensado: los autores que lee mi hija le hacen mucho daño, es como si echaran leña al fuego que ya está ardiendo dentro de esa cabeza. 
Cogí el novelón ese, Paradiso, y enseguida me di cuenta de todo lo que le sobraba. Había muchas palabras, frases enteras que estaban de más. No pude contenerme y empecé a tachar. Para mí arreglar lo que leo es como hacer crucigramas, lo disfruto muchísimo. A veces, donde Lezama ponía una palabra, yo le ponía otras más sencillas. Varias veces tuve que ir al diccionario, pero, sobre todo, taché y taché. Taché muchísimo (Mateo Palmer, 2010: 190-191).

La madre, entonces, se puede pensar desde su función de censora literaria vinculada con la reescritura porque, además, su trabajo siempre ha sido "arreglar lo que escriben otros" (Mateo Palmer 2010: 190): secretaria, taquígrafa-mecanógrafa en inglés y español.

Su hermana Estela se dirige a ella como "María" en cartas llenas de humor que traslucen la cotidianeidad de su vida lejos de Cuba, los avatares de su trabajo, las ayudas que dispensa a su familia cubana y también, su malestar. Para Estela la locura está asociada a las condiciones socio-económicas cotidianas que se viven en la isla. Sus sueños siempre rememoran la escasez y las penurias pasadas en Cuba. Para ella "no es posible vivir en medio de tantas escaseces sin que se produzcan descompensaciones nerviosas" (Mateo Palmer, 2010: 197)

La configuración de una identidad escindida se realiza ya desde la disociación entre el nombre de pila y el que ella elige para identificarse en su presente -Gelsomina-, nombre que está en diálogo con personajes ficcionales de Fellini y de Hernández Novás. La no-identificación con la elección materna significa una ruptura con la tradición femenina familiar ya que su nombre remite a sus dos abuelas y sus tías: María Mercedes Pilar de la Concepción. Desde niña reniega de su nombre, pero recién en la adultez se produce la identificación con Gelsomina en homenaje al amigo el poeta que se suicidó: recuerda la madre que "El problema del cambio de nombre empezó después, cuando un antiguo compañero suyo en la Escuela de Letras se quitó la vida. Él era poeta, ¿`sabe?, y tenía un libro de sonetos dedicados a una muchacha que se llamaba así, Gelsomina” (Mateo Palmer, 2010: 28). En ese momento, en medio de rituales realizados en su casa por la muerte de su amigo, adopta la decisión de llamarse así. Luego, cuando vuelve a la cordura (según la 
visión de la madre), no reitera ese deseo hasta el momento en que se recluye en el manicomio. Ahí, en ese espacio configurado en torno a la locura, explicita que ese es su nombre y, a partir de esta identificación se produce el proceso de re-construcción de su identidad. Su estadía en el manicomio y el proceso de reconstrucción identitaria se libra en los apartados que anclan a la protagonista en espacios determinados. $\mathrm{Y}$ es en estos recorridos por diferentes espacios (la costa, el jardín, el camino, el mapa de Europa), donde Gelsomina parte generalmente de su presente cotidiano en el manicomio para desplazarse, luego, hacia hechos puntuales de su pasado que le permiten reconstruir su identidad.

"Gelsomina en la costa" es precedido por un epígrafe de la novela Las tres mitades de Ino Moxo y otros brijos de la Amazonía de César Calvo (Perú 1940-2000): “Y me ordenó escribir, desde mi otra persona, este viaje dictado por la droga sagrada" (Mateo Palmer, 2010: 35). Dichas palabras que remiten a un doble viaje (físico y mental, producto del uso de drogas alucinógenas utilizadas por chamanes y brujos) sirven como desencadenante de la narración centrada en una conversación entre las pacientes, acerca de los beneficios de las plantas medicinales. ${ }^{36}$ Gelsomina coloca su viaje en el fluir horizontal de las palabras, en su sonido ya que, debido a la inmovilidad del cuerpo, es el único viaje que puede realizar. Una tercera persona narra imágenes y sonidos asociados a los efectos de las fuertes medicinas suministradas por la enfermera, que sumergen a Gelsomina en un sueño en el que aflora el uso de la primera persona para inmiscuirse en los dobleces de ese "yo" y que la traslada a su infancia: "Entonces llegó la música: un canto entonado en punto carvajal, que arrastraba las notas de la melodía en una especie de melisma quejumbroso. Cuando la melodía concluye, estoy sentada en un sillón frente al jardín” (Mateo Palmer, 2010: 36). Luego, cuando termina el sueño y los ruidos de la cotidianeidad en el manicomio

\footnotetext{
${ }^{36}$ La alusión a la droga sagrada también se puede conectar con el ensayo "Artaud y el peyotl" de Lezama Lima así como con la fascinación que tenían por el peyotl los surrealistas, los origenistas, Alfonso Reyes, por nombrar algunos.
} 
comienzan, vuelve el uso de la tercera persona: "Cada vez era más nítido el trasiego de los jarros y los cubiertos, el ruido de las cucharas contra las bandejas de metal. Gelsomina trató de ganar la superficie, de remontar el eje de verticalidad, esta vez nadando hacia arriba con mayor fuerza" (Mateo Palmer, 2010: 37). Pero nuevamente se sumerge en el espacio del ensueño donde se hace presente la enajenación cuerpo/alma:

Cada objeto -los libros, los papeles, los casetes—-parece resisitirse al viaje. Hacen un reclamo que no puedo detenerme a escuchar. Finalmente, yo misma entro en la maleta y apago todos mis deseos, todos mis proyectos. Cierro la tapa y siento que alguien la fija por fuera con un candado: me da igual. No necesito aire, ni mayor cantidad de espacio. Soy un fardo que no quiere partir, pero que de cualquier modo va a emprender el viaje (Mateo Palmer, 2010: 38).

La primera persona recupera los objetos que remiten a su pasado y lo significan (el vestido amarillo, la saya mexicana, el pulóver de la discordia), son los que debe colocar en una maleta para emprender un viaje que no desea, un viaje asociado a la reconstrucción de la identidad perdida. Y sin embargo, se inicia aquí, en y desde este presente en que su cuerpo inerme "ausente del alma, que ha permanecido confundida en la noche insular" (Mateo Palmer, 2010: 39) yace en la maleta-ataúd.

"Gelsomina en el jardín de la ciudad” comienza con un epígrafe de María Zambrano "Mas lo grave es ser un extraño para sí mismo, haber perdido o no haber llegado a poseer intimidad consigo mismo; andar enajenado, huésped extraño en la propia casa" (Mateo Palmer, 2010: 63) que remiten a La confesión: género literario (1943). Y nuevamente el epígrafe es el anclaje del texto en dos sentidos: en primer lugar porque se puede pensar a locura como un salir del "yo", el andar enajenado en el propio ser, exiliado de sí mismo; pero también como algo con capacidad de anclarse en algo material ya que en este apartado se narra la transgresión de los espacios en el ámbito doméstico donde los objetos subvierten el orden (invisible) del hogar, como resultado de las dificultades económicas: 
Si el portal, lejos de ser el sitio del placentero descanso crepuscular donde la conversación familiar fluía avivada por la suave brisa, se había convertido, dada la ausencia absoluta del combustible adecuado, en el lugar donde se encendía la fogata para ablandar los frijoles y para la destilación de la inefable fragancia de las hojas del naranjo, y en el comedor yacía el blando lecho donde reposaba el cuerpo fatigado durante la noche, confiado en que su reposo no sería perturbado por la lluvia que violentaba las frágiles ventanas del cuarto (Mateo Palmer, 2010: 63-64).

La locura puede ser asociada a la abrumadora cotidianeidad, las restricciones, el desmoronamiento de lo esperable, la pérdida de la lógica, es decir, la locura se podría trasladar o extender también a la ciudad y sus habitantes. Frente a este caos, Gelsomina imagina y configura el orden y la tranquilidad a partir de la disposición (y posesión) de determinados objetos - una amplia y pulida mesa de caoba, cubierta por la transparencia y el brillo de un cristal que refleja la potente luz de una lámpara pendiente del techo, unos cuantos libros, blanquísimo papel y lápices de puntas afiladas-y acciones -Gelsomina leía, Gelsomina estudiaba, Gelsomina escribía. Estas alusiones al espacio ideal para el conocimiento, el recogimiento y el pensamiento (el "cuarto propio" del que hablara Virginia Woolf) se contraponen a la precariedad de lo cotidiano en la isla, donde una antigua puerta sobre barriles sirve para amontonar "libros, viejos papeles de gaceta, plumas quebradas, lápices sin puntas, tazas de café, cucharas, hormigas, y algún que otro residuo de comida por aquello de que el cuarto también era el comedor, y la mesa de estudio una bandeja triclínea" (Mateo Palmer, 2010: 65).

La deglución antropofágica de las teorías se hace presente aquí cuando, en vez de tomar directamente la noción de acontecimiento de Iuri Lotman, opta por pensarla a partir de las enseñanzas del (en alusión al crítico cubano Salvador Redonet Cook) "Negro de los dientes de oro" (Mateo Palmer, 2010: 66) quien ponía en práctica múltiples identidades para integrarse a cualquier entorno:

la noción de acontecimiento depende claramente de la estructura espacial y de que un suceso solo alcanza esta condición cuando implica un desplazamiento a través del límite semántico. En este punto, el teórico estonio era muy claro: la transgresión del límite es imprescindible para conformar un argumento (Mateo Palmer, 2010: 66). 
Esta teoría que cruza el pensamiento de Lotman y la práctica de Redonet Cook, le permitió volver a mirar el caos interior desde otra perspectiva y tratar de deducir una clave que consistió en la necesidad de destruir fronteras, difuminarlas, romper los límites entre el adentro y el afuera. Ruptura material de los límites físicos entre lo doméstico y lo público, pero también entre el interior del ser y el exterior: "Hay que abrir todas las puertas, Gelsomina, ese era el mensaje cifrado" (Mateo Palmer, 2010: 69) y, de este modo, el jardín (referido en el título de este apartado), el espacio fronterizo entre el hogar y la ciudad, difumina los límites del hogar y convierte la ciudad toda en un vergel.

"Gelsomina en el camino" acude nuevamente a un epígrafe de María Zambrano: “...y la inmovilidad en el ser humano es intrascendencia. Conocerse es trascenderse. Fluir en el interior del ser" (Mateo Palmer, 2010: 89) que pertenece a De la aurora (1986) en el que la filósofa reflexiona sobre el sentido de su propio pensamiento. En la obra original, las palabras aluden a la aparición de algo, un suceso o una presencia que saca al sujeto de sí, de la situación en la que está apresado su conocimiento, y que le genera inmovilidad. ${ }^{37}$ En este sentido, la inmovilidad sería la falta de conocimiento, o de crecimiento en el conocimiento. $\mathrm{Al}$ anclar estas palabras en este apartado, la inmovilidad se puede pensar en función del cuerpo de Gelsomina, cuerpo cuya movilidad se reduce al espacio circunscripto por la lógica de la "institución total", aunque también la reconstrucción de la identidad de la protagonista se vislumbra a partir de un autoconocimiento. Un narrador en tercera persona reconstruye uno de los momentos límites en que Gelsomina se codeó con la muerte, pero logró correrse de esa frontera cuando intervino el Suicida (especie de entidad protectora que la acompaña y cobija), y logró que se identificara con un perro moribundo. Ese animal, infundido de muerte pero aún con un halo de vida, le permitió reflexionar sobre su propia situación:

\footnotetext{
${ }^{37}$ Consultar La razón en la sombra. Antología critica de María Zambrano (2003: 139).
} 
Aproximarse era tentar a la muerte y coquetear con ella: tenía miedo del contagio, de la herida en los ojos, de la mordida prognata. Sin percatarse recordó el poema: como una ternera acosada por tábanos, tras la legaña la sorprendió el milagro mortecino: más antigua y oscura que la muerte, a su lado, coronada de moscas, estaba la vida. Fue entonces cuando descubrió la mirada tierna de la bestia y comprendió que ambos eran parte de la misma unidad y de un destino común: ella con su ánima enferma, él con su cuerpo llagado (Mateo Palmer, 2010: 93)

Nuevamente la salva la apelación a la literatura: en este momento límite, la deglución del conciso y fulgurante poema “Ternera acosada por los tábanos” de la poeta peruana Blanca Varela se convierte en su tabla de salvación. ${ }^{38}$ Lo mismo sucede con la alusión a versos del poeta Suicida y de César Vallejo (poeta admirado por Hernández Novás) ${ }^{39}$ : en ninguno de los tres casos se nombra al poeta pero sus palabras se cuelan en el proceso de interpretación de los hechos y en la reconstrucción de su identidad; por ejemplo, "Observó fijamente la piedra y recordó los versos del Suicida: esta pequeña piedra del camino fue una estrella fugaz: cayó apagada y hoy recuerda, entre lodos ignorada, nuestra casa y se empiedran los caminos" (Mateo Palmer, 2010: 94) que juega con versos literales y reconstruidos del poema "Esta pequeña piedra" de los Sonetos a Gelsomina antes referidos. Y también, "Hasta que encuentre a cada minuto en mi calzado lo que he buscado en mi mano noche y día, de esta piedra nacerá la brújula que orientará el arco tendido hacia las estrellas desde mi orilla insular. ¿Tan pequeña soy, acaso, que hasta mis propios pies así me pisan?” (Mateo Palmer, 2010: 94), palabras que remiten a versos de "Poema para ser leído y cantado" en Poemas humanos (1938) de Vallejo.

38 Dice el poema que pertenece a Ejercicios materiales (1993): “podría describirla/¿tenía nariz ojos boca oídos?/¿tenía pies cabeza?/¿tenía extremidades?/sólo recuerdo al animal más tierno/llevando a cuestas/como otra piel /aquel halo de sucia luz/voraces aladas/sedientas bestezuelas/infamantes ángeles zumbadores/la perseguían/era la tierra ajena y la carne de nadie/tras la legaña/me deslumbró el milagro mortecino/la víspera el instinto la mirada/el sol nonato/¿era una niña un animal una idea?/ah señor /qué horrible dolor en los ojos/qué agua amarga en la boca/de aquel intolerable mediodía /en que más rápida más lenta/más antigua y oscura que la muerte/a mi lado/coronada de moscas/pasó la vida".

${ }^{39}$ Hernández Novás trabajó desde 1973 y hasta su muerte en el Centro de Investigaciones Literarias de la Casa de las Américas. Allí realizó la edición crítica de la poesía completa de César Vallejo (Arcos 2007: 7). Además, escribió el exhaustivo prólogo "Vida de un poeta" que aparece en la publicación Poesía completa de César Vallejo. Buenos Aires: Arte y Literatura, 1988. Digitalizado en: http://iberoamericanaliteratura.files. wordpress.com/2012/05/literatura-latinoamericana-poesia-completa.pdf 
“Gelsomina y las brujas" apela a versos de Luis Palés Matos "Pescad la luna, pescad la luna,/ el monstruo pálido que hechiza/ nuestra caza y nuestras mujeres/ en la soledad de la isla" (Mateo Palmer, 2010: 113) de "Candombe" en Tuntún de pasa y grifería (1937). Ya el título dispara la asociación que históricamente se ha realizado entre las mujeres y las brujas. Este vínculo adquiere densidad en el anclaje en los versos de Palés Matos y su recuperación de la identidad negra y, luego, en las primeras líneas del apartado cuando la construcción oracional recupera la musicalidad de la poesía de Palés Matos para comenzar a reflexionar en torno a las brujas: la posesión y uso de una escoba para barrer el portal de su casa, hacen que Gelsomina se asocie a las brujas y se pregunte por qué usan escobas y por qué ese objeto se convertía en símbolo fálico:

¿Sería por el gesto repetido ad infinitum de mover el instrumento acompasadamente sobre las baldosas del piso? Brum brum brum, una y otra vez las cerdas sobre el suelo; brum brum brum, fuera los despojos caídos, las migas de pan, las colillas de cigarro; brum brum brum, a la basura las hojas muertas, la tierra que saltó de las macetas, la guata de los cojines (Mateo Palmer, 2010: 113).

En este apartado, las asociaciones y relaciones intertextuales se producen con personajes femeninos: la Cenicienta, Sor Juana, las brujas insulares (Tituba, Annie Palmer). En este sentido, los actos cotidianos y rutinarios realizados (históricamente) por las mujeres se convierten en actividades que permiten el fluir del pensamiento (reminiscencia de Sor Juana) porque al ser mecánicas se repiten automáticamente y liberan el pensamiento:

De estas conversaciones con la escoba y la frazada habían surgido algunas de sus más intensas reflexiones. No había sido escuchando a Vivaldi desde una poltrona, ni recostada en un butacón admirando un bello paisaje. Tampoco observando las volutas de un habano que construía ciudades de humo en el aire, ni dialogando con lo ignoto. Del trasiego constante con el churre del hogar habíase iniciado el toma y daca de sus meditaciones. Aquellas habían brillado en las burbujas oscuras de la mugre del portal antes que en la página en blanco (Mateo Palmer, 2010: 115).

Como ya lo hiciera Sor Juana en la construcción intelectual de las mujeres (por ejemplo, cuando en la Respuesta a Sor Filotea se defiende planteando que estudia filosofía en la cocina), en este párrafo se recuperan las actividades cotidianas como medio y espacio que 
permite la reflexión en contraposición a los erigidos desde una visión burguesa y machista, en la que el hombre (blanco, culto) se asocia a la razón, así como la música clásica sería el empellón del pensamiento y el habano (objeto fálico por antonomasia en la confraternidad intelectual masculina),otro de los medios para la inspiración.

La reflexión sobre las brujas y lo fálico comienza a desplegar conexiones inesperadas a partir de los avances de Gelsomina en la limpieza de la casa: observa una bruja dibujada en el Árbol del mundo (un diccionario de símbolos que sobre la mesita de luz) y también recuerda a la protagonista de El maestro y Margarita de Mijaíl Bulgákov. ${ }^{40}$ Sin embargo, no elige identificarse con Margarita, el personaje que seduce al Maestro, sino que opta por la protagonista de Yo, Tituba, la bruja negra de Salem (1986), la novela de Maryse Condé anclada en la historia colonial atravesada por la trata, la esclavitud y en la que se cruzan cuestiones de raza y de género. Gelsomina lee los fragmentos de las cacerías de Salem y, desplegando habilidades de lectora experta (y crítica), no sólo establece relaciones semánticas con La letra escarlata además de elaborar posibles lecturas del texto ("Gelsomina comenzaba a anotar algunas ideas"; Mateo Palmer, 2010: 120) sino que formula un proyecto de escritura: "Definitivamente escribiría algo sobre las brujas caribeñas, utilizando para ello algunas claves ofrecidas por Lydia Cabrera en su monumental obra. Una cita de Bulgákov presidiría el texto" (Mateo Palmer, 2010: 121). Y en estas reflexiones en las que comienza a esbozar líneas y preguntas para un futuro trabajo se produce un juego de espejo e identificación entre la labor ensayística de la escritora real (Mateo Palmer) y la protagonista de la ficción, que se traslada desde los proyectos de escritura hacia el presente de la enunciación de la protagonista:

\footnotetext{
40 Mijaíl Bulgákov (Ucrania 1891-1940) fue un escritor crítico del realismo socialista. Escribió en secreto El maestro y la Margarita, considerada por algunos críticos, la gran novela rusa del siglo XX. Recién fue publicada pos-mortem, en 1967. Resulta significativa la mención a esta novela, cuestión que no podré trabajar aquí.
} 
¿Podría, efectivamente, establecerse una relación directa entre el sufrimiento y la vocación de bruja? ¿Podrían conducir el dolor y la angustia sostenidas, no ya a los altos manicomios, sino al inefable vuelo sobre la escoba? ¿Existiría una relación entre la mujer y la locura? (Mateo Palmer, 2010: 121).

Siguen dos apartados anclados en el mapa europeo, más precisamente, en un recorrido en tren por Francia y, luego, en la estadía de la protagonista en la Universidad Blas Pascal en Clermont-Ferrand. "Gelsomina en el mapa de Europa" comienza con un epígrafe del poeta guadalupeño Saintleger Leger "El mar, entre las islas, es rosa de lujuria; su placer/ es materia a discutir..." (Mateo Palmer, 2010: 167) que pertenece al poema XVI de Éloges (1911). ${ }^{41}$ A lo largo de su recorrido, en un tren nocturno que parte de Nîmes, Gelsomina entabla una relación intertextual con el Pierre Menard borgeano al que recuerda y copia (recordemos que en "Pierre Menard, autor del Quijote" Jorge Luis Borges señala que Menard, poeta y novelista francés, muere en Nîmes en 1939). Esta operación podría pensarse como una duplicación de la lectura irreverente que Borges realiza del Quijote o, en otras palabras, que duplica la rescritura que Menard realiza de Cervantes, a quien copia letra por letra, poniendo en jaque la noción de autor y de original. El texto se inscribe así en la línea borgeana que pone en primer plano el apócrifo, el plagio, la enciclopedia, la erudición: así como Menard lee al Quijote desde un contexto cultural distinto del original, la protagonista de la novela lee a Borges (y en esta operación, a Cervantes), también desde otro contexto. Gelsomina, en un estado entre el sueño y la vigilia mientras transita en el tren, se identifica con la baronesa Baucourt (del cuento de Borges) y su vecino de asiento se transforma en Pierre Menard, de quien imagina una asombrosa erección fálica:

\footnotetext{
${ }^{41}$ Alexis Legar (1887-1975), conocido por los seudónimos Alexis Saint-Léger Léger y, sobre todo, SaintJohn Persé. Resulta significativo el nombre que eligió para identificar al poeta porque un epígrafe con sus versos también se utiliza en "La noche insular" (Mateo Palmer, 2010: 47), pero allí se señala que pertenecen a Saint-John Persé. Tal vez lo elija porque, como Persé (nacido en una isla caribeña, pero de nacionalidad francesa) la protagonista, en este apartado es una cubana que emprende un recorrido por el país del poeta y esto connota toda la tradición colonial de Francia en el Caribe.
} 
Yo miraba al joven versallesco, y lo imaginaba resbalando a la francesa sobre la clara bahía de mi cuerpo bruñido por los soles del trópico, sentía el pabellón galo entrando en mi puerto, clavando su estandarte colonizador en mi pequeña ínsula para tornarse conquistador conquistado por las calientes arenas de mis playas. Ya sentía la voluptuosidad de la caricia francesa y de los espejos estratégicos, él, un perfecto gozador, yo, la mujer-pulpo con mi isla en peso sobre su ouroboros. Pero el muchacho galo no parecía dispuesto a lanzarse a la conquista del Caribe: las huestes continentales permanecían en calma, sin apercibirse para el desembarco, garabateando cifras cartesianas en el cuaderno, su propio cuerpo desdeñado por quien pensaba pero no existía (Mateo Palmer, 2010: 170).

La visión onírica reproduce la representación estereotipada de la conquista y de lo europeo/caribeño en la que el cuerpo voluptuoso y sensual de la mujer ha sido ligado al Caribe, mientras que la masculinidad, intelectualidad y poder han sido el correlato de lo europeo. Sin embargo, no es con el galo con quien se produce el encuentro sexual sino con un jamaiquino revisor de boletos que trabaja en el tren, episodio que se relata mediante un cambio de la narradora que pasa de primera a tercera persona para reflexionar sobre los hechos. Luego retoma la primera persona cuando el amante casual se baja del tren: "Un aroma de canela y miel comenzó a cubrirlos como un aura, y en aquella soledad los cuerpos se unieron en un tibio puente tendido de isla a isla que no reclamaba vencedores ni vencidos pues el ritmo de los cuerpos era uno solo, como si ambos bailasen un mismo son antillano que recuperaba espontáneamente las cadencias y los compases aprendidos en la infancia" (Mateo Palmer, 2010: 174). ${ }^{42}$ Este acto de comunión del mundo antillano podría leerse, entonces, como una respuesta a la cultura occidental aunque desde un clisé que liga lo caribeño al erotismo, en oposición al pensamiento.

"Gelsomina en la Universidad Blaise Pascal” comienza con un epígrafe del poeta cubano Roberto Valero que dice "Cada ínsula encierra su demonio./No podemos

\footnotetext{
42 En este episodio se produce una relación intertexual con su propia obra ya que la protagonista hace referencia a un hecho de Ella escribía poscrítica: "Despertáronse en su memoria imágenes galanas, y hasta apareció en la bruma de sus referencias librescas el mismísimo Nazir, marroquí por quien aún penaba Dulce Azucena" (Mateo Palmer, 2010: 172). Al igual que en el ensayo, en este episodio hay un viaje en tren por Europa y un encuentro sexual que en ninguno de los dos casos es con un europeo sino con un marroquí y un jamaiquino, respectivamente.
} 
acostumbrarnos a los dioses de otros sitios" (Mateo Palmer, 2010: 199) del poema "Las islas son malvadas y nadie lo sospecha". ${ }^{43}$ Este apartado se enmarca en un fin de semana durante la estadía de la protagonista en la universidad francesa. En este marco adquiere significación el epígrafe elegido, porque se da en una situación de extranjería o de ajenidad (una cubana en Francia) en la que se cruza con historias que no le pertenecen, por ejemplo, la entronización occidental de la figura de Blaise Pascal (su estatua y el nombre de la universidad) o una placa de bronce que recuerda la muerte de un profesor durante una intervención de la Gestapo. Mientras recorre las escaleras y pasillos en el trayecto hacia la biblioteca, la recuperación de estos objetos historizados le generan una situación de extrañeza y alucinación; sólo ante la presencia de la martiniqueña, encargada de la limpieza, siente cierta identificación. ${ }^{44}$

En este espacio dedicado al saber, la protagonista pone en primer plano su identidad de investigadora, lee sus apuntes a partir de la lectura de un libro de Lydia Cabrera sobre la superstición (probablemente sea "El monte") pero les suma consejos de su propia tradición familiar (oral). Esta confluencia con conocimientos no tradicionales se puede pensar en relación con el uso de la intertextualidad y la cita diferida: "El corazón tiene razones que la razón ignora, le había dicho Pascal a través de una cita de Lezama que Gelsomina recordó” (Mateo Palmer, 2010: 202), es decir, la recuperación de la cita original a partir de la deglución lezamiana (Lezama Lima leyó a Pascal y tiene algunos escritos sobre él: "Pascal y la poesía" en Tratados en La Habana, 1958). La universidad y la habitación en la

\footnotetext{
43 Roberto Valero abandonó Cuba durante el éxodo de Mariel. En EEUU trabajó como profesor en la Universidad George Washington. Miembro del consejo editor de la revista Mariel, publicó los poemarios Desde un ángulo oscuro (1982), En fin, la noche (1984) y No estaré en tu camino (1991), entre otros. Su novela Este viento de cuaresma fue finalista de los premios Nadal (1989) y Planeta (1992)

${ }^{44}$ En los dos capítulos dedicados a la estadía de Gelsomina en Europa, la protagonista sólo entabla algún tipo de intercambio con personajes "otros" (en términos de clase y de nacionalidad) dentro del contexto occidental, como el jamaiquino encargado de los boletos en el tren, o la martiniqueña encargada de la limpieza de la Universidad. En ese contexto, ella sería la única caribeña dedicada al trabajo intelectual (en contraposición al trabajo manual de los dos mencionados).
} 
que se aloja se representan como la torre de marfil, el espacio ideal para el estudio y el conocimiento. En ese espacio idílico ella es "la otra", así interpreta algunas marcas durante su estadía: "todo dirigido contra ella, testigo indeseado, presencia extranjera, para hacerla emigrar de la torre de marfil. Han inventado un plan para deshacerse de mí y volverme definitivamente loca, pensó" (Mateo Palmer, 2010: 204). ${ }^{45} \mathrm{Y}$ completa la imagen de la otredad frente a lo europeo cuando, para exorcizar sus demonios interiores, visita la iglesia de Notre Dame du Port para realizar "votos criollos frente a la estatua de San Antonio" (Mateo Palmer, 2010: 205) y realiza una reflexión sobre su presencia en la iglesia medieval que se conecta con el epígrafe: "sintió la poderosa fuerza del hilo que la unía a las deidades del país natal en medio de la selva oscura del paganismo y la superchería extrañas a ella, y pudo hasta vislumbrar una suave aura cubriendo su silueta como fino polvo de estrellas de la madrugada insular: dándole la fuerza necesaria para enfrentar a los demonios hostiles que la amenazarían mientras durase su prolongado viaje por el mapa de Europa" (Mateo Palmer 2010: 205). El gesto remeda el típico auto-reconocimiento de la diferencia latinoamericana en el seno de Europa.

Me interesa retomar aquí dos cuestiones medulares que tienen contacto entre sí. En primer lugar, la elección de una protagonista que elige aIslarse en un manicomio y desde ese espacio reconstruir una identidad no acabada sino múltiple; una identidad en la que ese “yo" no es unívoco sino que fluctúa, se desgaja y se reconstruye desde esa inestabilidad. Ese movimiento interno se proyecta en una visión de caleidoscopio: la protagonista se delinea en sus múltiples nombres (nombres pensados como máscaras: el de pila, el de

\footnotetext{
45 En este contexto, se carga de connotaciones negativas la asociación entre la martiniqueña y Tituba Indian, la bruja negra de Salem. A diferencia del fragmento dedicado a las brujas en que la leía desde la versión bondadosa y fantástica de Maryse Condé, acá presiente "toda la maldad que se desprendía de su testimonio durante los juicios de 1692, archivados en un Massachusetts aún poblado de brujas expertas en burlarse de la férrea moral puritana” (Mateo Palmer, 2010: 204).
} 
progenitora, el número de paciente en el manicomio, el elegido por su hermana) pero, sobre todo, en la elección de este nombre apócrifo (Gelsomina) en tanto elección literaria y homenaje lo que permite advertir los lábiles bordes de una identidad que coquetea con la muerte. En relación con esto, la otra cuestión medular es la identificación de la protagonista con lo insular que se materializa en el (auto) encierro en el manicomio, en la introspección, en la construcción de su propia isla ligada a la lectura de ensayos sobre el Caribe así como en los epígrafes de los apartados dedicados a Gelsomina.

\subsection{Decir el Caribe}

En los últimos años las discusiones en torno al Caribe han vuelto a ocupar parte de la agenda académica. La mayor parte de la crítica coincide en señalar que constituye una región histórica aunque surgen discrepancias en el momento de circunscribir sus límites geográficos y sus fronteras políticas. ${ }^{46}$ Diversas investigaciones consideran que el Caribe es una unidad de estudio y justifican su postura en la historia de la región: la larga experiencia colonial, las modernidades contradictorias generadas por la coexistencia de la esclavitud y el capitalismo y, también, por la circulación de administradores, religiosos, militares, viajeros, expatriados, estudiantes y refugiados. En esta línea, María Julia Daroqui, en un trabajo dedicado al Caribe Hispano (1998), señala que si bien existen semejanzas relacionadas con los determinantes históricos y con las transformaciones discursivas que la postmodernidad ha hecho globalizadas y globalizantes, no parece posible asumir al Caribe como una unidad homogénea e inquebrantable y propone, por el contrario, apelar a la heterogeneidad como uno de sus rasgos definitorios que se manifiesta en las elaboraciones escriturarias (los

\footnotetext{
46 Por ejemplo, Díaz Quiñones considera que los límites geográficos son difíciles de demarcar, mientras que Mateo Palmer, en Ella escribía poscrítica, nunca pone en duda esta cuestión. Para Díaz Quiñones, el Caribe también se configura por oposición, por ejemplo, ante EEUU. También por las sucesivas y masivas emigraciones a metrópolis europeas y norteamericanas que otorgaron visibilidad al mundo cultural caribeño.
} 
modos de representación y los usos del lenguaje). ${ }^{47}$ Tampoco Arcadio Díaz Quiñones (2006) considera que étnica, política y culturalmente el Caribe sea homogéneo como tampoco lo son las diferentes lenguas que conviven o se enfrentan. Advierte también que el nombre de la región no se ha generalizado en la historiografía moderna debido a que la misma ha estado más atenta a la emergencia de la "nación" y a la creación de estados independientes mientras que, por el contrario, en su carácter de "configuración cultural", "[s]í quedó consagrado en la literatura y en el pensamiento político, asociado, como se sabe, con los caníbales, con la isla perdida en el relato de The Tempest, y también con la isla de la Utopía de Tomás Moro. La presencia de estas y otras connotaciones ha hecho que el significado de Caribe permanezca oscuro y discutible" (Díaz Quiñones, 2006: 20; itálica en el original).

En este apartado analizo la construcción cultural del Caribe o, en otras palabras, la conformación conceptual del área como un espacio cultural con características propias, desde la mirada de los sujetos femeninos presentes en el ensayo Ella escribia poscrítica y en la novela Desde los blancos manicomios. ${ }^{48}$ Parto de considerar que la construcción identitaria de estos sujetos se vincula con una determinada imagen del Caribe que los textos delinean: la configuración de la identidad atravesada por múltiples pliegues fragua un proyecto escriturario para pensar la identidad cubana como parte de la caribeña. Una muestra

\footnotetext{
${ }^{47}$ Frente a quienes plantean la existencia de una cultura y/o civilización antillana, Daroqui (1998) niega el concepto de antillanidad por esencialista y, en cambio, subraya la fragmentación del área en vez de suscribir la afirmación de su unidad.

48 Como se señaló, Arcadio Díaz Quiñones (2006) define la idea de construcción cultural del Caribe. También parte de esta consideración el PIP-CONICET "La construcción cultural del espacio caribeño. Cruces, hibridaciones y nomadismos" dirigido por Celina Manzoni en el que además, se considera que la diversidad, la fragmentación y la heterogeneidad del área requieren considerarla como una zona de cruces, hibridaciones y nomadismos: un "archipiélago" en sentido literal y metafórico.
} 
explícita de la preocupación de Mateo Palmer por este tema es el hecho de que en 1990 publicara el ensayo Narrativa caribeña: reflexiones y pronósticos. ${ }^{49}$

\subsubsection{Ella escribía poscrítica o los modos de ser caribeños}

Como ha sido señalado por la crítica, pensar la configuración del mapa físico y cultural del Caribe implica atender al problema de la unidad y diversidad histórica, cultural, social, racial y política de la región. Por lo tanto, anclar el análisis de Ella escribía poscrítica supone atender a los intersticios materiales de las condiciones de producción del texto. Escrito en pleno "Período Especial en Tiempos de Paz", Ella escribia poscrítica se presenta como la estrategia de supervivencia de una mujer - escritora y profesora - ante las situaciones dramáticas que desencadena la crisis. Como se señaló, el primer capítulo académico cumple una función introductoria y se constituye en la base teórica del ensayo. Aquí la voz autoral señala las falencias de los análisis que intentan encontrar el canon posmoderno de América Latina a partir de subrayar la posición periférica, y advierte los riesgos de realizar el análisis de los textos atendiendo a categorías ya existentes en el discurso crítico sin tener en cuenta la dinámica y el contexto al que responden. Desde esta perspectiva, discute con Linda Hutcheon para quien la metaficción histórica es uno de los procedimientos novedosos y característicos del posmodernismo; por el contrario, Mateo Palmer considera que, por las

\footnotetext{
49 En una entrevista publicada en la edición digital de la UNEAC, Mateo Palmer (2012) advierte que "Durante muchos años de nuestra historia reciente las relaciones diplomáticas entre Cuba y los países caribeños se dificultaron debido a razones políticas; pero también creo que pesan otros factores como los prejuicios de tipo racial y aquellos derivados de una larga historia durante la cual miles de emigrantes caribeños que arribaban a nuestro país para trabajar como cortadores de caña, y en condiciones paupérrimas, eran menospreciados. Reconocer nuestra identidad caribeña es esencial para conformar una imagen cabal de nosotros mismos y de nuestra cultura, pero no siempre se insiste lo suficiente en esa dimensión de nuestro modo de ser, y, muchas veces, cuando se hace, adquiere visos de exotismo y se piensa en los estereotipos: las palmeras, el erotismo, las playas, el ron, el tabaco y, desgraciadamente, la abulia o el ocio tropicales".
} 
peculiaridades de América Latina, este procedimiento es una experiencia de tradición muy antigua.

Desde un planteo que parte de la contextualización del análisis, reconoce la marginalidad de América Latina y ubica al Caribe como un área

... marginal dentro de la marginalidad, periférica en el borde mismo de la periferia o, por así decirlo, una de las últimas fronteras de un mundo subalterno. En esta peculiar zona de América Latina, el tema de la historia ha estado presente desde los orígenes mismos de su literatura. Sin embargo, la relación con el devenir histórico a través del discurso literario siempre ha sido una relación tensa y problematizada, marcada por el cuestionamiento (Mateo Palmer, 1995: 10).

De esta forma, ya desde las primeras páginas del ensayo, el Caribe se configura como un espacio con características específicas que difiere tanto del resto de América Latina (por el exceso de marginalidad) como de Europa y EEUU (donde no ubica la marginalidad). ${ }^{50}$ Además de este plus de marginalidad, también caracteriza al Caribe por la relación tensa que ha mantenido entre historia y literatura, en tanto arguye que este último discurso siempre tuvo la necesidad de reescribir la voz oficial de la historia. Por eso, Mateo Palmer señala que

El documento historiográfico ha sido subvertido, y la pugna entre historia oficial e historia real se ha convertido en objeto de una atención reiterada. Lo que en otros países puede haber sido una experiencia más reciente -el fracaso de los grandes relatos y proyectos históricos, de esa Historia con mayúscula que hoy se pone en duda—, en el Caribe goza de una amplia tradición (Mateo Palmer, 1995: 11).

De este modo, su planteo se opone a los modelos promovidos por el centro y que han sido utilizados acríticamente para pensar el Caribe y todo el "subcontinente", término que utiliza para referirse a América Latina.

\footnotetext{
${ }^{50}$ La visión del Caribe como un área marginal dentro de lo marginal también está presente en los ensayos y crónicas del escritor puertorriqueño Edgardo Rodríguez Juliá. Esto lo advierte Carolina Sancholuz (2010) en su minucioso estudio de la obra de este escritor. En el tercer apartado del libro analiza la cuestión del lugar y la figuración del Caribe a partir del análisis de las crónicas y ensayos incluidos en Caribeños y sostiene que lo caribeño no se materializa como un espacio armónico sino que evidencia las alteridades, la historia compartida de la colonización y de la esclavitud, los problemas sociales y étnicos así como la diversidad lingüística y cultural. Esto hace que se visibilicen los desajustes y tensiones dinámicas propias de un "Caribe múltiple y desgarrado" (Sancholuz, 2010: 362).
} 
Frente a esta imposición teórica, Mateo Palmer remite al uso de la copia como forma de subvertir el código europeo o, también, al análisis de Fernando Ortiz cuando analiza el choteo cubano, la recusación solapada de la autoridad, la violación de las normas, la tendencia a la burla de la jerarquía. ${ }^{51}$ Considera que estas peculiares formas han estado condicionadas, en parte, por la vertiginosa inversión de cánones y posiciones sociales que fue característica de la sociedad colonial. En este sentido, pasa revista a los rasgos característicos de la cultura latinoamericana (aquí como una) que derivan de su condición colonial y dependiente. $\mathrm{Y}$ esto le sirve para señalar que "la recepción europea y norteamericana de los modelos supuestamente posmodernistas de la literatura latinoamericana que, desde luego, tiene un sentido para ese discurso crítico, resulta insuficiente, desde el punto de vista epistemológico, para la literatura latinoamericana" (Mateo Palmer, 1995: 14). En esta instancia de la argumentación, la ensayista incluye el Caribe y su literatura en el marco mayor de América Latina, debido a la similitud de las posiciones adoptadas ante imposiciones teóricas y metodológicas de los centros de poder intelectual. Mateo Palmer dibuja a América Latina como una unidad, ante la necesidad de elaborar una respuesta crítica a esta imposición.

Por otra parte, aún considerando los aspectos que unificarían al Caribe, la autora distingue las particularidades del posmodernismo en Cuba debido a la experiencia revolucionaria, ya que la isla ha protagonizado la puesta en práctica de uno de los proyectos modernos de justicia social más radicales y sostenidos del continente: "un proyecto que ha sido legitimado, entre otras formas, a través de un discurso humanista cuyos principales

\footnotetext{
${ }^{51}$ Respecto de las indagaciones de Fernando Ortiz sobre el choteo, Mateo Palmer remite a unas notas compiladas hace unos años en la revista Albur. Consultar Ortiz (1993). Sería necesario revisar desde qué perspectiva está analizando los aportes de Fernando Ortiz. Sospecho que es a partir de la lectura posmoderna que realiza Benítez Rojo (1989), debido a la vinculación filiativa que entabla con este crítico. Una perspectiva interesante para analizar el discurso literario latinoamericano en función del occidental es la propuesta del “entrelugar" de Silviano Santiago (1971).
} 
tópicos gozan de fuerte arraigo en la modernidad (Mateo Palmer 1995: 138). De esta forma advierte la paradoja de pensar la posmodernidad en el marco del proyecto moderno de la Revolución que ha marcado la experiencia histórica de las últimas décadas; por eso, señala que esta característica matiza y distingue el posmodernismo insular y le otorga una especificidad dentro del (también singular) posmodernismo de América Latina. Aunque el ensayo tiende a configurar al Caribe como una unidad dentro de América Latina y frente a los modelos imperiales, también se advierte la heterogeneidad y se ancla en cuestiones histórico-políticas que matizan, en este caso, el modo original de encarar determinados motivos y tópicos de la posmodernidad para crear un discurso propio.

Cuando Mateo Palmer analiza los signos escriturarios de los tatuajes, aunque sitúa el recorrido en Cuba, es posible establecer un paralelo con el resto del Caribe porque también constituye uno de los intentos de establecer diferencias con los modelos centrales. En este caso, discute la teoría de Jean Baudrillard respecto de los tatuajes. En una primera instancia, se caracterizan los tatuajes insulares:

Ambos, tatuador y tatuado, a través del contacto de la piel sobre la piel—se saben parte de un ritual íntimo. La tradición mística, humilde, demorada y laboriosa del tatuaje insular de algún modo desafía la rapidez, la impersonalidad, el carácter seriado y masivo de cuños y máquinas tatuadoras -inicial del amor que marca sus cabezas de ganado, hierro candente en la frente del esclavo calimbado-ajenos a la individualidad y al rasgo original (Mateo Palmer, 1995: 60).

Resulta interesante la contraposición que establece entre los actos individuales, únicos, y la copia en serie a través de la máquina. La originalidad de los tatuajes cubanos (y caribeños) reside en que lo moderno de la repetición se vincula con el pasado atroz de la esclavitud y con las marcas de pertenencia sobre el cuerpo cosificado del esclavo. Además, rescata el valor político que tiene esta tradición artesanal, paciente y dolorosa, en un país donde el 
tatuaje ha sido marginado. ${ }^{52}$ Revalorizar esta tradición implica un desafío porque el tatuaje tiene una particular connotación negativa en la tradición etnocéntrica del positivismo: el tatuaje es una marca "salvaje" en el cuerpo de los delincuentes. Esa tradición es el fondo sobre el que se revelan. De este modo, contrasta los signos despojados de sentido, que "se multiplican, se hipertrofian precisamente porque ya no tienen secreto, ya no tienen crédito. Signos sin fe, sin afecto, sin historia, signos aterrorizados ante la idea de significar" (Mateo Palmer, 1995: 62) de los que habla Baudrillard en De la seducción, con los signos del tatuaje insular que sí presentan una orientación que a veces se ancla en una funcionalidad tangible como, por ejemplo, imágenes de Ochún, Changó, Yemayá, San Lázaro, números cabalísticos, letras, nombres, serpientes, banderas.

En los capítulos ficcionales, se repite una y otra vez el problema de acceder a las obras originales a través de la copia. Esto remite a las problemáticas históricas en que se enmarca el Caribe, pero también es una exhibición de las dificultades económicas (y políticas) por las que atraviesa en ese momento Cuba ya que, como señalé, la crisis invade el espacio de lo privado y de lo público, en este caso, su vida como investigadora (tanto el personaje de ficción, como Mateo Palmer, la autora del ensayo). Por ejemplo, estas dificultades se plasman en el episodio (ya mencionado) en el que Surligneur-2 relata las artimañas a las que recurre para preparar la clase: la ausencia de libros en las bibliotecas, el uso de las fichas, el acceso a autores sólo por referencias en otros textos, etcétera. Recurriendo al procedimiento "de la cita a partir de la cita", Surligneur-2 recupera una cita de Hoffman donde explica que la indeterminación radical del posmodernismo ha atravesado el ego y ha afectado su anterior (y supuesta) estabilidad y de este modo, la identidad se ha vuelto algo incierto. En el epígrafe utilizado para este trabajo, Surligneur-2

\footnotetext{
${ }^{52}$ Esta distinción entre el desarrollo tecnológico de esta práctica y la tradición artesanal en Cuba también es trabajada por Severo Sarduy en La simulación (1982), perspectiva teórica que también es retomada por Mateo Palmer. Luego, en Escrito sobre un cuerpo Sarduy asocia el acto del tatuaje a la escritura.
} 
advierte que esa indeterminación es la que provocó que la literatura caribeña esté siendo más estudiada:

La búsqueda de una identidad-quimérica que se escapa-diluye-escamotea ha sido una obsesión en el Caribe. Y en medio de ese caos -la isla que se repite, la isla que se repite, la isla que se repite-el espejismo de un centro omphálicamente estable que también tiende a diluirse aunque a veces se vislumbre la unidad en la diversidad. Nada, lo de siempre: la transculturación, el ajiaco y la nación. Y ahora, además, como para acabar de volvernos locos, la isla y la diáspora (Mateo Palmer, 1995: 46).

Estas palabras incluyen un diálogo con La isla que se repite. El Caribe y la perspectiva posmoderna (1989) de Antonio Benítez Rojo (1931-2005). La relación es subrepticia porque tal vez se intente ocultar el modo o la forma en que accedió al texto de un crítico que luego de su exilio en 1980 fue considerado "apátrida" y cuyos textos dejaron de ser difundidos en Cuba. ${ }^{53}$ Mateo Palmer asume la genealogía de Benítez Rojo para pensar Cuba en el marco mayor del Caribe y, por lo tanto, también se entronca con Fernando Ortiz (1881-1961) a quien Benítez Rojo le dedica su libro (y un capítulo). ${ }^{54}$ De esta manera invoca una genealogía posmoderna del Caribe, es decir, aquella que piensa esta área como espacio privilegiado para la posmodernidad; por otro lado, estos lazos suponen lecturas que vinculan a Cuba en el espacio mayor del Caribe o, mejor dicho, que ubican a Cuba en el Caribe. Como señala Arcadio Díaz Quiñones:

\footnotetext{
${ }^{53}$ En las referencias bibliográficas no se menciona este ensayo. Sólo es posible conjeturar la lectura. Rafael Rojas (2009) aporta algunos elementos que permiten reconstruir la historia de la circulación clandestina de esta obra de Benítez Rojo que, aunque la editorial norteamericana Ediciones del Norte publica en 1989; no circuló entonces por Cuba.

${ }^{54}$ La primera edición está dedicada a Fernando Ortiz. En 1998, Benítez Rojo publica la edición definitiva en Barcelona y elimina el subtítulo sin realizar ninguna explicación al respecto. En esta edición, amplía la dedicatoria: además de Ortiz incluye a Aimé Cesaire, Kamau Brathwaite, Wilson Harris, Édouard Glissant. Es necesario aclarar que Benítez Rojo elige hacer una determinada lectura de Fernando Ortiz, en clave posmoderna. Al respecto, Díaz Quiñones advierte que "Ortiz prestaba más atención a la formación de los ciudadanos cubanos que al archipiélago del Caribe. Benítez Rojo, sin embargo, insistió en el valor de su legado, no sólo por el talante literario de su obra, sino porque Ortiz, aunque no abandonó el proyecto nacional, sentó las bases para el estudio etnográfico de la espiritualidad del mundo afrocaribeño, e insistió en estudiar las relaciones entre europeos, africanos, indígenas y asiáticos. Ese multifacético mundo había sido estereotipado en las representaciones de lo 'nacional' y desplazado mediante la celebración del mestizaje" (Díaz Quiñones, 2007: 13). Sobre la configuración de lo nacional en Fernando Ortiz, consultar Mailhe (2008).
} 
Benítez Rojo alcanzó su plenitud como ensayista con su propio mapa insular, su Liber Insularum. Pero, por paradójico que parezca, Cuba no estaba en el centro como la nación heroica celebrada por su Revolución; era una isla entre muchas otras, ni épica ni trágica. La visión que ofrecía era a la vez más expansiva e inclusiva. Desde las primeras páginas se constata su deseo de ir descubriendo otras islas frente al mar abierto. La anexión de espacios caribeños le permitía iluminar las zonas veladas tanto por el discurso nacionalista de 'lo cubano' como por el del 'hombre nuevo' del socialismo (Díaz Quiñones, 2007: 6).

Es decir, la isla heroica quedaba integrada a la región como un elemento más de la estructura rizomática, sin jerarquías ni centros organizadores del "meta-archipiélago" (Benítez Rojo, 1989), un área cuyo núcleo imaginario excedía lo nacional. En esta afiliación, Mateo Palmer cuestiona la búsqueda de una identidad cubana "quimérica" (¿el insularismo del grupo Orígenes? ¿el hombre nuevo proclamado por la revolución?) y la búsqueda de un centro (¿crítica al falocentrismo?) para, en cambio, dejar emerger la heterogeneidad de una región atravesada por fenómenos tan complejos como la histórica transculturación o, en la actualidad, el exilio, la diáspora cubana pero, también, la de otros lugares del Caribe.

Cuando Surligneur-2 prepara una clase sobre posmodernidad, se dedica a repasar qué se entiende por literatura caribeña. Encuentra como rasgo dominante

el problema de la identidad histórica y socio-cultural, proyectada también sobre el plano individual. El quién somos -más aún que el quién soy- había sido una constante de la creación literaria, que adoptaba las más diversas formas. En esta línea habían inscrito, en este siglo, obras aparentemente tan disímiles como Banana Bottom, Ecue-Yamba-O, Tuntún de pasa y grifería, Cabier d'un retour au pays natal, Gouverneurs de la Rosée, Hay un país en el mundo, Compere General Solei, etc. (Mateo Palmer, 1995: 43).

La mención de estas obras le permite repasar los problemas que unifican al Caribe: el género, la raza, el exilio, la historia. Y advierte que "aunque la afirmación de la identidad caribeña se apoyó casi siempre en la diferencia -incluso en el reconocimiento de una identidad plural, heterogénea, contradictoria, como correspondía a una experiencia histórica tan compleja- mantuvo el sentido de búsqueda de un centro en común. Pero ahora algunos teóricos posmodernos ponían demasiado énfasis en el problema de la individualidad, o quizá esa fuese una impresión suya, de tanto acceder a los originales de 
modo fragmentado y muchas veces a través de lo referido por otros autores" (Mateo Palmer, 1995: 43) Ese “suya” (énfasis mío) remite a Surligneur-2 (pero también a Mateo Palmer) y da pie para el comienzo de la reflexión sobre la cuestión de la identidad que aquí es problematizada en términos genéricos.

Como señalé antes, pensar la configuración del mapa físico y cultural del Caribe implica atender al problema de la unidad y la diversidad histórica, cultural, social, racial y política de la región. Por lo tanto, para anclar el análisis de Ella escribía poscrítica hay que tener en cuenta los intersticios materiales de las condiciones de producción del texto. Intersticios que conducen no sólo a revisar las problemáticas que el "Período Especial" conllevó para el día a día de cada cubano, sino también, para este caso específico, atender a las consecuencia que tuvo sobre quienes intentaron proseguir con su trabajo sobre la escritura. Como ya señalamos, para Mateo Palmer, ser mujer ensayista supone un posicionamiento y una trasgresión; la decisión de escribir se configura como un problema del "nosotras" más que del "yo", es decir, aunque interviene esta reflexión sobre las múltiples individualidades que conforman este yo, no deja de remitir a una problemática conjunta porque lo que le sucede a Surligneur-2 también le sucede a otras que como ella quieren escribir, elección dificultosa, más aún, en contextos de crisis.

Esta reconstrucción del sujeto en múltiples identidades se vincula con la configuración del Caribe que se puede leer en el texto. En primer lugar sería necesario señalar que Mateo Palmer se distancia de las posiciones que tienden a pensarlo como una unidad homogénea, para adoptar una mirada atenta a la compleja densidad que supone un acercamiento a esta región. En este sentido, resulta sugestivo el capítulo ficcional en el que Mitopoyética (el "yo" escritora de ficción de Surligneur-2) quiere escribir pero no puede. En un momento del discurrir de la conciencia, se pregunta:

¿Qué cosa fue Lucy in the Sky sino una gran utopía, profética canción? ¿Qué mito encarnó en Lennon, como años atrás otro mito encarnara en el Che? ¿Se arribará en 
la posmodernidad a un verdadero camino de paz, de armonía, de sabiduría, donde los pobres de la tierra tengan su lugar? Oriente y Occidente. Ni una cosa ni la otra. La verdadera simbiosis puede estar en todas partes, pero para mí, aquí, en el Caribe, Mediterráneo del nuevo mundo. Para ser más exactos, en la Psilocibe cubensis, Ultima Thule, mítica isla de los hongos tropicales. Diz el Almirante un 28 de octubre que nunca cosa tan fermosa vio, todo cercado el río con flores y sus frutos, cada uno de su manera, pajaritos que cantaban muy dulcemente y un perro que nunca ladró (...) La isla en peso, el peso de la isla, corcho que nunca se hunde, balsa a la merced de las olas, barquita de papel, amiga fiel del ancho mar (Mateo Palmer, 1995: 86-87).

Creo que en esta cita se sintetiza la complejidad de la propuesta de Mateo Palmer para pensar el Caribe. Aunque un marcado tono irónico recorre los lugares comunes tanto de la posmodernidad como de la preeminencia que históricamente se le ha dado a Cuba -la isla "elegida" (por Colón, por el proyecto Revolucionario, ahora por la Posmodernidad)—, vuelve a centrar el Caribe en una de sus islas. También alude a América como utopía (la Última Thule de Alfonso Reyes) ${ }^{55}$ y a los hongos alucinógenos, y este vínculo es lo que desencadena la ironía histórica y conecta el par Caribe-Mediterráneo porque desde allí fue pensada como utopía. En la última oración se realiza una sucesión e inversión de ideas a través de un recorrido que pasa por la póetica reflexión piñeriana sobre la insularidad (poética que parodia y desacraliza la visión origenista de la insularidad) ${ }^{56}$, su inversión centrada en la densidad de ese peso, la vulgarización implícita en la elección del término "corcho", la alusión política a los balseros cubanos, para luego terminar con el lugar ínfimo de una barquita perdida en el ancho mar. El ancho mar que justamente conecta la diversidad que supone Cuba con el resto del Caribe y, de este modo, entabla lazos históricos, culturales, sociales, raciales y políticos. Tal vez el último vínculo recupere aquello

55 El libro de Alfonso Reyes, Última Thule (1942), se refiere al "mundo nuevo" que anunciaba Séneca y que, por no haber salido del reino de la fantasía, merece llamarse la última. En ese volumen reúne diversos trabajos referidos a América. 
que tiempo después Díaz Quiñones visualiza al afirmar que "El Caribe parece reconstituirse en sus exilios contemporános” (Díaz Quiñones, 2006: 23).

\subsubsection{El aISLAmiento: pensar la isla y el Caribe desde los blancos manicomios}

Como se advirtió en el análisis de Ella escribia poscrítica, Mateo Palmer asume allí una propuesta que permite pensar Cuba en vínculo con un espacio mayor como es el Caribe. En su primera novela continúa la configuración de esta perspectiva, pero esta vez la reflexión parte de la condición insular como inherente al Caribe y se trama a partir de las lecturas que realiza Gelsomina desde su propia condición insular: elige leer aILSLada debajo de la cama del hospital. De este modo, la identidad de este sujeto enajenado se (re)construye, también, en las reflexiones teóricas que suscita la lectura, refugio y espacio de calma e intimidad frente a la violencia exterior. ${ }^{57}$

Una clave del análisis se delinea a partir de los títulos de las partes dedicadas a las lecturas de la protagonista y cuyos términos dibujan un campo semántico en torno a cómo ha sido pensada la insularidad: "La isla fugitiva", "La noche insular", "La isla maldita", "El vuelo insular", "La isla recobrada “, "Las islas del dolor", "La memoria insular", "El olvido insular". En la tercera parte de cada bloque coral, Gelsomina lee La Revista del Vigía dedicada a un análisis sobre la condición insular. Y en estos apartados son varios los símbolos que aparecen de manera recurrente (el agua, la isla, la insularidad, la poesía, la

\footnotetext{
56 Me refiero al poema "La isla en peso" donde Piñera polemiza con su planteo acerca de "la maldita circunstancia del agua por todas partes". Mientras la condición insular fue considerada por mucho tiempo como paradisíaca, en este poema se carga de valor negativo.

${ }^{57} \mathrm{La}$ lectura también se erige como una isla protectora. Así también lo percibió su hermana, ya desde niñas "también me acordé del día que explotó la olla de presión. Aquellos chícharos, lo único que teníamos para comer, desperdigados por toda la cocina, y tú diciendo que hasta que no terminaras lo que estabas leyendo no contáramos contigo, total, si ya no había nada que hacer. Esa imagen nunca se me ha borrado de la mente. Fue muy reveladora. Desde entonces me di cuenta de que la lectura para ti era como un calmante, una tablita de salvación. La necesitabas como otros necesitan drogas. Te recuerdo en los momentos más difíciles buscando la menor oportunidad par ponerte a leer, escapando de los problemas a través de la lectura. Era como si dijeras, estoy aquí, pero no estabas realmente” (Mateo Palmer, 2010: 60).
} 
creación misma) en las reflexiones puestas en el personaje de la alienada. ¿Qué lee en este autoencierro, en este aislamiento de los ruidos, de las miradas que la censuran? Establece una relación intertextual con su propio discurso cuando se advierte al reconocer fragmentos del capítulo dedicado a la insularidad en El Caribe en su discurso literario publicado por Margarita Mateo Palmer y Luis Álvarez Álvarez en el $2005 .^{58}$ La apelación a la intertextualidad se lleva al extremo porque cita su propia producción aunque en la novela, mediante los juegos del lenguaje, se puede observar un alejamiento de la rigurosidad o normas propias del trabajo crítico en cuanto a las citas de fuentes, por ejemplo, y es el ojo del lector el que debe desandar las lecturas puestas en juego. Así, en el primer fragmento, "La isla fugitiva", Gelsomina lee en torno a la condición de insularidad:

Es realmente el mar, leía Gelsomina, un límite objetivo para el habitante de las islas o del litoral, pero sugiere, a la vez, la noción de infinitud cuando la mirada se pierde en una distancia inabarcable. Esta dualidad de sentidos de la insularidad -cerco y lejanía, encierro y libertad-remitirá siempre a una conciencia de la distancia que puede asumirse hacia el interior, buscando un repliegue frente a la vastedad del paisaje pero también puede volcarse hacia fuera, en un afán de romper el aISLAmiento y suplir, con el viaje o la fantasía, aquel espacio otro que le está vedado. La mirada fija en el horizonte puede conducir al espejismo, a suplir lo ausente por la fuerza de la imaginación (Mateo Palmer, 2010: 23-24).

En los mismos términos, esta reflexión está presente en el libro sobre el Caribe, aunque hay sólo un detalle que los diferencia: lo que Gelsomina no lee o elude transmitir es un paréntesis: "vastedad del paisaje (“el insular vive hacia adentro" afirmó el poeta cubano José Lezama Lima en su diálogo con Juan Ramón Jiménez), pero también...” (Álvarez y

\footnotetext{
58 Gelsomina no hace explícito ese título, alude en cambio a un artículo de La Revista del Vigía en la que, pienso, es probable que los autores publicaran una versión de lo que luego incluirían en el libro Señalo esto como presunción porque, aunque consulté el libro para confirmar la intertextualidad, no he tenido acceso a la revista. Se trata de una publicación realizada en Matanzas desde hace más de veinte años en una edición artesanal, hecha a mano, conformada cada una por 200 ejemplares. Surgió bajo la dirección de Alfredo Zaldívar, su editor principal hasta 1998, y desde ese momento hasta la actualidad la dirección está a cargo de Agustina Ponce. El título remite a la Plaza de la Vigía, por el lugar geográfico donde se instala la Casa del Escritor de Matanzas. Bajo el emblema del quinqué y caracterizadas por un riguroso criterio de selección, el carácter inédito de sus publicaciones y un diseño singular, las ediciones están dirigidas a un público intelectual sin distinción de edad, sexo o nacionalidad. Para más información, consultar http://librinsula.bnjm.cu/secciones/229/nombrar/229_nombrar_5.html
} 
Mateo Palmer 2005: 96). Resulta significativa le elisión porque es nada menos que Lezama, el poeta homenajeado, el que aquí no se lee.

Este primer apartado comienza con el epígrafe "Una isla es para la imaginación de siempre una promesa. Una promesa que se cumple y que es como un premio de una larga fatiga" que pertenece a "Isla de Puerto Rico (Nostalgia y Esperanza de un mundo mejor)", donde María Zambrano, quien vivió parte de su vida en las islas, reflexiona sobre la condición insular del Caribe. ${ }^{59} \mathrm{Y}$ es desde aquí que Gelsomina construye su refugio debajo de la cama que convierte metonímicamente en "nueva casa que comienza a serle familiar" (Mateo Palmer, 2010: 21), espacio de protección ante los médicos y las enfermeras que la obligan a tomar pastillas y la inyectan tres veces por día. Desde esta perspectiva Gelsomina tiene su foco de percepción: el movimiento de los que transitan por la habitación, los zapatos blancos de las enfermeras, las patas de la mesita de luz. Es su refugio ante lo idéntico y repetido del encierro en el manicomio: la blancura de los altos pabellones, las hileras de camas, las batas replicadas de los pacientes, los uniformes blancos de las enfermeras. Esta isla, su isla, no se escapa tampoco de los límites del encierro: "Las sombras de las rejas, que se reflejaban en los cristales de los amplios ventanales, no dejaban dudas acerca de su condición de reclusa, con una libertad tan restringida que apenas podía tomar alguna decisión por sencilla que fuera" (Mateo Palmer, 2010: 23). En este sentido puede pensarse la configuración del encierro en el manicomio como los límites del Estado, como una metáfora del encierro en la isla: "unas manos muy fuertes, ejerciendo una presión desagradable sobre sus brazos, la sacaron de su escondite, casi a rastras, y la obligaron a acostarse en la cama" (Mateo Palmer, 2010: 26). ${ }^{60}$

\footnotetext{
59 Se consultó la edición preparada y prologada por Jorge Luis Arcos para la editorial Verbum (2007), disponible en internet.

${ }^{60}$ La isla como prisión también aparece en otros escritores cubanos. En la obra de Dulce María Loynaz, frente a la visión de lo insular como paradisíaco (asociada a la primera imagen edénica de Colón sobre la tierra
} 
En su refugio se dedica a la lectura, y el acto de leer, con su despliegue de mundos posibles se convierte en una isla, en una forma de aIslarse:

Estar así escondida le permite concentrarse en la lectura, en las islas que aparecen con palabras. Le gusta que se hable de las islas como si fueran seres con vida propia, y le gusta la leyenda de la isla que aparece y desaparece sin dejar huellas. Esta isla volandera del archipiélago canario -la Non Trovada--, solo se muestra fugazmente en la distancia para permanecer envuelta en el misterio que la vela, como señal de brevísima apertura hacia el mundo de lo desconocido. Isla fugitiva, parece indicarnos con su fugaz epifanía la posibilidad de un viaje similar al propiciado por los viejos chamanes del continente americano a través de sus plantas sagradas (Mateo Palmer, 2010: 22).

Esta isla, la Non Trovada (también llamada isla de San Borondón) ubicada en el archipiélago canario que, dice la leyenda, contaría con ocho islas y no siete es justamente la isla fugitiva elegida para comenzar un recorrido por distintas reflexiones en torno a la insularidad caribeña. ${ }^{61}$ La misteriosa isla buscada por marinos y reyes (y de la que hablara Colón en el Diario del Primer Viaje) a la que se puede arribar por casualidad pero que cuando se busca no se encuentra, se vincula con María Zambrano ya que la filósofa elegida para el epígrafe nació en Canarias.

"La noche insular" comienza con un fragmento de Saint-John Perse: “Todas cosas suficientes como para no envidiar las/ velas de los veleros que diviso a la altura del techo/de zinc sobre el mar como un cielo" (Mateo Palmer, 2010: 47). ${ }^{62}$ Más allá de este anclaje, hay que señalar que el título de este apartado remite al poema de José Lezama Lima "Noche insular: jardines invisibles" de Enemigo rumor (1941) en el que la oscuridad caribeña se vuelve un espacio fecundo para la proliferación de imágenes. Esta alusión indirecta se

caribeña, presente, por ejemplo, en el poeta Emilio Ballagas) contrapone imágenes de miseria, desesperación, encierro. En Virgilio Piñera la condición insular se carga, en "La isla en peso", de un valor semántico negativo y los elementos tradicionales, emblemáticos de "lo cubano", adquieren un carácter de pesadilla que alucina y desgarra a las criaturas de la isla.

${ }^{61}$ Consultado en: Moreri, Luis. El gran diccionario histórico o Miscellanea curiosa de la historia sagrada y profana. En: http:/ / books.google.com.ar/books?id=FAYZTrgkOLgC\&printsec=frontcover\&hl $=\mathrm{es} \# \mathrm{v}=$ onepage $\& \mathrm{q} \& \mathrm{f}=$ false

${ }^{62}$ Pertenece a Elogios (1911). El original dice: “toutes choses suffisantes pour n'envier pas les voiles/des voiliers/ que j'aperçois à la hauteur du toit de tôle sur la mer/ comme un ciel” (Persé, 2006: 10). Agradezco a Francisco Aiello el dato sobre esta obra. 
confirma cuando Gelsomina, nuevamente encerrada en su isla, retoma la lectura de La Revista del Vigía y recuerda que el epitafio en la tumba de Lezama en el cementerio de Colón reproduce uno de los versos de ese poema: "La mar violeta añora el nacimiento de los dioses, ya que nacer es aquí una fiesta innombrable, un redoble de cortejos y tritones reinando" (Mateo Palmer, 2010: 48). Versos que, por lo demás, suelen citarse para explicar la omnipresencia de la insularidad en Lezama (tal como la misma Mateo Palmer lo hace en Paradiso. La aventura mítica, 2002, su libro sobre el poeta) pero también para sostener una lectura política respecto del aislamiento oficial al final de su vida. Esa visita a la tumba del poeta se conecta también con Altazor de Vicente Huidobro: Gelsomina recuerda que, ante el gran hueco negro de la sepultura de Lezama, escucha "Abrid la tumba, al fondo de esta tumba se encuentra el mar" (Mateo Palmer, 2010: 50); entonces, discursivamente las dos sepulturas se confunden ya que es el epitafio en la tumba del poeta chileno. Y son la omnipresencia del mar que inunda las visiones del presente y del pasado de la protagonista, así como la cercanía de la muerte y el miedo ante la posibilidad del encierro permanente en esta isla blanca (manicomio), los tópicos que atraviesan todo este apartado. "Esta no es una fiesta innombrable; este es el pabellón de las incurables" es la frase que Gelsomina cree escuchar, una y otra vez, de la boca de la enfermera, frase que se vuelve persecutoria y que explica a partir de la influencia de la paciente que recitaba poemas de Lezama:

la 23, en ocasiones, invocaba a Lezama en sus delirios y repetía obsesivamente que nacer aquí es una fiesta innombrable. Por lo general afirmaba enfáticamente las palabras del poeta. Las que agregaba ella misma las pronunciaba con desgano. Otras veces convertía el verso en pregunta, subrayando exageradamente la entonación final de la interrogante, lo cual hacía más notoria la ausencia de respuesta. En su exaltación creciente, la 23 llegó a tararear el verso lezamiano con música de la trova tradicional, matizando su sentido con diferentes ritmos (Mateo Palmer, 2010: 53).

Y esta obsesión por Lezama de la 23 (que, no olvidemos, es el espejo de Gelsomina, su identidad desdoblada) termina en un castigo físico cuando, con un lápiz labial rojo 
bermellón, las escribe en las paredes de la habitación, en las sábanas, en la funda de la almohada.

"La isla maldita" comienza con un epígrafe del Canto V de Altazor de Vicente Huidobro: "El mar se abrirá para dejar salir/los primeros náufragos/que cumplieron su castigo" (Mateo Palmer, 2010: 75). Y su primera frase menciona a Virgilio Piñera ("Desde que abrió el ensayo sobre Virgilio Piñera, Gelsomina comenzó a preguntarse qué hacía debajo de la cama”; Mateo Palmer, 2010: 75), es decir, esta reflexión sobre lo insular está marcada desde el título por la contrapartida de la visión paradisíaca de la insularidad: la angustia del encierro, la negatividad de la "maldita circunstancia del agua por todas partes". Gelsomina lee, escondida en su propia isla, un ensayo sobre Virgilio Piñera y el sentimiento piñerano se traslada a su visión sobre la isla: "ha comenzado a sentir que el refugio es muy pequeño, que la frazada cubre con demasiado celo cualquier rendija, que el espacio cerrado la sofoca y le corta la respiración, le dificulta la lectura" (Mateo Palmer, 2010: 75-76). ${ }^{63}$ El grito “¡nadie puede salir! ¡Nadie puede salir!” del poema piñerariano, se traslada a los sentimientos del personaje que comienza a percibir con resquemor y claustrofobia los límites de su propio encierro. La reflexión sobre la noción de límite espacial, tan fuerte en el poema de Piñera, la utiliza para analizar su propia situación de encierro (en el manicomio, pero también el auto-encierro debajo de la cama), los límites impuestos a su identidad y, de esta manera, comienza a vislumbrar la posibilidad de salir, de liberarse, de elegir el espacio exterior. La percepción del propio encierro, la sensación de ahogo y claustrofobia, le permiten a Gelsomina mirar el exterior y reconocer una parte de sí en los otros personajes. Es en este episodio cuando se produce una superposición entre la mirada

\footnotetext{
${ }^{63} \mathrm{El}$ fragmento del ensayo que lee Gelsomina se incrusta en la novela sin marcas que aclaren tal añadido y es, nuevamente, una parte del libro escrito en co-autoría con Álvarez Álvarez aunque con algunas elisiones o modificaciones.
} 
y la voz de Gelsomina y la de la enferma de la 23 que vuelve a confirmar el desdoblamiento de la identidad: la paciente 23 es lo que ella no quiere ser, por eso, la mira desde abajo de la cama y observa contar obsesivamente los dedos de sus manos mientras permanece atada a la cama, luego de intentar escaparse la noche anterior: "Aquello era una pesadilla, una broma, una fantasía del médico de la guardia de la noche anterior. Ella no era la 23. Ella no estaba amarrada a una cama de hierro. Ella no estaba loca, ni recluida en un hospital psiquiátrico. Ella era una niñita azul contando los pequeños dedos de su mano y nada más” (Mateo Palmer, 2010: 80).

"El vuelo insular" comienza con un epígrafe de Nicolás Guillén: "Las islas van navegando,/navegando, navegando,/van navegando encendidas” (Mateo Palmer, 2010: 99) que pertenece a los versos finales del poema "Calor" de West Indies, Ltd. Este poema que contrapone el espacio mítico y paradisíaco con el espacio de la injusticia social, del hambre, de la explotación económica, es uno de los poemas centrales de la década del treinta del siglo pasado, cuando comienza a asumirse el problema de la identidad cultural en toda la región caribeña y se desentraña la situación de dependencia económica y sumisión. Los versos elegidos para el epígrafe delinean una metáfora que presenta las islas antillanas en estado de movimiento (avance) dentro de la historia. Y es justamente la búsqueda de movilidad, de avanzar, la que impulsa a Gelsomina a buscar una salida a su estado de inmovilidad física e identitaria. La reflexión se inicia con una referencia a Flight, la goleta de Shabine (el héroe de Derek Walcott en Tales from the Islands) que le permite salvarse y aventurarse a lo desconocido: “¿Dónde está la goleta Flight, aquella en la que se embarcó Shabine, el héroe, el que canta desde las profundidades del mar y recorre los blancos archipiélagos en un largo viaje destinado al olvido?” (Mateo Palmer, 2010: 99). Al igual que Shabine, Gelsomina debe buscar una tabla de salvación ya que su isla está en peligro a causa del agua que derraman las enfermeras durante la limpieza. 
En este fragmento, la lectura sobre la condición insular recupera la historicidad de las islas: "un mar convertido en historia, que encierra en la bóveda de sus profundidades el testimonio del devenir antillano: los restos monumentales de las batallas, los huesos de los héroes fundidos con la arena, las cadenas de los esclavos, los sables del pirata" (Mateo Palmer, 2010: 101). Gelsomina lee los comentarios sobre un poema, operación que repite una y otra vez en una lectura de poesía diferida, es decir, no lee el original sino a través de otras lecturas que ya deglutieron la versión primera. Así, por ejemplo:

retomó la lectura en el párrafo donde se comentaba otro poema. Seawell es el antiguo nombre del aeropuerto internacional de Barbados, nombrado actualmente Grantley Adams. Hacia allí se dirige el avión donde viaja un sujeto que se aleja de un territorio (Mateo Palmer, 2010: 101).

En este fragmento analiza el poema "El mar es historia" de Derek Walcott que no aparece transcripto, aunque sí en el capítulo sobre la insularidad de El Caribe en su discurso literario: “¿dónde está tu Renacimiento? / Señor; está encerrado en estas arenas marinas,/ más allá del bajío afanado del arrecife,/donde los hombres de guerra yacían luego de flotar/(...)/ y estas cuevas vaídas con crustáceos/horadadas cual piedras/son nuestras catedrales" (Álvarez y Mateo Palmer, 2005: 107). Las lecturas del poema de Walcott le sirven a Gelsomina para reflexionar sobre su propia situación, e incluso podrían ser una proyección del exilio como posibilidad:

No soportaba la idea de la despedida. No se sentía con fuerzas para abandonar su paisaje. No vería agitarse un pañuelito blanco como señal de adiós, no quería ver desaparecer en el horizonte los contornos de su isla sabiendo que nunca más la iba a habitar. No estaba preparada para esa ausencia. Prefería quedarse allí, anegada en agua, chapoleteando, defendiendo su espacio. Todos los intentos de la enfermera por hacerla huir serían fallidos, todas sus conspiraciones se verían frustradas. No partiría como Gertrudis, ni tendría que gritar adiós a las costas de su país natal cuando el ancla se alzara y crujiera la turgente vela (Mateo Palmer, 2010: 102).

Las referencias a su presente en el manicomio, a su alislamiento, a su identidad remiten también a Cuba. Son dos los poemas que sirven de intertexto (ambos, en parte, transcriptos en el ensayo antes mencionado); el primero pertenece a Tales of the Island de Derek Walcott 
en el que el sujeto lírico parte de su país natal y cuyos últimos versos son interpretados como expresión del deseo de permanencia, el afán de inmovilidad y la imposibilidad de esa quimera. El otro es “Al partir” de Gertrudis Gómez de Avellaneda. Gelsomina se detiene a reflexionar sobre la imposibilidad de las quimeras pero es la 23 , su otro yo, la que le dice que no hay quimeras imposibles. Y esta aserción se puede pensar a partir de las múltiples identidades que adoptaba el personaje en el manicomio cuando la 23 (la parte negada de Gelsomina, todo aquello que ella no quería ser) encarnaba a diferentes mujeres: la Iris Chachón, la máscara de Tituba, la viuda Pascuala de Historia de una pelea cubana contra los demonios de Fernando Ortiz, a la Condesa de Merlín.

"La isla recobrada" tiene un epígrafe de César Vallejo "Que soy dos veces suyo: por el adiós y por el/regreso" (Mateo Palmer, 2010: 127) que pertenece a "El buen sentido" de Poemas en prosa. Ya a partir de la elección de un poema en el que entabla un diálogo con la madre, se condensan evocaciones sobre esta relación, se alude a la partida del yo poético a París y a la posibilidad del regreso, es posible advertir el vínculo que se establece a lo largo de este apartado entre exilio e identidad. ${ }^{64}$ Gelsomina retoma la lectura de la revista cuando reflexiona sobre la posibilidad de regreso al país natal y se recupera Cuaderno de un retorno al país natal, el libro de poesía de Aimé Césaire (quien, al igual que Vallejo, también parte a un París luminoso y luego regresa a su país de origen). Nuevamente, no lee la poesía sino la interpretación, la lectura previa que se hizo de ella. ${ }^{65}$ Esta lectura teórica dispara la reflexión sobre otras partidas más ligadas a la historia cubana: Gelsomina piensa la partida no sólo desde el que emprende el viaje (por exilio o por elección propia) sino también desde las

\footnotetext{
${ }^{64}$ Además, el título puede leerse como una alusión a Memorias recobradas de Ambrosio Fornet (1998) en el que se recupera el discurso literario de la diáspora.

65 También este análisis está en El caribe en su discurso literario, en el apartado "Migraciones y viajes" (2005: 185-186), aunque acá sí aparecen fragmentos de la poesía de Césaire.
} 
consecuencias que genera la separación en los que se quedan (la nostalgia, la desintegración familiar, la pérdida de identidad, etcétera):

Al leer estas palabras sobre Césaire, Gelsomina pensó en sí misma, ahora ausente, enferma, recluida en un manicomio de altas paredes blancas, y sintió que el regreso era lo más difícil, quizás un objetivo inalcanzable. Quien regresa no es ya el mismo que partió, ni igual será su mirada sobre la tierra recobrada, repitió. ¿Cuánto perdería en ese viaje de regreso que ahora le parecía un camino, más que largo y tortuoso, interminable? ¿Cuándo y cómo se reconciliaría con ella misma, con su ser disociado y fragmentado en pedazos que aún se resistían a la reconciliación? ¿Cuáles de las zonas más dañadas de su ser podrían recuperarse y sanar, cuáles estarían irremediablemente marcadas por la enfermedad? (Mateo Palmer, 2010: 129).

La lectura de la revista se convierte nuevamente en su tabla de salvación, es decir, la lectura se erige como una forma de reconstruir su identidad, la identidad desmembrada y enferma que no se traduce en marcas visibles en el cuerpo aunque sí interiormente, con "monstruos que habitaban su cabeza, las deformidades de sus ideas, las pústulas y las llagas de su pensamiento" (Mateo Palmer ,2010: 130).

"Las islas del dolor" comienza con un epígrafe de Julia de Burgos "Entretanto, la ola,/amontonando ruidos sobre mi corazón./Mi corazón no sabe de islas sin naufragios" (Mateo Palmer, 2010: 143) que pertenece al poema "Entre tanto, la ola". ${ }^{66}$ La obra de esta poeta puertorriqueña se caracteriza no sólo por las rupturas con los discursos autorizados para la mujer, sino también por textualizar una dualidad que se construye a partir del desdoblamiento de la vOz poética. ${ }^{67} \mathrm{Y}$, justamente, en la disposición formal de este apartado se superponen las dos caras de la protagonista: en el manicomio y en la reflexión sobre lo insular. Se produce una exploración de la conciencia y un enfrentamiento consigo misma, cuestión que puede ser pensada a partir de la proliferación del yo (Gelsomina, la

\footnotetext{
${ }^{66}$ Apartado adquiere una connotación diferente porque (además del final) es la única sección que rompe la lógica de la estructura coral descripta en el inicio de este análisis. Acá se funde la parte "Gelsomina en...." con las reflexiones sobre la isla que aparecen regularmente después de "La carrera interminable".

${ }^{67}$ Esta poeta ha trabajado la duplicación del yo poético (en el mismo "Entretanto la ola" o también, por ejemplo, en "A Julia de Burgos", "Soy una amanecida del amor"). Para un análisis de la poesía de esta autora, consultar "De Burgos, Julia: el desdoblamiento del yo en la poesía de Julia de Burgos" Enciclopedia de Puerto Rico (Consultado el 20/02/2012) www.enciclopediapr.org
} 
paciente 23, hija -María Mercedes Pilar de la Concepción — madre, hermana) que tensa la noción de un yo coherente y fijo.

En este apartado se produce un juego de espejos entre la lectura y los actos de la protagonista y la 23 (su yo negado). Gelsomina vuelve a retomar la lectura de la revista, esta vez centrada en la obra de Julia de Burgos y la construcción del doble poético lleno de contradicciones donde se rechaza a la mujer convencional. Cuando interrumpe la lectura comienza a describir las acciones de la 23 , quien se transformaba para seducir al médico “amoldando su imagen a la que, según su imaginación, pudiera resultar grata al objeto de su deseo" (Mateo Palmer, 2010: 144) y luego continúa leyendo sobre el doble poético de la poeta. Al igual que Julia de Burgos, Gelsomina se construye desde el lenguaje, desde la lectura (y si pensamos a la protagonista como alter ego de la autora, también desde la escritura):

'Padece de amnesia', escribió un funcionario en la planilla de admisión a un hospital de los Estados Unidos, tachando los datos que Julia había escrito acerca de su ocupación: escritora, periodista, traductora. 'Padece de amnesia', fueron las palabras que sustituyeron los trazos de su mano, como si no fuera posible que una mujer, mestiza, pobre, rota, pudiera poseer esos atributos (Mateo Palmer, 2010: 146).

Se produce una superposición de planos entre la lectura y los hechos del manicomio: a la lectura de la historia de Julia de Burgos loe sigue un párrafo que se inicia con un "Padece de amnesia” (Mateo Palmer, 2010: 147), dicho por el doctor, cuando la 23:

después de muchas preguntas inútiles, no supo decir cuáles eran su edad y su ocupación, ni recordar su verdadero nombre. La 23 había ocultado las huellas de su identidad detrás de tantas máscaras que ahora ya no sabía quién era realmente. Pretendió que la ausencia de recuerdos borrar los centros dolorosos que irradiaban la angustia por todo su cuerpo. Travestida, mutante, desdoblada en personajes diversos, había emprendido una fuga que parecía no tener fin. Quería recordar su nombre y no podía (Mateo Palmer, 2010: 147).

Y luego narra una historia que remedad la vida de Julia de Burgos con el médico dominicano que residía en Cuba. Con todo, el quiebre con la historia de la poeta y la superposición de la identidad desdoblada se produce cuando el médico le pregunta si tenía 
hijos y la 23, como respuesta, se estira sobre la cama adoptando una posición rígida, inmóvil: “Gelsomina observó, sin embargo, que aun en su perfecta inmovilidad y magistral estatismo, no había podido evitar que las lágrimas rodaran, suaves y silenciosas, apenas perceptibles, por sus sienes” (Mateo Palmer, 2010: 149).

"La memoria insular" comienza con un epígrafe de Lezama Lima: "Llamadas voces corrían por el canto del cielo/ bordeando los dedos de las islas./ Una voz que se aislaba,/palmeras, islas nadadoras, hojas del recuerdo..." (Mateo Palmer 2010: 181) que pertenece al poema "Como un barco" de Enemigo rumor. En este apartado, Gelsomina lucha contra la muerte blanca en que la sume la monotonía de los altos manicomios, es decir, la modorra de una cotidianeidad que la hace sentir una tabula rasa, otra isla en la que se encuentra sumida su identidad: "sin angustias, pero sin alegrías; sin ansiedad, pero también sin fe" (Mateo Palmer, 2010: 182). En este contexto, la lectura vuelve a convertirse en la única tabla de salvación: "Leía entonces, morosamente detenida en cada palabra, buscando una brújula en la letra impresa que la alejara del silencio blanco de la locura" (Mateo Palmer, 2010: 182). Y en este intento de reencuentro con su yo, con su memoria, la protagonista elabora modos de reconciliarse con su cuerpo y, para esto, rememora momentos de su infancia en los que sintió armonía y plenitud con el entorno: la sensación de flotar en el mar o la imagen de un caballo capaz de ser dueño de su propio cuerpo después de someterse al otro.

"El olvido insular" es el último capítulo dedicado a la reflexión sobre la insularidad y se inicia con un epígrafe de Derek Walcott "Nostálgico, mi deseo/ se arrastraba sobre la nieve/ cual humo, en busca de su llama extraviada" (Mateo Palmer, 2010: 211). Como en estos apartados, la protagonista también se recluye en su isla-lectura para alejarse del mundanal ruido. La presencia cercana de la muerte de un paciente la lleva a reflexionar una y otra vez sobre la "rutina demencial" y su posibilidad de escapar de los blancos 
manicomios. La lectura de la revista se detiene en el último ensayo sobre las islas, dedicado a Claude McKay, un poeta jamaiquino que emigró a Nueva York y en cuya poesía, con el tiempo, el olvido se produce pero es asumido como fatalidad y, como respuesta, "su ser se afirma, entonces, en esas pequeñas islas donde la memoria pudo cobijarse" (Mateo Palmer, 2010: 214). En este apartado, la identidad de Gelsomina y la paciente 23 se superponen y se explicita el desdoblamiento de la identidad: "Miró los dos números delineados con pintura roja sobre una tablilla fijada al balaústre de su cama: 23 . Ahora que casi estaba de alta podía aceptar el número, la identidad que le habían otorgado durante su estancia en el hospital: la 23” (Mateo Palmer, 2010: 215). Próxima al alta, la configuración de la identidad se produce en esta aceptación pero, también, en el mismo acto, en olvido o borramiento de ese pasado aIslado: "Esa tarde dejaría atrás la cama 23. Nunca más habré de regresar", pensó" (Mateo Palmer, 2010: 215).

En "Gelsomina en la isla entrañable" y en "Gelsomina frente al mar" se superponen los dos espacios: aquel dedicado a la reflexión sobre la insularidad y el otro centrado en la identidad del personaje. El primero comienza con palabras de María Zambrano (palabras que aluden al poema "Lo fatal" de Rubén Darío): "No existe dolor más grande que el de vivir en lucidez, ni mayor pesadumbre que la vida conciente" (Mateo Palmer, 2010: 225) y, justamente, es el capítulo donde se reflexiona sobre el regreso, la vuelta a la vida fuera del encierro y el reeencuentro con otros desdoblamientos de su identidad: "Volver era más difícil que emprender el viaje. Al partir, todo había fluido imperceptiblemente. Gelsomina sabía ahora que esa dimensión en la que se refugió su ánima coexistía con las coordenadas del mundo cotidiano. Ambas habitaban un mismo espacio, superpuestas” (Mateo Palmer, 2010: 225). Esta recuperación de la conciencia, significa enfrentar "la realidad desoladora de su entorno" (Mateo Palmer 2010: 226) y, en este camino bajo los efectos de la clorpromacina, "[t]endría que mirarse por dentro como 
un espejo invertido, pues la lucidez no tornaría sin esa reconciliación con el lado oscuro de lo entrañable" (Mateo Palmer, 2010: 226).

En este camino final de reencuentro y reconfiguración con su múltiple identidad, realiza votos a tres deidades protectoras de los exiliados de su mente: a Orula (dios de la religión yoruba que personifica la sabiduría y la posibilidad de influir sobre el destino), a los libros, es decir, la "cartografía que la ayudara en su peregrinaje" (Mateo Palmer, 2010: 228), específicamente recurre a la lectura de María Zambrano (transcribe reflexiones de la filósofa sobre el saber del corazón) y, por último, recita como en letanía, los versos del Suicida:

...id y avisad a la que está en la orilla, la exiliada del mundo, Gelsomina.

$¿$ Ves esta piedra, Gelsomina, aislada, la piedrecita que empañó la huella de bestia y hombre y astro, abandonada, inútil como fondo de botella,

para qué servirá? Yo no sé nada, ni a los sabios comprendo en sus querellas, mas... si ella no sirviera, la ignorada, inútiles serían las estrellas (Mateo Palmer, 2010: 232).

Y el capítulo final, "Gelsomina frente al mar", comienza también con versos del Suicida: "Ma, dove val?, ¿adónde? Gelsomina/ ¿Por qué estas frente al mar arrodillada" (Mateo Palmer, 2010: 233) y Gelsomina arrodillada frente al mar. En un tono poético, ausente a lo largo del libro, el relato final está constituido sólo por dos párrafos que adquieren connotaciones de letanía por la repetición de los versos del poeta mediante recursos como la anáfora y el ritmo. Primero se repite tres veces el verbo que encarna la postura del cuerpo de la protagonista, redimida frente al mar: "Arrodillada, porque así el cuerpo, sin perder su absoluta dignidad erecta, desciende de su acostumbrada altura para contemplar el espectáculo de la vida desde abajo" (Mateo Palmer, 2010: 233) y así tres veces recupera, desde distintas perspectivas, reflexiones sobre la posición de la penitencia, 
del dolor, de la súplica, de la adoración. Ese "arrodillada" que luego se transforma en dos repeticiones finales: "De rodillas, porque el peso de la isla es a veces aplastante y no bastan las fuerzas para sostenerla" (Mateo Palmer, 2010: 234) en clara alusión a la isla piñeriana. Y el párrafo último que repite también cuatro veces "Frente al mar" retoma nuevamente alusiones lezamianas: "Frente al mar, porque siempre vivió cerca de la costa y creyó que haber nacido aquí era una fiesta innombrable, un redoble de cortejos y tritones reinando" (Mateo Palmer, 2010: 234) y son esos (tensos y polémicos) versos, es ese mar y su condición de isla lo que le otorga identidad: "Frente al mar, porque esas aguas han bañado su cuerpo desde la infancia le han otorgado la condición de isla cuando, flotando a la deriva cerca de los arrecifes, ha sentido que crecen ramas en sus brazos" (Mateo Palmer, 2010: 234). Identidad hecha de su condición insular, de la configuración del mar y de la orilla como espacio donde llegan "con más fuerza las brisas de otras regiones” (Mateo Palmer, 2010: 234), es decir, donde se engulle (y transforma) el pensamiento y que también es el espacio de sanación ligado a lo religioso: el mar como baño que lava y purifica y sana las heridas. La poesía y la religión, entonces, constituirían las vías para que el sujeto recupere la unidad.

La lectura del ensayo y la novela permiten percibir el esfuerzo de Mateo Palmer por anudarse a otras tradiciones que exceden lo nacional y permiten vincular a Cuba con el Caribe (y también con América Latina). En Ella escribia poscrítica esta apertura se realiza también desde el sujeto que enuncia: un sujeto que rompe con la homogeneidad y se abre a la multiplicidad. De la misma manera, la identidad nacional se deja de lado para, en cambio, realizar una apertura al Caribe. En la Desde los blancos manicomios la operación es similar pero se realiza a través del uso de la cita y de los epígrafes que permiten realizar un recorrido por las ricas matrices literarias del Caribe. Pero este recorrido lo realiza un sujeto enajenado, 
fuera de sí: no olvidemos que Gelsomina (nombre ficcional elegido por el personaje) es la que realiza las lecturas. Es decir, las reflexiones sobre el agua, la isla, la insularidad, la poesía, la creación, están puestas en el personaje de la alienada, hecho que no deja de ser significativo si se piensa que es ese espacio identitario marginal el elegido para enunciar. El alislamiento de Gelsomina alude a la materialidad de la condición insular y, en el mismo gesto, a la posibilidad de superar esta situación mediante la apertura a la multiplicidad del Caribe que estaría eximida así de los límites territoriales para, en cambio, conceptualizarse a partir de la riqueza cultural de un área atravesada por las convergencias y divergencias históricas, por el flujo constante y por la superposición de tiempos.

\subsection{Conclusiones parciales}

Frente a un modelo cultural como el cubano que se pretende unívoco, articulado en un sistema de convenciones, ideas y actitudes valoradas, las operaciones discursivas analizadas en el ensayo y en la novela de Mateo Palmer, en tanto productos culturales que funcionan como "estructuras del sentir", en términos de Williams, dan cuenta de desplazamientos en la construcción de la subjetividad de figuras femeninas que rompen con el modelo homogéneo y, por el contrario, se deslizan hacia la multiplicidad y la heterogeneidad. En Ella escribia poscrítica se construye un lugar de enunciación desplazado en el que la narradora/protagonista, en su afán diseminatorio, adopta distintos nombres según el "yo" con que se identifica en cada momento: la Mitopoyética, Dulce Azucena, Surligneur-2, entre otros. El posicionamiento del sujeto femenino que enuncia el discurso condensa un problema del "nosotras" más que del "yo"; es decir, remite a la situación de otras que como ella quieren escribir en un contexto atravesado por las crisis en el que la lucha por la subsistencia cotidiana dificulta encontrar el tiempo y el espacio necesarios para la escritura. 
En Desde los blancos manicomios, la fragmentación del sujeto femenino se observa en la elección de una protagonista que elige aIslarse en un manicomio y desde ese espacio reconstruir una identidad no acabada sino múltiple; una identidad en la que ese "yo" no es unívoco sino que fluctúa, se desgaja y se reconstruye desde esa inestabilidad. Ese movimiento interno se proyecta en una visión de caleidoscopio: la protagonista se delinea, nuevamente, en sus múltiples nombres. La fragmentación de los sujetos femeninos funciona en paralelo con la fragmentación de la estructura narrativa: tanto la novela como el ensayo están construidos por una densa trama de citas, alusiones, relaciones intertextuales que otorgan a los textos una multiplicidad de posibles lecturas, algunas de las cuales he desandado en el análisis.

Tanto en el ensayo como en la novela es recurrente la creación de figuras de escritoras así como los juegos entre la narradora y la autora (Mateo Palmer) es decir, entre realidad y ficción (aspecto cuyas implicancias también analizaremos en los siguientes capítulos). Esta operación pone en entredicho el lugar asignado a la mujer en el campo cultural cubano y, al mismo tiempo, plantea posibles subversiones: la construcción de una genealogía en la que reconocerse, el uso (y abuso) de la intertextualidad como modo de devorar y homenajear la literatura y la identificación con una tradición literaria caribeña. Ambos textos, además, en tanto géneros discursivos dialógicos (Bajtín 1986) rearticulan el espacio doméstico al que se ha confinado históricamente a la mujeres (Beauvoir 1949) ya que se vuelve un ámbito productivo en el que los quehaceres cotidianos de estos sujetos se conjugan con reflexiones teóricas y/o literarias. De esta manera, la ficción procesa la complejidad en que se debaten sujetos que también están insertos en un espacio público regido por leyes patriarcales.

Por último, estas obras de Mateo Palmer desestabilizan las fronteras genéricas o, en otras palabras, producen desplazamientos en términos de género literario: el ensayo está 
atravesado por apartados netamente ficcionales mientras que en la novela se traman hipótesis literarias y ensayísticas. Creo que ambas opciones pueden proyectarse como formas de pensar la crítica o, mejor dicho, la "poscrítica" (para utilizar la propuesta de Mateo Palmer) escrita por mujeres: un espacio en el que se conjuga autobiografía, ficción y crítica literaria. ${ }^{68}$ La desestabilización del género (sexual y literario) es un aspecto que se acentúa en las obras de Ena Lucía Portela que veremos en el siguiente capítulo.

68 En Por si nos da el tiempo Julio Ramos (2002) también produce un cruce de géneros en el que, llamativamente, la entrevista que cierra el libro se introduce con el título "Ella también escribía poscrítica". Esta alusión resulta sugerente por varias razones: en este corto texto atravesado por la ficción, la autobiografía y la crítica, Julio Ramos alude a una amiga cubana llamada Ana (recuerdo al lector que el nombre completo de la escritora analizada en este capítulo es Ana Margarita Mateo Palmer). Este intertexto (es decir, la alusión que hace Ramos al ensayo de Palmer) puede ser leído como un intento de hacer sistema entre dos modos semejantes de pensar la crítica literaria. 


\title{
III.Torsiones de género (sexual y literario):
}

\section{la construcción de la subjetividad en la narrativa de Ena Lucía Portela}

\author{
Malintencionado sí, pero falso no es... ;Un poco más y pone hasta \\ los nombres de la gente con segundo apellido y todo! No, lo peor no es eso (el viejo hablaba despacio, \\ saboreando las palabras). ¿Qué es lo peor? Lo peor es que ese librejo infame está bien escrito. \\ Ena Lucía Portela, El viejo, el asesino y yo
}

En el capítulo anterior aludí a la forma en que la obra de Mateo Palmer procesa las fracturas internas, la densidad y los bordes del campo cultural cubano signado por el conflicto inherente al contexto socio-histórico en que se enmarcan sus producciones y a la evidente supremacía patriarcal de las leyes que regulan el funcionamiento del campo. La reclusión en el ámbito de lo privado, en el silencio y en la soledad constituyen recurrentes posiciones adoptadas por las protagonistas de estas historias enmarcadas en la crisis que atraviesa Cuba desde principios de los noventa. Esta operación también está presente en la obra de Ena Lucía Portela (La Habana, 1972-) pero sus personajes femeninos traman otras modulaciones de la identidad de género sexual que se conjugan con torsiones en los géneros literarios. Portela irrumpe desde muy joven en el campo literario cubano con la publicación, en 1990, del cuento "Dos almas perdidas nadando en una pecera", la primera explícita narración lesbiana de la literatura cubana. ${ }^{1}$ En ese entonces comenzaba a estudiar Lenguas y Literaturas Clásicas en la Universidad Nacional de La Habana. Su primera novela sale a la luz cuando la década de los noventa no había llegado a su fin y en este periodo sitúa precisamente las diégesis de El pájaro: pincel y tinta china (1998) y de sus siguientes

\footnotetext{
${ }^{1}$ La obra de Portela ha sido estudiada sobre todo a partir de la presencia del homoerotismo ya que es la primera escritora que ingresa en estos temas. Para estos estudios, consultar Víctor Fowler (1998 y 2001).
} 
publicaciones: La sombra del caminante (2001) y Cien botellas en una pared (2002). En la actualidad trabaja como editora en la sección de narrativa de la Editorial Unión. ${ }^{2}$

En la producción de esta escritora la escenificación y problematización del acto de escritura son constantes. La literatura adquiere un lugar central, ya sea por la densa apelación a la intertextualidad, por las alusiones literarias, las reflexiones explícitas sobre el hecho literario y, sobre todo, por la recurrencia a figuras de escritora. La multiplicidad es un rasgo presente en la construcción identitaria de estos sujetos, cuestión que en Portela funciona en sintonía con fugas de los géneros literarios puestos en juego en la trama narrativa. Para explicar estos movimientos, en este capítulo analizo en "El viejo, el asesino y yo" (1999) y en Cien botellas en la pared (2002) cómo construye la figura de escritora porque esto permite leer cómo Portela configura su lugar en el campo literario: cómo se percibe a sí misma, su relación con sus contemporáneos y con sus precursores. Para analizar estas operaciones resulta útil la propuesta que realiza María Teresa Gramuglio (1992) en "La construcción de la imagen", cuando señala que los escritores construyen en sus textos figuras de escritor y que estas figuras suelen condensar (a veces oscuramente, a veces de manera más o menos explícita) imágenes que son proyecciones, autoimágenes, y también anti-imágenes o contrafiguras de sí mismos. En torno de las figuras de escritor, advierte, se arremolinan (en estado fluido y no cristalizado) una constelación de motivos heterogéneos que permite leer cómo representa en la dimensión imaginaria, la constitución de su subjetividad en tanto escritor, y también, más allá de lo estrictamente subjetivo, cuál es el lugar que piensa para sí en la literatura y en la sociedad. Además, Gramuglio precisa que “en estas figuras, el autor proyecta [...] tanto una idea de sí en cuanto escritor como una idea acerca de lo que la literatura es. En ese sentido, es posible postular que la construcción

\footnotetext{
2 Sobre el presente de Portela, remito a "Alas rotas" (2009), testimonio sobre el mal de Parkinson, enfermedad que padece desde 1993.
} 
de la imagen conjuga una ideología literaria y una ética de la escritura” (Gramuglio, 1992: 39).

En el primer apartado analizo "El viejo, el asesino y yo" (1999), cuento que examina el funcionamiento del campo literario y el oficio de escribir con especial énfasis en cómo resuelve (o no) esas problemáticas la mujer escritora. ${ }^{3}$ La hipótesis que guía esta lectura parte de considerar que, mediante la reflexión metatexual, Portela presenta la escritura como un espacio paradojal que permite asumir al mismo tiempo el riesgo y la libertad de su ejercicio, también como un espacio propicio para la búsqueda formal y para la proyección pública. De esta manera, pone en evidencia que el ámbito de la literatura es un campo de lucha donde se juega la aceptación o el rechazo de patrones y autoridades establecidos. En el segundo apartado ingreso en Cien botellas en una pared (2002) para realizar un cruce entre el desvío del género policial con la torsión de género sexual que representan los personajes femeninos de la novela. También analizo cómo se vinculan estas torsiones con la configuración de la ciudad -espacio por antonomasia del policial.

\subsection{Ars poetica: el autorretrato en "El viejo, el asesino y yo"}

No me gustan los grupos ni los partidos ni los tumultos, y eso de las generaciones en literatura me parece bastante artificial, puro invento de los críticos. No olvidemos que la crítica es todo un género literario, en modo alguno ajeno a la ficción. Los críticos fabulan, andan por abí como Adán, nombrándolo todo, y luego pretenden que la realidad sea como ellos la han inventado.

Ena Lucía Portela, ¿Quién le teme a Ena Lucía Portela?

"El viejo, el asesino y yo" transcurre durante unas horas en una reunión nocturna en la casa de un joven escritor. Los personajes principales son un viejo escritor consagrado (amante

\footnotetext{
3 Por "El viejo, el asesino y yo", en 1999 obtuvo el Premio Juan Rulfo de Cuento que otorga Radio
} Francia Internacional. 
del dueño de casa) y la joven escritora que narra la historia. Cada uno pertenece a una generación y a una época diferentes. A pesar de que alude a una relación amorosa con Amelia, la narradora siente una fuerte atracción por el viejo y, en el transcurso de la noche, mantiene una larga conversación con él. Esta situación incomoda al joven amante del viejo, dueño de la casa, y ocasiona un desenlace trágico ya anunciado en el título del cuento: la protagonista va detrás del viejo pero, luego de un forcejeo físico y verbal con el amante, cae por la escalera.

En El viejo, el asesino y yo, el título delinea los vínculos de este cuento con el policial: ya desde el paratexto sabemos que se narra un asesinato y, en los primeros párrafos, deducimos fácilmente que el asesino es el amante del viejo y la víctima la narradora. En el cuento sobresale (como en todas las obras de Portela) y con independencia de la brevedad de la anécdota, la reflexión sobre lo literario y sobre los límites entre realidad y ficción. El cuento dibuja una figura de escritora a través de una protagonista que narra en primera persona y que se acerca tanto biográficamente a la autora que llega a confundirse con ella: "Joven promesa de la literatura cubana" (Portela, 2000: 8), se refiere a sí misma la narradora. ${ }^{4}$ Esta estrategia contribuye a tejer la (con)fusión entre verdad y ficción, entre personaje y autora, más aún si se tiene en cuenta que se estetizan las "guerras" propias del mundillo literario (en particular, las dificultades de la joven escritora para ingresar a ese cerrado círculo). Así debe enfrentar la evaluación permanente de "el Viejo", que representa

\footnotetext{
${ }^{4}$ Primera edición: Nuevos narradores cubanos, edición a cargo de Michi Strausfeld. Madrid, Siruela, 2000. Para el presente trabajo utilizo la edición del año 2000 realizada por Letras Cubanas. En 2009 Iraida H. López publica una edición anotada por la misma Portela, El viejo, el asesino, yo y otros cuentos con un interesante trabajo crítico introductorio. Otro ejemplo del juego entre protagonista y autora es el siguiente fragmento del relato en que se alude a Pájaro, pincel y tinta china (1995), la primera novela de Portela: "el viejo se apareció en esta misma casa, todo agitado, con un ejemplar de mi primera novela en la mano. Se la tendió al muchacho y le dijo busca la página tal y lee, lee en voz alta. Y el muchacho le dijo ¿no quieres té?, ¿por qué no te sientas? Y el viejo le dijo lee, vamos, lee, como quien dice pellízcame a ver si no estoy soñando. Y el muchacho leyó. Unas diez páginas, en voz alta (...) ¡Un poco más y pone hasta los nombres de la gente con segundo apellido y todo! No, lo peor no es eso (el viejo hablaba despacio, saboreando las palabras). ¿Qué es lo peor? Lo peor es que ese librejo infame está bien escrito. Mira tú qué clase de oxímoron. Lo peor es que me gusta y que esta mujer perversa hasta me cae simpática" (Portela, 2000: 26). En el cuento "Alguna enfermedad muy grave" la protagonista se llama Ena Lucía Portela.
} 
al escritor consagrado, que posee prestigio y la experiencia del pasado. Como en otros textos de Portela, el escenario en que se mueven y actúan los personajes es cerrado, claustrofóbico — la sala de una casa — pero en este mundo pequeño y limitado donde los comportamientos de los personajes asumen densidad; además, este espacio adquiere un valor simbólico ligado a la insularidad como en la ficción de Mateo Palmer que vimos en el capítulo anterior.

Como se señaló, el cuento arma dos generaciones literarias: la de "el Viejo", ligada al pasado ("La Habana no es la de antes, los carros, los bares, los olores, la forma de vestir -el amor en La Habana tampoco es el de antes"; Portela, 2000: 7), pertenece a la de "mil novecientos cincuenta y tantos. Mediados de un siglo que no es el mío. Porque su época, según él, es la anterior a la caída del Muro de Berlín” (Portela, 2000: 8). Este personaje simboliza el aura intransferible del pasado, ese objeto deseado por la joven generación. En cambio, la de la narradora es otra época: "Todo cuanto escriba yo antes del XXI será una obra de juventud” (Portela, 2000:8). Salvador Redonet Cook, en la antología Los últimos serán los primeros (1993), denominó a los narradores de este período como los "novísimos", los “iconoclastas" y /o "la tercera generación de la Revolución". 5

A pesar de los intentos realizados por la crítica para caracterizar a cada generación (proximidad en los años de nacimiento, credos estéticos, historias vividas, formación intelectual semejante), el cuento tematiza la crisis de este concepto y también el parricidio

\footnotetext{
${ }^{5}$ Salvador Redonet Cook tuvo un papel central en la institución y consolidación de este grupo que constituía la primera promoción de escritores y escritoras nacidos y formados luego del triunfo de la Revolución: Rolando Sánchez Mejías, Ernesto Santana, Alberto Garrandés, Roberto Urías, Ronaldo Menéndez y Ena Lucía Portela, entre otros. Como señala Jorge Fornet, "estos jóvenes también son, desde cierta perspectiva, viejos, al menos en el sentido sartreano: sobrevivientes de una época. Aun cuando sean los primeros narradores del siglo XXI, ya han sido testigos de una transición - la que sobrevino a la Cuba de los noventa-y les corresponderá vivir cambios que hoy resultan imprevisibles" (Fornet, 2006: 96; itálica en el original). Para referirse a la producción de las últimas décadas del siglo XX, el crítico Francisco López Sacha (1996) ha advertido una "vuelta del péndulo", expresión que pretende contraponer la calidad y la cantidad de la producción artística de este período con respecto al inmediatamente precedente. La crítica coincide en que la nueva narrativa cubana se inicia en 1990 con un relato de Senel Paz, "El lobo, el bosque y el hombre nuevo", que recibió el premio "Juan Rulfo" de Radio France Internationale y que sirvió de guión para la película Fresa y chocolate.
} 
implícito en la sucesión de generaciones. A lo largo del relato la protagonista desestima los artilugios utilizados por "el Viejo" para tomar distancia de ella y de su estética y, por el contrario, señala las cuestiones que los aproximan: intereses, recursos estéticos, preferencias literarias, el placer por la divagación. Al mismo tiempo que manifiesta su cercanía con este personaje (no en términos de "generación" sino de individuo), toma distancia del amante de "el Viejo" quien -según los criterios etarios establecidos por la crítica- debería pertenecer a su generación:

El viejo hace un gesto de impaciencia:

- Sigue tú con tus divagaciones y déjanos a nosotros con las nuestras — dice en voz baja.

¿Las nuestras? ¿Las nuestras ha dicho? ¿Existe entonces algo que el viejo y yo podemos designar como "nuestro", aunque no sea más que la imposible suma de dos soledades? (Portela, 2000: 25).

Como se señaló, en el cuento aparece representado el espacio de confluencia e iniciación en el mundo de la literatura, lo que si bien pone de manifiesto las pugnas por lograr reconocimiento y consagración en el mundo de las letras no se centra en la dificultad de acceder al espacio literario público (dónde y cómo publicar, los vínculos con el mercado y/o con el Estado): el eje es el ingreso y/o reconocimiento en el circuito literario restringido, el de los otros escritores:

Como de costumbre, hay mucha gente en la casa. Ruedan de un lado a otro, comentan, murmuran, toman ron. Parece una escena bajo el mar, dentro de una pecera, en cámara lenta. Moluscos.

Otras tardes y otras noches resultan más animadas que ésta: discuten de literatura, hablan de la gente que no está en la casa, se interrumpen unos a otros, se apasionan. El viejo ironiza, grita, se queda ronco, le dan palpitaciones y luego es el insomnio, el techo blanco. Se promete a sí mismo no volver a acalorarse y reincide (...) No he estado presente en esos barullos que horripilan a los editores extranjeros. (No se pelean, es su forma de conversar, son cubanos -le ha dicho un mexicano a otro). Alguien me los describe. Siempre hay alguien para contarme punto por punto lo que ocurre. Menos mal, pienso (Portela, 2000: 9). 
En el fragmento anterior es posible advertir la ironía e irreverencia frente a una forma de sociabilidad (la tertulia) dentro del círculo literario. Y continúa:

\begin{abstract}
Porque delante de mí sólo dicen banalidades, sin alzar la voz apenas, como articulando muy a propósito unos diálogos más insípidos que los del Nouveau Roman o el cine de Antonioni. La asepsia verbal, la sentencia descolorida, la incomunicación. El gran aburrimiento.

Cualquier originalidad, incluso la que resulte de una vasta erudición, podría resultar comprometedora a largo plazo y quizás antes. No se oyen nombres propios, ni siquiera los nombres de los muertos (sólo Esquilo, Byron, Lawrence de Arabia y gente asî), ninguno suelta prenda. Se repliegan. Cierran filas. Actúan como conspiradores. En ocasiones, por provocar, hablo mal de alguien, de algún conocido en el mundo de los vivos, y entonces todos se apresuran a defenderlo. "Es una impresión errónea", me dicen. O se callan todavía más. No hay manera. Como en un retrato de grupo, todos quieren quedar bien (Portela, 2000: 9-10).
\end{abstract}

En estas líneas procesa la dificultad de los escritores jóvenes para ingresar al círculo literario y cómo los que pertenecen a ese espacio llevan adelante prácticas censurables: retaceos de información, el chisme, el corporativismo. Frente al statu quo, la narradora se posiciona como lo nuevo, lo emergente, aquello que desestabiliza a sus pares y a la crítica: "Me acusan de falta de creatividad, de resentida y envidiosa; intentan bloquear mis relaciones de negocios - de vez en cuando lo logran: un simple comentario delante de eso que llamo 'el lector poderoso' puede resultar demoledor-” (Portela, 2000: 12). Para comprender esta visión de la crítica como encorsetadora, resulta útil recordar la caracterización que hace Raymond Williams en Marxismo y Literatura, para quien las formas que asumen los conceptos de "literatura" y "crítica" son, desde la perspectiva del desarrollo social histórico, formas de control y especialización de una clase sobre una práctica social general. Así, demuestra cómo la crítica se convirtió en el único medio de validar la categoría de "literatura" de modo selectivo y especializado y cuya tarea consiste en "una discriminación de las obras auténticamente 'grandes' o 'principales', con la consecuente categorización de obras 'menores' y una exclusión efectiva de las obras 'malas' o 'insignificantes', a la vez que una comunicación y una realización práctica de los 'principales' valores” (Williams, 1997: 
66). Esta visión coincide además con el pensamiento de Portela (2002) recogido en el epígrafe de este aparatado, así como en un comentario realizado durante otra entrevista:

\begin{abstract}
¿por qué entonces tachar de sobreabundante, palabrera y cualquier otro sinónimo de lo que sobra, la prosa no concisa, la que maneja períodos extensos (aunque estén bien construidos, aunque fluyan) es ya un lugar común, algo que se repite y se repite, a menudo con sólo un par de lecturas? ¿Por qué la experimentación, hecha tradición y resemantizada después de las vanguardias, es una fiebre, un sarampión, una inmadurez? ¿Por qué la intertextualidad, las cadenas de citas, las parodias, tan habituales en la ficción posmoderna, son una pedantería, un alarde? ¿Por qué ese culto a la anécdota veloz al punto de que en un tiempo más espacioso no pasa nada? ¿Por qué la palabra que el crítico no conoce y no desea conocer (el diccionario muerde, cuidado con él) es expulsada de la lengua bajo la etiqueta de hipercultismo? ¿Por qué lo que supuestamente se admira en los clásicos es lo mismo que se condena en los contemporáneos? ¿Por qué, sobre todo, esa recurrente apelación a un lector manso (tan irreal y tan inventado como todos), que no quiere complicaciones en su vida y no entiende de sentidos ocultos, pues al parecer no ha leído ni un folletín, toma leche en biberón y se chupa el dedo gordo del pie? (Portela, 2002).
\end{abstract}

En esta sucesión de agudas preguntas retóricas, Portela cuestiona a los críticos literarios que ponen en práctica su función de juicio autorizado como si éste fuera neutro u objetivo. Sus interrogantes gravitan en torno a las valoraciones ideológicas que se enmascaran detrás de las razones supuestamente neutras que la crítica utiliza para analizar, seleccionar y clasificar los textos literarios. De este modo, deja al descubierto que detrás de esta actitud se esconde una distribución específica de poder -formas y dispositivos hegemónicos- que domina, buscando mantener al margen o acallar las formas emergentes.

Ahora bien, ¿Qué lugar ocupa Portela en el campo literario cubano? ¿Qué debates ha suscitado en ese campo su producción literaria? ¿Qué lectura crítica se ha realizado en y fuera de Cuba? A diferencia de otras escritoras cubanas que publican sólo en el extranjero, la narrativa de Portela se publica (y se lee) también en la Isla. Sus novelas y cuentos han aparecido en editoriales como Letras Cubanas, Unión, y fuera de Cuba en Random House Mondadori y Editions du Seuil, Stockcero, entre otras. ${ }^{6}$ Su producción no hace concesiones

\footnotetext{
${ }^{6} \mathrm{Ha}$ sido traducida a diferentes lenguas y editada en muchos países. Cien botellas en una pared ha sido traducida al griego, francés, portugués, italiano, polaco, turco. El pájaro: pincel y tinta china se publicó en 1999
} 
a los temas turísticos (me refiero a los que venden en el mercado), pero tampoco alaba el sistema político cubano. Por lo tanto, su posición resulta incómoda para muchos (eso se puede leer, por ejemplo, cuando la narradora señala que "Los escandalitos van y vienen; me acusan a la vez de oficialista y de disidente de un montón de causas; como tienden a hacer de todo una cuestión política, según las filias y las fobias de cada uno, me ponen lo mismo en la extrema izquierda que en la extrema derecha"; Portela, 2000: 11). ${ }^{7}$ Su producción ha recibido numerosas distinciones, su primera novela, Pájaro, pincel y tinta cbina, recibió el Premio Cirilo Villaverde de la Unión de Escritores y Artistas de Cuba (UNEAC); por la novela Djuna y Daniel obtuvo en 2007 el Premio Anual de la Crítica (convocado por el Instituto Cubano del Libro desde el Centro Cultural Dulce María Loynaz); Cien botellas en una pared, recibió en España el XVIII Premio Jaén de Novela y un año después el Prix Littéraire Deux Océans-Grinzane Cavour que la crítica francesa otorga cada dos años a la mejor novela latinoamericana publicada en Francia. En la isla han escrito sobre su obra Nara Araújo, María Luisa Campuzano, Sandra Lys Valdés; fuera de Cuba han escrito Jacqueline Loss, Iraida H. López, Jorge Rufinelli, Alessandra Riccio y circulan tesis de maestría y de doctorado así como artículos de revista. Sin embargo, este reconocimiento es posterior a la publicación de este cuento por lo que se puede hipotetizar que el marco aluda a sus años de estudiante en la Universidad. Respecto de este período, en una entrevista se refiere a su posición política:

Yo no era propiamente anarquista, por muy bien que me cayeran Alexander Berkman y Emma Goldman -la verdadera, no la de Doctorow -, por más que me hubiese deslumbrado Orwell con su estremecedor Homenaje a Cataluña. Pero igual no era comunista, jvade retro!, y me vanagloriaba de no serlo, y me la pasaba burlándome del

por Ediciones Unión (Cuba) y luego por Editorial Casiopea (España). La sombra del caminante fue publicada primero por Ediciones Unión (Cuba), en 2001 y en 2006 por Editorial Kailas (España).

7 Para caracterizar la posición incómoda que ocupa esta escritora en la isla señalo que en el año 2010 firma la campaña internacional que exige la liberación inmediata e incondicional de los presos políticos cubanos. De esta manera se convierte en la primera integrante de la Unión Nacional de Escritores y Artistas de Cuba (UNEAC) que se desmarca de la línea oficial. Para más información consultar: http:/ / www.elnuevoherald.com/2010/04/01/687391/ena-lucia-portela-firma-la-carta.html\#storylink=cpy También en una entrevista se refiere a esta cuestión, ver Portela (2010). 
gobierno y haciendo chistes «contrarrevolucionarios». Para más folclor, viajé a los USA como escritora antes de discutir la tesis, me tiré lindas fotos a la entrada de la Casa Blanca y junto a la Campana de la Libertad en Filadelfia, y le traje de regalo una bandera americana a una chiquita de mi grupo que era anexionista. Afoqué demasiado. Entre eso, la carencia de «humildad» y el mal de Parkinson que me habían diagnosticado en agosto de 1993 (y que nunca me ha impedido ser moi même en todo mi esplendor), me cerraron las puertas no sólo de nuestra Facultad, sino también las de la Casa de las Américas, las del Instituto de Literatura y Lingüística, las de la Fundación Alejo Carpentier y de no sé cuántas instituciones más.

Finalmente la doctora Graziella Pogolotti, quien prefiere la autenticidad, sea cual sea, al oportunismo, o al menos es la imagen que tengo de ella, me ofreció trabajo como editora en la redacción de narrativa de Ediciones Unión, la editorial de la UNEAC, donde permanezco hasta hoy con chapilla de inventario (Portela, 2010).

Por otra parte, en el cuento que estoy analizando, en este movimiento de ocupar lugares en el juego del campo literario, "el Viejo" aparece dotado de "aura" mientras que la protagonista es una "serpiente" que se desliza sigilosamente hacia él: "lo mejor que se puede hacer con una serpiente es mantenerla a distancia, lo comprendo" (Portela, 2000: 7). Esta es una referencia al bíblico pecado original que posiciona al cuerpo de la mujer como fuente de tentación y perversión, del lado del diablo, acá confundido o superpuesto a él ya que la mujer es la serpiente y no sólo la que se deja tentar por ella, mientras que "el viejo" representa al escritor legitimado con su hálito sagrado, rodeado del aura que otorga el beneplácito y el aplauso del reconocimiento. ${ }^{8}$ Sin embargo, más adelante, la protagonista manifiesta ambigüedad en la actitud de "el Viejo" cuando dice "Sublime encantador que mueve las manos mientras habla de su árbol preferido: la yagruma, se cubre de metáforas como si dirigiera una orquesta sinfónica (...) ¿Cómo le va a molestar a un encantador la atención de una serpiente?” (Portela, 2000: 19). Estas palabras dejan entrever una ambivalencia entre el peligro y la fascinación (ante la palabra del otro: la joven escritora, la

\footnotetext{
${ }^{8}$ Debido a que el objetivo del trabajo es otro, no me detendré aquí en el análisis de las posibles referencias a las que puede aludir la serpiente. Sólo mencionaré que constituye un elemento simbólico central en la cultura cubana y, si nos remitimos a lo literario, no pueden obviarse dos antecedentes ineludibles. Por un lado, el poema "Sensemaya" de West Indies Ltd. (1934) de Nicolás Guillén donde la serpiente adquiere connotaciones negativas y ha sido interpretada como una alusión al imperialismo. Otro antecedente es la novela Cobra (1970) de Severo Sarduy donde es el emblema clave de la novela en sus varias lecturas posibles: como símbolo fálico, como referencia a la Virgen del Cobre, patrona de Cuba, o como deformación del mismo nombre de la isla.
} 
serpiente). En ese sentido, la fascinación que ejerce el viejo, ¿no es también el deseo del pasado, del prestigio y de la épica del pasado? Pasados, todos, angustiosamente imposibles.

\subsubsection{La escritura del cuerpo y el cuerpo de la escritura}

A partir de los elementos señalados en los párrafos precedentes, es posible advertir un giro en las convenciones genéricas clásicas que establecen una división binaria del cuerpo varón/mujer según un patrón biologicista. Si se tiene en cuenta sólo la caracterización mostrada en el párrafo anterior, Portela parece reproducir este paradigma de la heteronormatividad. Sin embargo, la construcción de los personajes desafía estas convenciones genéricas y pone de manifiesto temas de los que antes no se hablaba o que eran silenciados por el discurso oficial: los tabúes vinculados con los cuerpos silenciados o escamoteados en décadas precedentes —el cuerpo y el deseo homoerótico pero también el cuerpo y el deseo de la mujer. Aquí se elude el estereotipo femenino y los cuerpos no se ubican en los clásicos lugares varón/mujer ligados al mandato social de la heterosexualidad obligatoria. ${ }^{9}$ Sin embargo, los personajes tampoco se posicionan en el espacio fijo del deseo homoerótico, ya que las representaciones tanto de la protagonista como de "el Viejo", establecen una amplitud del deseo: la narradora se debate entre el cuerpo de Amelia y el de "el Viejo" sin llegar a optar por uno de ellos; lo mismo sucede con él, cuyo deseo se traslada desde u joven amante hasta los juegos de seducción desplegados con la joven escritora. El cuento semantiza la complejidad del deseo: por un lado, la escritura y la pulsión erótica; por otro, el deseo del prestigio simbólico del pasado (representado en el

\footnotetext{
9 Adrianne Rich se refiere al sexo binario como el "principio de inteligibilidad de la cultura occidental" (Garrido, 2006) para explicar cómo la heterosexualidad es una forma de disciplinamiento social. En consonancia con este planteo, Judith Butler, en el primer capítulo de Género en disputa, deconstruye la continuidad que socialmente se establece entre sexo/género/deseo. Su intención es dislocar las categorías desde las que pensamos, conceptualizamos y vivimos nuestra identidad como sujetos sexuados y para esto pone en discusión no sólo la definición de género sino la de sexo. Desde el paradigma del giro lingüístico, plantea que el lenguaje crea identidades discretas, fijas y excluyentes que ignoran la fragmentación interna de la clase, el color, la edad, la religión o la opción sexual tanto del colectivo "mujeres" como del de "varones".
} 
viejo). Desde este entramado, resulta transgresiva la definición erótica de la escritura y el riesgo del deseo heterosexual en cuerpos que transitan la homosexualidad. Se produce, de este modo, una circulación del deseo que realiza deslizamientos y cruces de identidades:

Pienso en Amelia mientras observo el rostro del viejo, quien todo este tiempo ha estado divagando despacioso y algo frívolo sobre la importancia de los balcones y las terrazas en la vida de la gente. Recuerdas tú, la luna se asomó / para mirar feliz nuestra escena de amor... Ambas imágenes se yuxtaponen, el viejo y Amelia. Se cruzan. Parecen fundidas sin sutura, como las mitades de Bibi Andersson y Liv Ullman en el famoso primer plano de Persona. Quizás el deseo pone en entredicho las identidades, porque el viejo y Amelia se integran en una sola cara y no es el ron ni el aire de la noche (Portela, 2000: 15; itálica en el original). ${ }^{10}$

Esta reflexión respecto de los cuerpos se vincula con la de Judith Butler quien en El género en disputa sostiene que no sólo se construyen (y se disciplinan) lingüísticamente sino que también el lenguaje permite conocer el cuerpo y que la internalización de las normas se realiza a partir de actos, entre los que incluyen las prácticas visuales. En el cuento, la explicitación del deseo parece exacerbarse ante la celosa y vigilante mirada de voyeur del amante pero también de las demás personas presentes en la velada. Porque la mirada de los otros es también la que construye y dibuja el cuerpo de los personajes y también su perversidad. La protagonista es la que mira y explicita su mirada: en la sala, su mirada sigilosa parece una cámara que va detrás del viejo, intuye sus pensamientos, cierra los ojos para buscarlo en el pasado. También se describe a sí misma a partir de la mirada de los otros: la del viejo y la de su amante. Descubre que el viejo la mira "con el rabillo del ojo" (Portela, 2000: 7), que su indiferencia le otorga un lugar porque "no mirar es mirar, que la persona que te ignora puede hacerlo porque sabe justamente dónde estás a cada instante" (Portela, 2000: 16), es la búsqueda de su mirada la que la hace descender a la muerte. Pero también siente la mirada de su adversario: "la mirada de su amante clavada en mi espalda y

\footnotetext{
${ }^{10}$ En el cuento aparecen intercalados fragmentos del bolero En el balcón aquel de Leopoldo Ulloa, quizás con la función de parodiar el tono dramático de las clásicas historias de amor no correspondido, de mujeres abandonadas y amantes tristes.
} 
eso me complace aún más" (Portela, 2000: 12), unos ojos que la persiguen, una mirada intensa, que quema y atraviesa su cuerpo.

Para abordar el tema del cuerpo y la escritura, resulta de interés analizar la aproximación al hecho literario que se configura en este cuento. Para eso, partiré de la tercera acepción de "escritura" que propone Noé Jitrik en Los grados de la escritura (2000), según la cual escribir es un verbo que implica metafóricamente un sujeto de la acción (el escritor), un objeto (la escritura) y una conjugación (el proceso). La idea de "escritor" como sujeto del verbo implica a quien ejecuta o concreta esta acción, en este caso, Ena Lucía Portela. Desde esta perspectiva, es escritor de literatura aquel que "sabe lo que hace mientras lo hace, hasta sus consecuencias últimas" (Jitrik, 2000: 18). Portela también sabe de qué escribir, lo cual puede entenderse de tres modos. En primer lugar, el saber de la experiencia entendida como el conjunto de imágenes que elabora en relación con diversas determinaciones y que aspirarían a ser transmitidas por escrito. En este caso, las experiencias tienen un vínculo con lo "real", o para evitar la complejidad de este término, se puede decir que el tema pertenece a la experiencia de lo real, en tanto se puede anclar o vincular con alguna situación de la realidad exterior: el funcionamiento del circuito literario cubano, el lugar de las escritoras, el peso de lo estatuido. En segundo lugar, la acción de escribir supone una respuesta física ligada al cómo escribe: la posición del cuerpo (el largo y espigado cuerpo de Portela recostado sobre la silla de la habitación en que escribe, luchando contra el mal de Parkinson que la aqueja constantemente), las condiciones materiales y ambientales (penurias económicas de Cuba, la escasez, el apagón de luz a la hora convenida). ${ }^{11}$ Por otra parte, Portela pone en práctica un saber de la retórica lo que

\footnotetext{
11 Así termina el libro de ensayo analizado en el capítulo anterior, Ella escribía poscrítica de Margarita Mateo Palmer. El fragmento despliega las condiciones en que debieron escribir en Cuba durante los complejos años noventa: "Desde la habitación donde escribía sintió cómo las luces de la ciudad se apagaban a la hora convenida. Mutilación de miembros y arterias que horas después intentarían ser restituidos a su debilitada unidad como los fragmentos de Osiris. Encendió la vela que iluminaba humildemente sus manuscritos.
} 
posibilita que la acción de escribir pueda constituirse en el nivel discursivo. Esto se puede analizar tanto en las elecciones que suponen la escritura del cuento como, ya en el interior del relato, en el debate sobre los modos de escribir del escritor consagrado y de "la joven promesa de la literatura cubana". Si se analiza la estética elegida por la protagonista, resulta ilustrativo el siguiente fragmento:

Sucede que tengo mala reputación. Yo, la peor de todas, en principio asumo el comportamiento de un analista o un padre confesor. Me aprovecho de las crisis existenciales, de las depresiones, de los arrebatos de cólera. De todo lo que generalmente las personas no pueden controlar, al menos en nuestro clima tan fogoso. Ofrezco confianza, complicidad, discreción, nunca advierto a mi interlocutor que cualquier palabra que pronuncie puede ser utilizada en su contra (...) Sé escuchar. No interrumpo, no condeno. La atención es una droga. Olvidan que en verdad no soy analista ni padre confesor. Peligrosa amnesia que procuro cultivar (Portela, 2000: 10).

Es sugestiva además la referencia a la firma (con sangre) con que Sor Juana Inés de la Cruz inscribe su renuncia a la escritura. Remite a la situación de la protagonista — mujer y escritora que intenta penetrar en un mundo que en el cuento aparece circunscripto a los hombres y donde ella es la intrusa - y también es un indicio del final del cuento. Luego refiere la fuente de su creación literaria: la indagación en la psiquis de las personas que la rodean, en su interior, en lo íntimo, en lo no dicho, en lo oculto. En las reflexiones metaliterarias también explicita su pulida técnica de trabajo con la palabra ("Trabajo mucho, reviso y reviso cada frase, cada palabra"; Portela, 2000: 10-11), la predilección por la narración y los lábiles límites entre las temáticas y los personajes de sus producciones y el referente exterior.

Medioevales, pensó: por el color del papel, por su textura, por la oscuridad que los envuelve, por la antigüedad de sus fibras, por la luz de la vela, por la mano que los dibuja. Monástica, pensó: la mano, su vocación y el empeño que la sostiene en el sopor de la noche. Es tarde para continuar, para no continuar, para dormir y no [...]

La profesora revolvió las fichas, los manuscritos, los poemas inéditos de un novísimo escritor, las cartas del Tarot, la convocatoria a un evento en Tabasco, hasta que desistió de su afán de encontrar la pluma con la que había estado escribiendo una crítica de la crítica sobre una novela" (Mateo Palmer, 1995: 222). 
La protagonista también señala que teme aburrir a "el Viejo", comentario en el que es posible advertir la diferencia entre dos elecciones estéticas. En el relato, todo lo que sucede es narrado a través de la voz de la conciencia de este personaje en primera persona; este espacio de la descripción pero también de lo no dicho, es el espacio de lo reprimido ante la mirada evaluadora de lo consagrado. Para finalizar esta puesta en discusión de la elección estética, resulta iluminadora la siguiente escena de escritura:

Yo pensaba sentada en el suelo (él, por supuesto, en el sillón) y anoté que al viejo le disgustaba la vehemencia, el homenaje abrumador, la exuberancia intempestiva y desbordada de quien se lanza en pos de sus fantasías sin contar para nada con el protagonista de éstas. Un escritor no quiere ser descrito tan sólo como el objeto del deseo (admiración, ambición) de otro escritor. Un deseo furioso puede llegar a ser anulador (Katherine Anne: la deplorable mujercita que rechazó a Carson), un escritor aspira a existir por sí mismo. Qué cosa (Portela, 2000: 18). ${ }^{12}$

A partir de esta escena de escritura es posible realizar varias lecturas. Hipotetizo que es posible leer no sólo el eje superioridad/inferioridad por las posiciones en que se ubican los personajes, sino también, en otra lectura más sugestiva, pensar que la protagonista proyecta en "el Viejo" la visión que tiene Portela acerca del escritor y del acto de escribir, mientras que por antítesis, aparece descripta su posición. Es decir, por un lado, está la elección de la autora por el escritor ensimismado en el proceso creador, alejado de lo externo al acto de creación (homenajes, admiración, ambición) y cuya prosa es concisa, centrada en la psicología de los personajes. Mientras que en el otro extremo ubica la prosa de la fantasía desbordada, exuberante, que busca el reconocimiento y el elogio de sus pares.

Esta reflexión final referida al tenso vínculo entre lo emergente y la tradición también nos remite al planteo de Roland Barthes en El grado cero de la escritura. Allí ubica la

\footnotetext{
12 Se refiere a las escritoras estadounidenses Katherine Anne Porter (1890-1980) y Carson McCuller (19171967). La primera fue elogiada por la indagación psicológica y la excelencia técnica de sus textos. McCuller fue pionera de temas como el adulterio, la homosexualidad y el racismo.
} 
escritura entre la lengua y el estilo, en ese intersticio ligado a la corporalidad de la escritura y que implica la elección de un tono y de un ethos. El escritor no elige su escritura en una especie de arsenal intemporal de formas literarias, sino que son la historia y la tradición las que establecen las posibles escrituras. En este sentido, Barthes sostiene acertadamente que la escritura es el compromiso entre la libertad y el recuerdo, es decir, es una "libertad recordante" (Barthes, 1971: 24).

\subsubsection{Batallar la tradición: sujetos que desestabilizan el campo literario}

En la historia de la humanidad, poseer y dominar la escritura ha significado poseer el poder (Lévi-Strauss, 1955). La escritura ha sido la manifestación de la dominación o uno de sus instrumentos porque "quien dispone de la escritura ejerce un poder esencialmente apropiatorio" (Jitrik, 2000: 826). Este es uno de los ejes que se problematiza en este cuento en que el sujeto femenino entabla un duelo para ocupar un espacio de legitimación en un campo literario regido por leyes patriarcales. La tensión intelectual y sexual en el triángulo que conforman la protagonista, "el Viejo" y el joven amante se resuelve al final de cuento: la protagonista va detrás del viejo pero, luego de un forcejeo físico y verbal con el amante, cae por la escalera. Para concluir estas páginas, planteo dos posibles lecturas en clave simbólica como modos de interpretación de este final. ${ }^{13}$

Una lectura permite interpretar la caída como el descenso final de la protagonista: la búsqueda de reconocimiento le ocasiona la muerte, por lo tanto no es el camino a seguir ya que supone subordinarse a las leyes establecidas por el funcionamiento del campo literario, mundo que "pertenece a los hombres y todavía más a ciertos hombres, ya lo dijo Platón. ¿Una mujer? Bah” (Portela, 2000: 15). La sala adquiere valor simbólico de la condición

\footnotetext{
13 Otra línea de análisis que no desarrollo en extenso aquí (porque resulta más fructífera para pensar Cien botellas en una pared) pero que he advertido es la parodia del género policial, ya planteada desde el título del cuento.
} 
insular: en este sentido, se puede leer como una metáfora de la nación en la que se dirimen cuestiones de tradición nacional. En esta lectura, adquiere espesor la presencia constante de la mirada de los personajes y, ante todo, la mirada vigilante del joven amante de "el Viejo" Para analizar la metáfora, la mirada sería el ojo omnipresente del pacto entre varones de un orden patriarcal. Así, al igual que el "cuerpo de la nación" (espacio metaforizado en la descripción de la sala en la que transcurre la historia), el cuerpo del sistema cultural cubano ha sido construido como un espacio masculino. ${ }^{14} \mathrm{El}$ cuento denuncia que la mujer escritora ha sido más excluida que los homosexuales porque aunque estos fueron combatidos desde el discurso oficial como lo abyecto, sí han alcanzado cierta circulación en el discurso cultural (el cual no siempre se superpone con el anterior) dentro y fuera de la isla. ${ }^{15}$

En el marco de esta ficcionalización del espacio intelectual, "El viejo, el asesino y yo" construye una figuración de la mujer escritora como un sujeto "marginal" que cuestiona las reglas del campo intelectual, espacio vivenciado como predominantemente “patriarcal” (según los aportes de Amorós, 1991 y 1995). El cuento visibiliza tanto las formas más sutiles de represión "privada" de la mujer, como sus estrategias letradas de rebelión frente a ellas. De este modo, en Portela la escritura se erige como un espacio de resistencia a partir del cual se cuestionan los criterios de legitimación cultural.

Otra posibilidad es leer en el final un vínculo con la estética del cuento "La caída" (1964) de Virgilio Piñera. Relación que también es posible establecer a partir de ciertas alusiones presentes en el cuento de Portela: “el Viejo” remitiría a Antón Arrufat y también

14 En Comunidades imaginadas Benedict Anderson propone pensar la nación como una comunidad imaginada que se establece como una especie de religión laica de la modernidad. En La maldición: una historia del placer como conquista Victor Fowler (1998) analiza algunos textos literarios cubanos que han quedado afuera del modelo hegemónico revolucionario que constituyó una comunidad homogénea mediante la exclusión de los discursos que se alejaban de la norma.

15 Pienso en Reinaldo Arenas, Virgilio Piñera, Severo Sarduy. Las pocas escritoras que han circulado por el discurso oficial son poetas como Dulce María Loynaz o Fina García Marrúz. 
hay una referencia a un amigo muerto que sería Virgilio Piñera. ${ }^{16}$ En el final de "El viejo, el asesino y yo" la protagonista narra en primera persona su caída. Y en la descripción de este hecho el cuerpo se (des)compone en partes inconexas sin tragicidad ni horror ante la inminencia de la muerte. ${ }^{17}$ Literatura que narra desde los intersticios, que se centra en el detalle y que no dice o no nombra ante la imposibilidad impuesta por la palabra y como respuesta ante el desasosiego que provoca el mundo. Los dos cuentos apelan a la elipsis y, de este modo, se convierte en un no-final: sin llantos, sin caos, sin trascendencia, la muerte no se nombra. En este sentido es posible decir que el final es liberador ya que el sujeto alcanza el clímax al final de la caída: en el cuento de Piñera el clímax no está en la cima de la montaña, sino al final de la caída, cuando sólo lo constituye (y está constituido por) los ojos (el narrador convertido en un sujeto fragmentado observa impávido la barba de su

16 En un análisis preliminar del cuento intuí que "el Viejo" podía referir a Antón Arrufat (La Habana, 1939). Pero lo constaté luego, en la edición de Iraida H. López (2009) en la que la propia Portela anota las referencias de sus cuentos. Transcribo el fragmento en el que se alude a Virgilio Piñera y a su amistad con Arrufat porque resulta ilustrativa de la posición irreverente de Portela con la tradición así como sus preferencias: “Ay viejo! Querría decirte que a mí también me gusta tu muerto -quizás menos que a ti: prefiero el teatro de O’Neill, su largo viaje del día hacia la noche es único, es genial, es incomparable desde cualquier punto de vista y tu muerto debió saberlo—, querría decirte que me gusta sobre todo la relación que hubo, que hay, entre ustedes, un viejo y un muerto, que me fascina tal y como la describes en tu libro, que los envidio a los dos porque yo nunca tuve amigos así..." (Portela, 2000: 25). Alude a Virgilio Piñera: entre él y yo (1994) escrito por Arrufat. Que Portela tome distancia de Virgilio, no invalida su obra

17 En el cuento corto de Piñera, la historia es muy simple: dos alpinistas caen desde la cima de una montaña de tres mil pies de altura y uno de ellos narra, en primera persona, cómo en el despeñamiento causado por una ligera alteración de los movimientos - luchan por salvar una parte de sus cuerpos: los ojos de uno y la barba del otro. Con una prosa lacónica y a través de una narración lineal, el narrador toma al lector de la mano para conducirlo según su voluntad y condenarlo a una lectura denotativa del texto. El hecho — la caída e inminente ( $\mathrm{y}$ nunca dicha) muerte - pierde tragicidad y, en cambio, se desmitifica a partir de la comicidad que significa salvar una parte del cuerpo. Esta operación pone en primer plano el detalle: la minuciosa descripción de la caída del personaje preocupado por salvar los ojos y la barba. Piñera rechaza la idea del "todo", del "entero", de la totalidad y, en cambio, ubica en escena la parte, el resto y es a partir de estos elementos que se configura un sistema de producción de sentido. Omar Calabrese (1999) señala que la operación de detallar supone un mecanismo implícito: producir detalles depende de una acción explícita de un sujeto -en este caso, el narrador en primera persona- sobre un objeto -el cuerpo suyo y el de su compañero- y de que entero y parte están copresentes. Este sujeto es el que se hace presente a través de la mirada para describir los hechos, el espacio y el tiempo en el que se desarrolla la acción. De este modo, la mirada se traslada como una cámara cinematográfica que enfoca los hechos tal cual van sucediendo o, mejor dicho, tal como los percibe el narrador a través de los intersticios que dejan las manos de su compañero sobre sus propios ojos, unas manos que ocultan y velan la visión de la totalidad.

El efecto estético que logra el relato de Piñera es, justamente, la desdramatización de la caída y de lo no dicho: la muerte del sujeto. Entonces, la comicidad que puede generar este efecto de desdramatización a partir del intento fructífero de salvar las partes, se puede leer por su reverso: ya no resulta cómico sino que aparece la deshumanización por la mutilación y la desintegración y ante esto, la angustia del sujeto. 
compañero); en el cuento de Portela, se produce una separación entre el "yo" y el cuerpo que rueda por la escalera ("A partir del segundo descanso no soy yo quien rueda por la escalera, es sólo mi cuerpo"; Portela, 2000: 30), así parece haber una trascendencia en ese “yo" que pervive (¿en el hecho literario? ¿en la escritura?) más allá de la materialidad del cuerpo.

\title{
3.2. (Re)visiones de género: Cien botellas en una pared
}

\author{
cuando yo naci (en el Sagrado Corazón, un hospital justo \\ en el sagrado corazón de la barriada), ya el Vedado estaba \\ repleto de ciudadelas y se veía cualquier cosa, desde la bija del latifundista \\ que se habia negado a emigrar hasta el bandolero ex convicto que \\ planeaba atropellar a la hija del latifundista para robarle los cuadros y \\ las lámparas. Era ya la mezcolanza, el ajiaco, el carnaval.
}

Ena Lucía Portela, Cien botellas en una pared.

Ambientada en La Habana en la crisis de los noventa, una narradora protagonista, Zeta, relata la historia de dos asesinatos que se vinculan con su vida. En cada uno de los doce capítulos que componen Cien botellas en una pared, la narradora reconstruye parte de la historia en el intento de explicar o buscar un hilo conductor de los hechos que desencadenan la muerte de Moisés, su amante. ${ }^{18}$ Pero como lectores descubrimos que el "asesinato" (si realmente es tal) queda sin dilucidar y, por el contrario, la historia termina en una serie de suposiciones. En un juego de duplicación autoral, Zeta se construye como la escritora (casual) de esta historia, en contraposición con su amiga Linda Roth, escritora profesional y exitosa que está escribiendo Cien botellas en una pared, su última novela. La voz narradora da paso a una multiplicidad de voces por medio del uso del discurso directo y del

\footnotetext{
${ }_{18}$ Primera edición: Barcelona, Random House Mondadori, 2002. Para el presente trabajo utilizo la segunda edición: La Habana, Unión, 2003.
} 
discurso indirecto libre. De este modo, accedemos a la voz de los otros dos personajes principales -Moisés y Linda Roth- y a la de personajes secundarios como el padre Ignacio, la Gofia, Alix Ostión, Yadelis, entre otros. El tiempo se complejiza porque los racontos y las prolepsis que realiza la voz narrativa trasladan al lector hacia los recónditos pliegues del pasado de cada uno de los personajes (y con ellos, de la historia cubana) y adelanta acontecimientos. El efecto de simultaneidad de pasado, presente y futuro otorga densidad a los pliegues témporo-espaciales de la novela.

La violencia atraviesa toda la historia en la que son recurrentes los episodios de agresión física y psicológica e incluso los asesinatos. Los tres personajes principales conforman un triángulo que visibiliza los distintos tipos de violencia y cómo ésta se vincula con cuestiones de poder y de discurso. Más relevante que el tema es la forma en que éste es abordado, porque la novela se estructura a partir del cruce entre esta temática con el humor, procedimiento que desemboca en el uso de la ironía. Al comienzo de la novela, saturada de escenas de violencia doméstica, la narradora relata el inicio de su relación con Moisés, un ex magistrado del Tribunal Supremo de la República: Zeta lo ve por primera vez en un parque profiriendo un discurso cargado de críticas explícitas al gobierno al que se alude con el pronombre "ellos" para sintetizar los destinatarios de sus palabras: ellos son “los canallas predicadores" (Portela, 2002: 10). ${ }^{19}$ Fruto de esta relación, Zeta carga con un embarazo que oculta para preservarlo de una posible agresión, pero no toma iniciativas para terminar con la situación. Sin embargo, un hecho pone fin a esta relación: una mañana, Moisés, somnoliento, cae desde la ventana del departamento que ambos comparten y que, misteriosamente, alguien había dejado abierta. Al caer, su cuerpo derriba (y mata) a

${ }^{19} \mathrm{El}$ discurso de Moisés está atiborrado de citas eruditas en latín que Zeta traduce para los lectores. Por ejemplo, la primera cita es "si vis pacem, para bellum" y en la nota al pie, Zeta apela a los lectores para aclarar: "Hombre cultísimo y muy elocuente, le encantaba calzar sus discursos con latinajos. Como sé que la mayoría de las personas no tienen por qué entenderlos, están muy ocupadas y carecen de tiempo para buscar las traducciones en un diccionario, me he tomado el trabajo de buscarlas yo. Éste significa: Si deseas la paz, prepárate para la guerra” (Portela, 2002: 13). La primera vez realiza esta aclaración, luego, ante cada cita en latín, sólo aparece la traducción: "nibil novum sub sole” y en la nota: "No existe nada nuevo bajo el sol". 
Poliéster, un vecino que pasaba caminando. Alix Ostión, que también había pasado la noche allí, desaparece sin dejar rastros. Zeta encuentra en estas muertes y en esta ausencia una razón para emprender la escritura como forma de investigar qué sucedió y quiénes son los/las culpables.

A esta historia central se superponen otras que complejizan la trama de la novela. Zeta se configura como el espejo invertido de su mejor amiga Linda Roth, exitosa escritora profesional de novelas de género negro, quien se autodenomina una "sublime embustera" (Portela, 2002: 74). Escritora, lesbiana y judía son tres características de este personaje que bien podrían sumirla en la marginalidad: sin embargo, posee éxito social (es el centro de atracción de cualquier reunión) y cultural (sus libros se convierten en best sellers). ${ }^{20}$ Linda entabla también una relación con Alix Ostión de características contrarias: semianalfabeta, silenciosa, es casi muda (personaje sin voz propia cuyas escasas palabras siempre son referidas por otros), o es pura carnalidad. La violencia también estructura este vínculo ya sea por cuestiones psicológicas - hay una relación de sumisión y poder entre ambas- o físicas -Alix termina con golpes en la cabeza, inconsciente, abandonada en la calle y albergada luego por Zeta.

El vínculo de esta novela con el policial se fundamenta no sólo en la existencia del doble crimen, en el marco urbano de la novela y en la configuración de Zeta como investigadora de la historia que la involucra, sino principalmente en las reiteradas alusiones ficcionales y metaficcionales al género. Ya en el primer capítulo se explicita que Linda Roth está escribiendo Cien botellas en una pared, una historia de un doble homicidio que se vincula

\footnotetext{
${ }^{20}$ Esto se percibe sobre todo si se compara con la situación de marginalidad de Zeta, como su amiga, se ha recibido en la Facultad, es escritora (aunque ocasional) y es heterosexual. En la caracterización de Linda aparecen muchos rasgos de Ena Lucía Portela. Por otra parte, la identificación con la condición de "judía" remite al apellido de este personaje: Roth que, intuyo, alude al escritor norteamericano de origen judío, Philip Roth.
} 
genéricamente con sus dos novelas anteriores que, en el futuro, "llegarían a ser clásicos del thriller, de la Serie Negra" (Portela, 2002: 24). Zeta, apasionada lectora de los thrillers que escribe Linda Roth, se configura, a su vez, como la escritora de la historia que leemos. Este juego de desdoblamiento metaficcional, y otros procedimientos que veremos más adelante, producen un desvío del género policial. Por eso, más que la trama de la historia, en esta novela las claves de lectura se centran en el escribir mismo y en las reflexiones en torno al hecho literario.

¿Cómo se vincula el desvío del género policial con la torsión de género sexual que representan los personajes femeninos de la novela? ¿Cómo se vinculan estas torsiones con la configuración de la ciudad -espacio por antonomasia del policial_ como lugar de "la mezcolanza, el ajiaco, el carnaval"? Para acercarme a este problema propongo un análisis de los rasgos propios del género en la novela así como también de las subversiones que realiza. ${ }^{21}$ Luego analizo la presencia del género policial en la novela, qué rasgos aparecen así como también qué subversiones se realiza del mismo.

\subsubsection{Lecturas y relecturas del policial en Cuba}

En Cuba, el género policial tuvo un desarrollo particular debido a que en los setenta el gobierno impulsó la producción de la novela policial revolucionaria o de contraespionaje a través de editoriales, premios literarios, revistas y ediciones de las obras en grandes tiradas. ${ }^{22}$ Cuando en 1972, el Ministerio del Interior instauró el Concurso "Aniversario de la

${ }^{21}$ Para un recorrido acerca de los problemas que propone el género policial, consultar Boileau-Noarcejac (1968) Daniel Link (2003), Amir Valle (2007), Francisca Noguerol Jiménez (2008), Juan Ignacio Colil Abricot (2010), entre otros.

22 Antes de este período el género ya había tenido desarrollo en Cuba. Obras como El ojo de vidrio (1955) y El asesino de la rosa (1957) de Leonel López- Nussa son ejemplos de eso. Stephen Wilkinson (2006) realiza un resumen del género policial en Cuba antes de 1959. Hay quienes consideran a la "novela de contraespionaje" como una modalidad diferenciada dentro de la novela policial revolucionaria. Para Duanel Díaz (2009), por ejemplo, este subgénero se inicia en 1975 con Los hombres color silencio de Alberto Molina. Otra novela de estas características es Y si muero mañana (1977) de Luis Rogelio Nogueras. 
Revolución", con una convocatoria anual respaldada por la editorial Capitán San Luis (que publicaba las obras ganadoras), el concurso contribuyó a generar un modelo prototípico de literatura policial, un tipo de discurso y una manera de asumir el tema (Fernández Pequeño, 1994). ${ }^{23}$ Esta narrativa tiene como punto de partida el año 1971, con la publicación de las novelas Enigma para un domingo de Ignacio Cárdenas Acuña, No es tiempo de ceremonias de Rodolfo Pérez Valero, en 1974, y El cuarto círculo de Luis Rogelio Nogueras en 1976, entre otras. $^{24}$

En estas novelas se invierte la estructura del policial clásico, donde la figura principal es el detective y el tema es el crimen; ya que se otorga prioridad a la delación política, a un protagonista colectivo que es la antítesis del detective privado, al Estado revolucionario que se enfrenta al crimen y, en algunas ocasiones, al pueblo como agente en la lucha contra el crimen: el héroe se vuelve colectivo. ${ }^{25}$ También aparece "el hombre nuevo", presentado como íntegro, competente e integrante del movimiento 26 de julio o de algún otro grupo político. Estas novelas impusieron su carácter didáctico por encima del literario ya que su objetivo fundamental era recrear la actividad de los combatientes del

23 Duanel Díaz (2009) analiza cómo la asimilación de la contrarrevolución y la criminalidad común constituye una de las premisas de la novela policial revolucionaria a partir de que en 1972 la Dirección Política del Ministerio del Interior creara el concurso anual de novela policial. Caracteriza la configuración de este subgénero y vincula su final con un hecho extraliterario: el éxodo del Mariel en 1980 porque este hecho "si bien le permitió al régimen librarse de cientos de miles de personas potencialmente subversivas, [...] venía a constituir, entones, una inequívoca evidencia del fracaso de aquella ingeniería social que pretendía, entre otras cosas, que la delincuencia desapareciese progresiva pero necesariamente en la sociedad socialista" (Díaz 2009: 163).

24 Según Daylet Domínguez: "Visto desde una perspectiva diacrónica, la publicación de la novela en 1971 funcionó como antecedente del concurso Aniversario del Triunfo de la Revolución, instituido en 1972 por el Ministerio del Interior (MININT), y como modelo para las propias novelas que surgieran a raíz del certamen" (1990: 209). Ver otras opiniones en Seymour Menton (1990), Fernández Pequeño (1988) y otros estudiosos de la literatura policial revolucionaria.

${ }^{25}$ Claudia García Marrero (2008) realiza una síntesis de estos cambios en el policial y ejemplifica al héroe colectivo con la novela El cuarto círculo de Luís Rogelio Nogueras y Guillermo Rodríguez Rivera, donde jefes de personal, vigilantes del CDR, jefes de transporte y estudiantes aportan información al teniente Héctor Román: "Muestran de esta manera, el fuerte sentido colectivo en el enfrentamiento al delito con el apoyo de la población fundamentalmente a través de los Comités de Defensa de la Revolución". 
Ministerio de Interior en el enfrentamiento de la delincuencia y la contrarrevolución (Fernández Pequeño, 1988 y 1989; Marrero, 2008; Domínguez, 2009, entre otros).

Dos obras adquieren relevancia en este período: Joy de Daniel Chavarría y Si muero mañana de Justo Vasco, ambas publicadas en 1978. En ellas se critica -de una forma moderada- la situación del país a partir de tematizar cuestiones hasta entonces silenciadas como la prostitución, los negocios de dudosa legalidad, las influencias de los altos cargos y, en general, la crisis nacional. En estas obras, se rescata la experimentación y audacia frente a la producción del período fundacional del género en Cuba, con su típica fábula policial adaptada a una función ideológica, fórmula que se extendió hasta mediados de la década del ochenta (Fernández Pequeño, 1988 1989; Valle, 2007; Noguerol Jiménez, 2008). ${ }^{26}$

Claudia García Marrero (2008) señala también que en la segunda mitad de la década de los ochenta la producción autoral y editorial del género menguó y que es entonces cuando se inicia el proceso de Rectificación de los Errores que significó una revisión de cuestiones de índole política, ideológica, económica y moral. Duanel Díaz (2009) habla del "deshielo" para referirse al período posterior a la caída del muro. Señala que este proceso comenzó a abrir un espacio en el que la novela policial revolucionaria pierde protagonismo y, recién en esa época, de la mano de Leonardo Padura y José María Fernández Pequeño, comienzan a aparecer estudios críticos sobre esa producción: "El ciclo se había cerrado y la caída del muro de Berlín vino a ser, desde luego, el final definitivo" (Díaz, 2009: 164). ${ }^{27}$

\footnotetext{
26 Para Fernández Pequeño son ejemplos de esta reproducción de la forma obras como La ronda de los rubies (1973) de Armando Cristóbal Pérez, El cuarto círculo (1976) de Luis Rogelio Nogueras y Guillermo Rodríguez Rivera. Y añade que "hacia 1980 el género policial revolucionario desciende hasta el disparate con obras como, Asalto a la pagaduría de José Luis Escasena, o -lo que es peor-, al disparate acompañado de plagio, con No hay arreglo de Daniel Lincoln Ibáñez” (Fernández Pequeño, 1989: 206).

${ }^{27}$ Sobre el neopolicial o nuevo policial latinoamericano, consultar Leonardo Padura (2000), Paco Ignacio Taibo II (2002), Álex M. Escribá (2007) Ezequiel de Rosso (2011 y 2012), entre otros.
} 


\subsubsection{Torsiones al/del género: "Inmóvil, sedentaria, fija como un musguito a la piedra”}

La configuración identitaria de los personajes femeninos principales de Cien botellas en una pared produce desplazamientos genéricos que se imbrican con torsiones del género policial. Uno de los personajes centrales es Linda Roth que, como señalé, es una escritora, lesbiana y judía. Estos rasgos que podrían sumirla en la marginalidad, en esta novela son invertidos: Linda es exitosa, mientras que en Zeta recae el fracaso. En este sentido es posible decir que la construcción identitaria de estos personajes desplaza el lugar estereotípico de la elección sexual. Sin embargo, en la novela se establece un paralelo entre las actitudes de la figura de Linda y la de Moisés (mientras éste ejerce la violencia física y psicológica hacia Zeta, Linda lo hace con Alix) lo que permitiría pensar que la novela plantea que la inversión de la hegemonía (masculina o femenina) mantiene los mismos términos de la violencia sobre la que se asienta.

Frente al modelo de Linda, a primera vista, el personaje de Zeta podría resultar estereotípico: heterosexual (que en el presente de la enunciación está a punto de ser madre), maltratada, sumisa, ignorante. Aunque Zeta, en el rol de narradora protagonista, tiene la vOz en el relato, su figura se construye también a partir de distintas voces del texto, en general, despectivas: para Moisés, por ejemplo, es una "gorda subnormal", "gorda burra con estampa de puta francesa del siglo XVIII", descripción que ella misma avala y con la que se regocija mediante el recurso del paréntesis "(Esta descripción, un tanto rococó, me parecía fascinante)" (Portela, 2002: 14). Frente al personaje de Moisés, que condensa lo "valores" tradicionales de la maculinidad (fortaleza física y espiritual, agresividad, homofobia), Zeta adopta el rol de mujer sumisa y golpeada, denigrada por el poder patriarcal. Cuando inicia el segundo capítulo, Zeta dedica unas páginas a hablar de sí misma: "Inmóvil, sedentaria, fija como un musguito a la piedra" (Portela, 2002: 30). Se 
construye como poco letrada (aunque con estudios universitarios) frente a los grandes temas que dominaban Moisés o Linda: "la duda cartesiana, la duda kierkegaardiana (vaya palabrita), o la skepsis de Pirrón, la gran duda" (Portela, 2002: 15). En relación con esto, resulta significativo que esta narradora-guía no tenga nombre: es la última letra del alfabeto la que la identifica. En un momento del relato, Zeta reflexiona sobre el vínculo entre nombre e identidad, pero la reflexión no gira en torno a las personas, sino que se traslada a los animales, un cerdito que era su mascota al que le puso Gruñi de nombre: "He ahí el primer error: ponerle nombre. Porque nombrar es individualizar. Nombre equivale a espíritu, a personalidad propia. A lo que debe cuidarse, pues de algún modo es único e insustituible" (Portela, 2002: 77). El cerdo, además, tiene apellido "Gruñi Álvarez La Fronde" (Portela, 2002: 77).

El desplazamiento genérico más interesante se produce en la construcción identitaria de Zeta porque no se constituye como un modelo unívoco sino a partir del desplazamiento: si se despliega la continuidad $\mathrm{X} / \mathrm{Y} / \mathrm{Z}$ podría pensarse como los cromosomas que determinan el sexo biológico XX / XY, en esta correspondencia, Z constituiría, entonces, una anomalía en términos biológicos o una subversión en términos culturales. Esto permite decir que Zeta no se individualiza, entonces, porque no es una sino el espejo, la contracara de Linda; es decir, no es sino en oposición, o no es sino la narradora elegida por Linda para construir la novela policial que estamos leyendo. Y este desplazamiento se vincula con la torsión del género policial: Zeta, en tanto escritora y personaje (de la ficción dentro de la ficción de Linda) es quien narra la historia.

Desde las primeras líneas de Cien botellas en una pared, Zeta guía al lector por un laberinto de especulaciones en las que intenta hallar los móviles que desencadenaron las dos muertes vinculadas con su historia personal: la de Moisés y la de Poliéster, un músico 
vecino cuyas elecciones musicales molestaban a Zeta y a Linda. ${ }^{28}$ Pero como lectores descubrimos que el "asesinato" (si realmente es tal) queda sin dilucidar y, por el contrario, la historia del crimen termina en una serie de suposiciones. En la novela, Zeta se construye como la escritora de esta historia, escritora casual que, como se ha dicho, se contrapone a su amiga Linda Roth, escritora "profesional" y exitosa por sus novelas de género negro: "Ella es una escritora profesional, una escritora de verdad, viajera, ambiciosa y enérgica, a sus horas feminista y con pensamientos de gran envergadura" (Portela, 2002: 21). Zeta no se define como artista sino como escritora improvisada y apasionada lectora de los thrillers de su amiga aún que, entre los libros de la biblioteca de Linda, elegiría "el volumen con las historietas de Mafalda" (Portela, 2002: 140).

El entramado de esta historia establece vínculos con la novela policial no sólo a partir de la existencia de un supuesto crimen (el de Moisés) que intenta ser develado, sino también porque la novela pone en juego ficciones policiales: Linda Roth, a quien sus amigas llaman Agatha Christie recibe el premio Semana Negra para cuentos policiales por "El caníbal que untaba mayonesa" y el "Dashiell Hammett" por Nocturno Sebastián, su segunda novela, premio que entrega la AIEP (Asociación Internacional de Escritores Policíacos). ${ }^{29}$ Lectora ávida del género policial, Linda utiliza en su discurso referencias explícitas e implícitas a escritores y novelas de este género, ya sea del policial clásico, de la mencionada Agatha Christie y Patricia Highsmith, Dashiell Hammett, Raymond Chandler, entre otros.

\footnotetext{
28 Poliéster, "hijo de negra barriotera y fugaz técnico soviético" (Portela 2002: 48). A sus sonidos de corneta y tumbadora, los enfrentaron con Don Giovanni pero "Los vecinos en pleno se rebelaron, protestaron y blasfemaron, fueron en turba a cantarme las cuarenta y armaron un show de los más sonados en la historia de la Esquina, pues aquel espantoso ruido que brotaba de mi cuartito los ponía nerviosos y les provocaba un terrible dolor de cabeza". Ante esta situación de los "inmigrantes advenedizos orientales" (Portela 2002: 50), Linda propone “educarlos" con Arnold Schöenberg. La muerte de Políester, fruto de la casualidad, se puede leer en clave metafórica, ya que el enfrentamiento con los vecinos pone en juego una contraposición entre lo popular y lo culto.

${ }^{29}$ Institución fundada La Habana en 1986 por Paco Ignacio Taibo II (México), Julián Semionov (Rusia), Rodolfo Pérez Valero (Cuba), Alberto Molina (Cuba), Daniel Chavarría (Uruguay), entre otros.
} 
En el primer capítulo, Zeta cuenta que su exitosa amiga está escribiendo: "Su última novela, Cien botellas en una pared, era la historia de un doble homicidio, pero aún no sabía a quién matar -me apuntó con un dedo, como si quisiera matarme a mí-. Las dos anteriores, también sanguinarias y truculentas, ya habían crecido y caminaban solas" (Portela, 2002: 24). Este juego de duplicación de la escritura de la novela nos coloca de cara al policial negro. Zeta, la narradora de la novela que tenemos en nuestras manos, se convierte en protagonista de la novela que está escribiendo Linda Roth y, al mismo tiempo, el relato en primera persona de Zeta como escritora (no profesional) la convierte en un personaje que oscila en el juego explícito entre lo ficcional y lo real autobiográfico. Esta distensión de las fronteras entre la realidad y la ficción es una de las características de la producción de Portela.

La novela escrita por Linda se enmarcaría así en el nuevo policial latinoamericano, entre otros aspectos por la figura del Tte. Leví, un desencantado porque nunca logra resolver los casos o porque, si los resuelve, la corrupción le impide atrapar o condenar al culpable. Linda extrae de la realidad de La Habana actual, de sus problemas sociales, el material para sus novelas: la historia de Nocturno Sebastián se construye a partir del asesinato de un amigo de la Gofia - un homosexual hijo de un general- quien le provee toda la información sobre lo sucedido. Los crímenes de sus novelas no se esclarecen; lo impide la corrupción del sistema. En las novelas escritas por Linda en la ficción (dentro de la ficción), el detective -Tte. Leví- es un fracasado que no logra reunir las pistas ni puede arribar a la verdad y, entonces, se suma a la lista de detectives que engrosan las filas de esta variante del policial:

Astuto, perseverante, con buena memoria, gran capacidad de trabajo y el olfato exquisito que distingue a los mejores sabuesos, parecería destinado al triunfo. Pero de eso nada. Le falla la suerte. Y cuando a un detective, ya sea privado o de la policía, le falla la suerte, está frito. Así, el Tte. Leví jamás resuelve un caso. Descubre al asesino, pero no logra echarle el guante. Siempre hay algo que se interpone (Portela, 2002: 166). 
En Cien botellas en una pared el sistemático fracaso de los detectives, rasgo de la novela negra latinoamericana, es llevado al límite. En el crimen que es motor del relato de Zeta, no aparece la figura del detective, sino que es ella, la narradora, la que guía en esta “investigación” en la que está implicada por ser la amante del muerto. En este acto se plasman dos subversiones: la que investiga (Zeta) es detective no profesional y ella misma está implicada en el asesinato. Estas subversiones, además, se conectan con una paradoja: como ya se señaló, el móvil de su escritura consiste en explicar cómo y por qué se desencadenan los hechos, así como en descubrir al culpable cuando su mismo discurso explicita, en uno de sus niveles, que es Alix Ostión. La serpiente que se muerde la cola parece ser la figura que dibuja el relato de Zeta.

El trabajo que hace esta novela sobre el policial también puede pensarse como torsión irónica por una serie de alusiones que establecen distancias con el género (estatuido) a partir de la figura del padre Ignacio, confesor y confidente de Zeta, para quien su "detective favorito, que conste, sigue siendo su colega, el padre Brown, criatura de un escritor llamado Gilbert Keith Chesterton, mucho más famoso que Linda ('por ahora', dice ella)" (Portela, 2002: 174). Esto sucede inclusive en la ficción (dentro de la ficción) producida por Linda y su personaje, el Tte. Levi:

Al principio no le iba tan mal. Consiguió cazar al caníbal que untaba mayonesa. Pero ese cuento, según Linda, es muy inmaduro, juvenil, ingenuo. Una tentativa en los tiempos -añade — en que ella aún imitaba a Raymond Chandler. Cuando leía The Simple Art of Murder como si fuera la Biblia y tenía fe en que las palabras no sólo eran útiles para el engaño -dice esto como si hablara en voz alta consigo misma, tal vez por eso no la comprendo bien—, qué ilusa (Portela, 2002: 167).

Entonces, en la obra de Linda se puede leer una progresiva distancia respecto del género negro estadounidense, como lo muestra el hecho de que en la casa de la escritora, atestada de libros "del piso al techo, tapizando paredes enteras. Encima o debajo de los muebles. Sobre la banqueta del piano vertical, con toda clase de viandas y hortalizas. Hasta en el 
baño” (Portela, 2002: 100), Zeta haya encontrado “uno de sus favoritos" en la heladera: El halcón maltés de Dashiell Hammett, obra que marca el nacimiento de la novela negra en EE.UU. Este hecho adquiriría connotaciones simbólicas al aludir (¿irónicamente?) al congelamiento de la fórmula del policial negro y por contraste, a las torsiones experimentadas en la novela que estamos leyendo.

Cien botellas en una pared destruye los núcleos que sostienen las clásicas certezas del género policial: el saber sobre lo que ocurrió y quién lo cometió se vuelve confuso, la "verdad" (si la hay) se obtiene por fragmentos. Mientras el lector puede sospechar a través de la trama las razones del crimen y quién lo ejecutó, la narradora -la autoridad del textointroduce sospechas sobre la existencia misma del crimen e intenta inclinar la balanza para el lado de la casualidad. Una opción que resulta paradójica ya que la búsqueda de una explicación de las causas que desencadenaron el crimen constituye la justificación de la historia en el inicio de la novela. De esta manera, el lector se mueve entre indicios contradictorios según tenga en cuenta la trama, los personajes o la narradora. Como en el caso de las obras analizadas por Amar Sánchez (2000), la resolución del caso se vuelve imposible: imposible para el lector saber la verdad (aunque la sospeche), imposible tratar de resolver crímenes que quizá no se cometieron. De esta manera, la tríada crimen, verdad y justicia que sostiene el género policial clásico deja de funcionar. Amar Sánchez señala que “el relato latinoamericano quiebra este pacto, destruye la armonía entre sociedad/justicia/ley al representar el crimen como producto de las instituciones políticas y sociales. No sólo se quiebra el orden, sino que no hay espacio legal ni legitimidad a la que recurrir” (Amar Sánchez, 2000: 60-61).

Aunque en esta novela también se ha borrado la ilusión en las instituciones, los sistemas y la posibilidad de un orden justo, esto funciona de modo diferente. La muerte de Moisés es una forma de venganza y de intento de restablecer el orden perdido, pero no en 
cuanto a la justicia como conjunto de normas y reglas que establecen un marco adecuado para que una institución intervenga y regule, sino como una forma de aplicar una medida, un castigo que cree merecido, en este caso, contra alguien que ha ejercido en forma reiterada actos de violencia hacia una mujer. Para Zeta hay dos historias respecto de la muerte de Moisés: "lo que pudiera llamarse 'la historia oficial'. La única aceptada, la menos horripilante, la visible" (Portela, 2002: 268) y la otra, cuyas respuestas "Conforman 'la otra historia', la subterránea, la que se oculta bajo la oficial" (Portela, 2002: 269). Esa otra historia oculta la violencia de género (sexual y familiar), pero también, la violencia política que invisibiliza, silencia (y en este gesto) permite la otra violencia. ${ }^{30}$ La figura de Moisés encarna la misoginia y el machismo que se concretan en reiterados actos de violencia física y verbal contra Zeta. El peso bíblico de este personaje se acentúa por la asociación a las tablas de la ley: Moisés simboliza la ley y la masculinidad. Dice Moisés:

¡Ah, las mujeres! Siempre instaladas en la estulticia, en la sandez, maquinando frivolidades. Las mujeres eran el colmo del mongolismo ¿Quién las había inventado? Eran muy brutas, las mujeres. Ni por casualidad entendían la esencia de los fenómenos, el mundo como voluntad y representación (Portela, 2002: 12).

Esta referencia a la obra capital de Schopenhauer -El mundo como voluntad y representaciónaparece encarnada en Moisés, figura que condensa el machismo imperante en Cuba. En este sentido, también se deja entrever que la representación del poder está centrada en el hombre y que el machismo está institucionalizado. Cuando Linda propone castrarlo, Zeta dice “¿sabía ella que en nuestro país aún se aplicaba la pena de muerte, que la mayoría de los jueces eran hombres y que, probablemente, nuestra cariñosa faena no les haría ninguna gracia, sobre todo por tratarse de un antiguo colega?” (Portela, 2002: 23).

El asesinato (o mejor dicho la muerte) de Moisés se narra en el último capítulo. El lector ha leído casi la totalidad de la novela cruzada por alusiones a la existencia del

\footnotetext{
${ }^{30}$ La policía registra el caso con la expresión "la hipótesis de dos muertes accidentales" (Portela, 2002: 261).
} 
asesinato, pero sólo aquí descubre fehacientemente cómo se desencadenaron los hechos y quiénes fueron los muertos: Moisés con su caída mortal, mata a Poliéster. Hacia el final de la novela, se desnuda la realidad: Alix, quien sólo había representado el rol de voyeur de los actos de violencia de género de Moisés hacia Zeta (y también de Linda hacia ella), es la que provoca la muerte de Moisés al dejar intencionalmente abierta la ventana. Esto aparece entre líneas: es la versión de la historia que Zeta no le contó a la policía y la que sus amigos no le creen por inverosímil; la versión que elige contar al aventurarse en la escritura. Zeta no imagina la libertad a partir del crimen de su agresor; cuando Linda le propone castrarlo, como venganza ante su violencia, ella opta por cortarle la barba, para imprimirle una muerte simbólica: ${ }^{31}$

Lo de la castración, además, me parecía injusto, un tanto excesivo, puesto que Moisés nunca me había mutilado.

-Esas cosas se escriben -le dije-, pero no se hacen. Si tan empeñada estás en maniobrar con las tijeras, ¿no te parece mejor algo más simbólico? Recortarle la barba, por ejemplo (Portela, 2002: 23).

Frente a estos hechos cargados de simbología, la trama permite entrever que es otra mujer la que se encarga de aplicarla: Alix, la sin voz, la muda, la sombra o el fantasma, la mujer que estuvo siempre a la sombra de Linda. ${ }^{32}$ Su figura larga y extremadamente delgada, su mirada esquiva, animal, provoca el deseo y el temor de hombres y mujeres. Alix forma parte de las miles de personas que migraron desde los ambientes rurales hacia la ciudad en busca de educación. Aunque tuvo un fugaz paso por la Universidad, su palabra es clausurada porque ignora los temas importantes. Frente a la verborragia, la cultura y el cinismo de su amante -Linda Roth—, ella ocupa el espacio del silencio como resistencia. ${ }^{33}$

\footnotetext{
${ }^{31}$ En otras obras escritas por mujeres las protagonistas logran la libertad con la muerte o, en otros casos, imaginando un mundo donde afloran los deseos profundos, las ensoñaciones.

32 Alix es la contratara de Linda. Dice Zeta al respecto: "La sentía parte de sí misma, como si Alix fuera su propio lado oscuro. Un lado salvaje, atávico, intuitivo, ajeno a la razón y a los argumentos de la razón. Un lado violento que, si llegaba a desatarse, resultaría muy difícil de controlar” (Portela, 2002: 184).

${ }^{33}$ Los rasgos atribuidos a Alix reproducen, en cierta medida, el estereotipo del "otro".
} 
Ante la muerte consumada, Zeta muestra alegría y tranquilidad y opta, nuevamente, por un acto simbólico: la escritura como una forma de comprender o exorcizar los fantasmas del pasado y simultáneamente de proyectar un futuro. A diferencia del pesimismo propio del género policial (en las variantes que he comentado), aquí se vislumbra cierta esperanza como si la cifra del futuro residiera en lo amoroso de los pequeños actos (en este caso, la elección de la maternidad). En esta novela, atravesada por la violencia y la muerte, el embarazo de la protagonista de alguna manera funciona, en este contexto, como una instancia esperanzadora. ${ }^{34}$ Ante la angustia existencial, ante la posibilidad de dejarse vencer por los instintos primarios (y optar por el suicidio), la protagonista se apoya en el futuro que demanda ese hijo que lleva en el vientre pero que también puede ser la escritura de la historia. En una ciudad mutante, en perpetuo movimiento, la escritura se convierte en una forma de resistencia: Zeta, en un presente de definiciones, con humor e ironía recupera su pasado para, de este modo, reflexionar sobre la carnalidad de la existencia, con sus (sin) sentidos y luchas por existir y, finalmente, por encontrar cierto reposo en el tránsito por los bordes de la ficción.

\subsubsection{Nuevos trazos de la ciudad: La Habana y los espacios de creación}

Algunas ciudades se han constituido en sitios de recurrencia para los escritores. La Habana es una de ellas: convertida en una obsesión, se dibuja una y otra vez en el imaginario de la literatura cubana. ${ }^{35}$ Los escritores la han convocado e invocado y aún hoy lo hacen ya sea

\footnotetext{
34 En Pájaro: pincel y tinta china también hay un embarazo pero termina en un aborto. Zeta también ha sufrido un aborto.

${ }^{35}$ Respecto de las construcciones literarias de La Habana, Jorge Fornet advierte que en la narrativa de los noventa, ese regreso a La Habana se enmarca en la tendencia protagonizada fundamentalmente por los nacidos después de 1959 en que la visión de la ciudad (y de Cuba en general) es el "puro presente, sin causa ni consecuencias" (Fornet, 2006: 103). A diferencia de obras anteriores (Tres Tristes Tigres, La Habana para un infante difunto, entre otras), el regreso a esta ciudad se realiza a espacios acotados y que la igualan a cualquier
} 
desde la presencia o desde ausencia que engendra sueños, fantasmas, recuerdos, imágenes congeladas; debido a los innumerables ejemplos, cualquier mención de obras y/o autores resultaría insuficiente o caería en olvidos inintencionados y, otras veces, fruto del desconocimiento. ${ }^{36}$ El epígrafe citado al comienzo de este capítulo, con su insistencia en la mezcla y el deteriorio, condensa la imagen de la ciudad que se dibuja en la novela de Portela. Debido a su fecha de publicación, Cien botellas en una pared se puede incluir en el ciclo de la producción literaria que, a partir de los noventa, comienza a desmitificar la imagen homogénea de la capital cubana para pasar a identificarla con la del naufragio, de la agonía o, más recientemente, de las ruinas. ${ }^{37}$ La situación económica de los noventa transformó material y simbólicamente La Habana, por eso resulta interesante analizar cómo se produce esta configuración desde la ficción, en este caso de una escritora anclada en esta ciudad, no de aquellos que se fueron y pueden por eso construir una imagen mítica. ${ }^{38}$

ciudad del continente. Sin embargo, Fornet señala que La Habana "ha conservado, multiplicado, un extraordinario valor simbólico: su nombre" (Fornet, 2006: 106).

36 Por nombrar sólo algunos, en el siglo XIX aparece dibujada en la obra de José María Heredia y de José Martí. Ya entrado el siglo XX, resultan ineludibles las semblanzas de José Lezama Lima, Alejo Carpentier, Guillermo Cabrera Infante en Tres Tristes Tigres pero también en el Libro de las ciudades o los trecorridos de los personajes de Reinaldo Arenas. Más acá en el tiempo, Antonio José Ponte o Abilio Estévez, con otra estética y otros intereses, también se obsesionan con la recreación del espacio en el que se sitúan la memoria y las ruinas de la ciudad que rememoran. Pero también La Habana ha sido configurada por los escritores que están en la isla, por ejemplo Leonardo Padura o Pedro Juan Gutiérrez con sus espacios marginales.

${ }^{37}$ Una imagen que, con otras características, ya está presente en Alejo Carpentier, José Lezama Lima y Guillermo Cabrera Infante. El perfil de La Habana posrevolucionaria (pensada en términos homogéneos, armónicos e igualitarios) contrasta con el que, a partir de mediados de los ochenta, comienza a enfocar la diversidad de la vida en una ciudad en pleno cambio. Según Janett Reinstädler en este contexto, "la mayoría de los relatos, se orienta hacia una 'victoria' del capitalismo o hacia el hundimiento total (físico y político) del socialismo, o las dos cosas a la vez" (Reinstädler, 2000: 102). Con respecto a la metáfora de las ruinas, la crítica considera que esa perspectiva se corresponde con proyectos estéticos, morales y/o políticos. Este trabajo sobre la ciudad aparece en la obra de Antonio José Ponte, Abilio Estévez (Maristany, 2003; Basile, 2008; Kanzepolsky, 2008, entre otros) o, más cercana al realismo sucio, en la obra de Pedro Juan Gutiérrez (González-Abellas, 2005; Salto, 2005, entre otros).

38 En uno de los capítulos de Rompiendo las olas durante el período especial, María del Mar López Cabrales analiza cómo se reflejan en la narrativa de escritoras cubanas contemporáneas los cambios que ha sufrido La Habana durante la crisis de los noventa: "muestran una Habana decadente y deprimente, en la que sus protagonistas tratan de subsistir con el estómago vacío, pedaleando una bicicleta -los que tuvieron la suerte de tenerla $-\mathrm{y}$ buscando a diario con una jaba (bolsa) cualquier cosa para conseguir la alimentación básica" (López Cabrales, 2008: 46). En las novelas que se enmarcan en el momento posterior al "Período especial" vislumbra una ciudad más brillante: "no lucha contra sus personajes sino que los arropa y, en cierta manera, los protege, que les sirve de encuadre a sus sentimientos y que es cómplice de sus acciones" (López Cabrales, 2008: 46). 
Qué Habana ficticia está presente en Portela es algo que merece una investigación que aborde específicamente los rituales de la urbanidad. Aquí me centraré en la configuración de la ciudad desde la apelación al género policial que trama la novela. ${ }^{39}$ Pensar la ciudad como un dispositivo identitario con espesor histórico, como espacio de configuración de las subjetividades de los individuos que la transitan, permite establecer una metonimia entre el reducido sitio de lo privado y de las prácticas cotidianas -como espacios de lo político, en el sentido de Michel de Certeau (2007). En la novela de Portela los espacios en que transcurren las instancias de lo "privado" -las fiestas, los encuentros entre amigos, el pensamiento, las instancias de escritura, los paseos por la ciudad, entre otros- se pueden leer como una representación de La Habana en escala reducida.

La cita del epígrafe está anclada en una zona de la ciudad, el Vedado, barrio que se convierte en sinécdoque de los cambios que ocurren en el resto de La Habana porque, a lo largo de la novela, se descubre que esta caracterización se traslada a todos los espacios, desde los más comerciales o turísticos, hasta los más recónditos y marginales. En la obra de José Lezama Lima, El Vedado y Miramar se constituyen en la imagen del caos republicano, de la influencia del modo de vida norteamericano. Mientras que Ineke Phaf señala que es el barrio intelectual con un microclima cultural (Reinstadler, 2000), en Animal tropical, Pedro Juan Gutiérrez lo presenta como un espacio en el que se respira bienestar económico y tranquilidad, en contraste con el Centro Habana, más ligado a lo marginal. En Cien botellas en una pared, por el contrario, el barrio se connota por el lado de lo marginal y de la "mezcolanza". Arquitectónicamente, el edificio en el que vive la narradora se describe en forma irónica:

Inmóvil, sedentaria, fija como un musguito a la piedra, desde que nací habito en un palacete del Vedado que es una joya arquitectónica, un monumento a la extravagancia,

\footnotetext{
${ }^{39}$ En Portela la ciudad se asemeja a la de Pedro Juan Gutiérrez con su visión de La Habana cayéndose a pedazos (ver: Animal Tropical y El rey de La Habana).
} 
un prodigio de retazos y parches y costuras, un Frankenstein ecléctico según la moda de 1926 y hecho una ruina según la moda del año en curso (...) de gusto muy amplio, muy abarcador, ese que inspira la felicidad de respirar bajo un tejado colonial, entre vitrales neogóticos, arcadas románicas, balaústres barrocos, rejas art nouveau y columnatas griegas de distintos órdenes. El observador más o menos entendido en arquitectura se rasca la cabeza: no logra explicarse cómo es que faltan el minarete mudéjar, la cúpula bizantina y la pirámide egipcia (Portela, 2002: 30-31).

Esta descripción carnavaliza la ciudad barroca que describe Alejo Carpentier en La ciudad de las columnas (1970). "La mezcolanza" se transpone a los edificios de este espacio capitalino, transformados por las múltiples subdivisiones que los convierten en hormigueros humanos que responden a una lógica interna de organización. La narradora describe el lugar en el que habita y en pocas líneas configura las transformaciones que ha sufrido el edificio y en ese movimiento se describe: una actitud pasiva, "fija como un musguito a la piedra", ante las situaciones que atraviesa a lo largo de su vida (el abandono de su familia, la violencia física y psicológica ejercida por su amante) pero también una mirada que traslada al lector por los vericuetos de la historia; mirada que desnuda, poco a poco, cada uno de los invisibles pliegues de los personajes que aparecen en su vida.

El edificio condensa la historia de Cuba a través de los habitantes que albergaron sus paredes. Primero perteneció a algún “anónimo oligarca dueño de centrales azucareros o vegas o cafetales o fincas ganaderas" que un día desapareció sin dejar rastro; luego, fue ocupado por el club esotérico "Partido Pitagórico" y, con la Revolución a la que alude indirectamente, el palacete "devino propiedad estatal y se convirtió en una casa de huéspedes gratuita, más o menos de beneficencia, para individuos relacionados con el cine: directores, guionistas, actrices, camarógrafos, criticones y el resto de la farándula con sus

\footnotetext{
${ }^{40} \mathrm{La}$ alusión a la mezcolanza, el ajiaco y el carnaval permitiría realizar un vínculo con Fernando Ortiz y Alejo Carpentier. La palabra "mezcolanza" es una apuesta importante para pensar el Caribe y América Latina. Sería interesante analizar qué hace Portela con el discurso de la identidad de América Latina. En este sentido, señalo que ironiza la mezcla: el edificio es un Frankestein, una creación de mal gusto.
} 
respectivos perros, gatos y amantes" (Portela, 2002: 35). Finalmente, en la actualidad se configura a partir de la ruina, forma constituida en "moda", en clara alusión a la precaria situación económica y a la decadencia edilicia que atraviesa la cotidianeidad de la vida de los habaneros:

... y sí, tras los polvos que ciegan vinieron los lodos que salpican, lo que se conoce como "el decenio negro". Poco a poco, entre proscripciones y persecuciones, estalinismo puro y duro según papá, se disolvió la comparsa. Los del cine fueron mudados a otras casas y a otros países. Villa Miseria se sumergió en la penumbra (no así la miseria: se sumergió en la penumbra, entre otras causas, porque se robaron los bombillos), en el olvido, se hizo antigualla, anacronismo, algo siempre descolocado, algo de lo que no se habla (Portela, 2002: 42).

De este modo, de palacete aristócrata devino, poco a poco, en un solar (conjunto habitacional), espacio construido con tabiques, mamparas, biombos, remaches y trucos que multiplican el lugar otrora ocupado por una familia, en un espacio donde habitan cuarenta y cuatro personas que comparten el lugar con animales como se observa en la siguiente cita que, además, evidencia una forma de la xenofobia, que mantiene intacto el esquema campo-ciudad:

Sutil, sin escándalo, el palacete rodó por la pendiente. Descendió al nivel de solar o cuartería como ciertos palazzi renacentistas que, puro cascarón, por fuera siguen pareciendo lo que antes fueron mientras la carcoma los devora por dentro. Los recién habitantes, muchos de ellos con acento oriental y desconocedores de los usos urbanos, aportaron una nueva fauna, insólita en el paisaje citadino: gallinas, pavos, palomas, jicoteas, un cerdo, un chivo con una campanita colgada del pescuezo, una jutía y una especie de megaterio, cruza de mastín con rinoceronte (Portela, 2002: 42).

Además, en el fragmento es posible advertir la construcción de la alteridad ligada a lo monstruoso. En una sugerencia que puede leerse como comentario del deterioro y estancamiento de la construcción en La Habana también refiere el crecimiento hacia adentro, la multiplicación de los espacios, la mutación de lo existente y la conversión en otra cosa, cercana a lo monstruoso. Una situación a la que no se alude como pérdida de un 
origen impoluto sino con una carga de humor marcado, por ejemplo, por la reproducción del ruido constante y por el nuevo nombre que adquiere el lugar:

La ciudadela crece hacia adentro, se torna densa, una colmena, un avispero. Hay días en que parece a punto de explotar como un siquitraque o un partido pitagórico, aunque no sé si se trata de la ciudadela o de mi cabeza. Porque ellos clavan y clavan, siguen clavando, no paran de clavar. A todas horas se escucha el toc, toc, toc. Como si el lema fuera "levantad, carpinteros, la viga del techo", lo que se ha desatado es una epidemia de martillazos. Toc toc toc por ahí, toc toc toc por allá. Cuando no son unos, son otros los que martillan, pero el toc toc toc es tozudo, inacabable, sempiterno. El toc toc toc es un absoluto, una presencia fija responsable del último topónimo: la Esquina del Martillo Alegre (Portela, 2002: 46).41

Como señalé, la mirada no es nostálgica de algún pasado glorioso: con ironía y sarcasmo, la narradora advierte la multiplicidad de estilos que conforman este Frankenstein del Vedado. ${ }^{42}$ El edificio adquiere presencia a través de las ruinas que se extienden, metonímicamente, hasta volverse equivalentes al estado de la ciudad:

el techo se filtra y suelta boronilla, pedazos de estuco. He pensado en usar un casco de constructor, por si acaso, no vaya a ser que un día se me estropee el cráneo. También hay grietas en los muros. Grietas verticales, de las peligrosas. En temporada ciclónica el agua entra por todos lados (excepto por la pila, claro) y mi vida se llena de palanganas y cubos destinados a cazar goteras (Portela, 2002: 31).

Zeta misma es el fruto de esas transformaciones. Su madre, una hippie francesa del ámbito cinematográfico que viaja a Cuba en los años sesenta, muere en el parto. Su padre es un homosexual que dice haber sido engañado, y que en los ochenta emigra a Estados Unidos. Dice la narradora: "cuando por fin abrí los ojos a las bellezas de este mundo, lo primero que encontré fue una mirada de perplejidad, de asombro infinito. De angustia. De pánico" (Portela, 2002: 37). Este nacimiento fruto de la casualidad, sumado a la ausencia

\footnotetext{
${ }^{41}$ Intertextualidad con "Levantad, carpinteros, la viga maestra" es considerado uno de los mejores cuentos del escritor estadounidense Jerome David Salinger (Nueva York, 1919-2010).

${ }^{42} \mathrm{La}$ ciudad barroca es monstruosa, por ejemplo, en La ciudad de las columnas (1964) de Alejo Carpentier.
} 
física de la madre y simbólica del padre, es uno de los ejes fundamentales en la iniciación de este personaje como escritora, aspecto que se desarrollará en el último apartado. ${ }^{43}$ Zeta no pertenece al grupo que se traslada del campo a la ciudad y aunque su pasado tiene alguna reminiscencia burguesa, en el presente de la enunciación, no sólo enfrenta sola la maternidad, sino que la familia como espacio de configuración y sostén de la identidad se desdibuja (la madre muerta, el padre homosexual y exiliado).

Cuando Zeta recorre la ciudad su mirada se detiene en zonas degradadas: "Uno ve pordioseros en la calle, oleadas de mendigos, gente pidiendo limosna en la puerta de la iglesia, en las cafeterías, en la cola del 'camello', en cualquier sitio. Lisiados, leprosos, anormales, vagabundos, artistas callejeros y hasta profetas del Apocalipsis" (Portela, 2002: 127). Zeta no actúa como el flâneur benjaminiano en busca del placer o del conocimiento intuitivo. Su meta es práctica y parece articularse como respuesta a las carencias: acceder a algo de comida. Las características identitarias de Zeta y las prácticas en tiempos de limitaciones económicas están por ello más cerca del itinerario del pícaro medieval. Ese recorrido con un objetivo preciso - comer- se transforma en una excusa para el divagar del pensamiento en torno a las opciones posibles para su futuro: irse o no de la isla. La mirada de la narradora se detiene y en la descripción se cruza lo grotesco con lo sublime, lo que otorga una carga humorística a la situación:

Me acerqué un poco, no pude evitarlo, y a la admiración siguió el asombro. ¿De qué sentina, basurero o plan tareco había brotado mi coloso del monólogo feroz? ¿Cuánto tiempo llevaba de juerga, de fuga o de pelea? Porque la barba platinada, aún corta, era lo único limpio en aquella majestuosa figura. Su pulcritud contrastaba con los tirabuzones grises, un poco grasientos y desperdigados en todas direcciones, a comoquiera van los mangos. Con las gafas oscuras de cristales polvorientos, con rayones y una multitud de huellas dactilares impresas en la superficie húmeda... ¿de rocío? Con el traje Armani, lustroso de tanto churre, con pelusas y confetis y hojitas y guisazos y otras inmundicias sobre el azul oscuro del saco y la camisa que alguna vez

\footnotetext{
${ }^{43}$ La escritura y la figura del padre ausente (que desde una interpretación psicoanalítica, Zeta buscó en Moisés), fundan una nueva postura de Zeta al convertirse en escritora.
} 
fue blanca. Todo él embarrado aquí y allá, hasta los zapatos de cuero fino, de algo que lo mismo podía ser sangre, fango o salsa de tomate. Qué esplendoroso desastre (Portela, 2002: 127).

Esta imagen del summum de lo inarmónico, de lo "sucio" trastocado en objeto de enamoramiento -aun sin eludir la ironía de la representación- se puede trasladar a la valoración que realiza de la ciudad: no se añora la belleza perdida (o no alcanzada) ni se proyecta una reconstrucción; sólo se describe la mutación y sus efectos. Entonces, ¿qué funcionalidad (si la hay) tiene la mostración o la visibilidad del estado de las cosas? es la pregunta que desencadena el siguiente apartado.

\subsubsection{Balconear la ciudad y elegir el adentro}

La valoración de la cotidianeidad en tanto espacio político propuesta por Michel de Certeau (2007), constituye una manera apropiada para pensar cómo funciona la dominación en este ámbito. Frente a quienes percibían en el espacio cotidiano sólo la introyección del orden y la pasividad, de Certeau otorga politicidad porque desnuda el conflicto, la tensión, como los signos centrales. La mirada de este crítico constata la "reproducción" de lo existente y se desplaza hacia la potencialidad de su "transformación"; por eso, aunque en Cien botellas en una pared resulta complejo confirmar la idea de "transformación" a partir de la configuración de lo cotidiano, considero que resulta significativo ingresar en los entramados creativos de estos espacios reservados a lo privado que, como propone el crítico francés, son elusivos, dispersos, fugitivos, hasta silenciosos, fragmentarios y artesanales pero construyen "maneras de hacer":

Habitar, circular, hablar, leer, caminar o cocinar, todas estas actividades parecen corresponder a las características de astucias y sorpresas tácticas: buenas pasadas del "débil" en el orden construido por el "fuerte", arte de hacer jugadas en el campo del otro, astucias de cazadores, capacidades maniobreras y polimorfismos, hallazgos jubilosos, poéticos y guerreros (de Certeau, 2007: 46). 
Es posible pensar estas prácticas de lo cotidiano como estrategias políticas del "débil" a partir de la mirada de Zeta, así como también de sus prácticas (algunas ya esbozadas). Además de los recorridos a pie por la ciudad con un objetivo preciso -como la búsqueda de comida en tiempos de marcada carestía-, los únicos momentos en que la narradora transita por la ciudad lo hace desde un espacio de riesgo y de superioridad: desde la ventana de su edificio en la Esquina del Martillo Alegre, o desde el balcón de Linda Roth. En su departamento, tiene una gran ventana que comunica el espacio privado con el exterior. Zeta elige ese espacio de frontera para "disfrutar del paisaje" (Portela, 2002: 18) y para descansar. También es el lugar desde el que ve el cuerpo ya sin vida de Moisés y el de un vecino que la atormentaba con su música. Su amante odia la luz del sol y la obliga a cubrir la ventana con una cortina negra "(doble, triple, densa, impenetrable, un verdadero horror)" (Portela, 2002: 18). La insistencia en la imagen de la ventana permite pensarla como marco que media en la percepción de lo real: recordemos que el trabajo de escritura recala en el punto de vista, es decir, en los modos de acceder al conocimiento que adoptará una forma específica de la ventana desde la que se mira. ${ }^{44}$ En este sentido, esta novela problematiza el realismo: es el espacio que filtra el afuera que invade constantemente lo privado. Resulta significativo que sea el punto de encuentro con el exterior lo que ocasiona la muerte de Moisés ya que él, a diferencia de Zeta, se constituye a partir de su discurso en referencia con el afuera y lo político. ${ }^{45}$ Su discurso siempre alude a lo político y discute con

\footnotetext{
44 La crítica ha estudiado en la obra de Juan Carlos Onetti (1909-1994) la presencia de la ventana como marco que media en la percepción de lo real.

45 Más significativo aún si tomamos por cierta la hipótesis de que Moisés muere producto de un plan pergeñado por Alix Ostión, la ex pareja de Linda Roth que luego encuentra asilo en la casa de Zeta. Este personaje se configura a partir de la carencia de discurso: semianalfabeta, es pura carnalidad, alusión ya presente en el apellido.
} 
un "ellos" que Zeta no sabe en quién personificar pero, como ya se señaló, se refiere al poder estatal. $^{46}$

La narradora también elige la altura para mirar la ciudad cuando se posiciona en el balcón del departamento de su amiga Linda, donde reina el silencio y no el caos de la Esquina Martillo Alegre:

Ya ha pasado la época de las náuseas y los mareos. Sin embargo, aún no me atrevo a asomarme a la terraza. Antes lo hacía. Balconeaba para echarle un ojo a la ciudad, tan blanca y bella de lejos, desde la altura que oculta la devastación, que tiende un velo de recato sobre la miseria y el horror, La Habana tornasol y en el crepúsculo rosa, con sus carros como escarabajos, sus transeúntes del tamaño de hormigas, el Malecón interrumpido por la torre del Focsa y, más allá, la bahía. Aire puro, sensación de plenitud. Vértigo. (...) Tuvo que ser un violinista quien me mostrara el mundo desde la terraza, aquella insólita perspectiva del paisaje urbano, con el gesto majestuoso y algo irónico de quien ofrece un reino por conquistar. Nunca había subido yo tan alto. Me senté en la baranda con las piernas hacia afuera, balanceándolas en el vacío, sin apoyar las manos. El me sostuvo. Si llega a soltarme, hubiera sido la muerte (Portela, 2002: 100-101).

Como lectores, nos detenemos abruptamente en el tiempo verbal elegido para la última oración concesiva. La pulida escritura de Ena Lucía Portela convierte en presente el momento dramático; como si Zeta siempre se estuviera balanceando en el abismo. Además, páginas después se confirma la tentación por el abismo: "crujientes deseos de sentarme otra vez en la baranda, voltear de nuevo hacia la calle, ponerme de pie en el alero, despacio, todo muy despacio, en cámara lenta, respirar hondo y entonces...volar. Escuchaba la voz del precipicio, tan seductora como la de Félix o la de Moisés, una tentación casi irresistible"

\footnotetext{
${ }^{46}$ Los ejemplos son múltiples: "sabía, puesto que era un hombre muy sagaz, que ni ellos mismos, los canallas predicadores, se creían una jota de sus embustes. Qué iban a creer. Porque la gente convencida aseguraba entre alaridos y puñetazos encima de la mesa-, la gente verdaderamente convencida, nunca trata de convencer a nadie. No les hace ninguna falta el consenso. No se las dan de apóstoles. Se creen felices cuando creen dirigirse hacia lo que creen amar (esta frase me encantaba) y lo demás a la mierda" (Portela, 2002: 11). Otro: "Ah, pero ellos no. Qué va. Ellos no se iban a morir nunca. Ellos, los malditos hipócritas, se regodeaban en su espuria inmortalidad. No porque creyeran en la reencarnación ni en la trascendencia ni en nada. Ellos no creían ni en la puta que los había parido. Se limitaban a cerrar sus ojuelos cínicos para no ver el desastre que se les venía encima” (Portela, 2002: 131)
} 
(Portela, 2002: 101). Hay una asociación entre el deseo de muerte y el deseo sexual, pero en el desenlace de la historia vemos que la muerte del cuerpo se proyecta en la caída contra la ciudad: cuerpo sexual estrellado en el cuerpo social.

Nara Araújo (1999) advierte que los espacios privados, cerrados, establecen una relación oblicua con su referente y que, en la narrativa cubana, es posible pensarlos como una metáfora de la condición insular. En esta "narrativa de encierro", el "espacio otro" no sirve a un propósito teleológico porque ese espacio cerrado no se resuelve en sí mismo. Por el contrario, lo privado se conecta con el afuera. "Hay un marco, pero el marco no existe", Araújo insiste una y otra vez con la frase derridiana para advertir que "la metáfora del aislamiento, de lo de adentro, al mismo tiempo que pudiera remitir a la condición insular, trasciende lo territorial reconocible y prioriza lo local sobre lo nacional" (Araújo, 1999: 216). Estas reflexiones permiten examinar la significación que adquieren en la novela los espacios cerrados porque, aunque los momentos de fricción con el espacio exterior tienen importancia en la historia, Zeta elige refugiarse en el reducido ámbito de lo privado y es aquí donde las prácticas cotidianas, pensadas en términos políticos, adquieren valor de resistencia (recordemos que esta característica ya apareció en "El viejo, el asesino y yo"). Mayoritarias a lo largo de la historia, estas instancias crean espacios de encuentro: las fiestas organizadas en lo de la Gofia, "un islote dentro de la isla" (Portela, 2002: 199) que reúne, principalmente, a lesbianas; las reuniones organizadas por el padre (homosexual) de Zeta; las prácticas sexuales como espacio de placer y de libertad; las singulares charlas con el padre Ignacio y, en torno a la vida y a la literatura, con Linda. Estas instancias de reflexión sobre lo literario -en los bordes entre la ficción y la "realidad", las prácticas (ironizadas) de sus integrantes, los circuitos culturales, etc.- y la puesta en escena de la escritura -tanto de 
Zeta como de Linda- pueden ser pensadas como instancias de configuración de la escritura como lugar de resistencia. ${ }^{47}$

En Cien botellas en una pared, la reclusión en el ámbito de lo cotidiano configura un espacio laberíntico hecho de estructuras, tabiques, canales conductores pero, también, muros infranqueables. Si la cotidianeidad se vuelve laberíntica, con pasadizos que no conducen a ningún lugar y otros desde los que se vislumbra el abismo, ¿'es posible pensar estos espacios como formas de resistencia al control del Estado pero, también, a las normas estatuidas en el ámbito de la literatura?

\subsubsection{Tensiones en torno a la ficción}

Es posible rastrear en la novela diferentes instancias de reflexión en torno a la escritura, sobre todo se vuelven una y otra vez a debatir los límites entre la realidad y la ficción, problema histórico para la literatura en general pero que parece referir al policial latinoamericano que algunos autores consideran un nuevo realismo a partir de su vínculo con los autores norteamericanos que en la década de los treinta introducen el realismo social en las narraciones. ${ }^{48}$ En el discurso de Zeta y en el de Linda se establece un contrapunto acerca de la retórica de la escritura, contrapunto que se dirime principalmente

\footnotetext{
47 La puesta en escena del acto procesal de la escritura se puede observar, por ejemplo, cuando Zeta especula sobre las circunstancias en que desapareció el dueño original de la ex mansión del Vedado: “Quizás esté ahora mismo detrás de mí, leyendo esta página por encima de mi hombro con oligárquica reprobación y muchas ganas de arrebatarme el lápiz ¿Quién soy yo, tan fresca, para hablar así de él, de su vida privada? ¿Quién me dio permiso? ¿Y qué canallada es ésta de escribir con un mocho miserable en unas harapientas hojas de papel gaceta? ¿Por qué no hago algún esfuerzo por conseguir una computadora? ¿ $\mathrm{O}$ al menos una máquina de escribir, algo más digno de su alcurnia en todo caso?” (Portela, 2002: 32). Además, se observan las carencias con que se materializa el acto de la escritura: el mocho es el trozo de lápiz y las hojas de gaceta, el papel amarillento, barato, de mala calidad.

48 Ver Juan Ignacio Colill Abricot (2010): "La novela negra latinoamericana expresa los conflictos al interior de las sociedades modernas y desde ese punto de vista se convierte en heredera de la novela social. Esto se da en su forma de exponer conflictos, de desentrañar los nudos que atan a las sociedades en cuanto a relaciones de poder. Por supuesto ya no importan las duras condiciones de vida de los mineros de las salitreras o del carbón, lo que importa es resaltar los conflictos, los temas escondidos, lo que fluye bajo el discurso oficial".
} 
en los complejos límites entre la realidad y la ficción, así como en los diálogos que se establecen entre ambas esferas. La primera posición se dibuja en el discurso de Zeta para quien la ficción es una traslación literaria de hechos reales:

Volviendo al asunto de la férrea incredulidad que me rodea, quizás mi amiga tenga razón y deba dedicarme a la literatura, o sea, a escribir lo que nadie se presta a escuchar con un mínimo de fe. Lo estrafalario. Lo novelesco. Lo increíble. Pero no estoy muy segura. Si este libro fuese una novela, es probable que tampoco me creyeran. A ver si nos entendemos. Ya sé que la ficción está más allá de lo verdadero y lo falso. Es ficción y punto. Pero de algún modo debe convencer, por lo menos, mientras se lee, si no qué gracia tiene. A eso le llaman, creo, 'verosimilitud'. Contar lo que tal vez no fue, pero bien pudo haber sido (Portela, 2002: 263).

En la línea argumentativa de Zeta, su historia sería una traslación de hechos acaecidos en la realidad, muchos de los cuales no serían creíbles porque la realidad superaría a la ficción y, por eso mismo, sus conocidos dudarían de la veracidad de su versión. ${ }^{49}$ Por eso, la trama de su discurso se apoya en el relato de hechos demostrables sólo por haber sido testigo o partícipe ya que, en caso contrario, los pone en entredicho:

En este punto de la historia, como es de suponer, desaparezco. Linda me ha contado algunos detalles. Alix, nada. ¿Cómo proseguir el relato sin arriesgar mi credibilidad? Porque lo que sucedió entre ellas a solas en el penthouse, a ciencia cierta sólo lo saben ellas (...). Lo que sigue a continuación, se aproxima, pues, a la realidad. Quizás se aproxime bastante. Pero no me atrevo a asegurar que sea la realidad (Portela, 2002: 223-224).

Así, por citar otros ejemplos, comenta en referencia a cuestiones que no confesó a Linda: "Supongo que se enterará cuando lea este libro, si llego a terminarlo, si llega a leerlo, y quiera Dios que no me odie entonces" (Portela, 2002: 121) o respecto de una fiesta en lo de

\footnotetext{
49 Para Zeta la escritura es una forma de tratar de entender la realidad, de aproximarse a ella. Dice al inicio del capítulo sexto: "Qué coincidencia. Pero qué increíble, perturbadora, macabra coincidencia. Recién ahora, que intento reconstruir la historia a ver si pongo un poco de orden en mi pobre cabeza, me percato de que ambos hechos ocurrieron justo el mismo día, hace alrededor de cinco años" (Portela 2002: 123) Y luego, "Lo que sucedió en el celebérrimo apartamentito de Centro Habana me parece ahora bastante confuso. También me lo pareció entonces, sólo que aquella noche yo aún no pensaba en contar la historia y me importaba un bledo la confusión. Quizás los relatos deban ser inteligibles, pero la vida ciertamente no lo es" (Portela, 2002:144).
} 
la Gofia en la que "El puntillazo lo dio la visita de una famosa actriz alemana, cuyo nombre me confió Linda pero yo prefiero reservármelo, pues ella es de veras muy famosa y no sé si asume en público sus andanzas por el lado más recóndito de la nocturnidad habanera" (Portela, 2002: 199). En este hilo conductor del texto, la realidad superaría a la ficción en anormalidades, cuestión que hace que sea la ficción la encargada de tratar temas que, aunque reales, no serían creíbles en los medios de circulación usuales.

En esta línea hay, sin embargo, una inversión de la situación: literatura, pura creación pero equiparable a los hechos posibles de suceder (verosimilitud), puede pasar no como ficción sino como "real", como sucede con El año próximo en Jerusalén, ${ }^{50}$ la novela de Linda que Zeta relata a Moisés como un hecho realmente acaecido y que él cree como tal: "Se la conté, pues, como si no se tratara de una novela, o sea, una sarta de infundios, sino un hecho de la vida real" (Portela, 2002: 175). Respecto de esta novela negra Zeta dice:

Me produjo un gran impacto. No tanto por sus excelencias literarias, que no pongo en duda, como por la terrible historia que cuenta. O, más bien, por las implicaciones de esa historia. ¿Podía acaso ocurrir, en la realidad, o sea, en La Habana finisecular, un asesinato así de atroz y quedar impune? (Portela, 2002: 174; itálica en el original).

La otra postura respecto de los límites entre la realidad y la ficción es la que construye Linda en la creación de sus obras: parte de un hecho real, investiga, reconstruye lo que no conoce y organiza los materiales a su gusto. Esta opción la explicita cuando justifica su elección vocacional:

No, nada de eso. Las actrices y las agentes secretas recitaban guiones redactados por otros. Ella quería componer sus propios guiones, inventar sus propias mentiras y engañar a todo el mundo. Ella quería ser una consumada farsante, una sublime embustera. Ella quería ser escritora, y ese fue el primer gran parlamento de Linda Roth (Portela, 2002: 74).

\footnotetext{
${ }^{50}$ El título de la novela retoma la tradicional despedida pronunciada por los judíos en las festividades.
} 
En este sentido, se equipara la función de la escritora con la de una investigadora o detective que construye hipótesis sobre lo desconocido para otorgar verosimilitud a lo narrado. Este es el procedimiento utilizado en Nocturno Sebastián (el exitoso thriller de Linda, premio "Dashiell Hammett"), que narra la historia de un muchacho "que no se llamaba Sebastián, pero ese nombre le iba bien y así lo bautizó la escritora" (Portela, 2002: 188) al que no conoció pero cuya historia toca a Marilú "(Sandra en la novela)" (Portela, 2002: 208), hermana de la Gofia, y que deja al desnudo la homofobia imperante en las altas esferas gubernamentales: el padre de Sebastián era un brigadier que intentaba por todos los medios corregir la elección sexual de su hijo para evitar una mala reputación. Linda construye su historia a partir de los datos aportados por personas que conocieron a Sebastián. La novela está dedicada a “"Ana Cecilia Ramos, la más generosa entre las mujeres' lo cual me parece justo, pues a fin de cuentas fue ella quien le contó la historia a la escritora" (Portela, 2002: 213). Los hilos que le faltan son reconstruidos a partir de su imaginación:

mi amiga me contó una historia escalofriante. Parecida a la del primer inquilino del palacete, el oligarca, por incompleta. Por llena de huecos y puntos suspensivos, incertidumbres atroces, espacios para fabular a gusto. La Gofia le había contado algo, no todo. Linda sospechaba que ni siquiera la Gofia sabía todo, pero en fin (Portela, 2002: 185-186).

Cuando termina de contarle la historia, Zeta comenta:

- Puro Tte. Leví, ¿no? -traté de sonreír, a pesar de lo tenebroso que me resultaba todo aquello. Quizás me hubiera gustado que sólo fueran mentiras de Linda.

- Pues sí. Ahí lo tienes. Si una cuenta estas cosas en forma de crónica, reportaje o algo así, mucha gente no le cree. Dicen que son exageraciones, que La Habana es una ciudad aburridísima donde nunca pasa nada. Capaz que hasta algún hijoeputa te acuse de hacer propaganda política a favor del enemigo y ya tu sabes, el rollo, la jodienda estúpida...--resopló-. Por eso las novelas. Se cuenta algo cierto como si fuera falso, se reorganizan los datos, se inventa un poquitín me guiñó un ojo-, y ya. Todo el mundo se traga la papa. Hasta el hijoeputa. Que no se queda callado, claro. Dice que una es efectista, morbosa, truculenta, comercial, que escribe literatura para turistas y toda esa mierda (Portela, 2002: 186-187). 
El fragmento permite dilucidar el procedimiento literario de Linda para sus thrillers así como el valor que otorga a la literatura: contar cosas que de otro modo resultarían increíbles. Esta última postura respecto de la ficción se vincula con el poder simbólico de la palabra, como catarsis y, también, como forma de ejercer justicia donde en la realidad no la hay. En este sentido, Alix Ostión es la contracara de Linda. Por eso es en ella, y no en Linda, en quien -como lectores- depositamos todos los indicios que nos llevan a considerarla culpable de la muerte de Moisés. Dice Zeta: “Quizás los tipos en general le resultaban indiferentes, pero a Moisés llegó a odiarlo tanto o más que Linda. Sólo que ella, a diferencia de la escritora, carecía de palabras para expresar el odio" (Portela, 2002: 260).

En torno al debate realidad/ficción, resulta también ilustrativo el discurso con que Linda busca justificar el error que cometió al enamorarse de Alix Ostión:

Las escritoras inventamos patrañas porque somos una banda de neuróticas -dice 'escritoras', pero se refiere lo mismo a las mujeres que a los hombres-. Sabemos que dos más dos son cuatro porque no estamos locas, pero no nos gusta. Preferiríamos que fueran cinco. O nueve, o dieciocho, o la raíz cuadrada de menos uno, qué más da. Cualquier cosa excepto cuatro. Y urdimos tramas, enredos, fabricamos espacios donde eso ocurre. Y está bien. A veces hasta nos pagan por hacerlo. El problema, el verdadero problema, que no tiene nada que ver con la truhanería de los editores ni con la ceguera de los críticos ni con el alma palurda y rastacuera de los funcionarios que abogan por la censura ni con la mediocridad, la intolerancia, la envidia, la hipocresía y otros alacranes que deambulan por la ciudad letrada, el problema realmente grave comienza, creo yo, cuando pretendemos trasladar nuestras fantasías al mundo real, a esa tierra árida y opaca donde dos más dos son cuatro, sólo cuatro, siempre cuatro y no hay arreglo. O sea, cuando quedamos atrapadas en nuestra propia telaraña, cuando nos creemos nuestras propias mentiras. $\mathrm{O}$ las de otras escritoras, que viene siendo más o menos lo mismo. Hay escritoras fatales que la enganchan a una y le viran la existencia al revés, se la exprimen cual naranja, se la machacan cual diente de ajo, se la retuercen como hace con los cuerpos Afrodita Sáfica, la diosa del amor. La mejor de todas a mi juicio, fue aquella campesina pobre, ignorante, hosca, fea, que murió en plena juventud sin conocer el éxito (...) yo tal vez no hubiera transmutado mi vida por la suya, pero sí por la de uno de sus personajes. ¿Te das cuenta, Zeta? ¡Vivir dentro de una novela! Ahora me parece absurdo y hasta idiota, pero entonces no me lo parecía. Nada, que me tragué la papa entera con cáscara y todo. Luego conocí a aquella muchachita del pelo negro y fue el caos. Creí haber encontrado, ipor fin!, a Heathcliff, el gitano taciturno. Pero la realidad... (Portela, 2002: 147-149). 
Esta extensa cita permite abordar varias cuestiones. En primer lugar, vuelve a confirmar la visión de la literatura que tiene Linda: invención, patraña. Pero al mismo tiempo, visibiliza los riesgos de creer que la ficción es realidad y de buscar en ésta parámetros de aquella Linda se enamora de Alix Ostión porque cree emular la relación de Catherine con Heathcliff en Cumbres borrascosas. Sin embargo, se cumple el deseo de Linda porque se convierte en el personaje de la novela que narra Zeta (para quien, por otra parte, la realidad es su relato, la historia del crimen, historia dentro de la historia).

Estas posiciones respecto de la ficción vuelven a aparecen en las escenas de escritura. Como eventual escritora de ficción, Zeta se delinea en oposición a la figura de la escritora profesional Linda Roth. Esta oposición se puede leer como un juego de duplicación metaficcional: Linda es la antítesis de Zeta y las dos son escritoras, alteregos de Portela. En relación con esta estrategia, Zeta cuenta que Linda está escribiendo la novela Cien botellas en una pared y, como lectores avizoramos que es la misma que está narrando Zeta, la narradora y escritora del crimen. Es decir, en este juego interviene el tejido de una primera novela escrita por Linda en la ficción y otra que está siendo construida por Zeta, la narradora y, finalmente, la novela de Ena Lucía Portela que tenemos en nuestras manos como lectores. En otra lectura Zeta sería el personaje elegido por Linda para narrar Cien botellas en una pared. En cualquiera de las dos lecturas, el acto de la escritura se proyecta como un espacio de reflexión y de creación. Ese acto de creación se materializa en un espacio ligado a la "mezcolanza, el ajiaco, el carnaval" y que lejos está del cuarto propio pregonado por Virginia Woolf para que la mujer alcance el goce del ocio contemplativo y acceda a la escritura. Sobre esto se ironiza en la novela cuando Zeta describe su espacio de creación:

Volviendo al tema de la habitación propia diré que soy, en efecto, la feliz poseedora de un cuartito en miniatura con una ventana descomunal y un baño estupendo, lujosísimo con sus azulejos azules, el original de la casa más endemoniadamente estrepitosa de la Vía Láctea. Podrá parecer un deseo mezquino, surgido de la frustración y el resentimiento y hasta la envidia, pero no 
digo yo si no me encantaría ver a Mrs. Woolf escribiendo Mrs. Dalloway entre el cacareo de las gallinas, los atronadores ladridos del megaterio tratando de comerse al cobrador de la luz o a la pobre jutía que es tan buena, las fichas del dominó contra alguna mesa, "abran paso que ahí voy, porque llevo y puedo el sucio y la que se hinca, y te paso y te vuelvo a pasar porque tú lo que eres un macao, asere, tremendo macao", los gruñidos del cerdo que huye despavorido cuando pretenden ducharlo con una manguera a ver si le quitan un poco la peste, la guerra de los decibeles entre Compay Segundo, el Médico de la Salsa, NG La Banda, la Orquesta Revé, Paulo F.G. y su Elite, Adalberto y su Son, no sé quién y su Trabuco y la Charanga Habanera en un todos contra todos a ver quién es el más bárbaro, el más vociferante, el duro de la película, sin olvidar a Radio Reloj que da la hora, piiiii... doce meridiano en La Habana, Cuba, tres de la madrugada del siguiente día en Wellington, Nueva Zelandia, los berridos del chivo añadidos al din don de la campanita, las broncas de los borrachos, salpimentadas a gusto con todo un arsenal de palabritas vernáculas, expresiones folklóricas y demás estridencias, las broncas de los sobrios (igualiticas a las anteriores), como aquella estruendosa con rayos, truenos y centellas entre la dueña del megaterio y el dueño del cerdo (...) (Portela, 2002: 46-47).

Esta humorística confrontación con la situación ideal propugnada por Virginia Woolf dibuja, nuevamente, un espacio ligado a la mezcolanza y al ajiaco (de música, de clases, de géneros). Zeta caracteriza su lugar como un espacio en el caos de la cotidianeidad habanera, mientras que las escenas de escritura de Linda están más ligadas al reclamo por el que abogó la escritora inglesa en Un cuarto propio; por eso, aunque la critique son mayores las similitudes. Lejos del lugar de recogimiento necesario para el acto de creación y de un refugio apartado del mundanal ruido para poder encontrarse con la voz interior, Zeta se dispone a escribir en un departamento que no es ajeno al ajetreo y la "mezcolanza" en que está inserto, no sólo como lugar físico sino ella se aparta de lo establecido, de las normas del buen decir y del buen pensar: "No se trata de 'pensar' en el sentido recto, riguroso, lógico de la palabra. Eso creo que nunca he sabido hacerlo. Qué pena, con lo importante que es. Más bien divago, dejo suelta la memoria y es ella sola, animalejo silvestre, quien fluye, serpentea, se enrosca y termina por saltar al cuello de Moisés" (Portela, 2002: 26). ${ }^{51}$

\footnotetext{
51 Por ejemplo, narra Zeta: "Enclaustrada en el estudio de este soberbio penthouse, ella sigue escribiendo su nueva novela, Cien botellas en una pared, la de los dos homicidios (...) Desprecia todo lo que huela a tertulia, salón o bohemia. El tiempo, su tiempo, es sagrado. Yo entendería esto si mi vida - dice ella - tuviera algún sentido más allá del simple estar ahí, en el revoloteo" (Portela, 2002: 99-100). La cursiva pertenece al original.
} 
De este modo, para Zeta la escritura se convierte en una forma de acción y de conocimiento que, además, se sostiene a partir del juego que establece entre los difusos límites entre la realidad y la ficción.

La cita también permite advertir la superposición de voces entre la narradora Zeta y Linda que deja entrever el desdoblamiento en espejo que se produce entre ambas figuras: Zeta y Linda son (y no) las mismas: entre ambas se establece una relación en espejo distorsionada, ya que el reflejo invierte la construcción del cuerpo que se mira, es el anverso de lo que son en términos físicos (gorda/flaca), sexuales (heterosexual/ homosexual) y subjetivos. ${ }^{52}$ Esto sucede con la equiparación entre maternidad y creación literaria:

Para mí ser mamá significa lo mismo que para Linda ser escritora: un sentido más allá del simple estar ahí, en el revoloteo. Pero mi amiga se empeñó en atribuirme sensibilidad para las artes y talento para las letras (Portela, 2002: 112).

Se otorga el mismo lugar simbólico a la creación intelectual que a la procreación biológica: mientras una se realiza en la escritura, la otra lo hace en la maternidad. ${ }^{53}$ De esta forma parecería imposible conciliar la creación intelectual (espacio de libertad) con la vida cotidiana, con la maternidad, las obligaciones familiares. Sin embargo, un dato incluido en la última nota al pie permite reflexionar sobre cómo Zeta logra fundar un nuevo espacio de creación. La muerte de Moisés ocurre el 19 de diciembre y hay una nota al pie que dice:

¡Lo que son las casualidades! El desenlace de este drama tuvo lugar, en efecto, un 19 de diciembre, Gran Día de la Literatura Cubana según Linda. Es su cumpleaños y también el de un poeta inmenso que se llamó José Lezama Lima (Portela, 2002: 263).

Esta estrategia también fue advertida por Alberto Garrandés (1999) en algunos cuentos de Portela. Según señala este autor, la estrategia se puede relacionar con la analogía entre el pensar y el actuar. En "Sombrío despertar de la avestruz" también aparece el mismo juego: el personaje que narra es escritora y se hace referencia a un cuento anterior, "Dos almas nadando en una pecera".

${ }^{52} \mathrm{El}$ juego especular entre las amigas se advierte, también, en el error de Alix quien, dormida, confunde en sueños a Zeta con Linda.

53 Zaida Capote Cruz (2008) señala también la equiparación o separación entre maternidad y creación intelectual en otras producciones de escritoras cubanas. Por ejemplo, advierte que este planteo ya está presente en el poema "Canto a la mujer estéril" (1937) de Dulce María Loynaz. El asunto de fondo es cómo conciliar libertad y sexualidad, tema que se plantea a lo largo de todo el siglo XX. 
La muerte "real” y simbólica de Moisés el Gran Día de la Literatura Cubana supone tres nacimientos: el de los dos escritores aludidos y el nacimiento de Zeta como escritora, porque entonces decide comenzar a serlo. ${ }^{54}$ Deseo subrayar las implicancias simbólicas de este hecho: la protagonista construye su espacio de libertad para la creación a partir de la muerte del personaje masculino. El espacio escriturario está enclavado en un lugar marginal desde el género sexual (mujer), como desde lo profesional (escritora casual) o también de lo textual: el discurso marginal de Zeta se construye a partir de la oposición con otros y se configura desde el margen del texto: el uso de los paréntesis, las notas al pie. Sin embargo, este espacio secundario configura el primer plano de la escritura a lo largo del texto: lo marginal ocupa el centro porque el acto procesal de la escritura se construye en y con estos resquicios. Por ejemplo, como vimos, el uso del paréntesis sirve para acotar o comentar lo que dicen otros personajes. En el siguiente ejemplo, las palabras son de Moisés: "Se creen felices cuando creen dirigirse hacia lo que creen amar (esta frase me encantaba) y lo demás a la mierda" (Portela, 2002: 11). También, como ya se dijo, la narradora recurre al recurso de la nota al pie para explicar las frases en latín que utiliza Moisés o algunas referencias literarias de Linda: "Como decían los antiguos romanos: nibil novum sub sole" (Portela, 2002: 35) y, en la nota al pie, Zeta aclara el significado, "No existe nada nuevo bajo el sol". Sin embargo, al mismo tiempo, en el cuerpo del texto la narradora simplifica la expresión, acota su propia observación o impresión: "El latinajo me impresionó por su carga fatalista, inexorable como la cuchilla de la guillotina o los voltios de la silla eléctrica" (Portela, 2002: 35). Su voz resulta, entonces, mediadora entre un discurso culto (representado por Moisés y Linda) y un discurso popular: su palabra interviene para allanar las diferencias.

\footnotetext{
54 También ese día cumple años Ena Lucía Portela, la escritora.
} 


\subsection{Conclusiones parciales}

Los textos ficcionales de Portela que se han analizado ponen en evidencia -contra toda esencialización - los modos en que su escritura se constituye en un espacio fundamental para procesar la identidad del sujeto. Los desvíos de género (sexual y literario), el borramiento de los límites, el carácter construido y posicional de la identidad de género, así como la construcción de figuras de escritora, permite leer algunas de las tensiones que se libran en el campo literario cubano en relación con sus contemporáneos y con sus precursores, además de la percepción de sí misma. En "El viejo, el asesino y yo" se analizó la construcción de la figura de escritora y cómo ficcionaliza los posicionamientos en el campo cultural cubano a través del enfrentamiento de la narradora (en tanto joven escritora) con la tradición masculina, representada en la figura del viejo pero también en la de su amante. Portela construye complejas figuraciones de artistas/escritoras que se distancian de los esencialismos en torno a la escritura de mujeres. La desestabilización de la ideología falologocéntrica no se realiza desde la construcción de una "escritura femenina" que destruya los binarismos, las jerarquías, la gramática y la sintaxis de la lengua como pregona, entre otras estrategias, el feminismo de la diferencia. Portela socava desde las bases el sistema patriarcal que impera en el campo cultural cubano pero lo realiza desde un registro culto que construye sujetos difíciles de asir debido a los múltiples desdoblamientos de la sexualidad que rompen, también, con la homosexualidad y, por el contrario, el deseo transita de uno a otro sexo, más cerca de la libertad que de cualquier intento de encorsetamiento. Por ejemplo, en el cuento, el deseo de la narradora transita entre Amelia y "el Viejo"; en la novela, el desdoblamiento de Zeta (heterosexual) con Linda (homosexual) y de esta con Alix dibuja las tensiones de sujetos que rompen con estructuras sociales pero en cuyas relaciones también reproducen lastres de lógicas perversas, como la violencia entre Zeta y Moisés pero también entre Linda y Alix. Pensar los géneros literarios no sólo como 
formas sino como instituciones, permite reflexionar en torno a las tensiones que se suscitan entre los procesos de sedimentación y fosilización por un lado y, por otro, los movimientos que intentan fracturar las bases o, por lo menos, generar grietas que, poco a poco, modifiquen lo estatuido o la institución. En ese proceso el escritor elige mantener o alejarse de "lo dado": La escritura de Ena Lucía Portela se ubica en la segunda de las opciones: la torsión del género literario se produce a partir de una voz femenina a cargo de la investigación. ${ }^{55}$ Esta torsión se produce también desde la configuración del género sexual que la novela pone en escena a través de Zeta, Linda y Alix. Estos personajes femeninos entablan juegos de identidades especulares y desvíos, un juego de cajas chinas con voces que traman, dibujan y desdibujan los límites de la identidad y los debates en torno de la literatura. Zeta es el reverso de Linda: condensa lo popular y tiene el rol de cronista de "lo real". En Linda gravita la influencia extranjera, representada ya por su propio apellido. Sin intención de forzar la interpretación, se podría aventurar que estos personajes simbolizan la tensión entre los resabios del realismo socialista y la lucha por la autonomía de la literatura, es decir, se podría leer aquí una alegoría de la cultura: Zeta ocupa el lugar de mediadora, de lo maternal, mientras que Linda representa el espacio de lo racional, de la experimentación formal y sexual. Por otra parte, el personaje de Alix Ostión adquiere ya desde el nombre una fuerte connotación sexual: por la forma de vulva del ostión. Este personaje condensa la estigmatización de género y de clase social (proviene del ámbito rural): se podría aventurar entonces que lo popular aparece animalizado, un modo muy estereotipado de representar al otro (además, en la relación con Linda se reproducen las desigualdades, igual que en las relaciones patriarcales). Sin embargo, en el personaje de Alix Ostión también se deja abierta

\footnotetext{
${ }^{55}$ La parodia del relato policial ha tenido especial desarrollo en Puerto Rico con escritoras como Ana Lydia Vega, por ejemplo, en Pasión de historias (1987).
} 
la posibilidad de la subversión: ya que es quien tal vez provoca la muerte de Moisés (símbolo de la ley y de la masculinidad).

Por otra parte, el análisis permitió constatar cómo los desplazamientos en la construcción identitaria de los sujetos se produce en consonancia con torsiones de género literario. Ambos textos trabajan con los cimientos del policial. En "El viejo, el asesino y yo" esta cuestión ya está planteada (y resuelta) desde el título del cuento. En la novela, en cambio, la operación es más compleja y el desplazamiento se construye a partir del sujeto que narra e investiga el supuesto asesinato. En ambos casos, la escritura se erige como un espacio propicio para la búsqueda formal y para la proyección pública. De esta manera, las obras ponen en evidencia que el ámbito de la literatura es un campo de lucha donde se juega la aceptación o el rechazo de patrones y autoridades establecidos. Como veremos, las torsiones con el género literario son tramadas también en las novelas de Wendy Guerra y Karla Suárez que analizo en el siguiente capítulo.

En términos ideológicos, la imbricación entre ambas torsiones daría cuenta de un cuestionamiento de la imagen de un cuerpo político viril y heterosexual a través del cual la Revolución ha afirmado la unidad nacional y la autonomía política y cultural de la isla. El análisis de "El viejo el asesino y yo" permitió percibir también cómo la ficción procesa la lucha por la apropiación de la escritura y por alcanzar legitimidad, factores ligados al ingreso en determinado circuito intelectual, aspectos que permitieron reflexionar sobre la escritura, la sexualidad, la marginalidad y el poder.

"La mezcolanza, el ajiaco, el carnaval” recogidos en el epígrafe de este capítulo, puede considerarse un manifiesto literario de la escritura de Portela. El término central nos reenvía necesariamente a la metáfora utilizada por Fernando Ortiz (1940) para caracterizar a la sociedad cubana: "Hagamos mejor un símil cubano, un cubanismo metafórico, y nos entenderemos mejor, más pronto y con más detalles: Cuba es un ajiaco". Aún hoy esa 
figura retórica sirve para explicar la situación socio-cultural habanera: en "La Esquina del Martillo Alegre" conviven familias venidas del interior, personas de muy diferente origen social, algunas con un pasado "glorioso" ligado a la aristocracia o a la burguesía y que permanecen en la isla después del triunfo de la Revolución. Esta representación del espacio urbano es el marco en que se inserta una novela que trabaja el género policial a partir del desvío de los parámetros establecidos para el mismo en la década del setenta en Cuba. 


\section{Cuando el silencio dibuja el comienzo \\ Karla Suárez y Wendy Guerra}

El encanto del silencio es que se convierta en absoluto

Karla Suárez, Silencios

Para pensar ciertos sectores del campo cultural cubano resulta sugerente la imagen de un archipiélago de exilios interiores y exteriores. Los textos considerados en los capítulos anteriores fueron analizados en relación con la construcción identitaria de los sujetos femeninos, un tema que en el ámbito cubano se enlaza con los complejos diálogos entre la cultura de la isla y la cultura de la diáspora. El análisis realizado y las consideraciones vinculadas al mismo permitieron percibir las tensiones inherentes a un cuerpo literario que dialoga y batalla por construir una tradición en donde reconocerse. El corpus constituido para este último capítulo pone en primer plano las tensiones propias de un "campo diseminado" (Rojas 2006) en términos espaciales y simbólicos en el que, como ha advertido Celina Manzoni, la itinerancia ha generado "nuevas modalidades de escritura: una renovada articulación de los modos de la memoria" (Manzoni 2012: 3). En estas páginas abordo Silencios (1999) de Karla Suárez y Todos se van (2006) de Wendy Guerra, en ambos casos, dos primeras novelas que sitúan su diégesis en la crisis que atraviesa La Habana de los años noventa y que, en tanto espacios dialógicos (en términos de Bajtín), rearticulan los discursos sociales y procesan, de distinto modo, las tensiones que se dirimen en los cuerpos de quienes eligen quedarse en la isla.

En el capítulo anterior, mostré cómo los desplazamientos de género y la ficcionalización del acto de escritura que trama la narrativa de Portela funcionarían, de algún modo, como una manifestación de cierta resistencia de los cuerpos (sexuales y literarios) a ser aprehendidos y, en este sentido, serían una respuesta ideológica a las leyes 
que regulan el campo cultural cubano. Estas cuestiones también están presentes en las dos novelas que se consideran en este capítulo, aunque en ellas el quiebre con el discurso homogéneo y patriarcal no se realiza desde la construcción de identidades sexuales que resisten cualquier intento de clasificación, sino que remite a los (ab)usos de los géneros literarios utilizados en la construcción narrativa.

Ambas novelas de los "comienzos" son precursoras y configuradoras de los proyectos narrativos de las escritoras. Tal como vimos en la introducción a esta tesis, Edward Said (1978) postula el comienzo como el primer escalón en la producción intencional de sentido que puede recorrer toda o parte de la obra de un autor y que entraña, en consecuencia, un proyecto subyacente. En función de estos aportes, en este último capítulo analizo cómo cada una de las novelas urde un proyecto narrativo a partir de dos movimientos: desestabilizar los géneros literarios puestos en funcionamiento para contar la historia y erigir al silencio como estrategia medular de la construcción narrativa y, al mismo tiempo, de la construcción identitaria de los personajes femeninos que narran la historia. Respecto del primer movimiento, anticipo que las dos obras rozan los bordes del diario como género textual: en Silencios, la novela de Suárez, una narradora en primera persona reconstruye su historia a lo largo del complejo camino de formación moral, emocional e intelectual desde la infancia hasta la adultez y, en este sentido, puede ser leída como novela de aprendizaje; en Todos se van una narradora en primera persona, Nieve Guerra, escribe en el diario íntimo su infancia y adolescencia. ${ }^{1}$ En cuanto al segundo movimiento, advierto que en las dos novelas el silencio funciona en tres dimensiones -como alusión, como procedimiento escriturario (elipsis, saltos temporales, espacios en blanco) o como treta de

\footnotetext{
${ }^{1}$ Karla Suárez continúa con este género en La viajera (2005). Allí, en vez de diario se habla de "cuaderno de bitácora" en tanto plasmación de las vivencias e impresiones durante los sucesivos viajes que emprende Circe, una de las protagonistas. Este manuscrito se lo entrega a Lucía, su amiga, para que lo lea y sepa sobre su vida durante los años que estuvieron separadas. Ante este inesperado gesto e incitación a la lectura de algo prohibido, en tanto escritura íntima, Lucía reflexiona: "Un diario es como un desnudo" (Suárez, 2005: 34).
} 
los personajes (el callar, la mudez voluntaria o impuesta). En este sentido, en ambas historias la literatura (ya sea en la variante de la lectura o de la escritura) se configura como el reverso del silencio y como el espacio de resistencia en el que las protagonistas (re)construyen su identidad en un contexto signado por el abandono y la soledad.

Para leer cómo se pone en funcionamiento esta estrategia en dos novelas escritas por cubanas resulta sugestivo el comentario realizado por Rafael Rojas (2006) quien advierte que la estrategia de callar en público pueden aludir al callar las desavenencias respecto del gobierno que se reservarían, en cambio, para la esfera privada. Para este crítico el silencio es una estrategia de posicionamiento de intelectuales cubanos que no fueron adeptos al gobierno pero tampoco se opusieron ni se exiliaron. Considera que es una estrategia nueva y, al respecto, propone que "en el actual proceso de memorialización de la guerra civil cubana, las dos políticas intelectuales que ofrecen una mayor resistencia a la usura simbólica del poder son el silencio y el exilio" (Rojas, 2006: 23; itálica en el original).

\section{1. La lengua del silencio: una urdimbre identitaria}

Karla Suárez nace en 1969, en La Habana, en el seno de una familia en la que lo ficcional siempre estuvo presente a través de su madre profesora de literatura. Pese a escribir desde pequeña, estudia Ingeniera Informática en la Universidad de La Habana. En 1994 publica su primer cuento, "Aniversario", en la Revista Revolución y Cultura y, en 1998, la Fundación Alejo Carpentier de La Habana, le otorga la Beca de creación Razón de Ser por un proyecto de novela. Ese mismo año, Suárez traslada su residencia a Roma donde continúa escribiendo, además de ejercer la profesión de ingeniera y profesora de informática. En 1999 aparece en España su primera novela, Silencios, que gana, junto con La Piel de Inesa de Ronaldo Menéndez, el $V$ Premio Lengua de Trapo de Narrativa otorgado por la editorial madrileña del mismo nombre. Por esta novela también recibe el I Premio de Narrativa 
Americana Innovadora, convocado por la Casa de América. A partir de las repercusiones de esta obra fue seleccionada por el diario El Mundo entre los diez noveles escritores del año 2000 y, en 2007, es seleccionada, con su coetánea Wendy Guerra, para integrar el Grupo Bogotá 39, que reúne a los 39 escritores menores de 39 años más representativos de las nuevas tendencias de la literatura latinoamericana. En la actualidad vive en París.

Estructurada en veintiséis partes, Silencios puede pensarse como una novela de aprendizaje o de formación: una narradora en primera persona reconstruye su paso de la niñez a la juventud en un marco contextual que comienza en los setenta, atraviesa los ochenta y se extiende durante el llamado "Período especial". ${ }^{2}$ En la parte que se titula "La casa grande" la protagonista convive con un padre militar siempre ausente, una madre deprimida (es una argentina que arribó a La Habana en los sesenta para estudiar teatro y luego se enamoró de un joven oficial del ejército), una abuela con historias de abandonos e infidelidades, una tía soltera con tendencias suicidas y un tío homosexual. Cada uno de estos personajes vive encerrado en el silencio de su habitación, de sus secretos, de su microcosmos particular. A ese elenco de personajes se suman los amigos de la narradora que completan el escenario de este viaje iniciático por la vida: Cuatro, el Poeta, Dios, el Merca. En el camino de reconstrucción de su paso de niña a mujer, la protagonista desnuda las mentiras y silencios que sostienen la estructura familiar y pasa de la primera infancia, configurada como mundo feliz y marcada por sucesivos descubrimientos, a una adolescencia y juventud signadas por el silencio como marca de crecimiento. ${ }^{3}$ En esta operación de despojar los velos de quienes la rodean se va quedando sola y, primero de a

\footnotetext{
${ }^{2}$ Utilizo la primera edición de esta novela: Madrid, Lengua de Trapo.

${ }^{3} \mathrm{El}$ primer hecho que marca crecimiento fue la primera noche en que sus padres discutieron delante de ella: "Esa noche descubrí que después de las canciones que ella me cantaba, se quedaba despierta esperando el regreso de mi padre para irse a la sala a discutir. También descubrí que no todo andaba tan bien como yo pensaba" (Suárez, 1999: 20).
} 
poco y con el paso del tiempo con mayor insistencia, el silencio se configura como una práctica de resistencia de la protagonista y, al mismo tiempo, como la estrategia narrativa central de la novela que tenemos en nuestras manos. Esta operación adquiere espesor en el capítulo final, "Último acto", único narrado en presente (y que marca el presente de la enunciación) en el que la protagonista decide dejar de escribir y, por lo tanto, optar por el silencio (narrativo).

Ya desde el epígrafe que abre la novela, el silencio se vislumbra como clave de lectura: "No es que le falte el sonido,/ es que tiene el silencio. Charles Chaplin". Según la disposición gráfica, el actor aparece como autor de esas palabras, sin embargo, los versos pertenecen al poema "Cine mudo" de la poeta cubana Fina García Marruz: "No es que le falte sonido,/ es que tiene silencio" (García Marruz, 1990: 14 ). ${ }^{4}$ El plural del título convierte el silencio en una práctica colectiva o, que por lo menos indica cierta repetición. En la historia narrada, el silencio es una estrategia adoptada no sólo por la protagonista sino también por los otros personajes que la circundan, en particular, los de su entorno familiar. En este círculo íntimo, la puesta en práctica del silencio adopta una variante que consiste en callar para ocultar, es decir, los personajes guardan secretos. Por ejemplo, la abuela oculta el origen ilegítimo de su hijo menor; el tío, su elección sexual; el padre, sus amoríos extramatrimoniales y la razón de su regreso de Angola; la tía, su relación con un hombre casado. Estos silencios se configuran como "secretos de familia" y, como tales, son conocidos, en general, por todos los integrantes excepto por la narradora cuando es niña

\footnotetext{
4 El poema pertenece a Créditos a Charlot (1990). Me pregunto cuál es la razón del desplazamiento metonímico entre el título del poema y el actor más representativo del cine mudo, ¿por qué queda obliterado el nombre de Fina García Marruz? ¿Tal vez porque la poeta (como sinécdoque del lugar de las mujeres escritoras en Cuba) también queda tapada ante la figura de sus pares masculinos de Orígenes? No encuentro una respuesta que me satisfaga. Aunque García Marruz formó parte del célebre grupo intelectual conocido como Orígenes y en 1990 recibe el Premio Nacional de Literatura concedido por el Ministerio de Cultura de Cuba, ni su poesía ni su ensayística han gozado de la difusión que sí ha tenido la obra de la mayoría de sus pares masculinos de la familia poética: Cintio Vitier, José Lezama Lima, Eliseo Diego, Gastón Baquero, Virgilio Piñera, Octavio Smith, Lorenzo García Vega, Ángel Gaztelu y Justo Rodríguez Santos. Véase Arcos (2000: 13).
} 
aunque, poco a poco, descubre lo que se esconde. En este proceso ella también comienza a utilizar distintas variantes de esta práctica aunque adquieren otro sentido, ya que pone en práctica el silencio como arma de resistencia.

En el nivel del discurso, se observan formas de representación del silencio que adquieren categoría textual, por ejemplo, la inexistencia de nombres propios en los personajes (o su reemplazo por apodos) y la repetición de fórmulas para referir el contexto. Así, los personajes del ámbito familiar no tienen un nombre que los individualice ya que la narradora se refiere a ellos por el rol que cumplen: Mamá, Papá (ambos siempre en mayúscula, excepto en las variantes, "mi madre", "mi padre"), tía, tío, abuela, abuelo. Respecto de sí misma, las únicas alusiones son los motes de sus compañeros de escuela: "Marimacho" y, luego, "la Flaca". Los amigos tampoco son individualizados con el nombre de pila sino que se utilizan sobrenombres que aluden a algún rasgo físico, conductual o psicológico distintivo, por ejemplo: Cuatro Ojos (o Cuatro), el Poeta, Dios, el Merca. Significativamente, la gata es la única que tiene un nombre, se llama Frida (en clara alusión a Frida Kalho) y junto a ella se encierra la protagonista en el último capítulo.

$\mathrm{Al}$ contexto se alude en pocas oraciones que describen situaciones estereotípicas del momento que se quiere referir y se marcan con expresiones como "Era la época" o "Era una época" o, simplemente, "Era". Por ejemplo, "Eran los ochenta, yo ya había aprendido en la escuela que gusano se le decía a los que se iban del país" (Suárez 1999: 32), "Eran los ochenta y la Habana reía. Mamá compraba vinos búlgaros para ella y vodka para Papá” (Suárez, 1999: 66); "Era una época en que todos se interesaban demasiado por el mundo. Algunos usaban pulovers con rostros del Che y se declaraban quijotes en un mundo de paz, donde no hubiera dictaduras, ni diferencias, ni tanta gente muriéndose de hambre" (Suárez, 1999: 166). La elección de fórmulas estereotipadas (tanto por la repetición del verbo "ser" en pasado como por la mención de los hechos más conocidos) y de escasas oraciones para 
enmarcar el tiempo de la historia puede ser pensada como una retórica que bordea los contornos del silencio. Si, como veremos más adelante, la representación de la "casa grande" puede ser considerada como una metáfora de la situación socio-cultural cubana, también es posible pensar estas estrategias como formas de textualizar la lucha contra la coerción ideológica (tenga la forma de una represión política, personal o social), es decir, una forma de resistencia frente a la represión que impone el silenciamiento de la palabra.

Uno de los "secretos de familia" gira en torno al origen de su padre, fruto de un amor extramatrimonial de la abuela con un mulato. Ese secreto se configura como un espacio de doble pecado porque el engaño no sólo provoca el abandono de su marido sino por la deshonra implícita en la elección racial. Ese momento constituye un doble origen: el origen (bastardo) del padre de la narradora y el germen de la locura de la tía quien, en su niñez, utilizada por la madre como coartada de sus encuentros amorosos, los presencia. La tía debe callar también doblemente: primero, ante el padre, mientras compran su silencio con caramelos; luego, ante su hermano. Su silencio resguarda el orden familiar a tal punto que en las dos ocasiones en que se rompe el pacto se devela ese "secreto de familia", genera consecuencias negativas en su vida: cuando le cuenta la verdad a su padre, éste abandona a la familia; cuando el amante se presenta en la casa para conocer a su hijo, se genera la internación de la abuela y es otro elemento más para su propia internación en un psiquiátrico. En su discurso emerge la discriminación racial:

la puta se la llevaba de paseo para que su padre no sospechara y en vez de pasear se metía en casa del negro de mierda para templárselo y luego le regalaban caramelos para comprar su silencio. Mi padre la soltó y ella se dejó caer al piso y continuó moqueando, dijo que ella los había visto revolcándose, que el negro la volvía loca y mi padre era hijo del negro sucio (Suárez, 1999: 70).

Después de este descubrimiento, y aunque en la casa nunca más se volvió a hablar del tema se origina un nuevo secreto familiar: la narradora y su padre comienzan a visitar al abuelo: 
“--Este es nuestro secreto, tú y yo vamos a visitarlo, pero no podemos decírselo a nadie, ¿ok?” (Suárez, 1999: 72).

Otro de los secretos es la homosexualidad del tío. La elección sexual se convierte en un agravio, además, porque el padre de la narradora es militar de carrera y, por eso, opta por no dirigirle la palabra ya que significa una mancha que en su historia familiar tenga un homosexual y un hermano "gusano". De niña observa esta hostilidad y también percibe el silencio como una forma de ocultar lo que no se quiere nombrar por la vergüenza familiar que ese cuerpo produce: "Con el tío tercero también había problemas, no sólo que mi padre no le hablara, sino que existía algo en la familia que nadie se atrevía a pronunciar" (Suárez, 1999: 17). Para mantener este secreto (a voces), el tío esperaba la madrugada para entrar con alguien en su cuarto. Su coartada es descubierta por la protagonista, pero en vez de ponerlo en evidencia (y deshacer el secreto), elige fisgonear detrás de la puerta.

La infidelidad de su padre es otro de los secretos familiares. Ante estos recurrentes hechos, su madre opera con la secuencia de llanto y posterior silencio como muestra de su malestar:

Yo la observaba callada y me juré entonces que nunca lloraría así, nunca mostraría mis lágrimas porque detrás del llanto sólo había un tango y eso me daba ganas de llorar y no quería, nunca, nunca lloraría de esa forma, por nada, ni por nadie, ni siquiera por lo que en aquel entonces podía comprender (Suárez, 1999: 21).

Cada vez que está disconforme, su madre regresa una y otra vez al silencio: cuando se pelea con su marido, con su cuñada, con su suegra. Ella ocupa un lugar incómodo dentro del microcosmos familiar: es la extranjera que se alejó de su familia argentina para estudiar en Cuba durante la etapa de fervor revolucionario. Para la narradora, el modelo materno está vinculado con el fracaso, con aquello que no desea para sí y este se perfila como uno de los aprendizajes en el repaso de los hechos que marcaron su vida, aspecto que desarrollo en el apartado siguiente. 


\subsubsection{Apre(he)nder el silencio como práctica de resistencia}

Señalé en el inicio del capítulo que esta novela era posible ver rasgos del Bildungsroman (Bajtín, 1982; Amícola, 2003). ${ }^{5}$ El clásico Bildungsroman (la novela fundacional Wilhelm Meisters Lehrjahre de Goethe, 1796) tiene como eje central el proceso formativo de un joven que pasa por una serie de etapas (la niñez, juventud, el provincialismo y el viaje a la ciudad, el conflicto con la sociedad circundante y/o entre generaciones, la formación mediante una serie de experiencias vitales ligadas a la sexualidad y la búsqueda de una vocación y de valores éticos) que culminan con su integridad personal y social. En las historias, los héroes masculinos siempre logran la realización personal y tienden a elevarse o adquirir un lugar positivo dentro de la sociedad. Esta formulación del género ha sido utilizada para analizar también novelas escritas por o sobre mujeres, por lo que ha sido discutida por los críticos tanto porque no se ajusta al contexto socio-histórico en que se origina el Bildungsroman sino, además, porque sus protagonistas son héroes masculinos. En este sentido, resulta esclarecedora la síntesis que realiza José Amícola cuando señala que

el crítico alemán Bruno Hillebrand advierte, con razón, del peligro del uso indiscriminado de la etiqueta de Bildungsroman, como categoría ahistórica, en tanto es un producto típico iluminista alemán y, desde su estatuto de género literario, participa del debate social sobre la educación del adulto burgués en la Alemania de la época de la Revolución Francesa (Amícola, 2003: 55).

\footnotetext{
${ }^{5}$ José Amícola (2003) realiza un minucioso recorrido por las modificaciones que, a lo largo del tiempo, ha tenido este género. Señala que el Bildungsroman recuerda en su entramado a las novelas de aventuras de siglos anteriores pero que, al mismo tiempo, comienza a poner el acento en la "acción interna" o, en otras palabras, en la repercusión que cada aventura deja en el personaje y en qué medida posibilita un escalón en la maduración y reflexión crítica del héroe sobre la vida y el mundo. En este ensayo, Amícola toma la propuesta de Maggie Kilgour quien contrapone la novela gótica a la novela de aprendizaje como dos polos "generizados" (Amícola, 2003: 58). En este ensayo deshecha estudios que él mismo realizó antes en los que había afirmado que El juguete rabioso era la antinovela de aprendizaje de las vanguardias argentinas y señala que el problema "no está tanto en una cuestión de denominación ("novela de educación"/"novela de aprendizaje"/"novela de iniciación"), como en la cuestión de configuración de géneros europeos por transplante a otras regiones del globo y a otras circunstancias históricas" (Amícola, 2003: 146). El riesgo de estos usos es lo que llama "esencialismo genérico", es decir, considerar la novela de aprendizaje del clasicismo europeo como un molde eterno, de modo tal que las derivaciones surgirían como tipos literarios exentos de relación con el medio.
} 
Esto permite entender por qué el uso del Bildungsroman para analizar protagonistas femeninas ha sido problemático y ha motivado múltiples y divergentes propuestas. Por ejemplo, Edna Aizenberg (1985) habla del "bildungsroman fracasado" para pensar las narraciones escritas por mujeres en América Latina. ${ }^{6}$ En cambio, María Inés Lagos rechaza esta denominación y propone hablar de los relatos de formación de protagonistas femeninas, un subgénero aparte porque estas narraciones se diferencian del modelo tradicional en que la construcción de la feminidad difiere de la construcción de la masculinidad. Sostiene que la noción de "bildungsroman fracasado" es un ejemplo que ilustra “la tendencia a considerar 'desviado' o 'fracasado' aquello que difiere del modelo establecido (o masculino) y que no examina el modelo femenino en su diferencia $y$, al hacerlo, confunde novela (Roman) y Bildung (educación)" (Lagos, 1996: 37). Por su parte, Eliana Rivero (1986) propone el término "bildungstale" porque considera que la forma tradicional no se aplica a formas nuevas como son las narraciones chicanas o las escritas por mujeres. Zulma Moret (2008) opta por la denominación “novela de formación” con el fin de incluir al Bildungsroman y sus variantes temáticas y establecer parámetros que compara con los que corresponden a los de la heroína diseñada en el siglo XIX y a principios del XX dentro del marco de la literatura europea y, luego, en la tradición de la novela de formación latinoamericana del siglo XX. ${ }^{7}$

\footnotetext{
6 Aizenberg parte de la hipótesis de Cynthia Steele respecto del "bildungsroman fracasado" en el que se plantea que las protagonistas, en vez de lograr la autorrealización, terminan fracasadas, sacrificadas o muertas. Desde esta perspectiva analiza la novela Ifigenia de Teresa de la Parra.

7 Zulma Moret (2008) analiza la construcción del sujeto femenino en los Bildungsroman o novelas de formación de escritoras latinoamericanas en el siglo XX, en especial, en las décadas de los años setenta y ochenta. La autora configura un corpus de novelas de formación que le permite reconocer una serie de elaboraciones que muestren su 'diferencia' respecto de los modelos originales. La pregunta que vertebra el análisis de las obras es si mantienen lealtades respecto de la forma canónica o, por el contrario, cuáles han sido los cambios operados ya que, en muchos casos, observa un tratamiento paródico del modelo. La hipótesis central es que en la construcción del sujeto femenino y en su "diferencia" se observa un sujeto "borrado" en lo que respecta a la posible realización de sus deseos más profundos y que, por lo tanto, necesita recuperar esa voz silenciada por la historia.
} 
Debido a que no es el eje central de esta investigación, no tengo la intención de profundizar en los meollos de la problemática del Bildungsroman pero, a los efectos de la hipótesis que propongo en esta investigación, resulta productivo pensar los usos y reconfiguraciones de este género en Silencios. ${ }^{8}$ No desconozco que los géneros literarios han sido históricamente "generizados" (Amícola, 2003) y, por lo tanto, parto de la necesidad de establecer miradas sincrónicas y diacrónicas que otorguen densidad a la lectura ya que los textos, en forma intencional o no, buscan desestabilizar, repensar o reproducir cierta ideología y se recortan contra otros géneros y obras dentro del sistema literario (oposiciones dentro del sistema, en términos formalistas). ${ }^{9}$ Del mismo modo que Silvio Astier, personaje que a lo largo de El juguete rabioso (1926) madura psicológica y físicamente aunque su camino dista mucho de acercarse a los parámetros morales y éticos positivos, ${ }^{10}$ en Silencios la narradora realiza un recorrido que marca su crecimiento pero que, en vez de lograr la autorrealización, culmina en la mudez absoluta, encerrada con la gata en una habitación de su casa.

Los secretos conforman la matriz del funcionamiento familiar y este, que es el primer aprendizaje de la protagonista durante la niñez, poco a poco se convierte en su propio modus operandi: "Tengo la impresión de que mi vida fue un sueño hasta que papá decidió mudarse para la sala. Quizás fue que empecé a crecer y me faltaban las palabras que nadie dijo nunca" (Suárez, 1999: 24). Esta carencia marcada por el ocultamiento de la

8 Leasa Lutes (2000) realiza un estudio detallado sobre la posible existencia de este género en una forma contemporánea y femenina. Parte de las teorías de Julia Kristeva, Hélène Cixous, y Luce Irigaray para analizar la obra de Isabel Allende, Fanny Buitrago y Alessandra Luiselli.

9 En el capítulo dedicado a Roberto Arlt, José Amícola (2003) discute con lecturas propias y ajenas respecto de pensar El juguete rabioso como la anti-novela de aprendizaje y, por el contrario, sostiene que "Lo que aquí me interesa dejar en claro no es que no puede haber traspaso genérico por medio de mediadores culturales, sino que los géneros literarios pueden pasar a otros campos y ser adoptados desde otras latitudes y sistemas literarios relacionados siempre y cuando cobren significación en el nuevo marco de adopción gracias a operativos ideológicos fundamentales para ganar una nueva función en un sistema de fuerzas organizado y constituido en el nuevo campo operacional en que se insertan" (Amícola, 2003: 152).

${ }^{10}$ No está de más recordar que, según la lectura psicoanalítica de Oscar Masotta en Sexo y traición en Roberto Arlt (1982), el protagonista logra el aprendizaje de la maldad. 
verdad se convierte en el germen de su silencio como práctica configuradora de su identidad ya que la utiliza para actuar en la vida al mismo tiempo que la narradora elabora su arte poética en torno al silencio. Son muchos los aprendizajes que realiza a lo largo del recorrido por su infancia y juventud pero los sintetizaré en dos planos: el del amor y el de la producción artística, ambos cruzados por el silencio. El plano amoroso se configura por oposición al modelo familiar materno en el que el amor significa tristeza, llanto y tangos, por eso, no lo elige:

entonces yo pensé que el amor era en verdad una cosa verdaderamente triste, mi madre escuchaba tangos, mi tía era soltera, mi abuela había sido abandonada, y yo no quería eso. Lo que quería no lo sabía, pero el amor, esa palabra era lo suficientemente triste como para yo necesitarla, y entonces decidí rechazarla (Suárez, 1999: 36).

En el ámbito familiar, el amor es negado a los personajes femeninos por diferentes razones: si el amor es legítimo, como el de su madre y el de su abuela, termina en infidelidades, abandonos y llantos: su padre engaña reiteradamente a su madre, la abuela engaña al abuelo. Si el amor es clandestino, como el de su tía o el que dio origen a su padre, finaliza mal: el amante de su tía se suicida y ella realiza varios intentos de quitarse la vida, finalmente termina internada en un hospital; la abuela es abandonada por su marido luego de enterarse que lo engañaba con un mulato. A diferencia de estos personajes que sufren las consecuencias del amor, la narradora, durante la adolescencia, se vincula con este sentimiento en forma diferida (e irónica) ya que escribe poemas amorosos por encargo. Por el contrario, elige no enamorarse y mantenerse lejos de este sentimiento:

Entonces estuve absolutamente convencida: el amor, esa palabra que tantas vueltas da, podría seguir dando sus giros sin acercarse a mí. Yo no sabía exactamente qué era lo que quería, pero estaba totalmente convencida de lo que no quería. No quería llorar y hacerme sombra, ni achacarle mis culpas a los otros. Los seres más sensibles son los que más sufren, y los que siempre pierden. Yo no quería perder. Nunca (Suárez, 1999: 78). 
Vinculada con el amor, la sexualidad de la narradora también es una práctica conflictiva sin lazo con el placer (excepto en la relación que mantiene con el Merca) y, por el contrario, ligada a una experiencia violenta: en la escuela, la protagonista se somete a un acto vejatorio como medio para lograr respeto en el grupo de pares; en otra oportunidad, es sometida sexualmente contra su voluntad. En el primer caso, accede a un rito público de iniciación sexual en un episodio en que, junto a su amigo Cuatro, es descubierta por el grupo del Ruso en el techo de la escuela. Este personaje representa el poder dentro del aula, objeto de deseo de todas las mujeres y de adulación de los varones. En ese encuentro el Ruso le dice que podría estar con ella pero "es como si estuviera con un macho y a mí me gustan las hembras" (Suárez, 1999: 52); como respuesta, ella se propone mostrarle que es una hembra y comienza una secuencia en la que expone su pubis y le dice "Se puede tocar, Ruso, ven" (Suárez, 1999: 53), la misma frase del tío al adolescente cuando le mostró su miembro erecto (en el episodio en que la narradora descubre el secreto de su homosexualidad). Esta duplicación de la frase, sumada al apodo que recibe la protagonista ("marimacho"), evidencia la cercanía con la homosexualidad de un cuerpo que bordea los sexos, un cuerpo andrógino pero con genitalidad femenina y cuyo discurso explicita la construcción cultural en torno al género: "no me gusta que me llamen marimacho, porque soy hembra, ¿ves? — dije entre dientes y sonreí-, aunque me gustan los juegos de los machos" (Suárez, 1999: 53), entonces la respuesta se vuelve un juego de fuerza: muestra su sexo biológico (lo exhibe y permite que el Ruso lo constate) y, en el mismo acto, le perfora el brazo con un lápiz. De esta manera, el sometimiento que podría ser leído en el primer movimiento como sumisión ante la violencia de la ley es transgredido en el fuerte simbolismo sexual del segundo movimiento, en el que el acto (perforar), el medio (lápiz) y el objeto (brazo) son configuradores de lo masculino. Además, en este acto público, el lápiz se quiebra en la carne del Ruso y los dos caen al vacío; una caída a partir de la cual nada sería igual ya que 
aunque los dos optan por el silencio ante las preguntas (la protagonista pasa seis meses sin hablar), los órdenes se invierten: el Ruso pierde el lugar central en el curso y la narradora comienza a ser respetada. A diferencia de otras narraciones donde la mujer accede al mundo social por medio de un ritual de degradación y aceptación de la violencia, acá esa situación cambia.

En esta primera escena de sexo como práctica violenta, el violador (el Ruso) es una suerte de torturador que obra como un ser superior al que todo le es permitido. El acto de iniciación sexual tiene rasgos perversos en tanto es perpetrado con alguien a quien detesta y al que accede, en silencio, sólo para vengarse de él, para dar una lección y demostrar su superioridad:

lo observé callada, vi como levantaba su dedo confuso y se iba acercando al gran descubrimiento de la adolescencia que no olvidaría nunca, su dedo tocando mi carne, apartándose bruscamente para luego volver a posarse frío e inexperto sobre mi piel inexperta que lo detestaba (...) yo lo dejaba estar seguro, sentirse nuevamente emperador y chico malo y rey de los demonios reducido al mutismo ante la flaca más mala del aula (Suárez, 1999: 53).

El segundo caso sucede cuando un amigo, el Poeta, abusa de la vulnerabilidad de su cuerpo sumido en el alcohol luego de enterarse de la verdad sobre el regreso de su padre de Angola (le sacan los honores por desertar en una batalla). Descubre el abuso cuando se despierta y se da cuenta de que está desnuda en la cama del Poeta: "desnuda frente a él con su rostro de culpa y arrepentimiento y tanto de ternura y qué se yo. Abrí los ojos” (Suárez, 1999: 123). Sin embargo, aunque asume el silencio y la distancia como respuesta al atropello de su amigo, el descubrimiento de este acto no es explicitado como algo traumático en tanto pérdida de la virginidad sino como un abismo en el que no identifica su cuerpo con su ser: ser virgen me importaba una mierda, pero odiaba mi cuerpo y no quería tocarlo, no quería verlo, ni saberlo cierto, ni nada. Decidí odiar al espejo y al Poeta, y odiar mis ojos porque pueden ver, el rostro de la gente, la cara de mi padre, el tango en la mirada de mi madre, la mueca de mi abuela, el pelo rubio del tío, el asco de la tía y mi 
presencia; hasta mi presencia podía ver y por eso odié al espejo sustituto del ojo que delata (Suárez, 1999: 124).

Esta negación de la imagen como representación de lo real (en tanto materialidad) se condensa en el título del capítulo -"La fosa vacía" — que alude al espejo como máscara de lo real y a la negación de la función del ojo (ver lo concreto, lo tangible, lo "real") como posible aproximación a la verdad. Las reiteradas alusiones al abismo entre cuerpo y conciencia o la imagen del cuerpo como máscara del yo, dan cuenta del complejo recorrido en el camino de construcción identitaria que veremos más adelante.

El primer acto sexual consciente y consentido es con el Merca y esta elección, que implica enfrentarse con la desnudez de su propio cuerpo, su mayor prueba, es también la que por primera vez permite que se reconozca en su cuerpo: "Sentí que mi cuerpo era mi cuerpo, un poco más que el velo que me separa de los otros" (Suárez, 1999: 166). En ese momento, elige hablar, como sinónimo de mentir ("especialmente a ti, no quería mentirte" Suárez, 1999: 165): ficcionaliza su historia sexual conjugando elementos de la vida sexual de sus tías para, de este modo, cargar su propia historia de experiencia y esconder sus miedos.

Otro de los aprendizajes gira en torno a la verdad, sus matices y la forma de ocultarla. Las reflexiones sobre este tema se pueden pensar como una reflexión metaliteraria sobre el arte poética de la narradora. Su padre propone la verdad a medias como práctica cotidiana para relacionarse con los otros:

me sentó en un murito y explicó muy lentamente que en la vida nunca debía decirse toda la verdad porque esa no le interesaba a nadie; en la vida sólo había que decir la mitad de la verdad para no herir a la gente. Su razonamiento me pareció correcto, además él sabía más que yo y entonces fue cuando comencé a decir, no mentiras, sino parte de la verdad, solamente eso (Suárez, 1999: 26).

Esta estrategia puesta en boca de un militar adquiere fuertes connotaciones ideológicas ligadas con el funcionamiento estatal para encubrir determinadas prácticas. La verdad se 
delinea dolorosa; en cambio, la verdad a medias (eufemismo de la mentira) aparece como una salida afortunada ante la realidad y, al mismo tiempo, como estrategia de representación:

El día que mi madre me lo dijo no supe a cuál de los dos odiar, si a él con sus verdades a medias o a ella con su absoluta verdad. Al final alguien siempre queda herido y yo hubiera preferido seguir tirándole besos al hombre de la foto, porque era la mentira en la que yo creía. Entonces descubrí que mentir era mi signo, pero si iba a mentir tendría que hacerlo bien, muy bien, de mi padre había heredado el don de la mentira, de mi madre las cualidades histriónicas para representarla; estaba sin dudas absolutamente preparada (Suárez, 1999: 27).

En este relato sobre su propia vida, el crecimiento está marcado por el descubrimiento de la (dolorosa) verdad del funcionamiento familiar (que se puede pensar como sinécdoque de la isla) en torno a la mentira. Como respuesta a las cicatrices en el cuerpo (el sexo como violencia física en los episodios con el Ruso y con el Poeta) y a la vulnerabilidad que implica desnudar las mentiras, la protagonista elige no recordar para olvidar, es decir, elige no tener memoria: "Ni siguiera la historia con el Poeta podía existir, yo no recordaba nada, y la memoria es quien puede delatarnos, pero si no recuerdas nada, entonces nada existe. Opté por la amnesia. Eso estaba bien” (Suárez, 1999: 130).

\subsubsection{Apre(he)nder la literatura como refugio del silencio}

¿El arte es un reflejo de la vida o al revés? Quién los sabe. La tía en medio de su mundo de imágenes confusas habia optado por los finales felices y eso me parecía interesante.

Karla Suárez, Silencios

En esta instancia retomo el otro camino de aprendizaje medular en Silencios: la producción artística. En las novelas de aprendizaje, el encuentro con la lectura y la escritura se constituyen en las instancias de autoconocimiento y crecimiento debido a que son 
actividades imaginativas autorreflexivas. ${ }^{11}$ Con respecto a esta característica, Aizenberg (1985) explica porqué muchas novelas de iniciación son a la vez Kunstleromane o relatos del desarrollo de un talento artístico para quien la empresa creativa es un medio para explorar el yo. En Silencios, la protagonista está imposibilitada de acceder o de creer en la palabra (dicha) y, en estas circunstancias, la experimentación en la producción artística (primero a través de la pintura, luego con la escritura de ficción) se convierte en las forma de dar palabras al silencio. Durante la niñez, la narradora pasaba mucho tiempo dibujando lo que veía, sobre todo, cuando todos dormían o estaban en sus propios mundos, ella deambulaba por la casa. El dibujo se opone al silencio, es su forma de poner palabras al silencio y develar los secretos. Por eso inventa el juego de la puerta que consiste en pintar lo que ocurre del lado de allá de todas las puertas: a los padres los dibuja manteniendo sexo; como en la puerta de la tía no había sonidos, entonces la imaginaba como quería; al tío no lo pinta porque cuando la puerta está abierta descubre su homosexualidad y eso le produce una gran conmoción: "Quería borrar la imagen que no pintaría nunca, y juré no contárselo a nadie. Estuve mucho rato así, golpeándome y jurando silencio" (Suárez, 1999: 45).

\footnotetext{
${ }^{11}$ En la novela se describen muchas situaciones de lectura pero son pocas las veces en que se explicita qué se lee. Cuando la narradora alude a las lecturas de su madre siempre señala que leía "cualquier libro" (Suárez, 1999: 23). El primer libro que se menciona es el que le regaló su profesora de literatura: "Un día dijo que la belleza de las personas no estaba en la apariencia y me regaló El pequeño príncipe” (Suárez, 1999: 47). En un episodio menciona qué leían sus amigos: "Nosotros teníamos dieciséis años y estábamos descubriendo el mundo. Cuatro y sus amigos perseguían los Sputniks y las novelas famosas. Yo leía La náusea y trataba de decirles que me importaba una mierda si el hombre descendía del mono o no, lo que quería saber era cómo podía el hombre ser capaz de convertirse en mono nuevamente sin apariencias externas que lo demostraran" (Suárez, 1999: 92). Una lectura compartida es la poesía de César Vallejo (Suárez, 1999: 168). Cuando no logra ingresar a la Universidad por sus bajas notas, la madre le regala un libro de Borges, uno de Cortázar y otro de Sábato, y agregó que la verdadera universidad estaba en los libros” (Suárez, 1999: 111).
} 
En esta etapa, la pintura constituye la forma de protegerse y tomar distancia irónica de los hechos. En el ámbito escolar es marginada porque su cuerpo ("Ellos me miraban como a un bicho raro: la flaquita de los ojos claros y los labios gruesos, paliducha y despeinada, que se sentaba al final de la fila y a quien nadie quería besar. Eso era yo"; Suárez, 1999: 47) y sus prácticas ("eran unas idiotas que se pintaban las uñas y hablaban de cortarse el pelo y rizárselo a la moda"; Suárez, 1999: 39) son distintas a las del resto de las niñas; por eso la apodan "marimacho", y este travestismo impuesto por la mirada de los otros pero también elegido por ella se convierte en una máscara corporal que configura su identidad. Cuando describe a sus compañeros, divididos en grupitos que giran en torno del Ruso, el personaje admirado del curso, ella dice "Y yo, que me sentaba en el fondo a pintarlos a todos mientras ideaba formas de divertirme a sus espaldas” (Suárez, 1999: 48).

Esta forma de resistencia (la pintura como forma de narrar lo que calla) termina en el episodio sexual con el Ruso porque, en el interrogatorio por el accidente, un hombre le pidió que dibuje lo sucedido y se niega a hacerlo: "no pintaría nunca más, ni lo que él quería, ni nada, y para no correr el riesgo de dejar escapar palabras inútiles, me propuse que tampoco hablaría nunca más” (Suárez, 1999: 57).

Así, el silencio se constituye, poco a poco, en una estrategia de resistencia que la narradora lleva a la práctica en su sociabilidad cotidiana y mediante su contacto con (y su concepción de) la literatura. Como vimos, la historia se centra en las etapas que atraviesa la narradora protagonista desde la niñez hasta la juventud y, en un segundo nivel, gira en torno al hecho literario, sea porque varios de los personajes ejercen la escritura y la lectura (además de la narradora, la tía, el Poeta, Dios), o porque la historia pone en primer plano una reflexión sobre la literatura y, en particular, sobre la escritura de ficción en la Cuba de los noventa. En el primer sentido, se plasman distintos lugares comunes en torno al ámbito literario: espacio de placer para quienes lo practican y, simultáneamente, práctica 
estigmatizada por quienes no comparten este espacio y vinculan la figura del escritor con el estereotipo de un personaje de hábitos nocturnos, esnob, alcohólico, drogadicto, etcétera. Así, por ejemplo, la tía soltera es uno de los personajes que se dedica a la literatura, ya sea como lectora o como escritora. Su cuarto, espacio cerrado e íntimo, se configura como sitio de reposo, libertad y placer durante la niñez de la narradora:

Yo era feliz. El día lo alternaba entre mi madre y la tía, que era cuando más me gustaba, porque ella se ponía a escribir en la máquina y yo podía coger todo lo que quería, jugar con sus cosas, encaramarme en la cama y ella allí escribiendo, sin regañarme apenas. Yo hacía lo que me daba la gana (Suárez, 1999: 18-19).

La tendencia suicida, producto de un amor frustrado, y el posterior encierro en una clínica acentúan poco a poco los rasgos estereotípicos:

La tía, encerrada más que nunca dentro de su cuarto, por esa época parece que volvió a ser escritora; el día lo pasaba durmiendo y las noches tecleando en aquella vieja máquina que tanto me gustaba (Suárez, 1999: 66).

Otro de los personajes que ejerce la práctica literaria es "Dios" y en su caracterización también contrastan las visiones respecto de la figura del escritor: mientras para los vecinos es "borracho y mujeriego como todos los escritores" (Suárez, 1999: 28), para la narradora es un referente, una de las pocas personas con las que conversa. Dios representa el mundo de sus padres, de la juventud en una Habana que se levantaba y donde todo estaba por construirse. En el pasado Dios trabajaba en el ICAIC y tenía mujer, pero cuando la narradora lo conoce, no tiene trabajo y se junta con jóvenes que acuden a su casa a emborracharse con él "mientras soñaban con ser grandes escritores o poetas y llenar las librerías o salas de conciertos y Dios nos dejaba soñar. Me dejaba soñar y ordenar mis ideas, porque con él, no sólo tenía el don de la escucha, también tenía el don de la palabra" (Suárez, 1999: 117). El apodo sugiere una serie de rasgos que lo colocan en una posición de superioridad respecto de la protagonista y su grupo de amigos. En primer lugar, es mayor y, 
por lo tanto, los dobla en experiencia y conocimiento respecto de la literatura, por eso se convierte en su faro; en este sentido, su palabra es la palabra de Dios o es el verbo hecho carne: por ejemplo, dice la narradora: "mis días pasaban sin amigos y muchas noches prefería la palabra de Dios al silencio de mi cuarto" (Suárez, 1999: 107). Además, Dios encarna una concepción de la literatura, en especial, de la poesía, ligada a la pureza y a la imposibilidad de pensarla en otra lengua que no sea el francés: recitaba poemas de Paul Éluard y Charles Baudelaire en lengua original porque "la poesía no admite traducciones" y se convierte en el censor de los poemas escritos por la narradora:

Mi incentivo era mostrárselos a Dios, pero casi siempre él sonreía y entonces buscaba un libro y sin decir nada acababa por convencerme de que la poesía era otra cosa, más allá del simple ordenamiento de palabras, más allá de cualquier cosa que yo quería alcanzar (Suárez, 1999: 108).

A lo largo del relato de su vida hay varios momentos en que la narradora escribe poesía. Esta práctica se vuelve sistemática durante la estadía en la escuela de campo cuando, por un descuido, una compañera descubre un poema suyo y, a partir de ese hecho, comienza a escribir por encargue:

...me convertí en poeta, así me llamaban algunas, y empecé a escribir como quien hace salchichas. En las horas de trabajo, algunas se acercaban para contarme los problemas con sus novios; yo debía escribir, colocaba los dos nombres en un papel y sacaba versos relacionados con la situación que me contaban (...) De repente me vi convertida en la celestina del campamento (Suárez, 1999: 77).

La protagonista se convierte en espectadora irónica del amor y su producción responde a las expectativas de un público sin exigencias que suspiraba cuando leía los escritos. Menospreciada por la narradora, este tipo de poesía amorosa por encargue y comercial (en tanto recibe dinero por escribir) se configura como la única que tiene éxito en términos de divulgación. El resto de su poesía, sometida a la crítica vara inquisidora de un público de 
poetas o al gusto literario de Dios, termina siendo un género en el que no se siente cómoda o, mejor dicho, en el que percibe que nunca podrá hacer algo que la satisfaga. Este género no le pertenece (en tanto práctica escrituraria), sus poemas no son aprobados ni comprendidos por quienes la evalúan o la escuchan. Para su primera lectura ante otros poetas, en una peña bohemia, realiza un plagio de Paul Éluard:

Tengo quince años, me tomo de la mano. Convicción de ser joven con las ventajas de ser muy acariciante.

No tengo quince años. Del tiempo pasado, un incomparable silencio ha nacido. Sueño con ese hermoso, ese bonito mundo de perlas y de hierbas robadas.

Estoy en todos mis estados. No me tomen, déjenme (Suárez, 1999: 95).

Todos celebran el poema pero el único que advierte la copia es Dios y a partir de este hecho entablan una relación de amistad. Esta mera anécdota resulta significativa si se vincula con el hecho de que la narradora luego deja de escribir poesía y se suma a la concepción de Dios respecto de una poesía asociada a la pureza y a la lengua francesa: "Yo decidí que mi vida debía tomar algún rumbo. Estaba convencida de que mis poemas no pasarían de ser garabatos en hojas amarillas y entonces determiné estudiar francés para poder disfrutar verdaderamente a los franceses” (Suárez, 1999: 139-140). Cuando abandona este género comienza a "llenar cuartillas y cuartillas de monólogos interiores que jamás me atrevería a mostrar a nadie" (Suárez, 1999: 140). Esta escritura se vincula, en cierta medida, con la novela que tenemos en nuestras manos ya que esta reconstrucción de su historia personal remite fuertemente a la escritura íntima para desahogarse, comprender y/o representar lo que sucede o sucedió, pero no para ser compartida. En este sentido, los lectores actuaríamos como fisgones de una palabra que no nos está dirigida. La narradora elige el silencio como forma de enfrentar el mundo y, en esta lectura, la reconstrucción de esta historia en un presente de aislamiento y soledad se puede leer como un grito o la forma de poner palabras al silencio. Hacia el final de la novela, en el llamado "Período especial", la 
protagonista queda sola: la madre regresa a la Argentina, el padre se va a vivir con su nueva familia, la abuela y Dios muertos, la tía en un psiquiátrico, el tío y el Poeta en Miami, el Merca probablemente allí o en el fondo del mar, Cuatro en España. ${ }^{12}$ Ante esta situación de soledad (también elegida porque ella opta por no irse con nadie) y ante una ciudad que se desmorona durante la crisis de los noventa, la escritura se erige como refugio (lugar de creación de mundos propios) y como espacio de resistencia:

Ya no había conciertos, ni lugares adonde ir. Casi todo estaba cerrado y los muros llenos de carteles de «resistir, luchar, vencer» yo resistía, luchaba y vencía dentro de la casa grande, a pesar de que allí también las paredes estaban despintadas y las cucarachas subían por las tuberías del edificio (Suárez, 1999: 199).

En ese exilio interior se dedica a la escritura de "cuentos raros que seguramente no mostraría a nadie" (Suárez, 1999: 206).

Por otra parte, en diversas oportunidades la narradora reflexiona sobre la literatura y, en particular, la que se produce en Cuba durante la década del ochenta y noventa. Cuando recuerda su paso por la bohemia habanera, opina sobre la producción cubana y delinea, de este modo, una concepción de la literatura y una percepción sobre el espacio de lo literario durante esos años. La Habana de los ochenta es descripta como una ciudad con muchos lugares culturales adonde ir, como los conciertos de la nueva trova y múltiples muestras de cine y de teatro. Por el contrario, agudas observaciones pesan sobre las consecuencias del decrépito "Período especial" que se vislumbra en la deteriorada arquitectura de la ciudad, la escasez de alimentos y la reducción del auge cultural. Respecto de las temáticas literarias que se abordan en estos años, así describe, por ejemplo, el

${ }^{12} \mathrm{El}$ Merca se va a Miami en medio de la crisis de la década del noventa. En este período se produce una ola de balseros que se trasladan ilegalmente por cualquier medio hasta EE.UU. Esto generó una situación muy tensa hasta que, finalmente, en agosto de 1994 se abrieron las puertas para que se vaya el que lo desee. La narradora señala que, entonces, "La ciudad era un carnaval sin máscaras. Un verano de regatas. El circo de la suerte” (Suárez, 1999: 218). Sin embargo, nunca recibe noticias del Merca así que queda la duda sobre lo sucedido durante la travesía. 
impacto que tuvo el regreso de las tropas cubanas de Angola en 1986 y la incertidumbre que se signa sobre la isla luego de la caída del Muro de Berlín:

Casi todas las canciones y la literatura de los más jóvenes hablaban sobre Angola. Sobre amigos que se fueron y regresaron mártires. Sobre la incertidumbre frente a la nueva década. Yo no tenía nada que escribir. Mis poemas y mis monólogos se referían a cosas que no interesaban a nadie. Sólo Dios era mi escucha. Él seguía recomendándome lecturas e incitándome en su búsqueda eterna hacia una belleza que debía existir, lejos de fenómenos sociales, lejos de las circunstancias y de la oportunidad que puede brindar un hecho simplemente (Suárez, 1999: 154).

O, más adelante:

Me parecía que en Cuba la literatura la escribían los políticos, el resto eran redactores, colocaban signos de puntuación, le daban un título y voilà, la literature. No sé si sería la carencia de un periodismo verdadero, pero se me antojaba que los escritores hacían periodismo. Nadie contaba historias. Todos decían lo que yo podía ver con sólo asomar las narices fuera de mis paredes. Hablaban de gente fugándose en balsas de la isla, jineteras en las noches de La Habana, el dólar que subía y subía, la esperanza que bajaba y bajaba. Resultaba aburrido (Suárez, 1999: 217).

La narradora, por el contrario, piensa la ficción como un mundo posible, con historias sin referencias a lo real y es este el germen de los cuentos que le envía a Cuatro cuando está becado en Checoslovaquia o cuando, finalmente, su amigo se exilia en España.

\subsubsection{El cuerpo de la escritura y la escritura del cuerpo}

En el ininterrumpido recorrido por los vericuetos del crecimiento de la narradora, el cuerpo se delinea como un espacio en el que el "yo" no se reconoce. Hay recurrentes episodios de encuentros con (y frente a) el espejo, como forma de autorreconocimiento ante la mirada de los otros que la desean:

En mi cuarto, encendí velas para no estar completamente iluminada. Me paré frente al espejo y comencé a desnudarme. Yo odiaba mi cuerpo, lo seguía odiando. A medida que mi carne se iba descubriendo en el espejo sentía que me estremecía, una percepción de rechazo, algo confuso. No quería ser yo y ¿qué querían ellos ¿ ¿Qué había amado Cuatro? ¿Qué pretendía el Poeta? ¿Qué soñaba Dios? No lo sabía. Yo no 
sentía nada, o muchas cosas a la vez pero nada en mi carne, nada en mi piel. Me molestaba la imagen del espejo (Suárez, 1999: 142).

La protagonista se configura como diferente respecto de sus pares femeninas, y esa imagen extraña que les genera ese cuerpo se dibuja a partir de la mirada de sí que le devuelven los otros, por ejemplo, sus compañeros/as de escuela. Cuando compara su cuerpo con el de su madre se observa el contraste entre lo blanco con carga semántica positiva asociada a la belleza frente a los rasgos que heredó de su padre y lo extraño de su cuerpo con líneas físicas indefinidas que acercan su cuerpo a la androginia:

Mi madre era una mujer hermosa, tenía la piel muy blanca, el pelo castaño y lacio, los rasgos finos y unos ojos excesivamente azules que saltaban encima de cualquier cosa (...) En cambio yo..., no podría afirmarse que era una niña hermosa, eso lo sabía por el espejo, y a medida que mi cuerpo comienza a definirse, todos notaban el enorme parecido que tenía con mi padre (...)Extrañamente para mí, él era el único de sus hermanos que no tenía el pelo lacio (Suárez, 1999: 25).

También la primera vez que se nombra a sí misma como mujer lo hace ante un espejo porque necesita contrastar una foto de la niña con su cuerpo de mujer: "tomé la foto y me paré frente al espejo. Seguía siendo la misma, los grandes ojos azules, los labios gruesos, el rostro pálido. En realidad nunca fui hermosa. La niña de la foto era yo y yo era la mujer del espejo" (Suárez, 1999: 222). El extrañamiento con el propio cuerpo permite entrever una confrontación entre la mujer que se auto-ubica como sujeto de representación (es decir, como constructora de su subjetividad y de su realidad) y la mujer objeto de representación en tanto cosificación de un cuerpo construido por el discurso hegemónico (cuerpo de deseo). ${ }^{13}$ El poder se cuestiona desde la posesión del lenguaje: en esta lectura el silencio se convierte en un pretexto porque en realidad dibuja la vOz que intenta ser

\footnotetext{
${ }_{13}$ Para percibir este conflicto asumo que las producciones escritas por mujeres constituyen una categoría histórico-social que se instala en la lucha de los espacios representacionales.
} 
silenciada pero cuyo silencio dice. El gesto de optar reiteradamente por el silencio como verdad abre una grieta en el lenguaje del poder y esta es una subversión que se vincula con el epígrafe de la novela: el silencio dice y en este decir paradojal, hace estallar el discurso hegemónico.

En los fragmentos seleccionados el espejo se instaura como espacio de autorreflexividad ya sea en torno al encuentro con el propio cuerpo desde la mirada de ese yo que mira, como también en torno a la reflexión sobre el lenguaje ficcional. En este segundo sentido la obra admite una reflexión metaficcional sobre sus diversos mecanismos constructivos. Hacia el final de la novela, la muerte de Dios, su referente y censor literario, significa el ineludible encuentro con La poesía (la mayúscula marca la concepción de la poesía pura que tiene este personaje y porque los versos que se citan pertenecen al poema "Les yeux fértiles" de Paul Éluard) ${ }^{14}$ y con su propio cuerpo, en tanto escritura. Este encuentro se da ante el espejo:

Fui al cuarto y me paré frente al espejo. Del lado de allá vi unos ojos azules mirándome con odio. El espejo reflejaba un cartel a mis espaldas. Sonreí. A mis espaldas el cartel de letras grandes anunciaba las palabras de Paul que Dios me había regalado hacía tiempo:

Tus ojos los que nos revelan nuestra infinita soledad ya no son los que creían ser.

Odié mi mirada en el espejo y sentí rabia. Me golpeé la cabeza contra el cristal (Suárez, 1999: 209)

La superposición de planos que implican los ojos que miran en un espejo y ven reflejados versos que hablan de los ojos nos traslada a los dobleces que supone la construcción

${ }^{14}$ Los versos citados en la novela pertenecen al poema "Les yeux fértiles" (1936) de Paul Eluard (18951952): On ne peut me connaitre/ Mieux que tu me connais/ Tes yeux dans lesquels nous dormons/Tous les deux/Ont fait place à mes lumières d'hommes/ Un sort meilleur qu'aux nuits du monde/ Tes yeux dans lesquels je voyage/ Ont donné aux gestes des routes/ Un sens détaché de la terre/ Dans tes yeux ceux qui nous révèlent/ Notre solitude infinie/ Ne sont plus ce qu'ils croyaient être/ On ne peut me connaittre/ Mieux que je te connais. 
ficcional. ${ }^{15}$ Además, si el espejo refleja el cartel, los versos del poeta francés están escritos, grabados, en el cuerpo que mira. Pero ese imperativo estético (la poesía pura proclamada por Dios) se rompe cuando su cabeza golpea el cristal. En Escrito sobre un cuerpo (1969), Severo Sarduy establece vínculos entre mutilación, cuerpo y silencio a partir de las especulaciones acerca del soporte material de la obra de arte como cuerpo. El título del libro de Sarduy podría aludir a la página en blanco como cuerpo original sobre el que se escribe y esto, en relación con la novela, permite plantear algunas cuestiones. Si existe una correspondencia entre página en blanco y cuerpo, el cuerpo de la protagonista, desnudo, virgen, con miedo a crecer, puede ser pensado como la página en blanco, el momento anterior a la escritura. El no reconocimiento del cuerpo es entonces, la no satisfacción ante la palabra propia. El silencio se introduce poco a poco en la escritura y en ese proceso la narradora pierde las coordenadas biográficas y se (con)funde con el silencio.

\subsubsection{El silencio como imperativo estético e identitario}

Mi madre me abrazó y supe que volverían los tangos, porque uno siempre retorna a la semilla. Cuando todo se derrumba

y el mundo se vuelve absurdo, uno siempre se queda con ese extraño instinto de acurrucarse sobre sí, casi abrazando las piernas para quedarse dormido esperando el nacimiento.

Karla Suárez, Silencios.

En un presente signado por el período especial, ante una ciudad que literal y metafóricamente se desmorona mientras la soledad inunda su vida debido al

\footnotetext{
15 El ojo que mira en el espejo también remite a la figura de la escritora como alter-ego de la protagonista. En este sentido, la narradora puede ser pensada como la alter ego de Karla Suárez. Al respecto, en una entrevista la autora señala que: "de algún modo sí, pero no solo la protagonista, creo que todos los personajes son un desdoblamiento del propio autor, al menos en mi caso sucede así. Esta niña-mujer de la novela vive el tiempo que yo viví, y sus dudas son mis dudas, algunas superadas y otras en 'compás de espera'. Representa, digamos, un tipo de persona que conocí, compartí, y rechacé, en distintos momentos (Valle, 2001).
} 
desmembramiento familiar y a que sus amigos están afuera de la isla o perdidos en el mar, la narradora elige quedarse adentro en el doble sentido: quedarse encerrada en la casa y, también, quedarse (encerrada) en la isla. La protagonista se sumerge en un exilio interior para escribir: "El mundo de afuera continuaba deteriorándose, y entonces determiné que me quedaría dentro" (Suárez 1999: 205). La casa (o algunos lugares de ella) se vuelve ese espacio íntimo donde aislarse del (y construir el) mundo:

Después que Papá se fue, decidí cerrar los cuartos. Mi espacio serían los pasillos y lugares

comunes de la casa grande. Del lado de allá de las puertas se conservaban intactos los mundos de los otros: la abuela, la tía, Papá y Mamá. El poema de Paul y mi cruz de fotos decidí colocarla junto al sofá (Suárez, 1999: 224).

Un espacio semantizado como la casa permite dirimir los límites entre lo público y lo privado y, en este sentido, se configura como espacio íntimo de signos reconocibles sólo para quien la habita: "La casa grande era territorio prohibido, era mi espacio cuando estaba a oscuras y sus paredes despintadas cargaban tantas palabras ajenas a los otros que yo no podía permitir la intromisión de mundos diferentes” (Suárez, 1999: 192).

"La casa grande" es el título del primer capítulo en el que se caracterizan a los integrantes del grupo familiar y se relatan los aspectos centrales de la dinámica de funcionamiento. El nombre dispara una referencia intertextual inmediata y otra diferida que se puede leer en función del enigmático final de la novela. La primera alude implícitamente a Casa grande e senzala de Gilberto Freyre (1933) en la que la arquitectura de la casa representa una metáfora de la compleja conformación de la sociedad brasileña. ${ }^{16}$ De la misma manera (aunque no con la misma densidad), este microcosmos familiar en el que el silencio se erige como eje de funcionamiento, puede pensarse como una metáfora de los

\footnotetext{
${ }^{16}$ En medio de la crisis del orden oligárquico de Brasil, Casa-grande y senzala de Gilberto Freyre significa, aunque con tensiones y ambivalencias, una respuesta relegitimadora de ese orden. Es un intento de exaltar la cohesión social pero, en el mismo proceso de exaltación, es posible vislumbrar la coerción. Hay una extensa bibliografía sobre la obra de Gilberto Freyre. Entre las publicaciones consultar: Arroyo (2003), Mailhe (2005).
} 
avatares del país. En este espacio cerrado se condensan problemáticas como el exilio, la homosexualidad, los balseros, la caída de las utopías, la dinámica cultural de La Habana, las consecuencias del "período especial", etc. La novela encierra una sigilosa meditación acerca del proceso creativo, pero también una postura sobre la dinámica social de Cuba en los últimos años. El silencio entabla un espacio de resistencia ante el poder, por eso, en el último capítulo el mutismo se constituye, además, en punto final y suspensivo a la vez. Como señala Ludmer respecto de la operación discursiva de Sor Juana, acá también el gesto de no decir pero saber es una treta del débil (la única que opera acá ya que las otras tretas del subalterno, para Ludmer, son: decir que no sabe y saber, o decir lo contrario de lo que sabe). En este sentido, la casa funciona como microcosmos del país, metáfora que puede leerse en forma recurrente a lo largo de la novela, por ejemplo, cuando dice "Mi casa estaba llena de personas y silencios, y causas ignoradas" (Suárez, 1999: 73) o, en el último capítulo, mientras describe las dos Habanas:

¿Cuántos silencios hay detrás de cada rostro? Del lado de allá sonríen y mueven los labios. Andan como un gran rebaño abandonado en la punta de la colina y que ya no sabe qué hacer. El problema de las ovejas es que se acostumbran demasiado a que las guíen. Todos son piezas dentro de ese conjunto que llaman 'masa': la familia, el pueblo, la co-lec.ti-vi-dad. Hay que asumir demasiadas máscaras para insertarse en el conjunto, y cuando algo falla entonces viene el caos. Así como en la casa grande. Las modas y el tiempo deterioran las paredes. ¿O acaso siempre fuiste eso?, una casa vieja con las paredes pintadas. Yo qué sé. A veces pienso que con una simple escala puede medirse todo. Una familia dentro de un apartamento. El apartamento en el edificio. El edificio en el barrio. En el barrio en la ciudad. La ciudad en el país. Sí, definitivamente me basta una escala, siempre que se trate de conjuntos, claro (Suárez, 1999: 230).

En esta novela, el encierro de la protagonista en la intimidad parece potenciar otros encierros (país, ciudad). Retomando el tema de la tesis, la exacerbación de lo íntimo implica la percepción del espacio como cerrado, asfixiante, como resistencia cuando se trata de la construcción del sujeto femenino. 
La alusión diferida del título del primer capítulo, "La casa grande" (y en función del capítulo "Acto final" de la novela), que elijo leer es en clave cortazariana. Mientras que en "Casa tomada" (Bestiario, 1951) los ocupantes que toman la casa son también aquello que aterroriza porque no puede ser nombrado (Amícola, 2003), acá también el miedo es lo inexpresado por antonomasia. En el cuento, las puertas se cierran por miedo ante el avance de los "otros", los intrusos que en la sociedad argentina ocupan los espacios de la oligarquía representada por los hermanos que, finalmente, huyen de su propia casa. ${ }^{17}$ En cambio, en Silencios la narradora es la que, poco a poco, clausura los espacios que ocupaban otros familiares que han abandonado la casa. En el final de la novela, cierra la puerta de todas las habitaciones y elige residir en los pasillos y en los ambientes de tránsito común. Pero esta elección implica encerrarse sobre sí misma, como un espiral (una imagen más clara remitiría a la vuelta al útero materno). Esta última imagen se vincula con el epígrafe de este apartado que alude a "Viaje a la semilla" de Alejo Carpentier en el que el Marcial viaja en el tiempo desde la muerte hasta la juventud y la infancia en un recorrido que culmina con el retorno al vientre materno. Esta vuelta al origen puede leerse también en las palabras finales de la novela:

Me he pasado la vida observando cómo se mueven los otros para describir sus movimientos. Ahora en la casa grande sólo estamos Frida y yo. Ya no quiero escribir más. Me acuesto boca arriba y dejo que venga encima de mí para dormirse. La mejor cualidad que tenemos en común es el silencio. Sonrío. Entonces juego a hacer muñequitos con la sombra de mis dedos en el techo mientras tarareo un viejo tango, canciones de infancia, aquella que tanto me gustaba:

$$
\begin{aligned}
& \text {...que veinte años no es nada, } \\
& \text { que febril la mirada, } \\
& \text { errante en la sombre } \\
& \text { te busca y te nombra } \\
& \text { vivir...(Suárez, 1999: 232) }
\end{aligned}
$$

\footnotetext{
${ }^{17}$ Elijo la controvertida lectura que Juan José Sebrelli realiza del cuento de Cortázar en Buenos Aires, vida cotidiana y alienación (1964).
} 
Los puntos suspensivos luego de los versos del tango "Volver" de Carlos Gardel y Alfredo Lepera, refuerzan el final abierto de la novela. Volver al tango implica retornar a la semilla, al origen materno, una apuesta a encontrar el sendero que ayude a corregir los olvidos y a forjar la memoria. El final enigmático y abierto donde la narradora abandona la escritura mientras canta un tango de su infancia y su cuerpo yace tendido en la penumbra de la sala, admite una lectura metaliteraria: el final (de todo) es otro nacimiento en el que el silencio absoluto se erige como estética de la escritura; ese silencio final, ese dejar la escritura detrás de lo cual no hay nada. El silencio anunciado en el título y reforzado en el epígrafe revela el deseo de que se convierta en absoluto y esto sucede en el final de la historia. La pregunta sería, entonces, qué estrategias genera el silencio para hacerse oír en esta novela. En primer lugar, como vimos, se reitera hasta la saturación el término silencio: en el título, en el epígrafe, en la historia. En segundo lugar, en la escritura de la novela se observa una búsqueda de la desnudez expresiva, en tanto sobriedad y/o concentración del lenguaje, desnuda de ornamento (mínimas descripciones y referencias al contexto, escaso uso de adjetivos) y estas estrategias parecen cumplir una función higiénica contra los excesos. Esto nos llevaría a vislumbrar los rasgos de una escritura minimalista en contraposición a la proliferación barroca, es decir, una escritura despojada de artificio que dice en sus silencios o en su desnudez. En este sentido se podría hablar de una retórica del silencio y de una búsqueda del silencio como un imperativo para la creación.

Mientras que la Ifigenia de Teresa de la Parra así como Sor Juana son obligadas a abandonar la escritura y esta pérdida marca el final de su vida, aquí la protagonista decide voluntariamente dejar esa práctica y volcarse al silencio como imperativo estético e identitario. 


\title{
4.2. Construir (se en) el diario íntimo
}

\author{
El silencio es una cucbilla de seda. \\ Wendy Guerra, "Cumpleaños de silencio"18 \\ No sé en qué momento permití que me quitaran todo y me dejaran sola, desnuda, \\ con el Diario en una mano y un carmin en la otra, tratando de colorearme \\ la boca de un rojo que parece demasiado subido para esta edad indefinida. \\ Wendy Guerra, Todos se van
}

Nacida en 1970, Wendy Guerra es hija de la poeta y periodista Albis Torres y de un padre dramaturgo. Su adolescencia transcurre en La Habana donde se gradúa en Dirección de Cine en la Facultad de Medios de la Comunicación del Instituto Superior de Arte (ISA). A los diecisiete años publica su primer poemario, Platea a oscuras (1987) editado por la Universidad de La Habana. En 2006 recibe el Primer Premio Novela de la editorial Bruguera y edita su primera novela, Todos se van que se publica en varios países de Europa y de América Latina, excepto en Cuba. El mismo año, recibe el Premio de la Crítica del periódico español El País como Mejor Novela y en 2007 fue elegida, al igual que Karla Suárez, para integrar Bogotá 39 para "Bogotá Capital Mundial del Libro", un grupo que reunía a los escritores más representativos de la literatura latinoamericana, menores de 39 años. En 2008 publica Nunca fui primera dama y el poemario Ropa interior. En 2010 aparece Posar desnuda en La Habana. Diario apócrifo de Anaïs Nin, obra que conjuga el ensayo y la ficción.

En la actualidad, Wendy Guerra vive y escribe en Cuba, en un piso del distrito de Miramar, en La Habana, mientras mantiene el blog Habáname en el diario español El Mundo. Su obra poética fue editada en Cuba pero no su narrativa. En sus declaraciones (me refiero

\footnotetext{
18 "Cumpleaños de silencio en La Habana" es una reflexión que publicó en el blog en la víspera de su cumpleaños número cuarenta y dos, el 10 de diciembre de 2012. Wendy Guerra tiene el blog Habáname en el diario español El mundo http://www.elmundo.es/blogs/elmundo/habaname/2012/12/10/cumpleanos-desilencio-en-la-habana.html
} 
a entrevistas de acceso en la web o en su blog español) deja entrever referencias a cierta censura, que no he podido constatar. ${ }^{19}$ Wendy Guerra se proclama exiliada dentro de la isla. En un artículo publicado en su blog Habáname reflexiona acerca de esa condición:

Ser mujer, vivir en el tercer mundo socialista, escribir, pensar, creer en el misterio de reunirnos parece imposible.

Algunos describen su realidad drogados, otros lo hacen bebiendo sin parar. Muchos autores se suicidan al no poder más con lo que tienen que describir.

Conozco vidas apagadas por el miedo. Yo sueno como una corneta china sin carnaval, yo soy mi propia conga. Yo me protejo con un sombrero y cito una canción amada.

Me desnudo por dentro y por fuera, y como mi pequeña Cuba interior, me expreso desde la jaula personal: Uso un fular rosado y una pluma que dibuja puentes para VOLVER. Mi anhelo es la reconstrucción humana. No soy una heroína, no deseo mostrarme como tal, soy una autora que todavía tiene, curiosamente, muchos problemas semejantes a los de Anaïs Nin en 1922 (Guerra, 2011).

\footnotetext{
19 Sin embargo, también habría que considerar otras razones no siempre explícitas, es decir, debido a la reglamentación en torno a los libros que rige en Cuba, cuando los escritores publican algo fuera de la isla, solicitan a la editorial que excluya del territorio contratado a Cuba (porque allí no rige la ley del mercado del libro) y así pueden publicar ese mismo libro en la isla. No he podido verificar cómo se realizaron los contratos de publicación con esta escritora y tampoco puedo asegurar si efectivamente recae la censura política sobre su obra, si se debe a problemas legales o la censura proviene de sus pares debido a rencillas propias del mundo literario porque, es sabido, las capillas literarias funciona en todos los lugares. En Cuba, desde 1967 existe el Instituto Cubano del Libro, institución encargada de la edición, la comercialización y la promoción de libros y publicaciones seriadas en Cuba, así como de las relaciones del Estado cubano con los escritores, sus organizaciones representativas y los profesionales del libro. Forma parte del Ministerio de Cultura. Importa y exporta libros, revistas y otros artículos relacionados. Dirige quince Centros del Libro, ubicados en cada una de las provincias, a través de los cuales dispone de un Centro de Promoción Literaria, una pequeña editorial y librerías. Las instituciones fundamentales que integran el Instituto Cubano del Libro son: Agencia Literaria Latinoamericana; Cámara Cubana del Libro, Distribuidora Nacional del Libro; Ediciones Cubanas; Editorial Gente Nueva; Editorial Letras Cubanas; Editorial José Martí; Editorial Arte y Literatura; Editorial Nuevo Milenio; Editorial Electrónica (Cubaliteraria); Centro de Promoción Literaria "Dulce María Loynaz"; Centro de Promoción, Información y Análisis del Libro; Centro Cultural Doña Leonor Pérez; Servicios Comerciales; Revista La Letra del Escriba; Centro del Libro y la Literatura. La Ley n ${ }^{\circ}$ 14, del 28 de diciembre de 1977, "Ley del Derecho de Autor", El Decreto No 20, del 21 de febrero de 1978, creó el Centro Nacional de Derecho de Autor, el que se responsabiliza de la protección de los derechos de autores y tiene entre sus funciones básicas la de contribuir a que los valores culturales y la creación intelectual sean de beneficio universal, se difundan internacionalmente y se garanticen las remuneraciones correspondientes. La página del Ministerio de Cultura de Cuba señala que "En estos momentos se está realizando un proceso de revisión general de toda la legislación vigente en torno al Derecho de Autor". Para consultar la legislación vigente y la organización burocrática respecto de la industria del libro, consultar: www.min.cult.cu También se puede consultar el libro de Pamela María Smorkaloff Literatura y edición de libros. La cultura literaria y el proceso social en Cuba (1987).
} 
En Todos se van, su novela de comienzos, Wendy Guerra experimenta con el diario íntimo, género sobre el que vuelve en su narrativa posterior. ${ }^{20}$ La novela está precedida por un epígrafe del Diario de Anna Frank, una breve reflexión inicial y finaliza con una suerte de epílogo titulado "Recuento y confesión". El cuerpo del texto adopta la forma del diario personal de Nieve Guerra, estructurado en dos partes: "Diario de infancia", que abarca desde 1978 a 1980, y "Diario de adolescencia", desde 1986 a 1990; ambas etapas se encuentran atravesadas por referencias al contexto político-social y por la experiencia del abandono (por nombrar de alguna manera las complejas variantes del exilio que existen en Cuba) que sufre la protagonista que narra, una y otra vez, la sucesivas partidas de las personas que la rodean.

Como mencionamos en la introducción, en Cuba hay diferentes modos de nombrar y, en consecuencia, de considerar a los que se fueron de la isla. Este fenómeno tiene características diferentes del exilio político que se extendió en el resto de América Latina con las dictaduras militares que a partir de la década del setenta asolaron la región. Es un tema complejo que no pretendo abordar aquí, aunque deseo dejar constancia de algunas variantes. Por ejemplo, en el campo literario no es lo mismo el exilio de Reinaldo Arenas que el de Guillermo Cabrera Infante o el de Severo Sarduy (Machover, 2001). El caso de Severo Sarduy es singular ya que luego de cumplir el plazo de una beca en Francia, decide quedarse para completar sus estudios por lo que él mismo dice que más que un exiliado es un "quedado" o un "aislado". ${ }^{21}$ En el caso de Wendy Guerra, diferente de los anteriores y muy extendido en los últimos años (es paradigmático el de la bloggera Yoany Sánchez), se habla de un exilio dentro de la isla. Como dejé esbozado en el análisis de Karla Suárez, el

\footnotetext{
20 Primera edición: Barcelona, Bruguera.

${ }^{21}$ Sobre las características del exilio en Sarduy, consultar la tesis La construcción de la subjetividad en la narrativa de Severo Sarduy de Sonia Bertón (2010).
} 
silencio puede ser pensado como una variante del exilio o, también, como una forma de resistencia. En sintonía con esto, creo que son relevantes unas palabras de la nota que abre Todos se van: "Nacer en Cuba ha sido mimetizarme en esa ausencia del mundo al que nos sometemos. No he aprendido a usar una tarjeta de crédito, no me contestan los cajeros. Un cambio de avión de país en país puede descontrolarme, dislocarme, dejarme sin aliento. Afuera me siento en peligro, adentro me siento confortablemente presa" (Guerra 2006: 10).

Nieve emprende la escritura del diario en noviembre de 1978, cuando tiene siete años y vive en Cienfuegos junto a su madre, una periodista que trabaja en una radio y que está separada de su padre, un actor alcohólico. Con ellas vive también Fausto, un sueco que llegó a Cuba para trabajar en una Central Nuclear. La vida transcurre en una casa cercana a una laguna y es representada como una etapa idílica, de libertad y de contacto con la naturaleza y con la cultura: deambulaban desnudos disfrutando del agua, lejos del orden, en una casa en la que circulan libros y personas ligadas al ámbito artístico. Su madre trabaja en una radio y se dedica a las noticias pero cuando deja de ser confiable le destinan la sección de deportes y más tarde la envían a cubrir la guerra de Angola donde se enferma. Luego su padre gana un juicio para la guarda de su hija y debe ir a vivir con él y su grupo de teatro en las montañas, en El Escambray, durante tres años. Una experiencia traumática: el diario narra la violencia física, la falta de comida y el abandono. El diario de infancia se cierra con la salida del país de Leandro, un pintor amigo de su madre. A los dieciséis años comienza el "Diario de adolescencia". Esta etapa transcurre en La Habana y relata su paso por la Escuela Nacional de Arte, las diferentes experiencias artísticas de esos años (en particular, el grupo Arte Calle), el inicio en el amor, la sexualidad y nuevamente, el abandono y la soledad. $^{22}$ En esta parte de la novela tiene un lugar fundamental el encuentro con Osvaldo,

\footnotetext{
22 Arte Calle fue un movimiento cultural que entre 1986 y 1989 sacudió el mundo cultural cubano con happenings y performances. Surge a partir de un mural pintado en la "Playita de 16" de Miramar, en Ciudad de la Habana, por Aldo Damián Menéndez López (Aldito) e Irán Plata Fabregas, ambos estudiantes de la
} 
un pintor con prestigio (dentro y fuera de Cuba), mayor que ella y que pertenece a otro sector social. Mantiene una intensa relación hasta que él se queda a vivir en París y ella no puede trasladarse allí porque no tiene la mayoría de edad. A diferencia de la primera parte que está más centrada en la narración de hechos que traslucen el miedo a la pérdida de la madre, al abandono, a la soledad y a la muerte, la segunda se vuelve más reflexiva: el relato se detiene en comentarios o evaluaciones sobre los hechos, en la elaboración de opiniones estéticas y políticas.

Al igual que en la novela de Karla Suárez, en Todos se van la identidad de la narradora se construye mediante el ejercicio de la escritura aquí delineada a través de lo que la crítica ha llamado, con algunas variaciones, "escritura del yo" (Lejeune, 1994; Molloy, 1996; Giordano, 2006; Arfuch, 2007; Catelli, 2007), un espacio en el que Nieve Guerra (re) construye lo vivido. En clave autobiográfica, Nieve Guerra sería la alter ego de Wendy Guerra. En este sentido, la escritora declara en varias entrevistas que la publicación de la novela surge a partir de la muerte de su madre en 2004 y el encuentro con los manuscritos de su diario escrito durante su niñez y adolescencia (Friera 2006; Pascual 2006; Junieles 2007). En uno de los diálogos señala que "la lectura de mis diarios de infancia y adolescencia fue un viaje al dolor" y afirma que "las heridas ya han cicatrizado. Depositarlas en el libro fue una terapia literaria" (Pascual 2006: s/n). En la entrevista publicada en Página/ 12 comenta algunos aspectos del proceso de ficcionalización:

Agarré la columna vertebral de mi vida, pero también tomé cosas prestadas para escribir la novela: mi mejor amiga tenía la madre en Angola; mi mejor amigo, al padre en Miami. Quise regalarle a una generación una reflexión sobre lo que hemos sido, qué hicimos bien o mal, dónde estamos (Friera 2006: s/n).

Escuela Elemental de Artes Plásticas "20 de Octubre". La primera performance del grupo fue en 1987 -"Arte Calle. Experimento. No Queremos Intoxicarnos"— en la Sala Rubén Martínez Villena de la UNEAC. Esta puesta se puede ver en: http://www.youtube.com/watch?v=0afYghO59c0 Consultar: http://www.ovguide.com/arte-calle-9202a8c04000641 f8000000006b3ec10 
Esta información autobiográfica ha sido el dato medular que la crítica ha querido leer y que la autora, en muchas oportunidades, ha cultivado. ${ }^{23}$ Si se siguen las instrucciones dadas por Wendy Guerra, se podrían rastrear datos que permitan comparar o establecer paralelos entre la vida de la autora y la de la narradora, por ejemplo, las dos nacieron en diciembre, su primer amor las dejó en Cuba mientras se radicaba en Francia, etcétera. ${ }^{24}$ La autorreferencialidad llega hasta tal punto que la novela incluye citas de poemas de la propia Guerra, enmascarados en la narración, por ejemplo, el poema "Cuchilla al viento"; un gesto que también podría ser leído como una operación que buscar resignificar su propia producción. ${ }^{25}$ Sin embargo, de esto, y debido a las hipótesis que sostienen esta investigación, más que centrarme en un análisis biográfico que compare la historia de la autora y de la narradora, me detendré en los vínculos entre la configuración de la identidad de la narradora y la práctica de la escritura desde el punto de vista de su construcción textual. El diario contribuye a la creación de una imagen como escritora, entonces, cuando el diario íntimo sale del umbral de ocultamiento, de la privacidad, su contenido recupera la voz y la palabra, es decir, descubre la experiencia individual de un sujeto que, por medio del lenguaje, se representa a sí mismo y al mundo que lo rodea. Tendré en cuenta las estrategias

${ }^{23}$ Por ejemplo, además del fragmento citado en el cuerpo del trabajo, en otra entrevista le preguntan: “¿Era consciente, al escribir su libro, de la fuerza que tiene el lenguaje de una niña y la estructura de un diario para describir el mundo? ¿Es consciente de la eficacia que tiene el lenguaje poético para hablar de lo que no se habla, de lo que no se dice o no se podría decir con otras palabras más directas? ¿Hasta dónde su libro es ficción y hasta dónde autobiografía?" y Wendy Guerra responde "Lo hice mientras estaba entretenida en sobrevivir dentro de mi vida real, eso era inevitable, inconsciente. Cuando decidí entregarlo a un concurso y luego darlo a leer a los amigos, pensé: 'Soy una perfecta inconsciente. ¿Cómo dar mi vida a los demás, cómo exponerme de este modo, desnuda y sin velos?' A flote y sin remedio, ahora quedo a disposición de todos y en bandeja, abierta por siempre, luego de mis confesiones, que tienen más de verdad que de ficción". En "Un grito desde La Habana", por Guillermo González Uribe, http://www.revistanumero.com/51/wendy.html

${ }^{24}$ En "Diciembre de 1979", la narradora dice que al día siguiente cumple nueve años. "Yo sé que mañana viene mi madre, mañana cumplo nueve años” (Guerra 2006: 57). El diario comienza en noviembre de 1978, entonces, en ese momento tiene siete años. Aunque el dato tal vez parezca anecdótico, constato con fragmentos de la novela la edad porque otros trabajos señalan que Nieve tenía ocho años cuando comienza su diario (por ejemplo, Charlotte Michel, 2011).

${ }^{25} \mathrm{El}$ poema pertenece a Ropa interior editado por Bruguera. "Cuchilla al viento/ Siempre llega/alguien/y me rompe/ el pantalón que más amo. /Siempre es él, el mismo, con su cuchilla al viento/lacerando este cuerpo;/con el filo de mi propio miedo". 
de autofiguración en el sentido de Sylvia Molloy (1996), es decir, las estrategias a través de las cuales la narradora se autorrepresenta en privado, pero respondiendo a las expectativas de lo público: a qué codificaciones y retóricas apela para construir imágenes que, en esta novela, son literarias, políticas y sentimentales de sí misma. Esto es así porque, con todas sus ambigüedades, el cosmos personal del escritor/a de diarios íntimos es anotado en el diario en un acto de escritura $-y$ de conciencia de sí- por el que nos comunica y pone en contacto con su mundo. Un mundo, de más está decirlo, en el que también está presente la mirada de los otros.

\subsubsection{Flirtear con la autobiografía: el diario íntimo}

Como señalé, la novela comienza con un epígrafe del Diario de Ana Frank "Podríamos cerrar los ojos ante toda esta miseria, pero pensamos en los que nos eran queridos, y para los cuales tememos lo peor, sin poder socorrerlos", y ya de esta manera se establece una ligadura con el género del diario íntimo. La elección de estas palabras implica también entablar un juego con la autobiografía: como es sabido, la niña judía escribe su diario personal mientras permanece escondida en una buhardilla en Ámsterdam, durante la ocupación nazi en Holanda. En diálogo (tal vez forzado) con esta historia, el diario de Nieve Guerra también se escribe en situación de ocultamiento, ya sea por la censura que ejercen los hombres cercanos a su vida (primero su padre, luego su pareja), como por las dificultades materiales que conlleva la escritura.

La reflexión inicial que abre la novela marca el presente de enunciación en el que la narradora, ya adulta, recupera la experiencia de la escritura como el espacio de configuración de una identidad signada por el abandono y la fragmentación: "Ahora no soy capaz de atinar en lo que esperan de mí. Fui soltando los pedazos de lugar en lugar al que me arrastraron y hoy no sé cómo armar mi mundo disperso, cernido como arena en mi 
territorio personal” (Guerra, 2006: 9). Si no fuera por el pacto de ficción, el presente de la protagonista se (con)fundiría con el de la autora ya que no hay ninguna marca discursiva que indique si las palabras pertenecen a Wendy Guerra o a Nieve Guerra. Este gesto de mirar hacia atrás, de revisar lo escrito como si se revisara lo hecho para entender un presente en el que la edad se vuelve incierta, se puede vincular con lo que Alberto Giordano denomina "escritura del recuerdo" (Giordano, 2006: 44), entendida como aquella que explora la coexistencia problemática de un pasado que no termina de ocurrir y de un presente de inquietud que no alcanza a cerrarse sobre sí mismo. Como lectores de esta especie de prólogo a la novela asistimos perplejos a la actualización de una identidad que (se) busca en la revisión y construcción de la escritura y en la que el "yo" se configura a partir de cada partícula de arena dispersa.

Las dos partes en que se divide el Diario van precedidas por citas que aluden a cada una de las etapas referidas. Así, el "Diario de infancia" comienza con palabras que Wendy Guerra atribuye a Charles Baudelaire: "La patria es la infancia". ${ }^{26}$ Mientras que la segunda parte tiene un epígrafe de Eliseo Diego: "Sobre el infierno de la adolescencia pasaremos como por sobre ascuas, pues solamente un pobre diablo querría detenerse en el infierno", versos que pertenecen al poema "En el medio mismo del día", incluido en Los días de tu vida (Diego, 1992: 445). Ambos epígrafes otorgan pistas sobre la configuración de esas etapas: los años de niñez como días a los que la mente inexorablemente regresa para encontrar momentos en los que anclar la propia identidad; la adolescencia como años de fuego, de locura, de crecimiento.

El diario sigue un orden cronológico, pero no responde a una sistematicidad cotidiana sino a la lógica de la escritura por fragmentos debido a diversas interrupciones

\footnotetext{
26 Digo que Wendy Guerra se la atribuye a Charles Baudelaire porque esos mismos versos han sido
} relacionados con Rainer María Rilke, Antoine de Saint- Exupéry, Gabriela Mistral, entre otros. 
que dan cuenta de los saltos temporales: cambios de lugar de residencia, prohibición de su padre y luego de Osvaldo, pérdida del diario, entre otras. Así, la escritura se configura como una suma de fragmentos, de la misma manera que la identidad de la narradora, es decir, la suma de partes que fue hallando desperdigadas en el diario. Por ejemplo, cuando finalmente logra que le saquen la tenencia a su padre, la ubican en un Centro de Reeducación de Menores y Nieve dice: 'Ya es once de enero, no he podido escribir porque no tenía libreta, estoy escribiendo detrás de las nuevas que me dieron, que son cuadrículas. Después las pego a mi Diario normal. Cuando lo pueda recuperar, todo ha sido tan rápido" (Guerra, 2006:89). En algunos momentos la escritura mantiene cierta regularidad pero en otros hay baches temporales que no siempre se explican. Así, el quiebre más grande se observa entre el final del "Diario de infancia", el "Miércoles, 25 de junio de 1980" (Guerra, 2006: 132) y el comienzo del "Diario de adolescencia", fechado el "Domingo, 19 de octubre de 1987" (Guerra, 2006: 137). Entre estas dos fechas, no proporciona ninguna explicación: ni pérdida, ni robo, ni prohibición de la escritura. En cambio, sí media el crecimiento de la narradora que dejó de ser una niña de nueve años y retoma la escritura siete años después, a los dieciséis. La niñez, entonces, queda resumida en la narración de dos años, podemos inferir que son claves e intensos en su vida, en tanto que la adolescencia estaría concentrada en tres años ya que el diario finaliza el 22 de abril de 1990, cuando Nieve tiene diecinueve años.

Además de los saltos temporales, otra de las características de este diario es la variación en el formato del encabezado. Comienza con una disposición tradicional de lugar y fecha: "Laguna del Cura, Cienfuegos, Cuba, 1978)", luego la escritura aparece precedida sólo por la fecha, sin precisar el lugar, por ejemplo, "Sábado, 13 de noviembre de 1978" 
(Guerra, 2006: 15). ${ }^{27}$ Pero después el diario adopta otras disposiciones. Por ejemplo, durante la relación con Osvaldo, la escritura está precedida por el formato "Invierno de 1988" en el que se evitan las fechas precisas para, en cambio, marcar el tiempo con hechos concretos como "Encuentro con Cleo", "Sorpresas", "Husmeando en las galerías", "Adiós a Cleo”. Esta variación aparece marcada por lo que podría leerse como una explicación:

Tengo claro que el Diario está prohibido en esta relación, pero desahogarme en él es mi única posibilidad. Siempre ha sido así, hasta en los peores tiempos.

Llevo casi cuatro meses escribiendo muy poco. No quiero poner fechas, tampoco días, aquí toda la semana se convierte en una misma aventura. Esta casa parece una película. No me hace falta viajar: si vivo en una Europa inventada en medio del Caribe. Si quiero sentirme en 'el mundo' debo permanecer en este círculo y no decepcionarme, mucho menos flaquear.

La vida allá afuera contradice mi nuevo status. Contradice esta fantasía (Guerra, 2006: 229).

Ese fragmento forma parte de una "Nota" al final del "Encuentro con Cleo" y hace referencia a la censura impuesta por Osvaldo, cuestión que se aborda en el siguiente apartado, dedicado a las prohibiciones y silencios de la escritura. En este caso, "el mundo" que descubre Nieve cuando conoce a Osvaldo, descripto con detalles a lo largo de la novela, explicita un circuito elitista ligado a determinados sectores de la cultura cubana. ${ }^{28}$ Esa "otra isla", "otra Cuba", "otra Habana” impone una lógica de escritura diferente en la que la sorpresa rige lo cotidiano que Nieve contrapone a la otra vida, la que "cada día remonto sin desayunar hasta la escuela, al otro lado de la ciudad” (Guerra, 2006: 209). De ese otro mundo no pueden quedar registros en el diario, por eso Osvaldo le prohíbe la escritura.

\footnotetext{
${ }^{27}$ En el diario hay una fecha que quiebra el orden cronológico o, mejor dicho, que marca una falla o desliz: la secuencia jueves 26 de marzo de 1987, viernes 27 de marzo de 1987 se interrumpe con un salto al domingo 28 de marzo de 1987 que, siguiendo la secuencia temporal, debería haber sido domingo 29 de marzo.

${ }^{28}$ Como ejemplo de estas referencias en la novela, resulta esclarecedor un fragmento del apartado "Los amigos de Osvaldo" en el que describe sucintamente los rasgos que caracterizan a las personas con las que Nieve compartió la primera cena social en casa del pintor. Allí dice: "me preguntaron de qué barrio era. Cuando dije que de Cayo Hueso -Jovellar y Espada-, me dejaron de mirar por todo el resto de la noche. Y eso que en Cuba no existen las diferencias de clases" (Guerra, 2006: 221).
} 
Nora Catelli (2007) establece una diferencia entre lo público, lo privado y lo íntimo: contrapone los dos primeros términos mientras que la intimidad constituye el vértice de una triangularidad y puede enlazarse con los otros dos. Catelli advierte agudamente que lo íntimo es el espacio autobiográfico convertido en señal de peligro y, a la vez, de frontera; en lugar de paso y posibilidad de superar o transgredir la oposición entre privado y público. En ese sentido, lo íntimo se convierte en un espacio pero también en una posición en ese espacio: es el lugar del sujeto moderno -su conquista y su estigma- y al mismo tiempo algo que permite que esa posición sea necesariamente inestable. En esta novela, esta triangularidad aparece en tensión constante ya que en el diario, escritura de lo íntimo, se observa una alternancia inquietante entre la palabra en el ámbito de lo privado y la posibilidad de que esa palabra se vuelva pública. En este sentido, generan cierto extrañamiento frases que marcan la endeble frontera entre estos términos: "Yo le sé muchas cosas a Misuco, no las cuento aquí porque esto es sólo para contar mis cosas, no para chivatear a nadie" (Guerra, 2006:101); "Mi madre me ha escrito algo en el libro de Eliseo debajo de la dedicatoria. 'Para mi hijita, que está lejos, pero seguimos siendo: la soga detrás del caldero'. Mi madre es muy cómica. La dedicatoria de Eliseo es larga y escrita con una letra pequeña y elegante (Es privada así que no la escribo aquî)" (Guerra 2006: 67) ${ }^{29}$ o "No sé si escribir esto en el Diario. Me da miedo, no puedo decírselo a nadie, por favor, guarda el secreto" (Guerra, 2006: 43). ¿Qué diferencia hay entre lo privado y lo íntimo? ¿Por qué (y quién o qué) podría "chivatear” si lo escrito queda registrado en el diario? Estas y otras preguntas que refieren la punzante tensión entre los términos de la

\footnotetext{
${ }^{29}$ La nota alude al poeta Eliseo Diego (La Habana 1920-México, 1994). Fundador de la revista Orígenes junto a José Lezama Lima, Fina García Marruz, Cintio Vitier, entre otros. En la novela aparecen varias referencias a este poeta.
} 
triangularidad se podrían rastrear a lo largo de todo el relato. ${ }^{30}$ En este sentido, el diario dibuja en su propia corporalidad la amenaza constante de la delación, del fisgoneo, de la pérdida o del robo de este preciado objeto aunque también aparece encubierto el deseo de que esa voz se vuelva pública. ${ }^{31}$ Para demostrar esta afirmación resulta esclarecedor el siguiente fragmento:

Si leen este diario me odiarán. A veces me gustaría ampliar las páginas del Diario a gran escala y exponer las hojas en esta galería. La escuela es de ladrillos rojos, pero estos ladrillos son blancos y me encantaría pintar mis ideas sobre ellos. También tengo pensado hacer las letras de neón para que se puedan leer como si fueran escritas en fuego o en oro. Pero como en la escuela nunca hay corriente...

Mi madre se moriría de miedo. La cito textual en los Diarios y ella no puede decir en público lo que yo digo aquí. Debido a lo que escribo, los guardo en la barbacoa de mi casa, en el entrepaño. La humedad los destruye, pero yo les paso por arriba a las letras con tinta azul y en los nuevos no escribo todos los días para que no se les terminen las hojas. En la escuela tengo uno comenzado; no lo suelto, lo traigo conmigo escondido entre las libretas. Mi Diario es un lujo, mi medicina, lo que me mantiene en pie. Sin él yo no llego a los veinte años. Yo soy él, él es yo. Ambos sentimos desconfianza (Guerra, 2006: 144).

La extensión de la cita se justifica en que condensa una serie de rasgos presentes en forma reiterada en la novela. En primer lugar, la tensión entre lo que se piensa y se registra sólo en el ámbito de lo íntimo y el deseo de que esa palabra callada explote, se exhiba como una obra de arte, y se vuelva pública. En segundo lugar, se vislumbra la problemática de la censura y, por último, se recupera la materialidad de la escritura: el escribir, marcar y remarcar como forma de resistencia, con una fuerte impronta de la escritura en la construcción de la identidad.

\footnotetext{
${ }^{30}$ En esta novela, por ejemplo, la casa borra la dimensión de lo privado con la que se esperaría asociarla. La casa materna siempre está ocupada por artistas que duermen desperdigados en bolsas en todos los espacios: "Mi madre no tiene remedio: trato de entenderme con ella pero no hay manera. Fuimos hasta el parque de la esquina, el Parque de los Mártires, que es muy privado y amplio. Le he pedido despejar un poco la casa, estar juntas y estar solas, sin tantas personas ocupando el poco espacio en que nos tocó sobrevivir" (Guerra 2006: 186). En estas circunstancias, Nieve no encuentra las condiciones necesarias para la escritura y, por el contrario, las halla en el parque, espacio de lo público que para ella se vuelve privado. El apartado en el que aparece este fragmento se titula "Una hora con mi madre" y marca ya desde el nombre la intimidad como una imposibilidad.

${ }^{31}$ En el diario también se puede analizar la descripción de la situación política y social cubana desde la mirada subjetiva de una niña y, luego, de una adolescente. Esta perspectiva da cuenta de los borrosos límites entre lo privado, lo público y lo íntimo en el contexto cubano.
} 
Este último rasgo ligado a la materialidad de la escritura se encuentra supeditado a una función que le otorga sentido o razón de ser: Nieve decide registrar los hechos que no quiere olvidar, como una forma de dejar huella de situaciones traumáticas, cuestiones políticas y, también, experiencias ligadas al descubrimiento de la sexualidad. Así, una y otra vez se observan expresiones como: “Ahora como terminé la composición la paso al Diario para que no se me olvide" (Guerra, 2006: 79); cuando es sometida, junto con dos compañeros, al Tribunal de Disciplina señala "Estoy muy cansada, ahora sólo quiero escribir aquí lo que pasó para que no se me olvide" (Guerra, 2006: 184); o cuando describe poéticamente su primera experiencia sexual, expresa:

Allí quedamos tendidos, marcándome, marcándolo en esta pasión que se sostiene en mi cabeza y que anoto y anoto y anoto para no olvidarla nunca.

Para llevarla conmigo como una sentencia que me acompañe a mí y a todas las mujeres que nazcan en mi familia

Él duerme mientras yo escribo.

Él está rendido mientras yo apenas comienzo la guerra (Guerra, 2006: 213).

De esta forma, la escritura se proyecta como una práctica sexual en la medida que conjuga en un mismo espacio el cuerpo y el deseo, por eso, lo sexual no termina en el encuentro de los cuerpos sino que se propaga y (per)vive en la escritura y, por lo tanto, en la lectura.

Entonces, el diario como espacio en el que dejar testimonio escrito de determinados hechos es, al mismo tiempo, un lugar al que regresar para (re)visar las líneas que confluyen en el dibujo de la identidad: “Toda esa carga la lleva mi cabeza y si la vierto en el Diario es para aliviarme, para intentar postergar lo que no comprendo. Por eso siempre vuelvo a él" (Guerra, 2006: 184). Y en esta selección, todo aquello que desea someter a las leyes del olvido, no queda grabado en las páginas del diario. Por ejemplo, no transcribe las cartas que le envía Osvaldo desde París porque implicaría guardarlo en su memoria y ella quiere borrar ese abandono. Cuando Nieve cumple los dieciocho años y podría irse con él, los trámites para lograr el permiso de salida se dilatan, nada acontece, entonces el silencio de Osvaldo se traduce en tres meses en que no se escribe en el diario: 
"Sigo siendo la albacea de su memoria. Poco a poco me voy silenciando. No escribo, no pinto y no abro la casa a menos que sea absolutamente necesario" (Guerra, 2006: 247). Aquí el diario adquiere la función de albacea de lo vivido pero, al mismo tiempo, deja al descubierto la construcción escrituraria que supone toda selección.

Este sentido entra en contradicción con otra función que le otorga a la escritura en el diario: escribir para olvidar, para no recordar. Este sentido (paradójico) de la escritura se manifiesta en los fragmentos en que se escribe para olvidar, para no recordar y, de este modo, la práctica se vuelve un ejercicio mecánico que permite dejar en blanco la mente. Así, por ejemplo, después de que un edificio de la vieja Habana se derrumba y ella salva su vida, se sienta a escribir: "Aquí estoy ahora, en un banco del parque frente a la galería Habana, tratando de escribir para aliviarme. Intento olvidar todo como una amnésica" (Guerra, 2006:194). Este hecho trágico significó además el descubrimiento de la inexorable soledad: "Supe bien, lo supe definitivamente y para siempre, que no podía caerme en la calle: nadie respondería por mí. Soy fuerte porque estoy sola” (Guerra, 2006: 194).

El diario también es una suma de otras palabras que atraviesan su vida y de las que, por diversas razones, desea dejar registro. De esta manera se dibuja como una superposición de otros discursos que refieren desde cuestiones cotidianas (recetas; canciones que canta su mamá; una tonada de un viejito que iba a cantar al programa radial de su madre; las décimas que le cantan a un muerto en un velorio; una zarzuela que cantó con su madre en una Navidad; la canción de Luis Alberto Spinetta "Muchacha ojos de papel" que le dedican en la radio mientras ella está encerrada en el entrenamiento militar; un poema de Edward Cummings, otro que le dejó su madre una noche junto a un dibujo) ${ }^{32}$

\footnotetext{
32 Aunque no se explicita en la novela, el poema pertenece a Albis Torres (1947-2004), la madre de Wendy Guerra: "La niña duerme atrapada entre los libros/Quién vendrá a desatar sus pequeños demonios/Quién vendrá a defenderla un día cuando/apague el cigarro y la despierte,/acabando de una vez este sueño./Breve sueño./La niña duerme, al menos, mientras la dibuje" (Guerra, 2006: 32). Albis Torres era una poeta que
} 
hasta palabras que no se pueden decir, que bordean lo prohibido: por ejemplo, transcribe una lista de los músicos o de canciones que no se pueden pasar en la radio; ${ }^{33}$ copia una carta que le envía su madre mientras vive con el padre aunque su madre le había pedido que la rompa. También transcribe las frases que le dan en la escuela para que haga un comunicado para el acto del primero de enero:

\author{
Pioneros José Martí \\ Pioneros Moncadistas \\ XXI Aniversario del Triunfo de la primera Revolución Socialista de América \\ Guerra de guerrillas \\ Porvenir \\ Cien por cien de promoción \\ El triunfo del enero glorioso de la patria \\ Imperialismo despótico y brutal \\ La zafra y el cultivo del café \\ En tiempo de paz \\ El milagro de la revolución \\ Patria o muerte, venceremos (Guerra, 2006:73).
}

Y luego aparece el discurso que ella construye con esta suma de consignas y por el que es castigada. También transcribe un fragmento de una canción que Carlos Varela canta en el programa radial de su madre y cuya letra provoca el corte de la transmisión. ${ }^{34}$

De esta forma en Todos se van se vislumbran las dos caras de una estrategia que puede pensarse como opuesta pero que aquí se complementa: así como en determinados

nunca publicó en vida. En 2008 aparece La habitación más tibia (editorial Mecenas), que reúne lo que se ha podido recopilar de su producción en prosa y poesía.

33 "PROHIBIDO PASAR EN LA RADIO: Moncho/Raphael/Julio Iglesias/Celia Cruz/La Lupe/Olga Guillot/Miami Sound Machina/Ciertas canciones de Carlos Varela/Mike Porcel/Meme Solís/Willy Chirino/José Feliciano..." (Guerra, 2006: 166).

${ }^{34}$ Son versos del tema "Apenas abro los ojos" que luego aparece en el disco "Nubes" (2000). El músico Carlos Varela formó parte de lo que en Cuba se conoce como el relevo de la Nueva Trova junto a Gerardo Alfonso, Frank Delgado y Santiago Feliz. En la década del ochenta, este grupo conocido como "Novísima Trova" ofreció varios conciertos que sirvieron para señalarlos como el relevo de los fundadores del Movimiento de la Nueva Trova. No obstante, hoy se coincide en señalar que más que revelo, se presentaron en sus inicios como una continuidad con muchos nexos con Pablo Milanés, Silvio Rodríguez, Noel Nicola y Vicente Feliz. Los elementos que hacían pensar que marcarían una dirección diferente estaban vinculados a una crítica contra la representación del gobierno y las instituciones culturales de la isla. Varela es el autor del tema "Los hijos de Guillermo Tell" que ha significado un hito por la metáfora sobre el relevo generacional en la que el hijo se rebela ante el padre y quiere ser él quien dispare a la manzana colocada, esta vez, en la cabeza del progenitor. Este nombre fue tomado por el crítico Gerardo Mosquera (1991) para denominar a una generación "Los hijos de Guillermos Tell". Mosquera lee la canción como una metáfora de la necesidad de cambio en la isla, y así bautiza a una exposición de pintores cubanos en Caracas y Bogotá en 1991. Para consultar un minucioso estudio sobre el arte cubano leer Nosotros, los más infieles. Narraciones críticas sobre el arte cubano (1993-2005) de Andrés Isaac Santana. 
momentos las páginas en blanco o los saltos temporales funcionan como marcas del silencio escriturario y como estrategias de resistencia ante el dolor, otras veces, la elección de la palabra escrita para volver público lo íntimo y/o privado (en términos de Catelli), supone la elección del diario como "refugio de guerra" o "escondite secreto" , "verdadero confesor" (Guerra 2006: 184), en alusión al otro diario, a aquel en que Anna Frank, en el silencio del encierro de la pequeña buhardilla, elabora su propia historia. Y en este segundo sentido también la palabra escrita deviene refugio y se conjura como una estrategia de resistencia, como forma suprema de la libertad.

\subsubsection{Los límites del cuerpo: la escritura y el hambre}

Relacionar la escritura con términos como refugio de guerra o escondite implica vincularla con el peligro y/o el riesgo que conlleva esta práctica en circunstancias peligrosas. Excepto cuando está con su madre, Nieve debe escribir con premura para evitar la censura: de prisa (“apunto rápido lo que vivo", "no hay tiempo para narrarlo”), en lugares y tiempos insospechados (a espaldas del teniente, a la noche o de madrugada, con pequeños rayos de luz, a contrarreloj, en horas robadas al descanso) y, por lo tanto, escribir se vuelve un ejercicio riesgoso, amenazante, peligroso. A partir de estas consideraciones, en este apartado me interesa detenerme en la explicitación y puesta en discurso de una forma de censura: la prohibición del Diario por considerarlo una escritura que deja huellas y, como contrapartida y resistencia, la continuidad de esa práctica en un tiempo robado a la mirada de los otros.

Como mencionamos, la figura materna habilita y promueve la escritura de la narradora. En el relato, la escritura se erige como un ejercicio riesgoso que requiere un tiempo extra o por fuera de las actividades rutinarias. Así, Nieve escribe a escondidas, principalmente, de su padre, primero, y de Osvaldo, después, pero también debe ocultarse 
de la mirada controladora de los maestros pero también de sus compañeros en la escuela, del teniente del Concentrado Militar. Durante la infancia, el padre le impide escribir en el diario: "Quise escribir en el carro y me quitó la libreta, me dijo que había que dormir. No le gusta el Diario, por eso lo tengo escondido" (Guerra, 2006: 39). Ante esta prohibición, Nieve oculta a los ojos del padre las evidencias de la escritura aunque sigue ejercitándola a escondidas. En estas circunstancias, es decir, cuando la justicia determina que Nieve viva con el progenitor, es la madre quien le lleva el diario y el uniforme a la escuela; en este contexto (y también durante la adolescencia), la figura materna habilita y promueve la escritura.

Luego, en el "Diario de adolescencia", nuevamente una figura masculina prohíbe la escritura, en este caso, Osvaldo, su pareja:

Leyó todo lo que pienso de sus amigos, descubrió las opiniones de mi madre sobre él y se enfureció. No quiero discutir, odio las peleas. El machismo en Cuba está disimulado por la alta instrucción, pero ahí está, amenazándote todo el tiempo, entre el juego y la realidad.

No sé por qué mi padre y Osvaldo odian el Diario. La historia se repite en ciclos que regresan para recordarme que nunca he sido mi propia dueña (Guerra, 2006: 224).

Esta afirmación adquiere connotaciones históricas porque remite a la institución del pater familias en la que la mujer era posesión, primero del padre y luego del marido: acá se prohíbe la escritura, como una extensión del cuerpo de la mujer. En la novela hay repetidas referencias al machismo en Cuba, cuestión que referimos en la introducción de esta tesis y que acá se vislumbra en la densidad que implica la mediación literaria. En Todos se van se vislumbra cómo el machismo funciona desde el poder estatal pero también, fundamentalmente, en el espacio de lo privado. Esto refuerza la idea de que, en la práctica y en el nivel de conciencia cotidiana, Cuba sigue siendo patriarcal y, por lo tanto, la mirada panóptica del poder (Foucault 1992) actúa en los resquicios más ínfimos de la cotidianeidad. 
Esta censura impuesta por las figuras masculinas se plasma en el diario, también, en el abandono de la escritura. Por lo tanto, la textualización del silencio mediante los saltos temporales se debe, en muchas oportunidades, a la imposibilidad de la escritura por la prohibición expresa del padre o de Osvaldo (como ejemplificamos en el apartado anterior). En otras oportunidades los silencios textualizados o explicitados como una decisión deliberada adquieren la función de resistencia, es decir, el abandono de la escritura como forma de manifestar desacuerdo. Por ejemplo, cuando en el "Diario de infancia" narra que a su madre la destinan a Angola, Nieve expresa: "Estoy en huelga de Diario porque se llevaron a mi madre a la guerra de Angola. Esta página está en blanco en su honor" (Guerra 2006: 19). Esta página “en blanco” no está precedida de fechas, el blanco del papel forja el silencio de la escritura. La última vez que escribe es el 20 de diciembre de 1978 y retoma el diario en junio de 1979: "Mañana llega mi madre" (Guerra, 2006:20). Otras veces, la violencia le impide escribir por las marcas que deja en su cuerpo: "Querido Diario: perdóname por estar dos días sin escribir, no me abre un ojo y me duele el brazo derecho, aunque yo escribo con las dos manos, pero no tenía ganas de fijar la vista. Mi padre llegó borracho y tiró la casa abajo. Me dio una paliza delante de la maestra" (Guerra, 2006:85).

Mientras vive con su progenitor, éste también le impone el silencio mediante el uso de la violencia, pero también como práctica cotidiana ante determinados temas: no hablar sobre la vida del padre, sobre las faltas a la escuela, sobre la comida. Luego de pasar tres semanas sin ver a la madre, recibe la anhelada visita el día de su cumpleaños y en el diario se textualiza el miedo y el silencio que atravesó dicho encuentro: "No me atrevía a preguntarle por F. pero las efes estaban en todas mi libretas. En el baño, cuando hacía caca, escribía FFF, invisible sobre el piso gris de cemento. Tenía miedo que nos estuvieran espiando" (Guerra, 2006: 58). "F" es la clave para nombrar a Fausto, la pareja de su madre. 
El diario, entonces, visibiliza formas violentas o sutiles de represión privada, el machismo así como también estrategias de rebelión, generalmente letradas, frente a ellas. Pero, al mismo tiempo, también alude a la censura exterior; es decir, en determinadas instancias, la escritura se vuelve peligrosa en tanto plausible de ser requisada por la mirada panóptica del poder. Cuando muchas personas del círculo de Osvaldo planean la partida y poco a poco Nieve va quedando sola, anota en el diario: "No quiero comprometer a nadie en este Diario. Tampoco deseo contar mis planes al pie de la letra" (Guerra, 2006: 241). Como señala Foucault (1992), la mirada omnipresente del poder genera que cada persona se sienta en un estado de permanente vigilancia y eso determina su pasividad y el control de sus movimientos.

En Todos se van, la escritura como ejercicio riesgoso entra en sintonía con otro de los tópicos que recorren la novela: el hambre. De este modo, hambre y escritura se conjugan para dibujar sinuosos caminos en los que el sufrimiento atraviesa ambas instancias vitales: el alimento del cuerpo y el alimento de una identidad que se configura en la escritura. Durante el tiempo que vive con su padre, la falta de comida se reitera en innumerables ocasiones: "Ahora es muy temprano y voy a ir para el comedor con los actores, en la casa no hay nada de desayunar. Espero que no se ponga bravo, tengo mucha hambre" (Guerra, 2006: 47); "Mi padre ronca. No me ha dado de comer. Iré a buscar comida al grupo, tengo mucha hambre. Me duele el estómago, si lo despierto se pondrá bravísimo" (Guerra, 2006: 49); "A mi padre siempre se le olvida llevarme a comer y sólo puedo salir de la casa de madera cuando hay función del grupo o cuando me lleva a la escuela. Y no siempre me lleva; en dos semanas me ha llevado seis veces" (Guerra, 2006: 50); "Mi padre no vino a dormir en dos días. Me escapé y fui al comedor. Estaba al desmayarme; sólo tomaba agua con azúcar. No podía más. Ya llegó, guardo esto” (Guerra, 2006: 54). En esta secuencia, el hambre va in crescendo mientras se agudiza el estado alcohólico y violento del padre. 
La búsqueda de comida se conjuga con el riesgo que implica escribir lo que no se debe decir: "Ya llegó, guardo esto", dice la narradora para referirse al objeto en el que deja testimonio de la situación. Y, acto seguido, describe una fuerte escena de violencia a la que la somete el padre cuando descubre que actuó por fuera de lo que él le ordenó. Ante lo único que Nieve se paraliza y no puede actuar es frente a la violencia física: "Hace tres días que no voy a la escuela. Mi padre me fue arriba y me golpeó la cabeza contra la mesa. Pensé que me sacaba el ojo. Vino por detrás, sin decirme nada. Sabía que me pegaría, lo sabía bien. Pero no puedo hacer nada" (Guerra, 2006: 54). Sin embargo, lo que sí puede hacer es escribir para dejar testimonio de los hechos, por eso, después describe minuciosamente los golpes "me arrancó dos mechones grandes que están en la libreta" (Guerra, 2006: 54). En la novela son muy fuertes las escenas que describen la violencia física ejercida por el padre, por ejemplo, cuando narra el castigo por haber entrado en la habitación prohibida: "me agarró la oreja hasta que me fue sacando la perlita de Mallorca que F me compró en sus vacaciones de Navidad. Me rajó la oreja en dos, y después el golpe no lo escuché, pero solté más sangre que nunca por el oído. Todavía siento dolor y como es el mismo de la otra vez no escuché bien lo que dijo. Pero me hizo tragar la perla, me la metió en la boca a la fuerza y no me soltó hasta que me pasó por la garganta" (Guerra, 2006: 70). El diario dibuja marcas peligrosas, marcas del dolor grabado en el cuerpo que escribe:

Me salió mucha sangre porque el hierrito de la hebilla se me incrustó en el cráneo. Me costó sacármelo, parecía que tenía un hueco muy grande, pero era pequeño (...) Tengo hinchado el cachete y no escucho bien del oído izquierdo. La boca está un poco inflamada. Me da miedo salir al comedor. Pero tengo hambre, la barriga me suena como los trombones que tocan en la retreta del parque (Guerra, 2006: 55).

Como señalamos en el apartado anterior, en varias ocasiones la violencia genera silencio como respuesta, ya que las marcas en el cuerpo le impiden escribir.

En la adolescencia también el alimento y el hambre recorren un itinerario: desde la forma de comer que identifica al adolescente en Cuba (con una crítica a la normas 
impuestas por la práctica socialista), hasta el lujo de la comida que prueba en el círculo en que se mueve Osvaldo, pasando por la descripción de las comidas en los internados. En todos los casos, el relato deja traslucir una crítica y, al mismo tiempo, manifiesta las tensiones provocadas por el acceso o la carencia de alimento:

La comida es algo que se traga a mucha velocidad porque no aprendimos a usar el paladar en los semi-internados. Comemos como en una carrera de relevo, bajo el lema de 'el que termina primero ayuda a su compañero'. Si usas los cubiertos correctamente te dicen burguesa, así que es mejor palear' con la cuchara. Hasta hablar con la boca llena y empujar con el dedo pulgar (Guerra, 2006, 138).

La analogía entre escritura y alimento se traslada también a otra operación ligada a la literatura: la lectura, que aparece semantizada por la noción de peligro. Aunque con menor importancia que el lugar otorgado a la escritura, en el diario también se mencionan títulos de libros que su madre le sugiere leer, lecturas secretas, libros escondidos en la biblioteca, atrás de los visibles y cubiertos con papeles de colores ${ }^{35} \mathrm{El}$ par lectura/comida, asociado al peligro, aparece condensado en el episodio del Concentrado Militar en el que Nieve le presta tres libros prohibidos a una amiga quien, de esta manera, puede leer de contrabando las novelas de su abuelo exiliado: "Lucía no ha dormido. Parece un ratoncito blanco leyendo a su abuelo sobre la cama. Casi ni respira, se bebe el libro y no sé cómo va a poder entrenarse hoy" (Guerra, 2006: 168).

Así como elige dejar de escribir para manifestar disconformidad o resistencia ante tantas carencias y represalias con la comida, Nieve decide dejar de comer. Esto sucede a partir de la escena en que su padre tira a las gallinas una comida que la vecina le había llevado por su cumpleaños: “Ahora soy yo la que no voy a comer más. Se acabó” (Guerra, 2006: 60). Y esta decisión se convierte en una herramienta de lucha para manifestar su desacuerdo:

\footnotetext{
35 Susana Zanetti (2002) ha señalado la importancia de las escenas de lectura en las novelas. Advierte sobre la necesidad de considerar los múltiples sentidos y apropiaciones que despliegan: lectura obligada, lectura evasiva, lectura como escritura, lectura en cadena, lectura proveedora, lectura de goce, etc..
} 
No he comido más. No tengo que hacer ningún esfuerzo, ya no me da ni hambre. Cuando mi padre me obliga vomito todo lo que me da. Lo vomito porque sí, no porque tenga revoltura de estómago (...) Cuando vomito me siento calmada. No me salta el estómago y le gano a mi padre que no quiere darme la comida que me manda $\mathrm{F}$ (Guerra, 2006: 61).

Mientras la práctica de la huelga de hambre consiste en renunciar a cualquier tipo de alimentación para forzar la concesión de un bien, la abstinencia de Nieve, que también es voluntaria, no se manifiesta ante nadie por lo que la rebelión queda en el plano de su propio cuerpo.

En Todos se van sólo una figura masculina habilita la escritura: Antonio, un desconocido que se convierte en el amante de Nieve, el hombre al que le abre la casa para que documente en un film la obra de Osvaldo cuando éste ya está en París. Antonio la filma mientras escribe y a él entrega sus diarios:

No sé, no sé, no sé cómo diablos le he dado este Diario, tengo que ser sincera, al menos aquí: le confié tres volúmenes. Siempre escondo el Diario de los hombres. Hoy se lo entrego a un desconocido, alguien que vino a filmar y dijo llamarse Antonio. Un préstamo, prestar mi ropa interior, mi vida, mis escondites, prestar el secreto. ¿Cómo hice esto? (Guerra, 2006: 256).

Entregar la escritura de lo íntimo es una extensión de entregar el cuerpo y la historia de ese cuerpo. La referencia a la escritura como ropa interior también aparece en el poemario de Wendy Guerra que lleva ese nombre: alude a una anécdota de la poeta Anaïs Nin quien, en una de sus cartas, cuenta su visita a un editor que, al devolverle sus manuscritos, los tira encima de la mesa mientras le dice: "Madame, llévese toda su ropa interior, no nos interesa su libro" (Guerra, 2008: 1). ${ }^{36}$

Pero esta habilitación de la escritura adquiere un sentido diferente al de la escritura promovida por la madre: Antonio la incita a que su palabra deje el ámbito de lo privado y alcance estatuto público. La madre incita la escritura pero la limita al ámbito de lo privado,

\footnotetext{
${ }^{36}$ Esta anécdota abre el poemario Ropa interior, en claro homenaje a Anaïs Nin (Francia, 1903- EE.UU, 1977). Después escribe la novela Posar desnuda en La Habana. Diario apócrifo de Anä̈s Nin (2010).
} 
al mismo tiempo que promueve la autocensura: sus comentarios giran en torno de temas de los que no puede hablar o escribir, por ejemplo, "Mi madre ha dicho que la patria es una cosa y que la política es otra, y que tenga cuidado con lo que escribo” (Guerra, 2006: 7374). Y Nieve da cuenta de la transgresión de esta enseñanza: "Mi madre se moriría de miedo. La cito textual en los Diarios y ella no puede decir en público lo que yo digo aquí” (Guerra, 2006: 144). Por el contrario, Antonio la incita a saltar el cerco de la autocensura cuando le pregunta, después de leer sus diarios, por qué se condena al silencio: "piensa que es una obra tan completa como la de Osvaldo. Me pregunta por qué me mantengo en silencio. ¿De qué me escondo?” (Guerra, 2006: 257) y la incita a leer el Jardín, novela de Dulce María Loynaz (La Habana, 1902-1997), una escritora que elige el encierro, el ostracismo interior para escribir, lo que ha provocado la creación de un mito en torno a su figura y su obra, mitificación de la que la autora no es del todo inocente. ${ }^{37}$ Escrita entre 1927 y 1935, la novela de Loynaz recién es publicada en España, por la editorial Aguilar en 1951; en Cuba se publica en 1993. Optar por esta referencia en el seno de la novela permite hipotetizar que Wendy Guerra desea ser leída en esa tradición: cuando Nieve recorre la casa que habitó la poeta, escribe en el diario: "A pesar de todo sigue allí y se ha hecho inexpugnable y necesaria, sin moverse de su espacio. Ha volado más desde su ostracismo que muchos pilotos de combate" (Guerra, 2006: 258). ${ }^{38}$ En clave autobiográfica, al igual que Loynaz, Nieve/Wendy elige quedarse en Cuba y escribir desde ese exilio interior.

\footnotetext{
${ }^{37}$ Zaida Capote Cruz sintetiza este mito: “El 'personaje' Dulce María suele ser visto como un ente etéreo, desasido de la realidad que lo cobija. Se repite que compartió con sus hermanos, durante la niñez, el encierro en el claustro familiar, donde recibió clases de preceptores privados, a la manera del siglo XIX. Luego, por causas diversas -incluso por razones de carácter- permaneció aislada del mundo, lo cual hizo crecer esa idea, alimentada por ella misma, de su excepcionalidad, de su falta de contacto con el contexto literario de su época" (Capote Cruz, 2002: 45).

${ }^{38}$ En Jardín. Novela lírica, la protagonista, Bárbara, está encerrada en las paredes de su casa. Gran parte de la crítica ha leído esta novela como autobiográfica, en la que Bárbara sería Dulce María, el jardín el de su casa en la calle Línea, esquina 16, en el Vedado. Zaida Capote Cruz (2002) critica esta lectura intimista y autobiográfica de la obra de Loynaz porque considera que insiste en el hábito confesional alimentado por siglos de compulsión patriarcal. Por el contrario, Capote Cruz propone leer toda la obra de Loynaz como
} 


\subsubsection{La imposibilidad de la (auto) (re) presentación: Nieve en La Habana}

Hacia el final del relato hay una escena significativa que deseo describir: para graduarse y pasar al próximo nivel, el Instituto Superior de Arte, Nieve presenta una tesis titulada "Quemando naves" que consiste en incendiar una enorme pila de libros:

Cuando ardían los libros veía cómo poco a poco se iban quemando mis naves. Pensé en la cantidad de escritores a los que les han incinerado su obra a lo largo de la historia. Un libro de Marx ardía junto a uno de Milán Kundera, qué locura. Creo que mi tesis gustó por el efecto de una idea a gran escala. Siento que valió la pena (Guerra, 2006: 243).

Este hecho, como cualquier quema de libros, resulta muy simbólico y hay quienes la leen como una traslación directa de ruptura con el sistema represivo cubano (Ferrer 2010). ${ }^{39}$ Sin embargo, me interesa desplegar otra lectura. Nieve refiere que esta acción se inspira en la obra "Ahora cómo ordenar la biblioteca" de un amigo, Juan Carlos García. Ordenar y quemar la biblioteca constituida en una sola operación remite, necesariamente, a la actitud parricida de las vanguardias de inicio del siglo XX. Pero también, en cualquier ámbito literario, puede leerse como la necesidad de romper con los precursores para constituir una creación propia: los evaluadores aceptaron y premiaron la quema, pero también hubo un castigo ejemplificador: el examen no compensó su pasado así que no fue admitida para pasar al Instituto Superior de Arte.

una interrogación sobre el lugar de la mujer en el mundo, negándose a aceptar los mandatos de una organización social que la relega y encierra tras las rejas de la incomprensión.

39 En un artículo cuyo título promete más de lo que efectivamente analiza, "Escritura, identidad y ausencia. Todos se van de Wendy Guerra", Carolina Ferrer parte de considerar acertadamente que ya desde el nombre de la protagonista, el oxímoron constituye la figura central en la construcción de la novela y analiza la escena de la quema de libros como una manifestación de esta figura. Considera que esta escena constituiría una voluntad de que la situación represiva evidenciada a lo largo de la novela llegue a su fin: "Puesto que la dictadura castrista no da señales de ceder ante la eminencia del ocaso mundial del marxismo-leninismo, Guerra recurre a la pira literaria no con el propósito de repetir los múltiples actos represivos mencionados en el libro, sino como un acto de insurgencia, de denuncia y con la esperanza de estar anunciando la caída del régimen cubano" (Ferrer, 2010: 8-9). Para Ferrer, este acto no es uno de autodestrucción, sino el símbolo del fin de una larga represión: "es la expresión del deseo del término de la violencia que la revolución representa para una vasta mayoría de la población cubana y, en particular, para las mujeres cubanas” (Ferrer, 2010: 9). 
En la novela hay sólo una escena en que la narradora describe su cuerpo. Esto sucede durante la adolescencia, en un apartado titulado "Nieve en el espejo":

Mis ojos se alargan como almendras, soy breve como un dibujo japonés.

El pelo lacio ha crecido y cae suelto hasta mis senos pequeñísimos que contrastan con mis piernas, mis nalgas, mis caderas y mis pies tan fuertes.

Soy una niña, soy una mujer, también un demonio que recita versos incomprensibles y pinta muy mal.

Mi cuarto es un refugio de juguetes y lienzos.

Una vida adulta ahogada en fragmentos de juegos infantiles.

¿Quién seré yo?

Un poco de todo, un poco de nada, un rompecabezas de lo vivido.

Soy Nieve en La Habana (Guerra, 2006: 197).

La última oración condensa, por lo menos, tres recursos retóricos: a simple vista vislumbramos un oxímoron evidencia de una imposibilidad, nieve en La Habana; también, irremediablemente, presenciamos una imagen: una ciudad caribeña cubierta por un frío manto blanco; por último, a una metáfora que habilita pensar que la figura de la narradora condensa una lectura de la identidad nacional o, para ser más precisa, de los últimos veinte años de la historia de la isla. Pero más allá de estos tres recursos retóricos con sus posibles lecturas, la última oración se encuentra inserta en un espacio mayor en el que el "yo" que narra se mira al espejo para preguntarse por su propia identidad y cuya respuesta arroja vestigios de una identidad fragmentada, compuesta por partes de "un rompecabezas" cuyas piezas de "lo vivido" la narradora las busca en la imagen que le devuelve el espejo que no es otro espacio que el acto de (re)lectura de lo escrito en el diario. Una identidad cuyos fragmentos ya se encuentran insertos en el nombre que su madre eligió para dejarla marcada desde el origen por la inexorable partida de los seres que la rodean: su madre decide llamarla Nieve por las cartas de los amigos que partieron a Europa. En los años que abarca el libro presenciamos, como lectores, la partida de muchos personajes de su entorno familiar, partidas temporales (su mamá a Angola, ella misma a casa de Osvaldo), partidas sin regreso (el padre, Fausto, amigos, Osvaldo), partidas que marcan el exilio interior (Antonio y ella misma). 
A lo largo del periplo vital de la protagonista, la identidad no adquiere rasgos fijos e inmutables sino que se mueve según el flujo de los acontecimientos por los que atraviesa. Sin embargo, Nieve parece delinearse en función de lo que los demás quieren o ven en ella. Así su cuerpo va mutando como una serie de despojos y nuevas ropas que la cubren según la imaginan las personas con las que se mueve: la niña que habita la casa materna y es madre de su madre; la niña sumisa que el padre golpea y castiga una y otra vez; la del uniforme escolar, la que se confundía en una vestimenta que la igualaba al resto; la mujer que imagina y construye Osvaldo, la "nueva Nieve" (Guerra, 2006: 217) que viste con ropas nuevas compradas en tiendas de diplomáticos mientras despoja y tira en una lata de basura la Nieve anterior, para diferenciarla de "la masa" (Guerra, 2006: 217) informe del pueblo cubano. Esta identidad inconclusa sólo puede reconstruirse en la lectura del diario. Y, por lo tanto, la identidad se vuelve móvil, fragmentaria y con existencia sólo en el papel en los dos sentidos del término, en tanto materialidad que ancla la ficción y en tanto rol que asume en el cuerpo de la novela. Ante una realidad marcada por el abandono y la pérdida, Nieve debe erigirse una y otra vez en un presente signado por la ausencia: "La libreta telefónica está llena de rayas rojas. Ya no puedo marcar esos números. Nadie me contestará. Casi no hay gente conocida en la ciudad. Todos se van. Me dejan sola. Ya no suena el teléfono" (Guerra, 2006: 247-248).

En Todos se van, el diario se dibuja como una extensión del cuerpo de Nieve quien escribe todo el tiempo, en lugares insospechados, en circunstancias inadecuadas, con riesgo de ser delatada o maltratada. Aunque hay momentos en los que elige el silencio, Nieve no abandona el diario, no claudica y, en este sentido, la escritura se vuelve un espacio de resistencia. Su voz, en tanto marca en el papel, se configura como su instrumento o, para precisar la imagen, su herramienta sería la mano (como extensión de la voz) que toma la pluma: "Yo desafino, y yo afino. Depende de lo que logre hacer conmigo misma en 
circunstancias tan distintas como raras" (Guerra, 2006: 171). Así la palabra escrita se carga de un valor extra ligado a la perdurabilidad en el tiempo, o a su capacidad de atravesar el tiempo frente a la oralidad que, aunque genera repercusiones, tendría menos alcance o poder. Sobre esta dicotomía Nieve se pregunta respecto de la radio y la censura: "No sé por qué se preocupan tanto por lo que ocurre dentro de esta cajita negra, si al final las voces se olvidan y todo se lo lleva el viento" (Guerra, 2006: 171).

La escritura del diario, entonces, constituye el espacio de configuración de la identidad de la protagonista y esta construcción se puede anclar en dos momentos: cuando efectivamente escribe el diario y, en segunda instancia, cuando ese "yo" se posiciona como lector de lo narrado. El primer movimiento está signado por el uso del tiempo presente, lo que otorga la sensación de que, como lectores-voyeurs, asistimos a la inmediatez de lo narrado. El segundo momento se perfila en la especie de prólogo que abre la novela en el que un "yo" fluctuante entre la autora y el personaje reflexiona sobre los hechos de la vida que la dejaron en una edad indefinida, como recupera el epígrafe del apartado dedicado a esta novela. En ambos momentos la escritura se erige como un espacio en el que ese "yo" se mira y se reconoce y, en este sentido, la escritura sería un espejo que devuelve la imagen invertida de quien se refleja en esa superficie que arroja al vacío y que, en esta novela, semánticamente se traslada al agua, elemento primordial de la naturaleza en el contexto insular y con un fuerte espesor metafórico que remite la visión piñeriana de Cuba: esa entidad compleja, embriagadora, marcada por su insularidad y el peso con que se hunde. ${ }^{40}$

El inicio y el final de la novela están atravesados por este elemento. Ya en la infancia el cuerpo de Nieve se dibuja como fragmentos: cuando nada en la laguna que está cerca de su casa, escribe "Soy un pedazo de bote, un cristal, una muñeca rota, un pececito

\footnotetext{
${ }^{40}$ Los versos iniciales del poema de Virgilio Piñera "La maldita circunstancia del agua por todas partes me obliga a sentarme en la mesa del café/ Si yo no pensara que el agua me rodea como un cáncer habría podido dormir a pierna suelta" se han convertido en un tópico en tanto forma radical y rebelde de ver la isla. Entre sus discípulos se encuentran, entre otros, Abilio Estévez y Eliseo Alberto de Diego.
} 
de agua dulce aleteando, flotando a la deriva" (Guerra, 2006: 14). Del mismo modo, en los últimos párrafos de la historia, cuando constata que Osvaldo se olvidó de ella y que toda posibilidad de salida está vedada, Nieve huye corriendo a encontrarse con el malecón y la inmensidad del mar al que se arroja para ser albergada en su seno. Pero ese instante que parece convertirse en el final de la protagonista, sin embargo, se congela: la imagen cinematográfica se detiene en el cuerpo desnudo con la línea del agua que separa el delgado trazo entre la vida y la muerte: "De repente una lluvia blanca empezó a caer sobre el mar. Era nieve. Nevó muy tenue, sólo para mí, por unos segundos. Poco a poco se fue congelando el agua" (Guerra, 2006: 284). Mientras la mente lucha por nadar al otro lado del mar, al lugar en el que están todos los que se fueron, su cuerpo se sostiene en vida anclado al recuerdo de Antonio quien, enigmáticamente, eligió otro encierro. Y en un presente de inmovilidad física (que parece aludir a la elección de Dulce María Loynaz) la identidad continúa construyéndose en el movimiento vital de la escritura.

\subsection{Conclusiones parciales}

En el análisis de las novelas de comienzos de Karla Suárez y Wendy Guerra, en tanto primer paso en la producción intencional de sentido (Said, 1978), procuré demostrar cómo la construcción de los personajes femeninos y el funcionamiento de los géneros literarios procesan las fracturas internas de un campo cultural signado por el conflicto inherente al contexto socio-histórico de los noventa, a las tensiones culturales y políticas que suscita la diáspora y a la evidente supremacía patriarcal de las leyes que regulan el funcionamiento del mismo campo y de la sociedad cubana en general. Ya sea como alusión, procedimiento escriturario o treta de los personajes, el silencio, en tanto dispositivo de la cultura, estaría dando cuenta de problemas no resueltos de la sociedad cubana, de presiones en las que se debaten cuerpos que optan por el exilio interior. Por la presencia que adquiere esta 
categoría, ya sea en el nivel de la historia o en el nivel del discurso, tal vez no sea apresurado hablar de una retórica del silencio como procedimiento que condensaría, de diferente modo, la construcción de la identidad de los sujetos femeninos y la textualización de la lucha contra la coerción ideológica (bajo la forma de una represión política, personal o social).

La ausencia de palabras no significa necesariamente la ausencia de posibilidades comunicativas, ya que el discurso transmite toda una red de mensajes a partir de los silencios. Esto convierte el silencio en una de las estrategias más ricas y complejas de leer y a la que, históricamente, las escritoras han recurrido como forma de resistencia ante el poder de quien detenta el uso de la palabra (pienso en Sor Juana Inés de la Cruz -y la inteligente lectura del silencio que hizo Ludmer — o la poesía de Alejandra Pizarnik y Olga Orozco, por nombrar otras escritoras latinoamericanas más cercanas en el tiempo). ${ }^{41}$ En este sentido, proponer una reflexión y una lectura de las diversas maneras en que el silencio se hace presente en estas dos novelas supone partir de un presupuesto: estas obras significan en la medida en que se inscriben en una genealogía ya que el silencio también tiene una "tradición".

Recapitulo: en el primer apartado vimos que la construcción de la subjetividad de la protagonista de Silencios se produce en una sucesión de episodios traumáticos (la mayoría de ellos) en el recorrido que realiza ese "yo" desde la infancia hasta la juventud. Las reiteradas alusiones al abismo entre cuerpo y conciencia o la imagen del cuerpo como máscara del yo, dan cuenta de los vericuetos de la construcción identitaria de un personaje femenino desestabilizado en términos emocionales y que sólo logra reconocerse en el acto literario. El recurrente extrañamiento de "la Flaca" ante la imagen de su propio cuerpo permite entrever una confrontación entre la mujer que se auto-ubica como sujeto de representación

\footnotetext{
${ }^{41}$ Me refiero a Ludmer (1984).
} 
y la mujer representada por el discurso de los otros (recordemos que, excepto por el apodo, este personaje no tiene nombre propio que la distinga sino que adquiere el rol que le asignan los otros personajes con los que se relaciona: hija, nieta, sobrina, amante, etcétera). La narradora elige el silencio como forma de resistencia ante los sucesivos abandonos y ante un presente con el que no se identifica. En este sentido, la reconstrucción de la historia desde un presente de enunciación marcado por el aislamiento y soledad se puede leer como un grito o la forma de poner palabras al silencio. Del mismo modo, en Todos se van la narradora (re) construye su identidad desperdigada en la revisión y construcción de la escritura del diario íntimo, una identidad que ya está negada en el oxímoron de su nombre (Nieve) anclado en el clima tropical de La Habana.

En cuanto al cruce de la identidad con el género literario, en el análisis de Silencios señalé que el bildungsroman, un género de extensa tradición patriarcal, adquiere características particulares: al mismo tiempo que Suárez realiza un esfuerzo (consciente o no) por insertarse en esa tradición, el mismo gesto desestabiliza las bases del género porque allí se narra el periplo de un sujeto femenino que dista de ser una heroína y cuyo crecimiento no culmina en una integración social y personal. Además, el recorrido físico y simbólico no dibuja una línea recta sino más bien un movimiento circular (casa/escuela/universidad/ casa) que adquiere mayor peso simbólico al final de la novela, porque ese movimiento se vuelve centrípeto: lejos de la inserción social, la protagonista, como una sombra, yace tendida junto a su gata en el suelo de la habitación, encerrada en su casa. La opción por el encierro y el silencio como repliegue sobre sí misma adquiere una dimensión subjetiva que nos remite a otro encierro, el del personaje de Gelsomina de Mateo Palmer y que aquí deseo recuperar: la semantización de estos encierros (en la casa o en el manicomio) remiten necesariamente al espacio doméstico y de la locura a los que históricamente se ha relegado a la mujer (Beauvoir, 1949). Pero en ambos casos la ficción desgaja ese estereotipo porque 
los personajes femeninos logran posicionarse en otro lugar: como sujetos que enuncian el discurso y convierten ese encierro defensivo en un espacio de resistencia. La soledad y el silencio, otra simbología del encierro, se pueden pensar en Todos se van como una variante del exilio o, como en las otras novelas, como una forma de resistencia. No olvidemos que, en clave autobiográfica, Nieve/Wendy elige quedarse en Cuba y escribir desde ese exilio interior.

En la novela de Wendy Guerra, el trabajo de escritura y lectura del diario íntimo como espacio en el que la protagonista intenta armar su identidad también se erige, en su propia corporalidad, como un refugio privado y defensivo pero que está amenazado, constantemente, por la probabilidad de la delación, del fisgoneo, de la pérdida o del robo. La destrucción del diario implicaría el derrumbe de la identidad de la protagonista pero, al mismo tiempo, la posibilidad de hacer público lo privado. En este sentido es posible señalar el uso desviado que esta novela realiza de un género concedido históricamente a la mujer como el diario íntimo: en vez de reducir la palabra al espacio de lo íntimo, se percibe la tensión entre romper el silencio y volver público lo íntimo y/o privado (en términos de Catelli) y, al mismo tiempo, erigir a la palabra escrita como espacio de resistencia. El diario de Nieve visibiliza formas violentas o sutiles de represión privada y la censura exterior. Por eso, la escritura se erige como un ejercicio riesgoso en cuyo cuerpo, además, el motivo del hambre se materializa. 


\section{Reflexiones finales}

Inicié esta investigación intrigada por la cantidad y el tipo de textos literarios escritos por mujeres cubanas contemporáneas. Hoy, al cerrar provisoriamente este trabajo, debo rechazar la impresión inicial de escasez de títulos, en base a la abundancia de fuentes encontradas en el desarrollo de esta tesis, pero en cambio no debo rechazar sino confirmar mis intuiciones iniciales: en este corpus prolífico (frente al cual debí conformarme con el análisis de apenas algunos casos representativos), llama la atención cierta convergencia en la denuncia, en sordina y en diversos planos, del patriarcalismo vigente en Cuba luego de la Revolución.

Para ilustrar este clima de malestar -compartido en numerosas fuentes- ante la pervivencia cotidiana de la lógica patriarcal en Cuba, vale la pena mencionar dos anécdotas narradas por la investigadora cubana Zaida Capote Cruz en su libro La nación intima (2008). La primera: en un encuentro de las delegadas de la Federación de Mujeres Cubanas, con Fidel Castro, ocurrido el 8 de marzo de 2005 en el Palacio de las Convenciones, las mujeres recibieron de regalo una olla arrocera. La segunda: en los días previos a la discusión en la ONU de la propuesta de Cuba para el fin del bloqueo norteamericano, el ministro de Relaciones Exteriores -Felipe Pérez Roque- presentó un corto de la campaña: con el lema "Mientras más me bloqueas, más me crece", aparecía en escena un barbudo que, con un gesto levemente obsceno, plantaba una palma que empezaba a crecer desmesuradamente. Si la primera anécdota confirma el confinamiento de la mujer a la cocina, la segunda es una demostración más grosera del machismo cubano. Para Capote Cruz, estos hechos indican tanto el patriarcalismo sobreviviente a la Revolución, como la subestimación del pueblo, que posee un alto nivel educativo. 
Cuando comencé a bosquejar las líneas de esta investigación, una serie de preguntas me permitieron pensar problemas que se hacían evidentes al abordar el corpus y que, al cerrar este recorrido, vuelvo a retomar porque iluminan diferentes zonas analizadas a lo largo de los capítulos anteriores: ¿De qué modo la publicación de Estatuas de sal contribuye a crear una genealogía y un corpus de mujeres escritoras? ¿En qué medida esta construcción de un linaje forma parte de un conjunto mayor de estrategias de autolegitimación intelectual de figuras relativamente "marginales" que operan en un campo intelectual predominantemente "masculino"? ¿Qué figuraciones de la identidad de género elaboran las ficciones que integran el corpus y de qué forma ponen en cuestión la construcción identitaria del sujeto femenino tal como éste ha sido pensado por el sistema patriarcal? ¿Cómo se imbrica la construcción identitaria con la desestabilización de los géneros literarios puestos en juego en la trama narrativa? A partir de algunos ejes, intentaré responder a algunas de las preguntas que han atravesado este trabajo.

\section{Construir y congelar la tradición}

Las respuestas a los interrogantes desplegados tienen como punto de inflexión y convergencia la lectura crítica que propongo en el primer capítulo en torno a la antología Estatuas de sal, cuya publicación en el año 1994 produjo un quiebre en el campo literario cubano, pues por primera vez se erigía una genealogía de escritoras. Este hecho constituyó un gesto político-cultural que puso en evidencia la necesidad de construir un espacio legítimo en el cual reconocer las producciones escritas por mujeres. Si pensamos la circulación de los discursos en el marco de procesos sociales entendidos en términos de relaciones de poder, es factible ver en este gesto literario un carácter fundacional que busca ampliar los límites del canon e incluir a otros agentes. No es casual tampoco que esta 
antología se publique en un momento histórico en el cual se revisa e indaga el lugar que la mujer tuvo en la Revolución.

Esta compilación marca un punto de inflexión que ofrece la posibilidad de revisar cómo, en un momento determinado del proceso literario cubano, se configura una herencia y una contemporaneidad que entran en diálogo (por momentos tenso) con otros discursos. Al revisar el recorrido diacrónico planteado en Estatuas de sal, me pregunté algo que se volvía evidente: ¿Por qué el espacio temporal que queda desdibujado es el futuro, el espacio de las jóvenes (promesas) escritoras? La respuesta a esta pregunta me lleva a elegir el término "congelar", porque permite señalar la operación contradictoria que conlleva la publicación de este libro: la selección dibuja una genealogía que recorre el pasado y llega hasta el presente de la enunciación, pero está teñida por una distancia generacional que pone en duda "lo nuevo". ¿De quién serán deudoras estas hijas con su "tono de brutalidad intencional que tiene mucho sabor todavía a adolescencia rebelde” (Yáñez, 1998: 34)?

El análisis de esta compilación me ha permitido pensar el sistema sobre el que se recortan las posiciones que adoptan las escritoras que integran el corpus. Al examinar los supuestos que subyacen en esta antología que propone rupturas y desvíos se evidencia la intención de las compiladoras de construir una genealogía paralela o por fuera de la canónica, en un campo que se caracteriza por la recurrente necesidad de armar genealogías y tradiciones que permitan leer a los escritores desde una óptica diferente de aquella en que fueron leídos sus predecesores. Frente a un modelo cultural como el cubano que se pretende homogéneo y patriarcal, aún con las limitaciones señaladas, la publicación de esta antología significó un quiebre con el modelo hegemónico y un gesto que habilitaría simbólicamente la apertura a ficciones que construyan sujetos femeninos que, lejos de posturas esencialistas, rompan con la estabilidad y la tendencia a la homogeneidad. 


\section{Figuraciones de mujeres escritoras: desvíos de géneros sexuales y literarios}

En la investigación analicé una serie de obras en las cuales predomina la construcción de la identidad de género femenino por parte de sujetos de enunciación que narran experiencias de desvío de género sexual y/o literario. Así, la inscripción de la identidad individual (y especialmente de la identidad de género sexual) parece realizarse forzando los límites de la tradición literaria, mediante la apropiación de espacios simbólicos y de modelos discursivos hasta entonces obturados para las narradoras mujeres. En Ella escribia poscrítica y Desde los blancos manicomios de Margarita Mateo Palmer; "El viejo, el asesino y yo" y Cien botellas en una pared de Ena Lucía Portela; Silencios de Karla Suárez y Todos se van de Wendy Guerra el ejercicio de la escritura (en tanto actividad que despliegan, de diferente modo, los personajes) y los debates en torno a lo literario constituyen espacios fundamentales en donde leer cómo los sujetos que enuncian procesan su identidad. Para procesar esta identidad individual y de género, inscribiéndola en la tradición literaria cubana (predominantemente patriarcal), la mayoría de las autoras apela a la intertextualidad (y especialmente al epígrafe), para construir una afiliación en términos de apropiación del pasado.

En términos generales, el análisis del corpus puso en evidencia que la recurrente ficcionalización del espacio cultural que construye figuraciones de mujeres artistas/escritoras cuestiona fuertemente las reglas del campo intelectual patriarcal. De este modo, la escritura se erige como un complejo espacio de adaptación, negociación y/o resistencia a partir del cual se ponen en entredicho los criterios de legitimación cultural y, en otro plano, permite entrever tensiones no resueltas en una sociedad fuertemente atravesada por la crisis que se inicia después de la disolución de la URSS. El recorrido crítico demuestra que la construcción de las figuraciones de artistas/escritoras se produce en consonancia con torsiones de género literario: las obras del corpus realizan desvíos de 
los géneros y subgéneros como el ensayo, la narrativa policial, la novela de aprendizaje y el diario íntimo. Para este análisis partí de la idea de que los géneros literarios han sido históricamente "generizados", según Amícola (2003) quien entiende el término como el proceso por el que el imaginario social en las diferentes culturas ha venido percibiendo un género sexuado en cada uno de los objetos del mundo. Por lo tanto, consideré indispensable establecer miradas sincrónicas y diacrónicas que otorgaron densidad a la lectura, ya que las ficciones analizadas, en forma intencional o no, desestabilizan cierta ideología y se recortan contra otros géneros y obras dentro del sistema literario (oposiciones dentro del sistema, en términos formalistas). Para comprender cómo Mateo Palmer, Portela, Suárez y Guerra usan determinados géneros y se desvían de los mismos fue necesario revisar las características del ensayo, del género policial en Cuba, de la novela de formación y del diario íntimo. Excepto el último, todos los géneros mencionados tienen una tradición patriarcal; por lo tanto, los desvíos estarían dando cuenta de un esfuerzo por (re)escribir una tradición desde una posición marginal (en términos relativos). Desde el punto de vista ideológico, la imbricación entre ambas torsiones de género (sexual y literario) mediatizaría un cuestionamiento de la imagen de un cuerpo político viril y heterosexual a través del cual la Revolución ha afirmado la unidad nacional y la autonomía política y cultural de la isla. En este sentido, la narrativa contemporánea escrita por mujeres estaría rebelándose contra un orden patriarcal validado en Cuba aún después de la Revolución, confirmando así que este orden goza, aun en el presente, de gran arraigo en los diferentes grupos sociales, tanto de la Isla como de la diáspora cubana (tal como señala González Pagés, 2002, entre otros autores).

Así por ejemplo, en Ella escribia poscrítica (1995) y en Desde los blancos manicomios (2008) de Mateo Palmer se perciben desplazamientos genéricos en términos sexuales y literarios. Tanto en el ensayo como en la novela se construyen figuras de escritoras y de 
personajes femeninos que rompen con la concepción de la identidad en términos monolíticos. Por otra parte, ambos textos dialogan y producen desplazamientos en términos de género literario: el ensayo está atravesado por apartados netamente ficcionales mientras que la novela encubre elaboraciones críticas o ensayísticas. Ella escribía poscrítica se configura como un espacio productivo en el que se conjuga la reflexión crítica con elaboración ficcional (cuestiones "clásicas" en términos ensayísticos) pero la voz que enuncia es la de una mujer y esto ya significa un desplazamiento del ensayo, un género habitualmente asignado a una tradición de varones a los que se les ha concedido el poder de argumentar racional y analíticamente. La construcción identitaria de la voz que enuncia se multiplica en las voces que adopta el "yo" (Surligneur-2, Dulce Azucena, Siemprenvela, la Mitopoyética Intertextual, Lafeministadesatada y la Abanderada Roja) que plasman, en la conciencia del personaje, un debate sobre las diversas identidades (o máscaras) de la escritora. Este concierto de voces polifónicas pone en entredicho las diversas facetas en que se ha encorsetado la identidad "femenina". Con respecto a este juego especular, el texto de Mateo Palmer plantea una identidad múltiple, pero preservando, desde una perspectiva moderna, la unidad del sujeto en la diversidad: esa unidad no es cuestionada, a pesar del juego que escinde en múltiples capas la identidad.

La novela de Mateo Palmer construye un sujeto marginal (la protagonista anclada en un manicomio), y desde ese espacio reconstruye una identidad no acabada sino múltiple. Para (re)armar esta construcción identitaria, desanudé las implicancias de la proliferación intertextual y de los sentidos del encierro, este último, anclado en un primer espacio referencial (el manicomio) pero también en sus desplazamientos semánticos: la identidad de la protagonista, de la ciudad, de Cuba. Ese movimiento interno se proyecta en una visión de caleidoscopio: la protagonista se delinea en sus múltiples nombres, pensados como máscaras (el de pila, el de progenitora, el número de paciente en el manicomio, el elegido 
por su hermana) pero sobre todo, en la elección del nombre apócrifo de Gelsomina, como elección literaria y como homenaje.

El análisis de los textos elegidos de Ena Lucía Portela puso en evidencia los debates en torno al campo literario, y acerca de cómo las figuraciones de escritoras urden formas de insertarse y desestabilizar un campo con reglas fuertemente patriarcales. En "El viejo, el asesino y yo" se delinea la figura de una joven escritora que pugna por insertarse en un campo cultural regido por una lógica patriarcal. El enfrentamiento de la narradora (en tanto joven escritora) con la tradición masculina representada por "el viejo" se simboliza en la muerte en manos del amante que aparece como guardián del pacto entre varones. Este cuento sintomatiza la necesidad del sujeto femenino de adquirir legitimidad propia en un campo que intenta una y otra vez desplazarla a los márgenes. Cien botellas en una pared realiza un cruce entre el desvío del género policial con la torsión de género sexual que representan los personajes femeninos de la novela. La torsión del género literario se produce a partir de una voz femenina a cargo de la investigación, y también desde el desvío del género sexual que la novela pone en escena a través de Zeta, Linda y Alix. Estos personajes femeninos entablan juegos de identidades especulares y desvíos, como cajas chinas que traman, dibujan y desdibujan los límites de la identidad y los debates en torno de la literatura. Estos desvíos también se vinculan con la configuración de la ciudad, espacio por antonomasia del género policial.

Las novelas de Karla Suárez y Wendy Guerra que hemos considerado desestabilizan los géneros literarios puestos en funcionamiento para contar la historia, y erigir el silencio como estrategia medular tanto en la construcción narrativa como en la construcción identitaria de los personajes femeninos que narran la historia. Respecto del primer movimiento, Silencios trabaja con el Bildungsroman, y Todos se van con el diario íntimo. En cuanto al segundo movimiento, el silencio funciona en el nivel del discurso y en el nivel de 
la historia. En este sentido, es posible hablar de una retórica del silencio. En ambas historias, la literatura (en las variantes de la lectura y de la escritura) se configura como el reverso del silencio y como el espacio de resistencia en que las protagonistas (re)construyen su identidad en un contexto signado por el abandono y la soledad.

Por último, como señalé, la configuración de la identidad de los sujetos que enuncian se imbrica, al mismo tiempo, con el uso de la intertextualidad como un mecanismo para configurar una genealogía desde donde las escritoras quieren ser leídas. En el caso de Mateo Palmer, tanto en el ensayo como en la novela se observa un esfuerzo por entablar un diálogo con el espacio caribeño, un intento letrado de encontrar salida a la opresión condensada en la situación que atraviesan los personajes. El uso de los epígrafes, la prolífica intertextualidad así como las lecturas de Gelsomina, constituyen una forma de insertarse en la tradición literaria cubana pero, al mismo tiempo, la tensión que genera la enorme multiplicidad de citas y alusiones, así como las referencias a la obra de la propia autora permite vislumbrar el deseo de transformar esa tradición. Esta cuestión se acentúa por el desvío que implica el hecho de que las lecturas en torno al espacio caribeño converjan en un sujeto femenino enajenado.

\section{Espacios de resistencia: la escritura y el encierro}

Las protagonistas de las ficciones analizadas eligen el ostracismo interior para leer y para escribir. De hecho, en las ficciones analizadas predomina el sentimiento de encierro y resistencia desde la privacidad ante una sociedad en crisis y aislamiento. Sintomáticamente, Gelsomina/Mateo Palmer y Nieve/Wendy eligen quedarse en Cuba y escribir desde ese exilio interior. Por eso, en la construcción genealógica que establecen estas ficciones resultan significativas las alusiones a la novela Jardín de Dulce María Loynaz, donde el personaje de Bárbara se recluye tras los muros de su casa para ejercer la actividad literaria 
(así por ejemplo, en Desde los blancos manicomios de Mateo Palmer, Gelsomina se identifica con Bárbara, y en Todos se van, la protagonista lee Jardín en un contexto marcado por el abandono de sus seres queridos).

La reclusión en el ámbito de lo privado, en el silencio, en la soledad producto del abandono de los seres queridos o como elección de vida, constituyen recurrentes posiciones adoptadas por las protagonistas de estas historias enmarcadas en la crisis que atraviesa Cuba desde principios de los noventa. Este corpus narrativo se produce en un momento en el que el mercado editorial cubano adquiere tintes específicos, debido a la proliferación de ediciones realizadas, principalmente, en España (Rojas, 2007) y a que Internet ofreció una plataforma de difusión para las escritoras en un período de crisis económica. El análisis expuesto pone en evidencia cómo estas ficciones procesan las fracturas internas, la densidad y los bordes del campo cultural cubano signado por el conflicto inherente al contexto socio-histórico en que se enmarcan, a las tensiones culturales y políticas que suscita la diáspora y la evidente supremacía patriarcal de las leyes que regulan el funcionamiento del mismo campo.

En el corpus analizado, la casa adquiere un lugar central y se dibuja como un laberinto cerrado donde preservar lo interior y, en este sentido, casa y escritura se imbrican mutuamente. Dentro de esos espacios, los sujetos femeninos construyen mecanismos de resistencia ligados al acto de escribir. De esta forma, se modifican las implicancias del famoso encierro en la intimidad al que históricamente se ha relegado a la mujer. Las ficciones, además, realizan desplazamientos semánticos del encierro en la casa a otros espacios que se aproximan en sus connotaciones: el manicomio (Desde los blancos manicomios), la ciudad (en Cien botellas en una pared) y la nación (Ella escribia poscrítica, Desde los blancos manicomios, Silencios, Todos se van). 
En Desde los blancos manicomios la protagonista se identifica con lo insular que se materializa en el (auto) encierro en la introspección, en el manicomio y en la experiencia de la locura. Metafóricamente, la introspección y las lecturas sobre el Caribe desde ese encierro insano desestabilizan los discursos canónicos sobre la identidad cubana y caribeña. El uso de los epígrafes, la prolífica intertextualidad así como también las lecturas de Gelsomina pueden ser pensadas como un homenaje y una inserción en la tradición literaria caribeña, pero también como la creación de una nueva tradición. El aislamiento de Gelsomina alude a la materialidad de la condición insular y, en el mismo gesto, a la posibilidad de superar esta situación mediante la apertura a la multiplicidad del Caribe que estaría eximida así de los límites territoriales para, en cambio, conceptualizarse a partir de la riqueza cultural de un área atravesada por las convergencias y divergencias históricas, por el flujo constante y por la superposición de tiempos.

En las obras de Portela, Suárez y Guerra también aparecen tematizadosel encierro y la escritura como espacios de resistencia. Los sujetos femeninos que narran estas historias deambulan por espacios cerrados que se vuelven asfixiantes pero que, al mismo tiempo, les permiten recluirse para escribir y tratar de buscar una explicación a las diferentes circunstancias por las que atraviesan. En Cien botellas en una pared Zeta elige refugiarse en el reducido ámbito de lo privado y es aquí donde las prácticas cotidianas, pensadas en términos políticos, adquieren valor de resistencia. La protagonista de "El viejo, el asesino y yo" recrea un espacio letrado claustrofóbico regido por leyes patriarcales en el que encuentra su muerte. En Cien botellas en una pared los espacios cerrados implican encuentros con el otro: las fiestas organizadas en lo de la Gofia, "un islote dentro de la isla" (Portela, 2002: 199) que reúnen, principalmente, a lesbianas; las reuniones organizadas por el padre (homosexual) de Zeta; las prácticas sexuales como espacio de placer y de libertad; las conversaciones en torno a la vida y a la literatura entre Zeta y Linda. Estas instancias de 
reflexión sobre lo literario y la puesta en escena del acto procesal de la escritura -tanto de Zeta, la escritora "casual", como de Linda, la escritora profesional- pueden ser pensadas como instancias de configuración de la escritura como lugar de resistencia. En el último capítulo, "la Flaca" y Nieve, abandonadas por sus seres queridos, terminan optando por el silencio como resistencia (otro modo de encierro) y mientras la narradora de Silencios dibuja un círculo que la devuelve al centro de la casa, Nieve intenta huir lanzándose a la inmensidad del mar pero la imagen cinematográfica congela el movimiento: el cuerpo desnudo flota en la delgada línea que separa el adentro del afuera.

En estas narrativas el espacio privado como reducto al que históricamente se ha relegado a la mujer adquiere otras connotaciones, porque no es irreductible en sí mismo sino que se conecta con el afuera y es una respuesta defensiva ante la violencia exterior. Además, la exacerbación de lo íntimo puede leerse como una resistencia ante el Estado que no puede controlar los cuerpos que se desvían de una construcción homogénea del género. Como advierte Williams (1997), las formas y los dispositivos de la cultura (que en las ficciones estudiadas se concentrarían en el silencio como estrategia y en la configuración de espacios cerrados en los que se mueven los personajes) darían cuenta de problemas no resueltos de la sociedad cubana, de "reacciones y respuestas, presiones y bloqueos con que 'lo vivido' se produce en términos de un excedente que siempre deja 'constancia de las omisiones’ y altera tarde o temprano los límites de una hegemonía que sólo parcialmente puede incorporarlo" (Dalmaroni, 2001: 45). Aún sin poder definir con mayor precisión el alcance de la crítica política que estos textos pueden tener (dadas las posibles presiones del contexto enunciativo en el que se inscriben), dejan entrever una "estructura de sentimiento" (en términos de Williams, 1997) ligada a un clima opresivo de encierro en varios sentidos: entre otros, del género femenino frente a un orden patriarcal todavía 
hegemónico, de la escritura de mujeres frente a un campo intelectual predominantemente masculino, y de la intimidad frente al aislamiento de un orden social y político en crisis.

Pero como desconfío de las verdades que no admiten réplica, creo imposible poder "cerrar" el trabajo de manera definitiva. Apenas aspiro a abrir nuevos interrogantes entre sus lectores. 


\section{APÉNDICE 1 \\ Recorrido que constata la escasa o nula presencia de escritoras en las antologías cubanas $^{1}$}

En 1937, Federico de Ibarzábal publica Cuentos contemporáneos, primera antología del cuento cubano, y en una sección aparte incluye a las "mujeres cuentistas": Lesbia Soravilla, Aurora Villar Buceta, Hortensia de Varela, Dora Alonso y Cuca Quintana. La segunda antología, Cuentos cubanos (Antología) (1945), aunque elaborada por una mujer, Emma Pérez y un grupo de estudiantes, sólo incluye a dos escritoras: Dora Alonso y Aurora Villar Buceta. En 1946, José Antonio Portuondo edita en México Cuentos cubanos contemporáneos, incluyendo textos de Lydia Cabrera, Dora Alonso y Rosa Hilda Zell. En 1953 Salvador Bueno publica Antología del cuento en Cuba. 1902-1952 e incluye textos de las tres autoras antes mencionadas y de Aurora Villar Buceta y Surama Ferrer. Este recorrido permite constatar que la presencia de las mujeres en las antologías previas al triunfo de la Revolución se reducía a la mera repetición de dos o tres nombres, situación que se mantendrá aún después del triunfo de la Revolución Cubana.

\footnotetext{
${ }^{1}$ Por cuestiones materiales que dificultaron el acceso a todas las antologías mencionadas, constato que he podido consultar la siguientes: Nuevos cuentistas cubanos 1948-1958 compilación realizada por Antón Arrufat y Fausto Masó (1961); Los muchachos se divierten; nuevos cuentistas cubanos de Senel Paz (1989); El submarino amarillo (Cuento cubano 1966-1991). Breve antología de Leonardo Padura (1993); Los últimos serán los primeros de Salvador Redonet Cook (1993); La isla contada. El cuento contemporáneo en Cuba de Francisco López Sacha (1996); Aire de luz. Cuentos cubanos del siglo XX. (1999) de Alberto Garrandés; Nuevos narradores cubanos por Michi Strausfeld y Narradores cubanos de hoy de Rogelio Riverón. Cuando me fue imposible acceder a los libros porque no se encontraban en nuestro país, me valí de referencias que aparecen en "Antologados y antologadores: qué comunican nuestras antologías de cuentos" (2003) de Lino Verdecia Carlunga y La nación intima (2008) de Zaída Capote Cruz. Esta ensayista rastrea las compilaciones antes y después del triunfo de la Revolución Cubana y lee esta exclusión como una prueba de la marginalidad de la mujer respecto del proyecto nacional y luego, revolucionario.
} 
En 1961 Antón Arrufat y Fausto Masó publican Nuevos cuentistas cubanos 19481958, (editada por la recién creada Casa de las Américas) que se propone "aportar nuevos nombres a la cuentística nacional, y quizás nuevas obras" y donde se incluye a Ada Abdo, Esther Díaz Llanillo, Leslie Fajardo, Josefina Jacobs y Ana María Simo. Esta última será la única presente en la Antología del cuento cubano contemporáneo (1967) de Ambrosio Fornet, publicado en México. Tres años después, en Chile Fornet publica Cuentos de la Revolución cubana y no selecciona a ninguna escritora. En 1975 aparece El cuento en la Revolución. Antología con selección de Félix Pita Rodríguez editado por Unión: entre los veintisiete escritores representados en ella sólo hay una mujer: Dora Alonso. En 1979 se publica Dice la palma destinado a presentar la narrativa de veinte años de Revolución. Con veintisiete relatos de autores (catorce eran los mismos de la recopilación anterior y trece eran nuevos), aparece además de Dora Alonso el nombre de Mirta Yáñez. En 1989, Senel Paz publica Los muchachos se divierten; nuevos cuentistas cubanos, una antología que puso en circulación nuevas voces pero sólo se incluye a una escritora -Zully Jaspe- aún cuando el título escogido habría permitido hipotetizar su exclusión. ${ }^{2}$ Sin embargo, en la introducción Paz señala: "Lamentablemente, sólo se incluye a una mujer" (Paz 1989: 6-7), expresión que, más que aclarar, confunde, no sólo por el uso del gerundio sino porque no se explica ni por qué se lamenta ni por qué no incluyó a otras escritoras. Ya en la década del noventa, Leonardo Padura publica El submarino amarillo (Cuento cubano 1966-1991). Breve antología (1993) y las únicas antologadas son María Elena Llanas, Mirta Yáñez y Aida Bahr. El mismo año, Salvador Redonet Cook publica Los últimos serán los primeros, antología que configura la generación de jóvenes narradores, y allí son seis las escritoras —Elvira García Mora, Rita Martín, Elena María Palacio Rame, Verónica Pérez Konina, Karina Mendoza Quevedo y

\footnotetext{
2 Agradezco infinitamente a Amir Valle la versión digital de esta antología que, de otra manera, no hubiera podido consultar.
} 
Ena Lucía Portela - frente a treinta y un escritores. ${ }^{3}$ En Anuario del cuento de 1994, editado por la Unión de Escritores y Artistas de Cuba, sólo cuatro nombres son de narradoras frente a noventa y un narradores. El mismo año aparece Fábula de ángeles (Antología de la nueva cuentística cubana) de Salvador Redonet y Francisco López Sacha, donde a pesar de que se dice ofrecer una visión amplia de la nueva cuentística, se excluye totalmente a las escritoras: no se las menciona en la nota introductoria ni se intenta esbozar una justificación. Resulta llamativo que este último libro haya sido publicado sólo dos años antes de que Estatuas de sal irrumpiera en la palestra pública. ${ }^{4}$ El mismo año que aparece Estatuas de sal, Francisco López Sacha publica, en una editorial española, La isla contada. El cuento contemporáneo en Cuba. Junto a dieciséis escritores aparecen cuatro escritoras: María Elena Llana, Aida Bahr, Mirta Yáñez y Marilyn Bobes.

Después de la publicación de Estatuas y sus consecuentes repercusiones en el ámbito literario cubano, la situación no tuvo cambios significativos. Así, por nombrar sólo algunos ejemplos de la prolífica producción antológica cubana, al año siguiente se publica Poco antes del 2000. Jóvenes cuentistas cubanos en las puertas del nuevo siglo, compilación realizada por Alberto Garrandés en la que no se incluye a escritoras. En 1999 aparece Aire de luz: Cuentos cubanos del siglo XX, compilación realizada nuevamente por Alberto Garrandés y esta vez sí aparecen siete escritoras -Dora Alonso, Évora Tamayo, María Elena Llana, Mirta Yãnez, Ena Lucía Portela, Anna Lidia Vega y Gina Picart Baluja — frente a cincuenta y nueve escritores. Los títulos elegidos para ambas antologías permiten preguntarnos qué

\footnotetext{
${ }^{3}$ Entre las antologías enumeradas se observan distintos propósitos e intereses delos compiladores. por ejemplo, El submarino amarillo reitera autores bastante conocidos mientras que Los muchachos se divierten y Los últimos serán los primeros, al poner en circulación escritores jóvenes y poco conocidos, establecen el carácter de ruptura y pronóstico. Para una aproximación a este tipo de operaciones antológicas, consultar Verdecia Carlunga (2003).

${ }^{4} \mathrm{El}$ mismo año que aparece Estatuas de sal, Francisco López Sacha publica en una editorial española La isla contada. El cuento contemporáneo en Cuba. Aquí las escritoras son María Elena Llana, Aida Bahr, Mirta Yáñez y Marilyn Bobes junto a dieciséis los escritores.
} 
cambió en dos años para que de ignorar a las escritoras en las puertas del siglo XXI, mientras se incluyen siete sólo dos años después. En el 2000 se publica Nuevos narradores cubanos de Michi Strausfeld y, junto a veinticinco escritores se incluye a Zoé Valdés, Adelaida Fernández de Juan, Mylene Fernández Pintado, Ana Lidia Vega, Karla Suárez y Ena Lucía Portela. En 2003 Fondo de Cultura Económica publica Cuento cubano del siglo XX compilado por Jorge Fornet y Carlos Espinosa Domínguez y sólo se incluye a Mirta Yáñez, Lydia Cabrera y Dora Alonso (no deja de llamar la atención los nombres clásicos ya entrado el siglo XXI) mientras que son treinta y siete los escritores antologados. ${ }^{5}$ Dos años después, Rogelio Riverón edita Narradores cubanos de hoy. Entrevistas y relatos que, entre los mencionados en esta lista, resulta ser el más equitativo en términos numéricos ya que están Mirta Yáñez, Mayra Montero, María Elena Llana, Karla Suárez, Marilyn Bobes, Aida Bhar junto a diez escritores.

\footnotetext{
${ }^{5}$ Además de la mencionada, Fondo de Cultura Económica publica, al iniciarse el siglo XXI, dos antologías más: una dedicada al ensayo y otra a la poesía. Como toda obra de carácter antológico, estas han suscitado encendidos debates. Ver, por ejemplo, la lectura que realiza Ernesto Hernández Busto (2003) en la no menos polémica Letras Libres.
} 


\section{APÉNDICE 2}

\section{Escritoras incluidas en Estatuas de sal. Cuentistas cubanas contemporáneas}

A continuación, detallo las obras y escritoras incluidas en Estatuas de sal. Cuentistas cubanas contemporáneas para aquellos lectores interesados en consignar a quiénes se incluye y excluye en la selección. También dejo esbozadas algunas líneas de análisis.

En el apartado "Antepasadas...y todavía vivas" abarca un arco temporal que se extiende desde el siglo XVII hasta 1930. A diferencia de la sección "Cuentistas cubanas contemporáneas" que incluye una nota bio-bibliográfica de las escritoras, aquí sólo se consignan la fecha de nacimiento y los datos editoriales del texto seleccionado. Las dos primeras escritoras cubren el espectro temporal que va de fines del siglo XVIII a fines del XIX, y son María de las Mercedes Santa Cruz y Montalvo con "Carta II", de Viaje a La Habana y Gertrudis Gómez de Avellaneda, con un fragmento de Sab titulado "Martina y Sab". Continuando con la cronología sigue Lydia Cabrera con "La virtud del árbol dágame”, Renée Méndez Capote con el fragmento "Capítulo VII. La historia de Pepe” de Memorias de una cubanita que nació con el siglo; Ofelia Rodríguez con el cuento "El piano"; Loló de la Torriente con el fragmento "Para hacer El Retiro" que pertenece a Los caballeros caballerosos de la marea roja; Aurora Villar Buceta con el cuento "El farol"; Dolores Soldevilla Nieto, más conocida como Loló Soldevilla con el fragmento "La despedida", título “ocasional” (Yáñez 1998: 89) para el fragmento seleccionado de la novela El farol. Finalmente, las incluidas en este primer apartado y que aún están vivas cuando se publica Estatuas son Dora Alonso con el cuento "Sofía y el ángel”; Dulce María Loynaz con el fragmento "Ceniza imperceptible" de Un verano en Tenerife, Iris Dávila con "Cumpleaños", Mary Cruz (con el cuento "Ña Jacinta”) y, por último, Hilda Perera "Saigón afuera, en el 
barrio hecho aprisa...", título ocasional (Yáñez 1998: 107) del fragmento seleccionado de $M a{ }^{1}$

“Cuentistas cubanas contemporáneas" congrega textos de treinta escritoras manteniendo un orden cronológico (según la fecha de nacimiento) que abarca desde 1930 a 1972. ${ }^{2}$ Cada cuento o fragmento de novela seleccionado va acompañado de una breve nota bio-bibliográfica que describe la trayectoria profesional, algún juicio valorativo (muchas veces se retoman comentarios de otros críticos o escritores) y un apartado dedicado a las publicaciones y premios recibidos. En esta segunda sección se incluyen "Relato de cuando la Florida era española", un fragmento de El columpio de Rey Spencer (sic.) ${ }^{3}$ (1993) de Marta Rojas; "Anónimo" (1968) de Esther Díaz Llanillo en Cuentos cubanos de lo fantástico y lo extraordinario de Rogelio Llopis (selección y prólogo); "Nosotras” de María Elena Llana, cuento que integra la antología de Rogelio Llopis; "El olor del desenfreno" (inédito) de Sonia Rivera-Valdés; "María Valdés o la Colina de la Universidad” (1993) de Lourdes Casal publicado en La Gaceta de Cuba; "Toda agua" (1984) de Omega Agüero, cuento publicado en la revista Bohemia; "Los misterios de Teresa" en La vieja y el mar (1965) de Évora Tamayo; "Una visita para Benemérita" (inédito) de Josefina Toledo; "Niña del arpa" (1969) de Olga Fernández que pertenece al libro del mismo nombre; "La fiesta" de Ana María Simo publicado en Nuevos cuentos cubanos (1964); "No puedo más" en No puedo más y otros

\footnotetext{
${ }^{1}$ Rojas advierte que la crítica literaria (aún la dedicada a realizar específicamente una crítica literaria feminista) "ha soslayado o francamente ignorado la porción más radical, en materia de género, de la escritura practicada por mujeres cubanas durante la República” (Rojas, 2000: 56). Puedo hipotetizar que la acusación salpica a Estatuas de sal porque la selección sólo incluye a una -Ofelia Rodríguez Acosta- de las escritoras enumeradas por Rojas: Lesbia Soravilla, Serafina Núñez, Berta Arocena, Julieta Carreta y Teté Causo "fundadoras todas del Club Femenino de Cuba y de la Unión nacional de Mujeres: dos instituciones cívicas cuyas historias se desconocen en la cultura cubana actual" (Rojas, 2000: 56). Las otras que menciona son: Mercedes García Tudurí, Herminia del Portal, Josefina de Cepeda y Julia Rodríguez Tomeu. Además advierte que estas últimas y otras de las antes mencionadas, ni siquiera aparecen en el Diccionario de la Literatura Cubana (1984).

2 Para 1996 estaban fuera de Cuba, por diferentes razones, las siguientes escritoras: Sonia Rivera-Valdés, Ana María Simo, Uva Clavijo, Achy Obejas, Mayra Montero, Ruth Behar y Zoé Valdés.

${ }^{3}$ El título de la novela tiene una coma -El columpio, de Rey Spencer- que no se encuentra en la edición de Estatuas de 1996, error que se salva en la edición corregida de 2008.
} 
cuentos (1977) de Uva Clavijo; "Con la casa entre las manos" en Los protagonistas (1977) de Nora Macía; "Obba" en Kelé Kelé (1986) de Excilia Saldaña;" "Potosí 11. Dirección equivocada" (inédito) de Rosa Ileana Boudet; "El diablo son las cosas" (1988) de Mirta Yáñez que pertenece al libro de cuentos con el mismo nombre; " "Mujer con techo de paja y meras visiones" (inédito) de Enid Vian; "Diente por diente” (inédito) de Nancy Alonso; "XXII" en El reino del abuelo (1993) de Josefina de Diego; "Corinne, muchacha amable" (1990) de Mayra Montero que apareció publicado en la revista Casa de las Américas; "Pregúntaselo a Dios" (inédito) de Marilyn Bobes;" “¿Vinimos desde Cuba para que te pudieras vestir asî?" en We Came all the Way from Cuba so you Could Dress Like This? (1994) de Achy Obejas; ${ }^{10}$ "Cuando el amor se ausenta" (inédito) de Ruth Behar; "Mímesis S.A."

\footnotetext{
${ }^{4}$ Resulta significativa la valoración negativa (o toma de distancia) que se observa en la nota sobre esta escritora. Transcribo la síntesis: "A esta autora se le conoce un solo libro publicado en los años setenta, cuando imperaba el tono épico y la reproducción mecánica de la realidad. Sus breves narraciones responden al estilo de esta década, con un lenguaje que simplifica la relación hombre-suceso histórico. De hecho, el mero título del libro clasifica las intenciones de la autora en destacar a los 'protagonistas' de la historia, priorizando el mensaje” (Yáñez, 1998: 188). Esta apreciación se puede contraponer, por ejemplo, con un solo fragmento de la valoración de Excilia Saldaña, la escritora que le sigue en la lista: "Sus narraciones presentan un lenguaje híbrido entre la poesía y la prosa que les otorga un encanto peculiar" (Yáñez, 1998: 192).

${ }^{5}$ Resulta cuanto menos llamativa la nota de las compiladoras cuando se advierte que "Aun cuando ha dedicado una gran parte de su obra a la literatura para niños, muchos de sus textos rebasan esa clasificación" (Yáñez, 1998: 192). ¿Se supone que la literatura infantil es un género menor? ¿o la aclaración intenta justificar la inclusión del texto en esta selección?

${ }^{6}$ Hay que señalar que es la nota más extensa. La valoración es positiva: "Es una de las voces más originales del actual panorama literario cubano (...) su dominio del idioma se extiende a una acertada utilización de modismos y giros estilísticos del habla popular (...) y una acertada construcción de sus personajes, constituye el reflejo de una cubana asumida auténtica y naturalmente" (Yáñez, 1998: 211; la itálica me pertenece). Cabe preguntar: ¿Quién realiza la nota de la escritora que realiza la selección? ¿Puede existir la distancia crítica? Si se parte de una identidad esencialista que se vincularía con un tipo de narrativa, ¿influiría en la selección así como en las valoraciones que implican la realización de una antología?
}

${ }^{7}$ Un solo libro publicado hasta 1996: Tirar la primera piedra (1995), aunque señalado con cierto eufemismo "En su primer libro....". También se observa una valoración positiva de su obra: "la autora da muestras de unas aguzadas dotes de observación y sensibilidad para revelar aquellos fragmentos del entorno cotidiano que pueden resultar contradictorios e inquietantes" (Yáñez, 1998: 223).

$8 \mathrm{Al}$ igual que la anterior, también contaba con sólo un libro publicado pero este también es valorado positivamente "hermoso primer libro", "con un fino lenguaje y delicado tono no exento de matices irónicos" (Yáñez, 1998: 233).

${ }^{9}$ Se repiten las características (y, por ende, las preguntas) de la nota de Mirta Yáñez.

${ }^{10}$ En la edición de 1998 el título del libro, We Came all the Way from Cuba so You Could Dress Like This? fue traducido como Para que sepas lo fuerte que aqui somos. La traducción resulta tendenciosa porque "fuerte" en Cuba sería parecido a lo que aquí entendemos como "machona" o "mujer masculina". En la entrevista de 
(1984) en La poza del ángel de Gina Picart; "Confesiones de un búho convencido” (1992) de Chely Lima publicado en la revista Universidad Autónoma del Estado de México; "Ausencias" (inédito) de Aida Bahr; "Mujer de alguien" (inédito) de Zoe Valdés; “Los egipcios" (1994) en Dolly otros cuentos africanos de Adelaida Fernández de Juan; "Anhedonia (historia en dos mujeres)" (inédito) de Mylene Fernández Pintado; "Sergio" en Adolesciendo (1978) de Verónica Pérez Konina ${ }^{11}$ y, por último, Ena Lucía Portela con "La urna y el nombre (un cuento jovial)" que había aparecido publicado en la compilación de Salvador Redonet Cook Los últimos serán los primeros (1993).

2011 Mirta Yáñez señaló que la decisión deliberada fue tomada por los editores y ellas pudieron corregir este “error" en la edición 2008.

${ }^{11}$ Resultan llamativas las fechas: nacida en 1968, una década después ya había publicado su primer libro de cuentos, Adolesciendo, al que pertenece el cuento seleccionado. 


\section{APÉNDICE 3}

\section{Entrevista a Mirta Yáñez}

Buenos Aires, 29 de marzo de 2011

\section{Sobre Estatuas de sal. Cuentistas cubanas contemporáneas}

\section{¿Cómo surge el proyecto de Estatuas de saP ¿En qué se enmarca? ¿Qué estaban haciendo Marilyn Bobes y Ud. en ese momento? ¿Responde a un proyecto institucional, de difusión editorial o a intereses de lectura de ustedes?}

Ante las constantes muestras de marginación en actividades llamemos paraliterarias como jurados, asistencia a congresos, etcetera, la respuesta era siempre: "no hay narradoras". En cierta ocasión la feminista y amiga mexicana Elena Urrutia me había dicho que ya bastaba de protestar o quejarse, que actuara. Entonces se me ocurrió demostrar que sí había narradoras. Se enmarca alrededor del año 1994, muy difícil para Cuba porque estábamos en pleno periodo especial, y en lo particular para mi porque mi mamá estaba con una enfermedad terminal. En la literatura comenzaba una etapa de apertura, de cambios aunque muy restringidas las publicaciones por problemas económicos. El mundillo literario estaba en manos de unos cuantos, todos hombres que se daban bombo entre ellos. Aunque también por supuesto, teníamos figuras honestas, de alta lucidez intelectual, como Abel Prieto que entonces era Presidente de la UNEAC, y nos apoyó con el proyecto.

Entonces le propuse el proyecto a Marilyn y ella aceptó.

Yo no sé qué estaba haciendo ella, yo escribía cuentos, trabajaba en tareas para ganarme el salario y cuidaba de mi mamá.

Fue un proyecto nuestro, aceptado por la UNEAC. 
En nuestro país el libro fue publicado en 1998 por la edición de Culturales Hierbabuena SRL, ¿Qué sucedió con esa edición?, ¿Cómo nace el interés de publicarlo aquí? ¿Se publicó también en otros lugares fuera de Cuba? ¿Cuál ha sido la recepción en Cuba? ¿Y fuera de Cuba?

De esa edición no se prácticamente nada. Marilyn me dio el nombre de la persona que lo hizo, una cubana, Claribel Terré. No supe nada ni nada me han dicho de esa edición.

Para fuera de Cuba, yo en solitario preparé otras antologías, pero NO son Estatuas de sal. Esta fue un panorama inclusivo con todas las escritoras posibles. Las antologías para España, USA, Inglaterra y una que salió en Salta, fueron realizadas bajo mi responsabilidad únicamente, con mis prólogos, y eran selecciones de quienes yo consideraba los mejores cuentos en cada momento.

Al principio en Cuba muchas personas del mundillo literario le pusieron todos los obstáculos posibles y trataron de que no saliera. Después, ante su venta y su éxito, nuevos editores de la UNEAC como su directora Olga Marta Pérez apoyaron la edición para vender en Argentina y luego diez años después una bella reedición.

Los lectores han sido la máxima recompensa a las sucesivas ediciones. Todas se han agotado.

En una nota a la edición de 1998 se aclara que es un "Panorama" y no una “antología”, cuestión que luego ha sido desatendida por la crítica porque elige la segunda denominación para aludir a este libro. ¿Qué las llevó a optar por “panorama”? ¿Por qué piensan que la crítica lo ha leído como antología?

La crítica lee lo que le parece, en primer lugar por vagancia reflexiva. Son desatentos porque todo eso se explica muy bien en las notas y el prólogo. Me llevó a optar por el panorama porque no había ningún antecedente de una selección de escritura femenina en 
Cuba, y yo quería "historiar" el proceso. El acuerdo fue poner una muestra de las narradoras que tuvieran publicado al menos un libro en esa fecha. Hubo ausentes por problemas técnicos, como Ana Luz García Calzada que nunca llegó a tiempo su colaboración por vivir en provincia.

Se trataba de dejar establecida una trayectoria ante la repetida falacia de que en Cuba no había narradoras.

En la introducción señala la vigencia del pensamiento de Camila Henríquez Ureña pero apoyándose en lo doloroso de esa actualidad porque resulta dramático que algunas ideas sobre la difícil situación de la mujer y de la mujer en la cultura, mantengan vigencia casi sesenta años después de haber sido dichos. ¿Qué sucede hoy con las mujeres y la cultura?

Querida amiga, esa es una pregunta para una tesis, y además yo estoy un poco desactualizada en estos momentos. Creo que el machismo sigue, pero ya hay fuerzas que se le oponen. En el campo cultural hay una editorial dedicada al tema, hay cátedras de la mujer, hay una conciencia de género, pero al mismo tiempo he notado que entre las más jóvenes hay como una tendencia a apartarse de esa identidad. En fin...

Por otra parte la mujer y la cultura va más allá de la literatura, y excepto en el cine, en los demás géneros artísticos la mujer tiene un lugar destacadísimo.

El asunto más recalcitrante sigue siendo en las actividades colaterales.

En el trabajo introductorio se observa cierta alternancia entre las posiciones respecto a la teoría de género, por ejemplo, se usa indistintamente: discurso 
femenino, intelectuales o narradoras cubanas, voz de la mujer entre otras ¿Cómo evalúa estas decisiones hoy, a casi quince años de la primera edición? ${ }^{12}$

Es cierto, yo no soy una especialista teórica sobre el tema del género, y en aquel momento había en Cuba un desconocimiento casi total. La cuestión ha cambiado radicalmente y hay numerosas estudiosas del tema. Aunque, en mi caso, seguiría usando, no indistintamente, pero si en su lugar, esa misma terminología porque, ya te dije, no soy una teórica dedicada al género, sino una narradora. Y creo que esos términos pueden usarse, siempre explicando sus contextos.

En ese momento entabla una diatriba con la crítica al señalar que habían contribuido a invisibilizar a la mujer, por ejemplo, con el trazo divisorio entre "Narrativa" y la "narrativa de las mujeres", ¿Eso aún hoy es así? ¿Qué cambios hubo y qué problemas siguen vigentes?

De alguna manera se mantiene el intento de invisibilidad en algunos. La crítica es muy pobre. Aunque, debo decirlo, yo he recibido una abundante crítica favorable con mi última novela. El cambio que ha habido es que las escritoras se han ido ganando su lugar con premios, participación en eventos y demás. La división no suele gustar a nadie. Creo que no es conveniente crear el ghetto de "narrativa femenina", porque eso ayuda al aislamiento malintencionado de aquello que se considera la "gran literatura". Muchos problemas quedan sepultados por un tiempo y luego vuelven a asomar. Y ahora, a esos problemas se suma que algunas jóvenes escritoras, sin saber de lo que hablan, reniegan del feminismo, o

\footnotetext{
${ }^{12} \mathrm{Ya}$ da cuenta de este cambio la ponencia "Feminismo y compromiso. Ambigüedades y desafíos en las narradoras cubanas" presentada en el XXVII Congreso de la Asociación de Estudios Latinoamericanos, Montreal, en septiembre del 2007.
} 
de las teorías de género. Caen en la trampa de querer ser tratadas como "hombres" para salvarse de la diferencia y de hecho están cayendo en una diferencia más grave.

También establece una distinción entre "presencia femenina" (en las antepasadas) y “conciencia femenina” (enfoque femenino), ¿Podría explayarse en la diferencia entre ambas perspectivas? ¿Están presentes en la literatura que se produce en la actualidad? ¿Ejemplos?

No sé si me expliqué bien cuando lo dije, pero en las antepasadas no había una identidad de mujer clara. Esto comenzó en la década de los años veinte y treinta con el feminismo cubano, pero en muchas de ellas no se hizo visible. En las décadas finales del siglo pasado, en mi generación comenzó a hablarse con claridad y entenderse la concientizacion de género. O sea, asumir con autoridad las marcas de género en la literatura, y de la problemática en torno a esto. Creo que hay crisis de identidad. En algunas está muy claro, y en otras siento un rechazo.

Si tendría que actualizar este proyecto, ¿a quiénes incluiría? ¿qué escritoras considera que son promesas o, ya en la actualidad, promesas cumplidas/referentes ineludibles?

No me atrevo

\section{Sobre la producción narrativa de Mirta Yáñez}

¿Cuándo y por qué inicia su camino en el ámbito de las letras? ¿Y cómo crítica? ¿Cuáles son los desafíos de asumir ambas facetas?

Comencé a escribir desde niña, pero fue en el preuniversitario donde tenía un excelente grupo de profesores de Literatura y donde se organizó un concurso literario donde definí 
mi vocación. Antes no me había decidido entre algunas de las artes, la pintura, la música, las letras. Mi padre era periodista, y en mi casa se leía, y gradualmente decidí que mi profesión sería la misma, el periodismo, la literatura. Mucho ayudaron también mis profesores, algunos de ellos escritores en sí mismos como Ezequiel Vieta.

El Camino de la crítica fue más bien obligatorio, como desprendimiento del oficio que desempañaba para vivir y por obligación moral, el de la enseñanza de la literatura. Daba clases de Literatura hispanoamericana en la Universidad de la Habana, y una cosa trajo la otra, de hecho en la crítica podía ejercer la verdadera y grande vocación de mi vida que es el periodismo.

No vi desafíos entre la crítica y escribir ficción. Más bien se complementan. Cuando tengo mucho trabajo en algún sentido, me lamento de no tener tiempo para una cosa u otra.

Observo diferentes características en su producción literaria. Por ejemplo, La hora de los mameyes trabaja con elementos del realismo mágico mientras que en E1 diablo son las cosas las preocupaciones estéticas son otras ¿Estás de acuerdo en que tu producción ha pasado por distintas etapas? $\mathrm{Y}$ en ese caso ¿Cómo puede caracterizar cada momento?

Esa novela fue un empacho con García Márquez que luego rechacé. Antes, y después me sentía más afín a los realistas como Vargas llosa, o en todo caso a los imaginativos como Rulfo. Pero ya lo he dicho en otra ocasión, cuando veo que algún personaje levita o trae fantasmas al cuento me siento compulsada a cerrar la lectura. Ya me tienen harta los epígonos del realismo mágico.

Las de los cuentos son las mismas de mis cuentos anteriores. Pienso que la novela fue como un paréntesis en mi trayectoria. Mis preocupaciones estéticas, no sé si llamarlo así, o las búsquedas de un estilo propio van por el camino de un realismo con alguna 
contaminación de elementos no del todo realistas que creo que ha culminado en mi novela segunda Sangra por la herida. En todas está el humor, la ironía, la inquietud por un lengua que aunque lo rebusque y lo pula, se manifieste como natural.

Creo que tu primera narrativa se podría enmarcar en una tradición realista con vínculos con el testimonio instaurado en Cuba a partir de la década del setenta. Por ejemplo, en los cuentos de Todos los negros tomamos café (1976) la mayoría de las historias se pueden vincular con circunstancias históricas y sociales por las que ha atravesado Cuba y se ambientan en el espacio rural. ¿Cómo se movió dentro de los límites que significó el realismo en los sesenta y setenta (principalmente)? ¿Cómo percibe esa etapa hoy a treinta y cinco años de su publicación?

Sí, estoy de acuerdo con lo que dices. Pero mis primeros cuentos tenían una tónica de humor negro y de algo metafóricamente ficcional que tratan de dar una imagen que rebase el estrecho realismo testimonial. En ese propio libro está la historia del cartero o del cura. Yo me sentía como con un vestido apretado en los años setenta. Yo había ido más allá con mis cuentos iniciales, y me trataba de esforzar con las demandas epocales. Creo que fue un poco de la clásica "autocensura". Así lo veo desde hoy.

Alguna vez dijo que en la primera mitad de los años ochenta se inicia lo que se llama “cuentística del deslumbramiento" por ocuparse de la revelación de sucesos nuevos con una mirada subjetiva que se colocaba generalmente en un personaje niño o adolescente, y también por adjudicarse recursos del llamado "realismo mágico", ¿Se podría ubicar aquí a La hora de los mameyes?

Realmente no lo dije yo, esa terminología es de algunos críticos que le dieron ese nombre. Se refería más bien a los cuentos de la recogida de café. La novela no cabría ahí porque quien 
narra es un adulto bastante azotado por la vida. No es el niño o adolescente de muchos de mis cuentos.

\section{¿Cuáles eran los rasgos distintivos formal y temáticamente de tus primeras producciones? ¿Tenías preocupaciones u objetivos poéticos distintos a los que llegaron después?}

Eso es difícil de responder. No creo que tuviera, al principio, conciencia clara. Pero sí siempre tuve una voluntad de estilo, ganas de esforzarme en escribir al máximo de lo que pudiera dar, rechazar el facilismo de quedarme con lo primero simplemente porque me había quedado más o menos bien. Soy inconformista con el lenguaje, y lo llevo hasta sus últimas consecuencias. En cuanto a la temática mi premisa es la autenticidad, la honradez al enfocar cualquier asunto. Lo que me de un toquecito en el corazón, sino, no funciona. Creo que uno de alguna manera evoluciona, y espero no ser ni tener las mismas inquietudes de aquella jovencita que escribió La hora de los mameyes (tenia 22 años), pero de laguna manera hay constantes: la inquietud por hacer trascender un tema del que he creído ver una arista no contada todavía.

\footnotetext{
¿Cuáles son sus obsesiones escriturarias? Según su propio autoanálisis, ¿cuáles son las recurrencias en su escritura?

La soledad, la lealtad, la pérdida, el abandono. Y de manera muy recurrente: el sitio donde confluyen los sueños de realización y los verdaderos destinos. Se ve en el cuento del cartero, en el cuento de la mujer que se pierde en el mar, en el búfalo ciego y en mi reciente novela
} 
Según mi recorrido, escribió dos biografías de mujeres importantes en el ámbito cubano, Camila Henriquez Ureña (Camila y Camila, 2003) y Rosario Novoa (Una memoria de elefante, 1991), ¿Cómo se enmarcan estos proyectos? ¿Es posible vincularlos con la necesidad de historiar y crear una genealogía de mujeres intelectuales y/o escritoras?

Es eso que dices, naturalmente, pero también son razones sentimentales, fueron mis profesoras, me enseñaron a ser persona. Y creo que tenía una deuda con ellas. Me siento a veces como necesitada de impartir justicia con figuras olvidadas, y si no hago más es porque no me alcanza el tiempo. Los proyectos se enmarcan de manera distinta aunque tienen un fondo común.

Rosario fue amiga de mi abuela, y conversando con ella me di cuenta de que tenía una memoria prodigiosa y que de alguna manera se podía historiar a través de ella a mi querida Universidad y Escuela de Letras. Entonces empecé a grabarla.

Con Camila hice el guion para el documental (está en el libro) y ya fue tan profunda la investigación que me di cuenta de que tenía un libro de hecho y después lo armé.

¿Qué piensa de la cuestión generacional, es decir, si es posible percibir cierta recurrencias en la literatura cubana? ¿Hay elementos poéticos con el peso suficiente como para hablar de modelos y/o generaciones? ¿O cree que esto resulta un encorsetamiento de la crítica? Esta pregunta no la respondo porque me he quedado por el momento un poco desactualizada.

¿Cuáles son las fuentes de las que abreva hoy la literatura en Cuba? ¿Ves mayores rasgos piñeriano, lezamianos, carpenterianos, etc? ¿A qué se debe? ¿Y 
particularmente en las escritoras? Respecto de las influencias por fuera del ámbito nacional, ¿quiénes piensa que han calado en las producciones de los últimos años? Como te dije, estoy un poco desactualizada. Si nos guiáramos por lo que se dice hay muchos lezamianos y pieñerianos, pocos carpenterianos. Pero no creo que sea así, creo que tocan de oído, y no conocen de verdad a sus antepasados. Mucha propaganda al respecto, pero lo que y noto es un afán de experimentación que daña a veces la textura de los textos. Algunos se dicen influenciados por el llamado "realismo sucio" pero no saben a derechas de qué se trata y piensan que la palabra sucio se refiere a escribir "suciedades". En las escritoras lo mismo. Aunque por suerte se nota una cierta recuperación en algunos en aras de sobrepasar el nivel de la ignorancia y la incultura.

La crítica ha señalado que después de la crisis de 1989 y el consecuente "Período Especial” se han producido quiebres en la literatura (y no sólo en este ámbito), ¿acuerda con esta valoración? ¿Qué pasó con tu propia producción? ¿Marcó la producción, por ejemplo, Leonardo Padura, Juan Gutiérrez, Ena Lucía Portela, entre otros? ¿Hay continuidad o la caída del muro de Berlín significó un sismo? Lo que yo creo es que en los noventa se cumplió una especie de apertura a temas hasta entonces tabúes. Y la paradoja de la escasez de papel, por un lado, y la abundancia de publicaciones sin mucho nivel estético por el otro. Pero fue el destape de los temas eróticos, de las escritoras, y del salto a cierta promoción internacional que se interesaba por el descalabro en la sociedad cubana,y ese fue el resquicio por donde se colaron verdaderos escritores como Ena o Padura, y otros que meramente abusaron de los temas sórdidos para colocarse en el mercado.

Mi producción se detuvo en cuanto a la ficción, sobre todo porrazones de índole personal. Se me rompió el equilibrio entre lo que estaba viendo que sucedía en mi país y mi 
concepción de la estética. La ética me paralizó. Seguí haciendo ensayos, trabajando en las antologías, pero no podía expresar con humor o ironía (mis fuertes) en la narrativa, y así estuve buen tiempo sin escribir hasta que salieron los relatos algo evasivos de Falsos documentos. Cuando me recuperé, retomé una vieja novela que había empezado a principios de los noventa, y esa es Sangra por la herida.

No creo que el Muro haya tenido que ver directamente. Indirectamente tal vez. En Cuba fue el Periodo Especial en cuanto a lo económico, pero en cuanto a las rupturas estéticas... ya se veían venir desde finales de los ochenta.

¿Cuáles son sus móviles e intereses escriturarios actuales? ¿Qué motivó la producción de tu última novela? ¿Se vincula con tu producción anterior, digo, temática o estilísticamente? ¿Siguen presentes la ironía y el humor, dos de tus armas más trabajadas? En una entrevista que te hizo hace tiempo Sara Cooper (2000), comentaste que querías escribir una novela con lo que han sufrido las mujeres de tu generación, "con el infierno", aunque reconoce que escribir es también estar en el infierno. ¿Es esta la novela que quería escribir o salió otra cosa? Mis móviles actuales son por una parte el enfoque de género para mis textos de no ficción, y sin salirme de esa premisa, cuando pueda volver a escribir ficción, si puedo volver alguna vez, pues seguir tratando de revelar verdades que han permanecido enterradas o silenciadas. Mi última novela fue motivada por la sensación de que se estaba tergiversando con trivialidades una década importante de mi generación, los años sesenta. Que los que la vivimos en su grandeza y tragicidad estábamos obligados a contar lo que nos pasó.

Sí se vincula en cuanto a que retomo la ironía y el lenguaje tragicómico de muchos de mis cuentos, en efecto. Y en la voluntad de estilo, de encontrar un lenguaje propio, que sin dejar de ser sencillo y popular, sea esmeradamente culto. 
Sí, esa es la novela que quería escribir. Era lo que estaba haciendo, y creo que salió en su complejidad tanto el infierno personal, como los infiernillos que nos rodean

Tengo entendido que tenía esta novela escrita hace ya algún tiempo, ¿Por qué pasó tanto tiempo para publicarla?

La terminé el 31 de agosto de 2008, la mandé a un concurso que quedó desierto, entonces comenzó a sufrir algunos traspies, hasta que, después de algún batallar, y con el apoyo de algunos amigos, logré que saliera. Ahora va a salir también en Francia.

\section{¿Cuáles son sus proyectos de escritura?}

Ahora mismo estoy terminando en volumen en compañía de la escritora y amiga Nancy Alonso sobre las mujeres intelectuales de las décadas del veinte y del treinta del siglo pasado que publicaron en la revista "Social". Es un recorrido para el rescate de muchos nombres olvidados. Ya lo estamos entregando a la editorial.

Y así mismo entregué una noveleta infantil y una segunda colección de ensayos sobre el tema de la mujer. De hecho no tengo nada inédito.

Como siempre, uno tiene ideas en la cabeza sobre otro cuento, o sobre otra novela. Pero nada concreto.

\section{¿Qué desafíos tienen los estudios sobre la producción de las mujeres cubanas? ¿Qué resta hacer?}

A mi modo de ver, en la actualidad hay investigadoras muy serias trabajando sobre el tema, y hay un pequeño grupo de muchachas jóvenes decididas a mantener los estudios de género. El desafío que tienen es enfrentarse a la indiferencia, a la oposición de algunos, incluso al sarcasmo de muchas de nuestras más jóvenes escritoras. 
Hay cátedras de la mujer, una editorial, un conjunto de premios que respaldan la obra. Pero lo que siempre resta por hacer es escribir. 


\section{Bibliografía}

\section{Fuentes primarias}

Guerra, Wendy. (2006). Todos se van. Barcelona: Bruguera.

Guerra, Wendy. (2010). Posar desnuda en La Habana. Diario apócrifo de Anaïs Nin. Madrid: Alfaguara.

Mateo, Margarita. (1995). Ella escribía poscritica. La Habana: Abril. . (2008). Desde los blancos manicomios. La Habana: Letras Cubanas.

Portela, Ena Lucía. (2000). El viejo, el asesino y yo. La Habana: Letras Cubanas. . (2002 [2003]). Cien botellas en una pared. La Habana: Unión.

Suárez, Karla. (1999). Silencios. Madrid: Lengua de Trapo.

Yáñez, Mirta y Marilyn Bobes, (comp.). (1998 [1996]). Estatuas de sal: cuentistas cubanas contemporáneas, panorama crítico. La Habana: Unión.

\section{Fuentes secundarias}

Adorno, Theodor. (1962 [1954]). "El ensayo como forma". Notas de literatura, (traducción de Manuel Sacristán). Barcelona: Ariel, 11-34.

Aedo, María Teresa. (1995). "Cecilia Valdés: Diosas, vírgenes y madres en la identidad mestiza de Cuba". Acta literaria, 20, 5-22.

Agudelo Ochoa, Ana María. (2006). "Aporte de las antologías y de las selecciones a una historia de la literatura". Lingüistica y literatura, 49.

Aguilar, Carolina, Perla Popowski y Mercedes Verdeses. (1996). "Mujer, Período especial y vida cotidiana". Temas, 5 (enero/marzo), 11-17.

Aizenberg, Edna. (1985). "El Bildungsroman fracasado en Latinoamérica: El caso de Ifigenia de Teresa de la Parra”. Revista Iberoamericana, 132/3, (julio-dic), 539-546.

Alburquerque Fuschini, Germán. (2000). "Las redes de escritores latinoamericanos en los años sesenta". Universum, 15, 337-350. 
(2001). "El caso Padilla y las redes de escritores latinoamericanos". Universum, 16, 307-320.

Alcoff, Linda. (1988). "Feminismo cultural versus post-estructuralismo: crisis de identidad en la teoría feminista". Journal of Women in Culture and Society, 13. [Fecha de consulta: 15 de enero de 2008]. Disponible en: http://www.creatividadfeminista.org/ articulos/2004/fem04estrucultur_02.htm

Alemany Bay, Carmen. (2003). "Muestrario de narradoras hispanoamericanas del siglo XX: mucho ruido y pocas nueces". Anales de literatura española, 16, 109-152.

, Remedios Mataix et. al. (eds.). (2001). La isla posible. Alicante: Biblioteca Virtual Miguel de Cervantes.

Alfonso, María Isabel. (2012). "Ediciones El puente y dinámicas raciales de los años 60: un capítulo olvidado de la historia literaria cubana". Temas 70, 110-118.

Altamirano, Carlos. (2010). Historia de los intelectuales en América Latina II. Buenos Aires: Katz.

Álvarez Álvarez, Luis. (2000). "La literatura cubana a partir de los años ochenta". [Fecha de consulta: 20 de julio de 2006]. Disponible en: www.oasis.go.kr/...1/plaza.snu.ac.kr〜 iberoampublica_48408/plaza.snu. ac.kr iberoamdb11집a_48413/alvarez.doc y Margarita Mateo Palmer. (2005). El Caribe en su discurso literario. Santiago de Cuba: Oriente.

Álvarez Borland, Isabel. (1998). Cuban-American Literature of Exile: from Person to Persona. Charlottesville and London: University Press of Virginia.

Álvarez, Mayda. (1995). "Mujer cubana, problemas de estudio”. Temas, 1 (enero/marzo), 77-84.

Amar Sánchez, Ana María. (2000). Juegos de seducción y traición. Literatura y cultura de masas. Buenos Aires: Beatriz Viterbo Editora.

Amícola, José. (2003). La batalla de los géneros. Novela gótica versus novela de educación. Rosario: Beatriz Viterbo.

Amorós, Celia. (1991). Hacia una crítica de la razón patriarcal. Barcelona: Anthropos.

Anderson, Benedict. (1993). Comunidades imaginadas. México: Fondo de Cultura Económica. 
Angenot, Marc. (2010). El discurso social (los límites históricos de lo pensable y lo decible). Buenos Aires: Siglo XXI. . (1998). Interdiscursividades. De hegemonías y disidencias. Córdoba: UNC.

Araújo, Helena. (1982). "Narrativa femenina latinoamericana”. Hispamérica, 32, 23-34. - (1989). La Scherezada criolla. Ensayos sobre las escrituras femeninas contemporáneas. Bogotá: Universidad Nacional.

Araújo, Nara. (1998 [1996]). "La escritura femenina y la crítica feminista en el Caribe: otro espacio de la identidad”. En: Mirta Yáñez y Marilyn Bobes, Estatuas de sal. Cuentistas cubanas contemporáneas. La Habana, Unión, 373-384.

. (1997). El alfiler y la mariposa. Género, vozy escritura en Cuba y el Caribe. La Habana: Letras Cubanas.

. (1999-2000). "Repensando desde el feminismo los estudios latinoamericanos". Lectoras, 5/6, 55-65.

. (1998-1999). "El espacio otro en la escritura de las (novísimas) narradoras cubanas". Revista Temas, 16-17(octubre-junio), 212-217.

_. (2001). "Feminismo, posmodernidad y poscolonialismo en Ella escribia poscrítica”. Signos Literarios y Lingüisticos, III (julio-diciembre), 75-84.

Arcos, Jorge Luis. (2002). "Prólogo”. Antología poética. Fina García Marruz: México: Fondo de Cultura Económica, 7-13.

(2007). "La poesía de Raúl Hernández Novás”. En Raúl Hernández Novás, Poesía. La Habana: Fondo Editorial Casa de las Américas: 7-35.

Ares, Patricia. (2001). Identidad de género y su especificidad en Cuba. La Habana: Editorial de la Mujer.

Arfuch, Leonor. (2007). El espacio biográfico. Dilemas de la subjetividad contemporánea. Buenos Aires: Fondo de Cultura Económica.

Armstrong, Nancy. (1991). Deseo y ficción doméstica. Una bistoria política de la novela. Madrid: Cátedra.

Arroyo, Jossiana. (2003). Travestismos culturales. Literatura y etnografía en Cuba y Brasil. Pittsburgh: Universidad de Pittsburgh. 
Bajtín, Mijail. (1982). Estética de la creación verbal. México: Siglo XXI.

Barthes, Roland. (2006 [1973]). El grado cero de la escritura. Nuevos ensayos críticos. Buenos Aires: Siglo XXI. . (2006 [1973]). El placer del texto. Lección inangural. Buenos Aires: Siglo XXI.

Basile, Teresa (comp). (2008). La vigilia cubana. Sobre Antonio José Ponte. Rosario: Editorial Beatriz Viterbo.

Beauvoir, Simone. (1949). El segundo sexo. Buenos Aires: Sudamericana, 2007.

Benhabib, Seyla. (2002). Las reivindicaciones de la cultura. Igualdad y diversidad en la era global. Buenos Aires: Katz, 2006.

Benitez Rojo, Antonio. (1989). La isla que se repite: el Caribe y la perspectiva posmoderna. Hanover: Ediciones del Norte.

Bertón, Sonia. (2010). La construcción de la subjetividad en la narrativa de Severo Sarduy. [en línea] Tesis Doctoral. Universidad Nacional de La Plata. Facultad de Humanidades y Ciencias de la Educación. [fecha de consulta: 7 de marzo de 2012]. Disponible en: www.fuentesmemoria.fahce.unlp.edu.ar/tesis/te.358/te.358.pdf

Bobes, Marilyn. (2000). Cuentistas cubanas de hoy. Buenos Aires: Instituto Movilizador de Fondos Cooperativos.

Bobes, Velia Cecilia. (2000). Los laberintos de la imaginación: repertorio simbólico, identidades y actores del cambio social en Cuba. México: El Colegio de México.

Boileau-Narcejac. (1968). La novela policial. Buenos Aires: Paidós.

Bourdieu, Pierre. (1983). Campo del poder y campo intelectual. Buenos Aires: Folios.

(1995 [1992]). Las reglas del arte. Génesis y estructura del campo literario. Barcelona: Anagrama.

Butler, Judith. (2007 [1990]). El género en disputa. El feminismo y la subversión de la identidad. Buenos Aires: Paidós.

Calabrese, Omar. (1999). “Detalle y fragmento”. La era neobarroca. Madrid: Cátedra, 84-105.

Cámara, Madeline (1991a). "Adiós a los ochenta: ajuste de cuentas con la joven literatura cubana”. Plural, 228 México.

(1991b). "La joven literatura cubana". Plural, 228, México: 66-72. 
(1995). "Feminismo vs. Totalitarismo: textos y contextos femeninos en Cuba contemporánea". Bordes, 2: 54-64.

. (1999). "La mulata, un cuerpo sin voz en la cultura cubana". AfroHispanic Literature, XV, 121-129.

. (2000). "Una promesa incumplida: la emancipación de la mujer cubana." Encuentro de la cultura cubana, 3, 212-216.

Campuzano, Luisa. (1988). Quirón o del ensayo y otros eventos. La Habana: Letras Cubanas. . (1996). "La voz de Casandra. Para presentar Alguien tiene que llorar, de Marilyn Bobes”. La Gaceta de Cuba, 4 (julio-agosto), 52-53. - (1997). "Cuba 1961: los textos narrativos de las alfabetizadoras. Conflictos de género, clase y canon". Unión, 26 (enero-marzo), 52-58. • (1998 [1996]). "La mujer en la narrativa de la revolución: ponencia sobre una carencia”. En Mirta Yáñez y Marilyn Bobes (comp.), Estatuas de sal. Cuentistas cubanas contemporáneas. La Habana: Unión, 351-372. (2004). Las muchachas de La Habana no tienen temor de Dios. La Habana: Unión.

Capote Cruz, Zaida. (2002). Contra el silencio. Una lectura de Dulce María Loynaz. La Habana: Facultad de Artes y Letras de la Universidad de La Habana. . (2004). "El cuento cubano entre 1989 y 1999. Panorama de su desarrollo". Moenia, 10, 249-262. [fecha de consulta: 20 de septiembre de 2009]. Disponible en: http://www.dspace.usc.es/bitstream/10347/5761/1/pg_251264_moenia10.pdf (2008). La nación intima. La Habana: Unión.

y Susana Montero (comps.). (1999). Aproximaciones cubanas a los estudios de género. La Habana: Editorial de la Mujer/ Instituto de Literatura y Lingüística.

Casamayor Cisneros, Odette. (2002). "Cubanidades de un fin de siglo o breve crónica de ciertos intentos narrativos para salvar u olvidar la cubanidad." La Gaceta de Cuba, 6, $36-40$.

(2002). “Incertidumbre resplandeciente. Breve incursión en la narrativa escrita durante la década del 90 en la Isla de Cuba." Caravelle, 78, 179-196. 
2004. “¿Cómo vivir las ruinas habaneras de los años noventa?: Respuestas disímiles desde la isla en las obras de Abilio Estévez, Pedro Juan Gutiérrez y Ena Lucía Portela”. Caribbean Studies, vol. 32 (julio-diciembre), 002. [fecha de consulta 10 de julio de 2010]. Disponible en: http://www.redalyc.uaemex.mx/src/inicio/Art PdfRed.jsp?iCve=39232203

Castro-Klaren, Sara. (1985). "La crítica literaria feminista y la escritora en América Latina". En Patricia González y Eliana Ortega. La sartén por el mango. Puerto Rico: Huracán, $27-46$.

Silvia Molloy y Beatriz Sarlo (eds.). (1991). Women's Writing in Latin America. Colorado and Oxford: Westview Press.

Catelli, Nora. (2007). En la era de la intimidad. Rosario: Beatriz Viterbo Editora.

Caulfield, Carlota. (2002). "Cuban Literature and Culture: Critical Junctures". Latin American Research Review, 3, 231-247.

Caulfield, Sueann. (2001). "The History of Gender in the Historiography of Latin America". Hispanic American Historial Review, 81, 3-4.

Chapad, Martín. (2006). “Testimonio de partes o quién es quién”. En Marcela Croce (comp.), Polémicas intelectuales en América Latina. Del "meridiano intelectual al caso Padilla (1927-1971), Buenos Aires: Simurg, 207-212.

Cella, Susana. (1998). Diccionario de literatura latinoamericana. Buenos Aires: El Ateneo.

Ciplijauskaité, Biruté. (1988). La novela femenina contemporánea (1970-1985). Hacia una tipología de la narración en primera persona. Barcelona: Anthropos.

Ciriza, Alejandra. (1997). "Desafíos y perspectivas. Qué feminismo hoy". Anuario de Filosofia Argentina y Americana, Mendoza, 14, 153-168.

Cixous, Héléne. (1995 [1975]). La risa de la medusa: ensayos sobre escritura. Barcelona: Antrophos.

Ciplijauskaité, Biruté. (1994 [1988]). La novela femenina contemporánea (1970-1985). Hacia una tipologia de la narración en primera persona. Barcelona: Antrophos.

Colaizzi, Giulia. (1990). "Feminismo y Teoría del Discurso. Razones para un debate". Feminismo y Teoría del Discurso. Madrid: Cátedra, 13-25. 
Colil Abricot, Juan Ignacio. (2010). Novela Negra y Espacio Público "Los tipos duros no leen novelas policiales". [fecha de consulta: 9 de junio de 2011]. Disponible en: http://www.librosdementira.com/author/juan-ignacio-colil-abricot/ Constitución de la República de Cuba. (1992). La Habana: Editora Política.

Cooper, Sara. (2000). Entrevista con Mirta Yáñez: una manera de pensar diferente. California State University-Chico. [Fecha de consulta: 20 de mayo de 2008]. Disponible en: http://www.lehman.cuny.edu/ciberletras/v07/cooper.html

Corbata, Jorgelina. (2002). Feminismo y escritura femenina en Latinoamérica. Buenos Aires: Corregidor.

Correa de Zapata, Celia. (1985). "Escritoras latinoamericanas: sus publicaciones en el contexto de las estructuras del poder.” Revista Iberoamericana 51, 132-3, 591-603.

Daroqui, María Julia. (1998). (Dis)locaciones: narrativas híbridas del Caribe bispano. Valencia: Universidad de Valencia.

(2005). Escrituras heterofónicas: narrativas caribeñas del siglo XX. Buenos Aires: Beatriz Viterbo Editora.

Davies, Catherine. (1996). "Women Writers in Twentieth Century Cuba: an Eight Point Survey". En Joan Anim-Addo, Framing the Word: Gender an Genre in Caribbean Women's Writers. London: Whiting and Birch. . (1997). A place in the sun? Women writers in twentieth-century Cuba. London: Zed.

Deleuze, Gilles y Félix Guattari. (1985). El anti-edipo. Capitalismo y esquizofrenia. Barcelona: Paidós.

De Certeau, Michel. (2007 [1980]). La invención de lo cotidiano. El arte de hacer. Tomo I. México: Universidad Iberoamericana.

De la Nuez, Iván. (2006). "Más acá del bien y del mal”. [Fecha de consulta: 12 de febrero de 2008]. Disponible en: http://www.cubistamagazine.com/050116.html

De Lauretis, Teresa. (1984). Alica doesn't: Feminist, Semiotic, Cinema. Bloomington: Indiana University Press.

De Miranda Parrondo, Patricia. (2002). "Una mirada sobre el presente y futuro de la sociedad cubana en torno a las relaciones actitudinales. Papel de la familia." Ponencia leída en XIV Congress of Latin American Studies Association (LASA). 
De Rosso, Ezequiel. (2011). Retóricas del crimen: reflexiones latinoamericanas sobre el género policial. Alcalá la Real: Alcalá Grupo Editorial. . (2012). Nuevos secretos. Transformaciones del relato policial en América Latina 1990-2000. Buenos Aires: Liber.

De Toro, Alfonso. (2006). "Margarita Mateo: posicionalidades y estrategias de hibridación". [Fecha de consulta: 8 de abril de 2008]. Disponible en: http://www.uni- leipzig.de/ detoro/sonstiges/2006_MagaritaMateo.pdf>

Desnoes, Edmundo (selección y notas). (1981). Los dispositivos en la flor. Cuba: literatura desde la Revolución. Hanover: Ediciones del Norte.

Díaz, Duanel. (2004). "Bloom: las tareas de la crítica cubana y el debate del canon cubensis". La Habana elegante. Segunda época [en línea], 28 (invierno). [Fecha de consulta: 22 de marzo de 2011]. Disponible en: http://www.habanaelegante.com/ Winter2004/Verbosa.html (2005). Los límites del origenismo. Madrid: Colibrí. (2007). "El fantasma de Sartre en Cuba". La Habana elegante. Segunda época [en línea], 37 (primavera). [Fecha de consulta: 10 de octubre de 2011]. Disponible en: www.habanaelegante.com/Spring2007/Verbosa.html (2009). Palabras de trasfondo: intelectuales, literatura e ideología en la Revolución Cubana. Madrid: Colibrí.

Díaz Quiñones, Arcadio. (2006). Sobre los principios. Los intelectuales caribeños y la tradición. Buenos Aires: Universidad Nacional de Quilmes Editora. . (2007). "Caribe y exilio en La isla que se repite de Antonio Benítez Rojo". Orbis Tertius, revista de teoría y critica literaria, 13, 1-17.

Diego, Eliseo. (1992). Poesía y prosa selecta. Caracas: Biblioteca de Ayacucho.

Domínguez, Daylet. (2009). “Antiintelectualismo y género policial en Cuba”. Revista encuentro, [en línea], 53/54: 205-212. [Fecha de consulta: 15 de mayo de 2010]. Disponible en:http://www.cubaencuentro.com/revista/revista-encuentro/archivo/ 531-54-verano-otono-2009

Domínguez, Nora y Perilli, Carmen. (1998). Fábulas del género. Sexo y escrituras en América Latina. Rosario: Beatriz Viterbo. 
Domínguez, Jorge. (1998). “Cuba, 1959-1990”. En Bethell, Leslie (ed.). Historia de América Latina. Barcelona: Grijalbo Mondadori.

Durán, Diony. (2000). "El Otro habla: la escritura femenina en el cuento cubano". En Janett Reinstädler y Ottmar Ette (eds.), Todas las islas la isla. Nuevas y novísimas tendencias en la literatura y cultura de Cuba. Frankfurt-Madrid, Vervuert-Iberoamericana: $59-67$.

. (2006). “¿Contar La Habana? Discurso, contradiscurso, transgresiones”. En Gabriela Knauer, Elina Miranda y Janett Reinstälder (eds), Transgresiones cubanas. Cultura, literatura y lengua dentro y fuera de la isla. Madrid-Frankfurt, IberoamericanaVervuert: 69-88.

Eagleton, Terry. (1983). Una introducción a la teoría literaria. México: Fondo de Cultura Económica. . (1991). Ideology: An Introduction. Londres: Verso.

Escribá, Alex Martín y Javier Sánchez Zapatero. (2007). "Una mirada al neopolicial latinoamericano: Mempo Giardinelli, Leonardo Padura y Paco Ignacio Taibo II”. Anales de literatura Hispanoamericana, vol. 36: 49-58.

Espín, Vilma. (1990). La mujer en Cuba. La Habana: Editora Política.

Espina, Mayra. (1997). "Transformaciones recientes de la estructura socioclasista cubana". Papers 52: 83-99. . (2001). "Género y cambios en la estructura socioclasista cubana en los 90". Fecha de consulta: 6 de junio de 2005]. Disponible en: http://socrates.berkeley.edu:7001/Events/spring 2001/01-29-01-espina/paper.html

Espina Prieto, Rodrigo y Pablo Rodríguez Ruiz. (2006). "Raza y desigualdad en la Cuba actual". Temas 45: 44-54.

Evans, Mary. (1997). Introducción al pensamiento feminista contemporáneo. Madrid: Minerva.

Fe, Marina (coord.). (1999). Otramente: lectura y escritura feminista. México: Fondo de Cultura Económica.

Femeninas, María Luisa. (2000). Sobre sujeto y género. Buenos Aires: Catálogos. . (2002). Perfiles del feminismo iberoamericano. Buenos Aires: Catálogos. . (2003). Judith Butler: introducción a su lectura. Buenos Aires: Catálogos. 
. (2005). Perfiles del feminismo iberoamericano/2. Buenos Aires: Catálogos.

Fernández, Antonio. (2002). "The Island, the Map, the Travelers: Notes on Recent Developments in Cuban Art". Boundary 2, 29: 3.

Fernández Martínez, Mirta. (2012). "Visión de la mujer negra en la poesía". Temas 71: 137-145.

Fernández Pequeño, José María. (1988). "Teoría y práctica de la novela policialrevolucionaria". [Fecha de consulta 16 de abril de 2010]. Disponible en: http://www.cdigital.uv.mx/bitstream/123456789/2029/1/198866P93.pdf (1989). "La novela policial cubana ante sí misma (1979-1986)". [Fecha de consulta 16 de abril de 2010]. Disponible en: En http://www.cdigital. uv.mx/bitstream/123456789/1931/1/198970P205.pdf . (1994). Crítica sin retroceso. La Habana: Unión.

Fernández Retamar, Roberto. (1995). "Apuntes sobre Revolución y literatura en Cuba". Para una teoría de la literatura hispanoamericana. Bogotá: Instituto Caro y Cuervo, $177-$ 193.

. (2000). "Introducción a la literatura cubana". América sin nombre, 2 (diciembre): 5-15.

Fernández Rius, Lourdes. (2000). "Mujeres y estudios de género en Cuba." [Fecha de consulta: 27 de junio de 2006]. Disponible en: http://www.sociologiadip.unimib.it /abcd/Intern_pdf/MUJER-CUBA.pdf

Fernández, Teodosio. (2000). "La narrativa cubana del Siglo XXX. Notas para la reconstrucción de un proceso". América sin nombre: boletín de la unidad de Investigación de la Universidad de Alicante, 2, 84-91.

Ferrer, Carolina. (2010). "Escritura, identidad y ausencia: Todos se van de Wendy Guerra". Ponencia presentada en el XLVI Congreso de la Asociación Canadiense de Hispanistas [Fecha de consulta: 30 de noviembre de 2012]. Disponible en: http://www.ach.lit.ulaval.ca/Congreso_abierto/2010/Ferrer.pdf

Fleites-Lear, Marisela (1996). "Paradojas de la mujer cubana". Nueva sociedad, 143 (mayojunio), 41-55. 
Font A. Mauricio (ed.). (2004). "Cuba Today. Continuity and Change since the 'Período Especial"'. [Fecha de consulta: 12 de febrero de 2007]. Disponible en: http://www.web.gc.cuny.edu/bildnercenter/publications/cubatoday book.pdf

Fornet, Ambrosio. (1983). "La nueva novela cubana: pronóstico de los '80". Suplemento literario de Revolución y cultura, 2 (abril-junio), 1-5.

- (2000). Memorias recobradas. Introducción al discurso literario de la diáspora. Santa Clara: Capiro.

. (2001) "La diáspora cubana y sus contextos (glosario)." Casa de las Américas, 222 (enero-marzo), 22-29.

- (2007). "El quinquenio gris: revisitando el término". [Fecha de consulta:

20 de mayo de 2008]. Disponible en: www.criterios.es/pdf/fornetquinqueniogris.pdf.

Fornet, Jorge. (2006). Las nuevos paradigmas. Prólogo narrativo al siglo XXI. La Habana: Letras Cubanas.

Foucault, Michel. (1990 [1961]). Historia de la locura en la época clásica. Buenos Aires: Fondo de Cultura Económica (1991). Microfísica del poder. Madrid: La Piqueta. (1992). Vigilar y castigar: nacimiento de la prisión. Madrid: Siglo XXI. . (1992 [1970]). El orden del discurso. Buenos Aires: Tusquets Editores. . (2000). Los anormales. Buenos Aires: Fondo de Cultura Económica.

Fowler, Víctor. (1998). La maldición. Una bistoria del placer como conquista. La Habana: Letras Cubanas. . (2001). Historias del cuerpo. La Habana: Letras Cubanas. (2002). "Estrategias para cuerpos tensos: po(li)(é)ticas del cruce interracial". Temas, 28: 107-119.

Franco, Jean. (1986). "Apuntes sobre la crítica feminista y la literatura hispanoamericana". Hispamérica, 45, 31-43. . (1988). "Si me permiten hablar: la lucha por el poder interpretativo, en: Casa de las Américas, 171 (nov-dic): 88-94. 
Galster, Ingrid. (1997). "Entre hagiografía y matricidio. La recepción actual de la obra de Simone de Beauvoir". Utopía y Praxis Latinoamericana, 2, 3, 71-76.

Gamba, Susana Beatriz (coord.). (2007). Diccionario de estudios de género y feminismos. Buenos Aires: Biblos.

García de Coronado, Domitila. (1868). Álbum poético-fotográfico de las escritoras cubanas. La Habana: Imprenta Militar de la Viuda de H. del Soler.

García Marruz, Fina. (1994 [1990]). Créditos de Charlot (edición facsimilar). La Habana: Letras Cubanas.

García Yero, Olga. (2002). "Dos reflexiones sobre la literatura cubana a partir de los años ochenta". [Fecha de consulta: 12 de mayo de 2006]. Disponible en: http:/www.adelante.cu/literaria /2002/cuba/cuba80.htm

Garrandés, Alberto. (1993). "La cuentística cubana en la Revolución (1959-1988)". Revista de Literatura Cubana 11, 21, 5-44. (comp.). (1997). Poco antes del 2000. Jóvenes cuentistas cubanos en las puertas del nuevo siglo. La Habana: Letras Cubanas. (comp.). (1999). Aire de lu₹. Cuentos cubanos del siglo XX. La Habana: Letras Cubanas. . (2002). "El cuento cubano en los últimos años". Anales de literatura Hispanoamericana, 31, 65-82.

Garrido, Beatriz. (2006). "Feminismos, estudios de género y la visión performativa de género". [Fecha de consulta: 15 de septiembre de 2008]. Disponible en: http://www.espacioblog.com/beatrizgarrido (15/09/08)

Gilman, Claudia. (2003). Entre la pluma y el fusil. Debates y dilemas del escritor revolucionario en América Latina. Buenos Aires: Siglo XXI.

Giordano, Alberto. (2006). Una posibilidad de vida. Escrituras intimas. Rosario: Beatriz Viterbo.

Goffman, Erving. (2001 [1961]). Internados: ensayos sobre la situación social de los enfermos mentales. Buenos Aires: Amorrortu. 
González-Abellás, Miguel. (2005). "El problema del yo: Autor y narrador en la ficción cubana reciente". Espéculo. Revista de estudios literarios de la Universidad Complutense de Madrid. [Fecha de consulta: 5 de octubre de 2012]. Disponible en: http://www.ucm.es/info/especulo/numero29/probleyo.html

González Aktories, Susana. (1995). "Antologías poéticas en México. Una aproximación hacia el fin de siglo". Anales de literatura hispanoamericana, 24, 239-250.

González Echevarría, Roberto. (1976). Relecturas: Estudios de literatura cubana. Caracas: Monte Ávila Editores.

- (1985). La voz de los maestros. Escritura y autoridad en la literatura latinoamericana moderna. Madrid: Verbum.

(2004). "Oye mi son: El canon cubano". En Anke Birkenmaier y Roberto González Echevarría (coords.), Cuba: Un siglo de literatura (1902-2002). Madrid: Colibrí, 19-36.

González, María Virginia. (2010). "La transgresión del ensayo: Ella escribia poscrítica de Margarita Mateo Palmer". En: Graciela Salto (ed.). Memorias del silencio. literaturas en el Caribe y en Centroamérica. Buenos Aires: Corregidor, 199-224.

González Marrero, Claudia. (2008). "La novela policial en Cuba durante la década del '70".

[Fecha de consulta: 14 de abril de 2010]. Disponible en: www.rebelion.org/noticia_pdf.php?id=76949

González, Patricia y Eliana Ortega (eds.). (1984). La sartén por el mango. San Juan: Huracán.

González Pagés, Julio César. (1998). "Historia de las mujeres en Cuba: del feminismo liberal a la acción política femenina." Diez. Nuevas Miradas a la Historia de Cuba. Valencia: Publicación de la Universidad de Jaime I, 271-285.

(2002). "Género y masculinidad en Cuba: ¿El otro lado de una historia?”. [Fecha de consulta: 12 de febrero de 2006]. Disponible en: http//www.cubaliteraria. com/estudios_genero/index.asp

Gramsci, Antonio. (1972). Los intelectuales y la organización de la cultura. Buenos Aires: Nueva Visión. 
Gramuglio, María Teresa. (1992). “La construcción de la imagen”. En Héctor Tizón, Rodolfo Rabanal y María Teresa Gramuglio. La escritura argentina. Santa Fe: Universidad Nacional del Litoral/Ediciones de Cortada.

Grant, María. (2002). “Mujeres en líne@, con Luisa Campuzano”. Revista Opus Habana, [en línea] VI, 3, [Fecha de consulta: 20 de mayo de 2006]. Disponible en: http://www.opushabana.com/noticias.php?id_brev=366

Grüner, Eduardo. (1996). Un género culpable. La práctica del ensayo: entredichos, preferencias e intromisiones. Rosario: Homo Sapiens Ediciones.

Guerra, Wendy. (2007). Entrevista. [Fecha de consulta: 20 de mayo de 2006]. Disponible en: http://www.letralia.com/170/entrevistas03.htm

- (2006). Entrevista. Página 12 [en línea]. [Fecha de consulta: 10 de noviembre de 2011]. Disponible en: http://www.pagina12.com.ar/diario/ suplementos/espectaculos/ 4-4475-2006-11-14.html

(14/10/2011). "El derecho de ser yo y escribir desde La Habana". [Fecha de consulta: 2 de noviembre de 2012]. Disponible en: http://www.elmundo.es/blogs/elmundo/habaname/2011/10/14/el-derecho-deser-yo-y-escribir-desde-la.html

Guevara, Ernesto. (1997). "El socialismo y el hombre en Cuba". Obras completas. Buenos Aires: Macla, 1968: 204-239.

Guiar, Susan. (1988). “'La página en blanco' y las formas de creatividad femenina”. Seminaria, 1 (junio), 6-16.

Gutiérrez, Pedro Juan. (2000). Animal tropical. Barcelona: Anagrama.

Henríquez Ureña, Camila. (1982). Estudios y conferencias. La Habana: Instituto Cubano del Libro.

(1985). Feminismo y otros temas sobre la mujer en la sociedad. Santo

Domingo: Taller.

Hernández Busto, Ernesto. (2003). "Un escándalo canónico. Sobre las antologías de cuento, poesía y ensayo cubanos del siglo XX”. Letras Libres, [en línea] 51. [Fecha de consulta: 2 de septiembre de 2009]. Disponible en: http://www.letraslibres.com/revista/libros/ un-escandalo-canonico 
Hernández Novás, Raúl. (2007). Poesía. La Habana: Fondo Editorial Casa de las Américas.

Hernández, Rafael. (2002 [1999]). Mirar a Cuba. Ensayos sobre cultura y sociedad civil. México: Fondo de Cultura Económica.

Hernández, Rafael y Rafael Rojas (comp.). (2002). Ensayo cubano del siglo XX. México: Fondo de Cultura Económica.

Hierro, Graciela (coord.). (1995). Diálogos sobre filosofía y género. México: UNAM/Asociación Filosófica de México.

Holgado Fernández, Isabel. (2000). ¡No es fácil! Mujeres cubanas y la crisis revolucionaria. Barcelona: Icaria.

Hormilla, Helen. (2011). Mujeres en crisis. Aproximaciones a lo femenino en las narradoras cubanas de los noventa. La Habana: Publicaciones Acuario, Centro Félix Varela.

Huertas Uhagón, Begoña. (1993). Ensayo de un cambio: la narrativa cubana de los '80. La Habana: Casa de las Américas.

James Pérez, María Victoria. (2001). La imagen en el espejo: la mujer cubana vista a través de personajes literarios. Santiago de Cuba: Santiago.

Jennissen, Therese y Collen Lundy. (2001). "Women in Cuba and the Move to a Private Market Economy”. Women`s Sudies International Forum, 24, 181-198.

Jitrik, Noé. (1996). "Canónica, regulatoria y transgresiva". Orbis Tertius, revista de teoría y crítica literaria, 1, 153-166. . (2000). Los grados de la escritura. Buenos Aires: Manantial.

Knauer, Gabriela, Elina Miranda y Janett Reinstädler (eds.). (2006). Transgresiones cubanas: cultura, literatura y lengua dentro y fuera de la isla. Madrid-Frankfurt: IberoamericanaVervuert.

Kutzinski, Vera M. (1993). Sugar's secrest. Race and the Erotics of Cuban Nationalism. Virginia: New World Studies, James Arnold Series Editor.

Lagos, María Inés. (1996). En tono mayor: relatos de formación de protagonistas femeninas en Hispanoamérica”. Santiago de Chile: Cuarto Propio.

Larguía, Isabel y John Dumoulin. (1971). "Hacia una ciencia de la liberación de la mujer". Casa de las Américas, 65-66 (marzo/junio), 37-55. 
(1983). Hacia una concepción cientifica de la emancipación de la mujer.La Habana: Editorial Ciencias Sociales.

- (1988). La mujer nueva: teoría y práctica de su emancipación. Buenos Aires: Centro Editor de América Latina.

Leclercq, Cecile. (2004). El lagarto en busca de una identidad. Madrid: Vervuert- Iberoamericana. Lejeune, Philippe. (1994). El pacto autobiográfico y otros estudios. Trad. Ana Torrent. Madrid: Megazul-Endymion.

Link, Daniel (comp.) (2003 [1994]). El juego de los cautos. Literatura policial: de Edgar A. Poe a P. D. James. Buenos Aires: La Marca.

Lombardo, Verónica. (2006). "El difícil oficio de calcular, o dónde me pongo". En Marcela Croce (comp.), Polémicas intelectuales en América Latina. Del "meridiano intelectual al caso Padilla (1927-1971). Buenos Aires: Simurg, 213-219.

López Cabrales, María del Mar. (2007a). Arenas cálidas en alta mar: Entrevistas a escritoras contemporáneas en Cuba. Santiago de Chile: Cuarto propio.

(2007b). Una isla con cara de mijer. Prominentes mujeres de la cultura en Cuba. New Jersey: Nuevo Espacio.

- (2008). Rompiendo las olas durante el periodo especial. Creación artística y literaria de mujeres en Cuba. Buenos Aires: Corregidor.

López, Iraida L. (2010). "Prólogo". Ena Lucía Portela, Cien botellas en una pared. Doral: Stockcero,

López Sacha, Francisco (comp.). (1996). La isla contada: el cuento contemporáneo en Cuba. Donostia: Tercera Prensa.

(2001). Tres revoluciones en el cuento cubano y una reflexión conservadora. La Habana: La Letra del Escriba.

López Pardina, María Teresa. (1994). “El feminismo de Simone de Beauvoir". En Celia Amorós (comp.), Historia de la teoría feminista. Madrid: Universidad Complutense de Madrid.

Löwy, Michael (ed). (1982). El marxismo en América Latina (de 1909 a nuestros días). México: Era. 
Ludmer, Josefina. (1984). "Las tretas del débil”. Patricia Elena González y Eliana Ortega, (eds.), La sartén por el mango. San Juan: Ediciones Huracán: 47-54.

Lukács, Georg. (1985 [1910]). "Sobre la esencia y forma del ensayo”. El alma y las formas. La teoría de la novela. México: Grijalbo, 15-39.

Lutes, Leasa. (2000). Allende, Buitrago, Luiselli. Aproximaciones teóricas al concepto del "Bildungsroman” femenino. New York: Peter Lang.

Machover, Jacobo. (2001). La memoria frente al poder. Escritores cubanos del exilio: Guillermo Cabrera Infante, Severo Sarduy, Reinaldo Arenas. Zaragoza: Universitat de València.

Mailhe, Alejandra. (2005). "Epistemologías, oligarquías y escrituras en crisis. Del racialismo al culturalismo en el ensayo latinoamericano de los años treinta”. Anuario de Estudios Americanos, Vol 62, 1. [Fecha de consulta: 18 de junio de 2011]. Disponible en: http://www.estudiosamericanos.revistas.csic.es/index.php/estudiosamericanos/arti cle/viewArticle/67

(2008). "Entre la exuberancia y el vacío. Identidad nacional y alteridad en tres ensayistas latinoamericanos: Gilberto Freyre, Fernando Ortiz y Ezequiel Martínez Estrada”. En Gloria Chicote y Miguel Dalmaroni (eds.), El vendaval de lo nuevo. Literatura y cultura en la Argentina moderna entre España y América Latina (18801930). Buenos Aires: Beatriz Viterbo.

Manzoni, Celina. (2001). Un dilema cubano. Nacionalismo y vanguardia. LaHabana: Casa de las Américas.

. (2007). "Diáspora, Nomadismo y Exilio en la Literatura Latinoamericana Contemporánea". [Fecha de consulta: 20 de abril de 2013]. Disponible en: http:/ / repositories.lib.utexas.edu/handle/2152/4102

. (2009). Errancia y escritura en la literatura latinoamericana contemporánea. Alcalá la Real: Alcalá Ediciones.

Maristany, José. (2003). Topografías urbanas: de los andamios a los apuntalamientos. A propósito de Contrabando de sombras de Antonio José Ponte. Encuentro 28/29 (primavera-verano): 62-69.

Martí, José. (1989). Obra literaria. Caracas: Ayacucho. 
Martín Sevillano, Ana Belén. (2002). “Algunos aspectos del cuento de los Novísimos narradores cubanos". Anales de Literatura Hispanoamericana, 31, 295-312.

Masiello, Francine. (1997). “Tráfico de género: mujeres, cultura y política de identidad en esta era neoliberal." Revista Mora, 3.

Masotta, Oscar. (1982 [1965]). Sexo y traición en Roberto Arlt. Buenos Aires: CEAL.

Mateo Palmer, Margarita. (2002 a). “La narrativa cubana contemporánea: las puertas del siglo XXI." Anales de Literatura Hispanoamericana, 31, 51-64.

. (2002 b). "Literatura latinoamericana y posmodernismo: una visión cubana.” En Rafael Rojas (comp.), Ensayo cubano del siglo XX. México: Fondo de Cultura Económica, 595-619.

. (2002 c). Paradiso: la aventura mítica. La Habana: Letras Cubanas.

Mattalía, Sonia y Milagros Aleza (eds.). (1995). Mujeres: escrituras y lenguajes (en la cultura latinoamericana y española). Valencia: Universitat de Valencia.

Menton, Seymour. (1990). “La novela de la revolución cubana, Fase cinco: 1975-1987”. Revista Iberoamericana, 56, 152-153 (jul.-dic), 913-932.

Mesa-Lagos, Carmelo. (1994). Breve bistoria económica de la Cuba socialista. Política, resultados y perspectivas. Madrid: Alianza.

Ministerio de Justicia. (1977). La mujer en Cuba socialista. Publicación oficial. La Habana: Orbe.

Moi, Toril. (2006 [1988]). Teoría literaria feminista. Madrid: Cátedra. · (2001). “Apropiarse de Bourdieu: la teoría feminista y la sociología de la cultura de Pierre Bourdieu". Feminaria, 14, 26/27 (julio), 1-20.

Molloy, Silvia. (1996). "Introducción”. Acto de presencia. México: Fondo de Cultura Económica.

Montero, Susana. (1989). La narrativa femenina cubana (1923-1958). La Habana: Academia. (1999-2000). "De la conquista de la escritura o evolución de la literatura femenina cubana hasta el presente.” Lectoras, 5/6, 5-17.

y Zaida Capote Cruz. (1999). Con el lente oblicuo. Aproximaciones cubanas a los estudios de género. La Habana: Editorial de la Mujer. 
Morán, Francisco. (2005). "Cuba.com: escapes, descosidos y reinvención del espacio nacional'. Katatay, I (junio), 18-25.

Moraña, Mabel. (1998). "El boom del subalterno”. En Santiago Castro-Gómez y Eduardo Mendieta, Teorías sin disciplina (latinoamericanismo, poscolonialidad y globalización en debate). México: Miguel Ángel Porrúa.

Morejón, Nancy. (2002). Cuerda veloz. Antología poética 1962-1992. La Habana: Letras Cubanas.

Moret, Zulema. (2008). Esas niñas cuando crecen, ¿dónde van a parar? New York-Amsterdam: Rodopi.

Mosquera, Gerardo. (1991). "Los hijos de Guillermo Tell”. Plural, 238, 60-63.

Murillo, Soledad. (1996). El mito de la vida privada: de la entrega al tiempo propio. México: Siglo Veintiuno Editores.

Naranjo Orovio, Consuelo (coord.). Historia de Cuba. Madrid: Doce Calles.

Navarro, Desidero. (1997). “Intertextualité: treinta años después”. Intertextualité. Francia en el origen de un término y el desarrollo de un concepto. La Habana: Casa de las AméricasUNEAC - Embajada de Francia. V-XIV.

Nicholson, Linda J. (1992). Feminismo/Posmodernismo. Buenos Aires: Feminaria.

Noguerol Jiménez, Francisca. (2008). "Neopolicial latinoamericano: el triunfo del asesino". [Fecha de consulta: 9 de abril de 2011]. Disponible en: http://www.cenicientademendigosyladrones.blogspot.com/2008/07/neopoliciallatinoamericano-el-triunfo.html

Núñez Sarmiento, Marta. (2004). "Los estudios de género en Cuba y sus aproximaciones metodológicas, multidisciplinarias y transculturales (1974-2001)”. En Los estudios de género en Cuba y sus aproximaciones metodológicas, multidisciplinarias y transculturales (19742001). [Fecha de consulta: 5 de noviembre de 2006]. Disponible en http://bibliotecavirtual. clacso.org.ar/ar/ libros/cuba/cemi/ genero.pdf

- (2001). "Estrategias cubanas para el empleo femenino en los noventa: un estudio con mujeres profesionales". Paper, 63/64, 141-170. 
Oliva Portolés, Asunción. (2005). "Las teorias de las mujeres como clase social: Christine Delphy y Lidia Falcón”. En Celia Amorós y Ana de Miguel (comps.), Teoría feminista: de la Ilustración a la globalización. Madrid: Minerva, 109-146.

Ortega, Julio. (1999). "Diálogos sobre género, diferencia y literatura”. En Rocío Silva Santiesteban (comp.), El combate de los ángeles. Literatura, género, diferencia. Lima, Universidad Católica del Perú: 15-25.

Ortiz, Fernando. (1940). "Los factores humanos de la cubanidad". Revista Bimestre Cubana, La Habana, Tomo XLV, 2: 11.

(1993). "El choteo". Albur, La Habana, IV, número especial.

Padura, Leonardo. (1994 [1993]). El submarino amarillo (Cuento cubano 1966-1991). Breve antología. Un libro para Cuba. México. UNEAC e Insituto Cubano del Libro. . (2000). Modernidad, posmodernindad y novela policiaca. La Habana: Unión.

Pastor, Brígida. (1999). "La autobiografía como acto de transgresión". En Erich Fisbach,Discursos transgresivos en Europa y América Latina. Angers: Université d' Angers, 45-56.

(2005). "Subjetividad femenina y "retratos femeninos" en el cine cubano de la post-revolución”. En María Luisa Femenías, Perfiles del feminismo Iberoamericano 2. Buenos Aires: Catálogos, 293-328.

Peña-Jordán, Teresa. (2005). Cuerpo político del deseo: literatura, género e imaginario neocultural en Cuba y Puerto Rico (1863-2000). Tesis presentada en la University Pittsburgh.

Percia, Marcelo (comp.) (1998). Ensayo y subjetividad. Buenos Aires: Eudeba.

Pérez Firmat, Gustavo. (1989). The Cuban condition: translation and identity in modern Cuban literature. Cambridge (England); New York: Cambridge University Press. . (1999). My own private Cuba: essays on Cuban Literature and Cultures. Boulder: Society of Spanish-American Studies.

Pérez-Hernández, Reiner. (2002). "Sobre Ella escribia poscrítica”. Revista Unión, [En línea], 46, [Fecha de consulta: 13 de octubre de 2009]. Disponible en: http:/ / www.foros.uneac.org.cu/index.php?module=publicaciones\&act=publicacio n_ numero\&id $=54 \&$ idarticulo $=574$

Persé, Saint-John. (2006 [1911]). Elogios. México: Ediciones Era. 
Piñera, Virgilio. (1964). "La caída”. Cuentos. La Habana: Unión, 11-13.

Pogolotti, Graciela. (1991). "Escritoras, mujeres". Casa de las Américas 31, 183 (abril-junio), 913.

. (2006). Polémicas culturales de los 60. La Habana: Letras Cubanas.

Ponte, José Antonio. (1992). "La lengua de Virgilio". Dossier de Virgilio Piñera, Diario de Poesía. Servicio de documentación de la Universidad de Brasil. [Fecha de consulta: 5 de julio de 2008]. Disponible en: http://www.fflch.usp.br/sintesint/ virgilio/ens_ponte.htlm (2002). El libro perdido de los Origenistas. México: Aldus.

Portela, Ena Lucía. (1912 [1998]). Pájaro: pincel y tinta cbina. La Habana: Unión. . (1999). "Literatura vs lechuguitas.” En René Vázquez Díaz (ed.), Breve esbozo de una tendencia, en Cuba: voces para cerrar un siglo. Estocolmo: Centro Internacional Olof Palme, 77-78.

(2010). "Entrevista". La Habana Elegante. Segunda Época, [en línea], 48, (otoño-invierno), [Fecha de consulta: 20 de octubre de 2011] http://www.habanaelegante.com/Fall_Winter_2010/Entrevista_Portela.html • (2006). "Entrevista: ¿Quién le teme a Ena Lucía Portela?”. La Habana Elegante, segunda época [en línea]. [Fecha de consulta: 4 de septiembre de 2007]. Disponible en: http://www.habanaelegante.com/SpringSummer2006/Angel.html Pozuelo Yvancos, José María, 1996, “Canon: ¿estética o pedagogía?”, Revista Ínsula, Madrid,(LI), 600. http://www.insula.es/Articulos/INSULA\%20600.htm

Pratt, Mary Louise. (1990). "Women, Literatura and National Brotherhood". Women, Culture and Politics in Latin America, Seminar on Feminism and Culture in Latin America. Berkeley: Universidad de California, 48-73.

Quintero Herencia, Juan Carlos. (2002). Fulguraciones del espacio. Letras e imaginario institucional de la Revolución Cubana (1960-1971). Rosario: Beatriz Viterbo.

Rama, Ángel. (1985). "Algunas sugerencias de trabajo para una aventura intelectual de integración". En: Ana Pizarro (coord.). La literatura latinoamericana como proceso. Buenos Aires: CEAL.

Ramos, Julio. (1989). Desencuentros de la modernidad en América Latina. Literatura y política en el 
s. XIX. México: Fondo de Cultura Económica.

. (1996). "Trópicos de la fundación: poesía y nacionalidad en José Marti”".

Paradojas de la letra. Caracas: Escultura, 153-164.

Randall, Margaret. (1972). La mujer cubana ahora. La Habana: Instituto Cubano del Libro.

Redonet Cook, Salvador. (1993). Los últimos serán los primeros. La Habana: Letras Cubanas. . (1994). Vivir del cuento. La Habana: Unión.

Reinstädler, Janett y Tomar Ette (eds.). (2000). Todas las islas la isla: nuevas y novísimas tendencias en la literatura y cultura de Cuba. Madrid: Iberoamericana.

Reyes, Alfonso. (1969 [1952]). “Teoría de la antología”. La experiencia literaria. Buenos Aires: Losada, 125-129.

Riccio, Alessandra. (2002). "Ena Lucía Portela: presa y cazadora". La Jiribilla [en línea], 37, [Fecha de consulta: 12 de diciembre de 2007]. Disponible en: http://www.lajiribilla.cu/2002/n37_enero/942_37.html

Richard, Nelly. (1999). "Feminismo, experiencia y representación”. Revista Iberoamericana LXVV, 176-7 (julio-diciembre), 733-744.

Rivero, Eliana. (1986). "The House on Mango Street. Tales of Growing Up female and Hispanic". SIROW Working Paper Series, n 2I (University of Arizona-Southwest Institute for Research on Women): 2-19

Riverón Rogelio. (2005). Narradores cubanos de hoy. Entrevistas y relatos. La Habana: Letras Cubanas.

Rodríguez, Emilio Jorge. (1989). Literatura caribeña. Bojeo y cuaderno de bitácora. La Habana: Letras Cubanas.

Rodríguez Feo, José. (1990). La literatura cubana ante la crítica. La Habana: Unión.

Rodríguez Monegal, Emir. (1972). El boom de la novela latinoamericana. Caracas: Tiempo Nuevo.

Rojas, Rafael. (1999). "Diáspora y literatura. Indicios de una ciudadanía postnacional”. Revista Encuentro, 12/13 (primavera-verano): 136-146. (2000). Un banquete canónico. México: Fondo de Cultura Económica. 
(2005). "El campo roturado. Políticas intelectuales de la narrativa cubana".

Katatay I, 1 (junio), 42-51.

. (2006). Tumbas sin sosiego. Revolución, disidencia y exilio del intelectual cubano.

Barcelona: Anagrama.

. (2009). "Entre fronteras". Revista de Estudios Hispánicos, 43, 171-188.

. (2010). “Anatomía del entusiasmo. Cultura y revolución en Cuba (1959-

1971). En Carlos Altamirano. Historia de los intelectuales en América Latina II. Buenos

Aires: Katz, 45-61.

Romeu, Raquel. (2000). Voces de mujeres en la literatura cubana. Madrid: Verbum.

Rubio Castro, Ana. (1990). "El feminismo de la diferencia: los argumentos de una igualdad compleja." Revista de Estudios Políticos (Nueva Época), 70, (octubre-diciembre): 185207.

Sabas Alomá, Mariblanca. (1930). Feminismos. Cuestiones sociales: crítica literaria. La Habana: Hermes.

Said, Edward. (2004 [1983]). El mundo, el texto y el crítico. Buenos Aires: Debate.

. (1985). Beginnings. Intention \& Method. Nueva York: Columbia University

Press.

Salto, Graciela. (2005). "El silencio del Rey de la Habana y el neorrealismo cubano".

Ponencia leída en el $I^{\circ}$ Congreso Regional del Instituto Internacional de Literatura Iberoamericana "Nuevas cartografías críticas: problemas actuales de la Literatura Iberoamericana", Rosario, 23, 24 y 25 de junio.

(ed.). (2010). Memorias del silencio. literaturas en el Caribe y en Centroamérica.

Buenos Aires: Corregidor.

Sancholuz, Carolina. (2010). Mapa de una pasión caribeña. Lecturas sobre Edgardo Rodríguez Juliá. Buenos Aires: Dunken.

Santa Cruz, María Isabel et. al. (1994). Mujeres y filosofía. Teoría filosófica del Género. Tomo I y II. Buenos Aires: Centro Editor de América Latina.

Santiago, Silviano. (2000 [1971]). "El entrelugar del discurso latinoamericano". En Adriana Amante y Florencia Garramuño, Absurdo Brasil. Polémicas en la cultura brasileña. Buenos Aires: Biblos, 61-77. 
Santiesteban (comp.), El combate de los ángeles. Literatura, género, diferencia. Lima, Universidad Católica del Perú: 15-25.

Schutte, Ofelia. (1993). Cultural Identity and Social Liberation in Latin American Thought. Albano, State University of New York Press. . (1995). "Crítica de la normatividad del género". En Graciela Hierro (coord.). Diálogos sobre filosofía y género. UNAM/Asociación Filosófica de México, México, 6771.

(2002). "Posmodernidad y utopía: exigiendo bases feministas para nuevas tierras." Femenías, M. Luisa (comp.). Perfiles del feminismo Iberoamericano. Buenos Aires: Catálogos, 257-278.

Scott, Joan. (1993). "El género: una categoría útil para el análisis histórico". En María Celia Cangiano y Lindsay Dubois, De mujer a género. Teoría, interpretación y práctica feminista en las ciencias sociales. Buenos Aires: Centro Editor de América Latina.

Sejourné, Laurette. (1980). La mujer cubana en el quehacer de la historia. México: Siglo XXI.

Sibilia, Paula. (2009). La intimidad como espectáculo. Buenos Aires: Fondo de Cultura Económica.

Sierra Madro, Abel. (2002). La nación sexuada. Relaciones de género y sexo en Cuba (1830-1855). La Habana: Editorial de Ciencias Sociales.

Sigal, Silvia. (1991). Intelectuales y poder en la década del sesenta. Buenos Aires: Puntosur.

Silva, Guadalupe. (2009). "Del insularismo a metaarchipiélago". Celina Manzoni (ed.). Errancia y escritura en la literatura latinoamericana. Alcalá la Real (España): Ediciones Alcalá, 95-112.

(2012). "Lo cubano en Cintio Vitier", Actas de las XXIII Jornadas de Investigación del Instituto de Literatura Hispanoamericana, Facultad de Filosofía y Letras, Universidad de Buenos Aires, 9, 10 y 11 de diciembre de 2009. Edición digital en CD ISBN 978-987-1785-25-4.

Smith, Verity. (1989). "Recent trends in Cuban criticism and literature". Cuban Studies, 19, 81-99. 
. (1995). "What are Little Girls Made of under Socialism? Cuba's Mujeres [Women] and Muchacha [Girl] in the Period 1980-1991". Studies in Latin American Popular Culture, 14.

Smorkaloff, Pamela María. (1987). Literatura y edición de libros: la cultura literaria y el proceso social en Cuba (1900-1987). La Habana: Letras Cubanas.

. (1999). Cuban Writers on and of the Island. Contemporary Narrative

Fiction. Ed. David Williams Foster. Arizona: Arizona State University.

Sommer, Doris. (2004 [1991]). Ficciones fundacionales. Las novelas nacionales en América Latina. México: Fondo de Cultura Económica.

Stone, Elizabeth (ed.). (1981). Woman and the Cuban Revolution. New York: Pathfinder.

Strausfeld, Michi. (2000). "La literatura cubana es una (estudio preliminar)". Nuevos narradores cubanos. Madrid: Siruela.

Strauss, Lévi. (1955). Tristes trópicos. España: Paidós.

Suárez, Karla. (2005). La viajera. Barcelona: Rocaeditorial.

Taibo II, Paco Ignacio. (2002). Semana negra de Gijón. [Fecha de consulta: 2 de junio de 2010]. Disponible en: http://www.cubaliteraria.cu/delacuba/ficha.php?sub=2\&Id=1535

Torres, Roberto. (1999). "La crítica literaria cubana: hacia una búsqueda de sí y de la(s) poética(s) del fin de siglo". Casa de las Américas, 215, 37-42.

Torres-Pou, Joan. (1998). El eterno femenino: Aspectos de la representación de la mujer en la literatura latinoamericana del siglo XIX. Barcelona: Promociones y Publicaciones Universitarias.

Urrello, Antonio. (1986). Verosimilitud y estrategia textual en el ensayo hispanoamericano. México: Premiá Editora.

Valdés Fernández, M. Teresa y Edith Felipe Duyos. (1996). "La crisis y el ajuste cubano en los noventa: apuntes en torno a lo social”. Perfiles Latinoamericanos 8 (enero/junio): 97-114.

Valero, Silvia. (2011). “Figuraciones de 'lo afro' y 'lo negro' en las producciones culturales cubanas contemporáneas". Orbis Tertius, XVI, 17, 41-50. 
Valladares Ruiz, Patricia. (2005). "Lo especial del período: políticas editoriales y movimiento generacional en la literatura cubana contemporánea. Neophilologus, 89/3, 383-402.

Vallejo, Catharina. (2009). "La gozadora del dolor y otras novelas de Graziella Garbalosa: erotismo, naturalismo y vanguardismo en la narrativa femenina cubana de los años veinte". Revista Iberoamericana, 226, 153-166. - (2012). "Vasos comunicantes: persistencia, revisión y el nuevo ensayo de mujeres cubanas (1947-2007). Revista Iberoamericana, 240: 521-538

Valle Ojeda, Amir. (2001). Brevísimas demencias. Narrativa joven cubana de los 90. La Habana: Extramuros.

(2007). "Marginalidad y ética de la marginalidad en la nueva ciudad narrada por la novela negra latinoamericana". Anales de Literatura Hispanoamericana, 36, 95-101.

Vasallo Barrueta, Norma. (1995). "La evolución del tema Mujer en Cuba". Revista Cubana de Psicología, 12, 1-2.

(1997). "Social Subjectivity of women. A study of Cuban women: Different roles and different generation in Cuba in the Special Period". Studies in Third World Societies, Virginia.

(1999). "La mujer cubana ante los cambios económicos; impactos en su subjetividad". Hacia una mutación de lo Social. Zaragoza: Egido. (2001) "Identidades en tránsito: cubanas de tres generaciones". Ponencia leída en XIII Congress of presentada en Latin American Studies Association (LASA), Washington.

(2002). "Ecos del pasado, voces del presente (Un acercamiento a ideas y objetivos feministas de las cubanas)". En María Luisa Femenías, Perfiles del feminismo Iberoamericano. Buenos Aires: Catálogos, 11-25.

(2004). "La formación de centros y programas académicos sobre estudios de las mujeres o de género en Cuba". EnRedos de Género, 1: 2-4.

Vega Quintana, Laritza. (2003). "La marginalidad en la literatura: una visión de la desigualdad en la Cuba de los 90". [Fecha de consulta: 12 de diciembre de 2006]. 
Disponible en: $\quad$ http://bibliotecavirtual.clacso.org.ar/ar/libros/cuba/cips/ caudales05/Caudales/ARTICULOS/ArticulosPDF/03V015.pdf

Vera Méndez, Juan Domingo. (2005). "Sobre la forma antológica y el canon literario". Espéculo. Revista de estudios literarios, 30 [Fecha de consulta: 10 de noviembre de 2009]. Disponible en: http://www.ucm.es/info/especulo/numero30/antcanon.html

Verdecia Carlunga, Lino. (2003). “Antologados y antologadores: qué comunican nuestras antologías de cuentos". Actas II del VIII Simposio Internacional de Comunicación Social. [Fecha de consulta: 8 de septiembre de 2011]. Disponible en: http://www.santiago.cu/hosting/linguistica/actas.php?Simposios=VIII\&Actas $=2$

Voloshinov, Valentin. (1976). El signo ideológico y la filosofía del lenguaje. Buenos Aires: Nueva Visión.

Weigel, Sigrid. (1986), "La Mirada bizca: sobre la historia de la escritura de las mujeres". En Gisela Ecker (ed.), Estética femenina. Barcelona, Icaria, 69-98.

Weinberg, Liliana. (2001). El ensayo, entre el paraíso y el infierno. México: Fondo de Cultura Económica.

Williams, Lorna V. (1985). "From Dusky Venus to Mater Dolorosa: The Female Protagonist in the Cuban Antislavery Novel." Women as Myth and Metaphor in Latin American Literature. Columbia: University of Missouri Press, 121-35.

(1993). "The Representation of the Female Slave in Villaverde's Cecilia Valdés". Hispanic Journal, 14/1: 73-89.

Williams, Rymond. (1977). Marxismo y literatura. Barcelona: Península, 1997. (2000). Palabras claves. Un vocabulario de la cultura y la sociedad. Buenos Aires: Nueva Visión.

Woolard, K. and B. Schieffelin (1994). "Language Ideology". Annual Review of Anthropology, 23: 55-82.

Yáñez, Mirta. (ed.). (1998). Cubana. Contemporary Fiction by Cuban Women. Boston: Massachusetts: Beacon Press. - (2001). "Ruidos y cuartos propios". En La Jiribilla [en línea], 17 [Fecha de consulta: 20 de abril de 2005]. Disponible en: http://www.lajiribilla.cu/ 2001/n17 agosto/493 17.html 
(2003). Camila y Camila. La Habana: Ediciones La Memoria.

(2009). "Feminismo y compromiso. Ambigüedades y desafíos en las narradoras cubanas." Temas, 59 (julio-septiembre), 158-164.

Zambrano, María. (1993). La rąón en la sombra. Antología crítica. Madrid: Siruela, 2003.

Zanetti, Oscar. (2005). Isla en la Historia. La historiografía de Cuba en el siglo XX. La Habana: Unión.

Zanetti, Susana. (1994). "Religación. Un modo de pensar la literatura latinoamericana". El Dorado I, 1: 5-8.

. (2000). “¿Un canon necesario? Acerca del canon literario latinoamericano”. Voq y escritura (10): 227-241.

- (2002). La dorada garra de la lectura. Lectoras y lectores de novela en América Latina. Rosario: Beatríz Viterbo Editora.

Zaragoza Zaldívar, Francisco. (2002). "La narrativa cubana de los noventa”. Ponencia leída en Congresso Brasileiro de Hispanistas, San Pablo. Extraído el 12 de diciembre de 2006 desde http://www.proceedings.scielo.br/scielo.php?script=sci_arttext\&pid= MSC0000000012002000300024\&lng $=$ en\&nrm $=$ iso

Zurbano Torres, Roberto. (2001). “Etnos, literatura y nación: el triángulo invisible del siglo XX cubano". Ponencia leída en XIII Congress of Latin American Studies Association (LASA), Washington.

. (2005). "Re-pasar El Puente". La Gaceta de Cuba, 4, La Habana, (julio-agosto).

(2006). "El triángulo invisible del siglo XX cubano: raza, literatura y nación”. Temas 46, 111-123. 
